University of Nebraska - Lincoln

DigitalCommons@University of Nebraska - Lincoln

Digitized Afghanistan Materials in English from

the Arthur Paul Afghanistan Collection

Afghanistan: The Arthur Paul Afghanistan Collection at the University of Nebraska-Omaha

August 2005

\title{
A dictionary of the Pathan tribes on the north-west frontier of India (1910)
}

General Staff Army Headquarters, India

Follow this and additional works at: https://digitalcommons.unl.edu/afghanenglish

Part of the Asian Studies Commons

, General Staff Army Headquarters, India, "A dictionary of the Pathan tribes on the north-west frontier of India (1910)" (2005). Digitized Afghanistan Materials in English from the Arthur Paul Afghanistan Collection. 4.

https://digitalcommons.unl.edu/afghanenglish/4

This Article is brought to you for free and open access by the Afghanistan: The Arthur Paul Afghanistan Collection at the University of Nebraska-Omaha at DigitalCommons@University of Nebraska - Lincoln. It has been accepted for inclusion in Digitized Afghanistan Materials in English from the Arthur Paul Afghanistan Collection by an authorized administrator of DigitalCommons@University of Nebraska - Lincoln. 



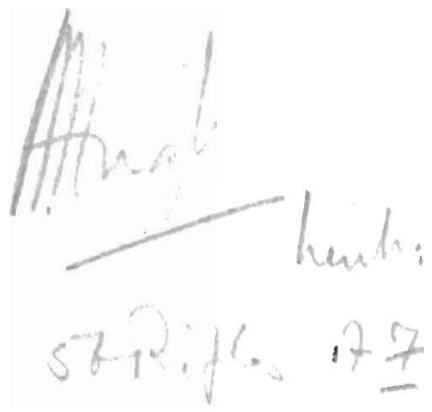


A

\section{DICTIONARY OF THE PATHAN TRIBES}

ON THE

NOR'IH-WEST FRONTIER OF INDIA 


\section{A \\ DICTIONARY OF THE PATHAN TRIBES \\ ON THE \\ NORTH-WEST FRONTIER OF INDIA}

Prepared by the General. Staff Army Headqurtors, India

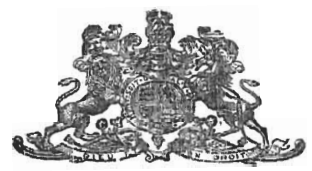

CALCUTTA

SUPERINTENDENT GOVERNMENT PRINTING, INDIA 1910 


\section{CONTENTS.}

Part I.-All Pathan tribes north of the Kabul river and west of the Indus . . . . . . 1 to 51

Part II.-Tribes between the Kabul and Kurram rivers,

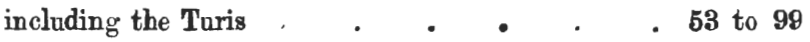

Part III.-Tribes between the Kurram and Guma] rivers, and those on the Derajat border. . . . 101 to 200

Part IV.-Pathan tribes south of the Gumal, and Tribes, such as the Shiranis, which orcupy country on both sides of the border betreen the North-West Frontier Province and Baluchistan . . • . 201 to 262 


\section{EXPTANATORY NOTE.}

The elassification adopted in this dictionary is as follows :-

1. The tribe.

2. The clan of the tribe.

3. The division of the clan.

4. The sub-division of the division.

5 . The section of the sub-division.

6. Other minor fractions of the section.

The headings in the dictionary read from the lesser to the greater, thus;-DADO KHEL are a minor fraction of the Dreplara section, of the Khusrogi sub-division, of the Nasruddin division, of the Zakka Khel clan, of the Afridi tribe.

Figures in brackets indicate the number of the fighting men of the fraction immediately preceding the figures.

The locality of the tribe, clan, or division, etc., is also given within brackets, where this is capable of accurate definition, and is not sufficiently indicated in the name of the tribe, clan, etc. In many cases the names of the hearmen have been given.

"GAR " AND "SAMIL."-WThe terms refer to the two political factions into which the tribes on the Peshawar and Kohat borders are divided. At some remote period a bitter feud existed between the Gar and Samil branches of the 
great Bangash trihe, and all the neighbouring tribes appear to have joined one faction or the other ; although the origin of the quarrel has been forgotten the division still rermains. . "Suinis" ard "Shialis."-The vast majority of the frontier tribesmen beling to the former sect; and this may be assumed to be the case where not otherwise expressly stated.

"Hausay.s." - Yasial or dependent settlers, amongst an alien tribe.

This dictionary only gives the Pathan or Pushtu-speaking tribes within the Durand Line. Tribes, which are Afghan subjects, are only mentioned, when the tribe in question dwells on both sides of the border, or when for any reason we have political lealings with it. Also, tribes within the administrative border under our rule are not, in most cases, given in fall detail.

The distinction, made by Dr. Bellew, between Afghan and Pathan tribes is not observed in the dictionary, the words, Afghan and 'athan, being taken as practically synonymous terms for the people who call themselves Pashtána lo: Pakhtana), plural of Pashtun (or Pakhtunj. 


\section{DICTIONARY OF THE PATHAN TRIBES}

ON THE

\section{NORTH-WEST FRONTIER OF INDIA.}

\section{Part I.}

North of the Kabal River, inclading all Mohmands, and tribes west of the Indus.

\section{A}

ABA KHEL. - A section of Nekpi Khel, Khwazazai, Akozai, Yusafzai Swatis.

ABA KHEL.-A minor fraction of Aka Maruf, Babuzai, Baizai, Akozai, Yusafzai Swatis.

ABA (or ABAO) KHEL. - A section of Makhozai, Nasuzai, Iliaszai, Bunerwals.

ABA KHEL (1,200).-A section of Babuzai, Baizai, Alozai, Yusafzai Swatis.

ABA KHEL $(2,000)$. - A section of Kuz Sulizai, Baizai, Akozai, Yusafzai Swatis.

ABA KHEL.-A section of Khadakzai, Khwazazai, Akozai, Yusafzai Swatis.
$A B A$ KHEL - A section of Ismailzai Daulatzai, Malizai, Bunerwals.

ABA KHEL.-A sub-division of Nurizai, Malizai, Bunerwals.

ABA KHEL (Mohmand country).-A sub-division of Masaud, Safis, a vassal clan of the Mohmands.

$A B_{A}$ Kon.-A sub-division of Maimana Khel, Khwaezai, Mohmands. Headman; Attai.

ABAZAI* (250).-A sub-division of Khrazazai, Akozai, Yusafzai Swatis.

ABBAS KHEL.-A minor fraction of Aba Khel, Ismailzai, Daulatzai, Malizai, Bunerwals. 
AbIb KHan Kreu.-See Habio Khan Thel.

Adar Kor.-A section of Hasani Kor, Muhammad Khan Kor, Burban Khel, Nlohmands. Headman; Shahlai.

ADIN KHeL, - A section of $B_{B b i}$ Ehel, Hamza Khel, Gandab Ha. limzai, Mohmands.

ADINZAI $(3,000 ;$ Uch, Shaws and Ramora valleys).-A sub-dirision of Khwazazai, Akozai, Yusafzais of Swat. Headraan; Nasrullah Khan of Uch.

ADRIZAI-A division of Alizai, Utman Khels.

AGGaI KHei (Bajanr).-A sab-division of Ilal Khel, Salarzai, Tarkanis.

AHSD KOR.-A Eub-division of Darat or Daata Khel, Khwaezai Mobmands.

AHMAD KEEL. - A minor fraction of Ismail Khel, MLakhozai, Nasuzai, Iliaszai, Bunerwals.

AHMadar Eor.-A sub-division of IIrhammad Khan Kor, Burhan Krbel, Pandiali Mohmands. Headmen : Namdad, Nasir, Narai.

AHMADAFZaI (Basawal, Kabul River).-A division of the Kukozai, who are affiliated with the Mobmand clans.

AIB Ker (Western Buner).-A sub-division of Salarzai, Iliaszai, Bunerwals.
AIB KOR.-A minor fraction of Shekh Khel, Aib Khel, Salarzai, Iliaszai, Bunerwals.

AIMA KHEL. - A minor fraction of Hati Khel, Mali (or Muli) Khel, Salarzai, Iliaszai, Bunerwals.

AIPaI Kor.-A sub-division of Hasan Khel, Dawezai, Moh. mands. Headman; Sandan.

A $а$ a KHEL (about 300 ; Bajaur).-A division of Samilzai, (or Ismailzai) Tarkanris.

AKA KHEL.-A section of Khadakzai, Khwazazai, Alrozai, Yusafzai siratis.

ArA KHeL (Goshta, Kabul River). -A subedivision of Dawat or Dauta Khel, Khwaezai, Mohmands. Headmen; Zama Shah, Akram.

A KA KHEL. - A section of Khalil Khel, Kasim Khel, Tarakzai, IIohmands. Headman; Khaista.

AFA KHEL.-A minor fraction of Aziz Khel, Shamozai, Khwazazai, Akozai Yusafzais.

AKA KOB. - A section of Khalil Khel, Kasim Khel, Tarakzai Nohmands. Headman: Sher Ali.

AEAL KOB.-A minor fraction of A saf Kbel, Dalkha Kor, Dadu Khel, Tarakzai, Mohmando. 
AEA M Maf $(1,500)$.-A section of Babuzai, Baizai, Akozai, Yusafzai Swatis.

AKAZAi. - A section of Ismailzai, Daulatzai, Malizai, Bunerwals.

Arazar.-A section of Panjpai, Nasuzai, Iliaszai, Bunerwals.

ArmazaI (1,380, Black Mountain).A division of Isazai, Yusafzais. Headmen ; see Tasan Khel. Aziz Khel, Barat Khel, and Painda Khel.

AkazaI (125 ; Mahaban).-A subdivision of Utmanzaj, Mandan Yusafzais. Headmen; Pir Khan and Alrbar Kban.

Akbar KHel (Bar Yalshdand).-A division of Utmanzai, Mohmands.

AKHUN KHEL (980).-A clan of the Allaimals.

AkHCND KHEL (Black Mountain). - Headman ; Amir Khan.

AmHOND Khex (400; Chagarzai portion of Buner).-A religious body, not belonging to any particular clan.

A go Kher (Chamla).-A division of Razar, Nandan Yusafzais.

Arozat (70 ; Black Mountain)A section of Tasan Khel, Akazai, Isazai, Yasafzais.
AmozaI $(15,800 *$ left bank of Swat river; 11,150* right bankin Dir ; Swat Valley from the Panjknra junction to Kohistan).-A large clan of Yusafzais, inhabiting both banks of the Swat river, sometimes known as Upper and Lower Swatis ; see also "Swatis."

A LazaIs (50; north of Torbela). -A sub-division of Utmanzai Mandan Yusafzais. Headmen; Isaf Khan and Ismail.

ALI BEg KHEL (Shontalai valley, Bajaur).-A division of Isazai Tarkanis.

ALI KHEL - A minor fraction of Jinki Khel, Bar Sulizai, Baizai Aizozai, Yusafzais.

ALI KHEI. A minor fraction of Mast Ali, Shekb Khel, Aib Khel, Salarzai, Iliaszai, Bunerwals.

ALI KHEL.-A section of the Makbozai, Nasuzai, Iliaszai, Eunerwals.

A II KHEL. A minor fraction of Khan Khel, Kuz Sulizai, Baizai, Akozai, Yusafzai Swatis.

AlI KHEL (2,000; opposite Chakdara main Swat ralley).-A sub-division of Bar Ranizai, Akozai, Yusfzai Swatis. Headmen; Sharif Khan and Sargand Khan.

ALI KWAJA KHEL. -A section of ranjpai, Nasuzai, Iliaszai, Bunerwals.

* Nore. - This does not include Mians, Gujars, and other "Fakirnama," nor are the Malizais of Panjkora or the Baizais of the Indus valley included in these totals. 
AlI Sher KHel.-A sub-division of Gadaizai, Iliaszai, Bunerwals.

AlI Sher KHel.-A minor fraction of Warkham Khel, Aib Khel, Salarzai, Iliaszai, Bunerwals.

Ari Sher KHel (Buner).-A subdivision of Nurizais, Iliaszai, Yusafzois.

AlizaI (1,000 ; North of Koh-iMohr peak). - One of eight clans of the Utman Khels.

AllaH KHEL.-A minor fraction of Maturizai, Bar Sulizai, Baizai, Akozai, Yusafzais.

AltaHi KHEL. - A minor fraction of Kemal Khel, Abazai, Khawazai, Akozai, Yusafzai Swatis.

Altaiwar $\quad 8,720$; Allai valley, north of Nandihar and south of Kohistan).-A considerable tribe, of Swati origin. See "Swatis." The principal Allai village is Pokal. Headmen; Bahadur Khan, Ghazi Khan (son of Arsala Khan), Abdulla (Akhundzada), and Nawab Khan.

Alrabi KHel (Mahaban).-A section of Barid Khel, Mada Khel, Tsazai, Yusafzais. Headmen; see "Bazid Khel."

AMADDI KHEL.-A minor fraction of Mulla Khel, Bahram-ka-Khel, Bar Ranizai, Akozai Yusafzai Swatis.
Amandlla Kor.-A minor fraction of Shabbaz Kor, Musa Khel, Sepab, Baezai, Mohmands.

AmazaI (1,500; Mababan).-A division of Usmanzai, Mandan Ynsafzais. Headman; Mauza Khan.

Amina Krel.-A section of Alisher Khel, Gadaizi, Iliaszai, Bunerwals.

AMIn KoR.-A section of Rasul Kor, Wali Beg Kor, Gandab Halimzai, Mohmands. Headmen ; Gulabdin, Umardin, Shamsuddin.

AMroHi (Mohmand country).-A sub-division of Kandahari Safis, who are one of the vassal clans of the Mohmands. Headman; Abbas.

ANAR KOR.-A minor fraction of Shahbqz Kor, Musa Khel, Sepah, Baezai, Mohmands.

ANDAR KHAN KHeL.-A sub-section of the Panjpai, Musa Khel, Nurizai, Malizai, Bunerwals.

ANGOR KoR.-A minor fraction of Muradi Khel, Dalkha Kor, Dadu Khel, Tarakzai, Mohmands.

ANKI B.HEL - A minor fraction of Ismailzai,' Makhozai, Nasuzai, Iliaszai, Bunerwals. 
$A R A B$ KHEL - A minor fraction of Ghaibi Khel, Bahram-ka-Khel, Bar Ranizai, Akozai, Yusafzai Swatis.

AraNG (Barang).-A minor fraction of Madak, Bada, Asil, Ismailzai, Utman Khels.

Asaf KHEL (400).-A section of Dalkha Kor, Dadu Khel, Tarakzai, Mohmands. Headmen; Jang, Abdulla, Lalo, Nawab, Sardaro.

Asgrar Kor.-A minor fraction of Jinki Khel, Bar Sulizai, Baizai, Akozai, Yusafzais.

Asha Kret.-A section of Nekpi Khel, Khwazazai, Akozai, Yusaf. zai Swatis.

AshazaI ( 1,000 ; centre of Buner). -One of the four dirisions of the Iliaszai, Bunerwals.

AsHLORS (200; north of Agror). -One of the leading clans of the Tikriwals. See also "Swatis." Headmen; Hakam Khan, Abbas Khan, Sadals, Hamidulla, Mursalin.

AshraI (225).-A clan of the Allaiwals.

AsIt.-A division of Ismailzai, Utman Khels.

As KHEL. - A section of Usman Kbel, Bar Ranizai, Akozai, Yusafzai Swatis.
Aso Kor.-A sub-division of Babazai Kor, Dawezai, Mohmands. Headmen; Moza Khas, Khan Zada.

Atamar Khel.-A sub-division of Usman Khel, Baezai Mohmands.

Ato KHeL(200). - A sub-division of Busha KKhel, Kamali Halimzai, Mohmands. Headmen; T'or Khan, Zarin Rahim, Dad.

Atrap KHEL.-A division of Samilzai, Tarkanis.

A USA KHEL. - The Nura Khel and Shekh Khel sections of Malizai Khwazazai, Akozai, Yusafzais, are known by this name.

Awal KHel (70; Black Mountain).-A section of Painda Khel, Akazai, Isazai, Yusafzais.

AYA KHEL (300). - A minor fraction of Babu Khel, Adinzai, Khwazazai Akozai, Yusafzais.

Afa KHel (Ya KHeL).-A subdivision of Ashazai, Iliaszai, Bunerwals.

AFAZ KHEL (Dir).-A section of Painda Khel, Sesada, Malizai, Yusafzais.

AFMENA KoR-A minor fraction of Hyatai Kor, Shah Mansur Khel, Dadu Khel, Tarakzai. Mohmands. Headman; Babu Jan. 
AzI KHEL (2,100).-A section of Bar Sulizai, Baizai, Akozai, Yrsafzai Swatis. Note-Above numbers include 1,200 men living outside $\mathrm{Sw}$ ati limits.

AzI KHEL. - A section of Ali Khel, Par Ranizai, Akızai, Yusafzai Swatis.

AZIZ KHEL - A section of Alishe: Khel, Gadaizai, Iliasz ai, Bunerwals.

Azrz KHEL.-A minor fraction of
Karu Kbel, Mali (or Muli) Ehe, Salarzai, Iliaszai, Bunerwals.

Aziz KHel (250; Black Mountain).-A sub-division of Akazai, Isazai, Yusafzais. Headmen ; Khanistan, Nur Khamad, Pir Zaman, and Abbas Khan.

AzIZ KHEL.-A section of Usman Khel, Ranizai, Akozai, Yusafzais.

Azız KнеL.-A section of Shamozai, Khwazazai, A kozai, Yusafzais.
BaBAKARKHEL. - A minor fraction of Alisber Khel, Musa Kbel, Nurizai, Malizai Bunerwals.

BABA KHEL.-A section of Khakizal A shazai, Ilaizai, Bunerwals.

BABA KHEL. - A miner fraction of Fatteh Khel, Abazai, Khwazizai, Akozai, Inaafzai Swatis.

BABAZAI (Pipal).-A division of the Udredunkai Darezai, Mohmands. Headmen; Hazur Khan, Jafar, Kochai, Moza Khan, Mobmandai.

$\mathrm{B}_{\mathrm{ABI}}$ - A minor fraction of Sultan Khel, Aka Khel, Dawat Khel, Khwaezai, Mohmands.

BABI KHEL.-A sub-division of the Hamza Khel, Gandab Halimzai, Mobmands. Headmen; Seth,
Saiyid Alam, Saiyid Albar, Paindal Khan.

Bazi KHBL.-A minor fraction of Bazid Khel, Shamozai, Khwazazai, Aknzai, Yusafzais.

$\mathrm{B}_{\mathrm{ABI}} \mathrm{KHEL-A}$ sub-division of Hamza Khel, Kamali Halimzai, Mohmands.

BABI KOR.-A section of Babi Khel, Hamza Khel, Gandab Halimzai, Mohmands.

$B_{A B U} K_{A R} K_{H E L}-A$ minor frac. tion of Sultan Khel, Malizai, Khwazazai, Akozai, Yusafzais.

BABD KHEL.-A section of Adinzai Khrazazai, Akozai, Yusafzai. Swatis. 
$B_{\triangle B U}$ KHEC.-A minor fraction of Maddi Khel, Utmanzai, Bar Ranizai, Akozai, Yusafzai Swatis.

BABU KHEL. - A minor fraction of Sherga Khel, Utmanzai, Adinzai, Khwazazai, Akozai, Yusafzai Swaiis.

BABUZAI $\left(5,200\right.$; $^{*}$ left bank of Swat River). -A sub-division of Baizai, Akozai, Yusafzai Sratis. Headmen; Firoz Khan, Pasayc: Khan, Mir Abdalla, Jamroz.

Babozar.-Another name for the Sepah division of Baezii, Mohmands.

BADA.-A sub-division of Asil Ismailzai, Ütman Khels.

\$BDAI-A minor fraction of Marghat Kbel, Aka Khel, Dawat Khel, Khwaezai, Mohmands.

BADALZAI.-A sub-division of Wara, or Wur, Mamund, Tarklanris.

BADIN KHEL.-A section of Nahaki or Yusaf Kor, Ibrahim Khel, Kamali Halimzai, Mohmands. Headmen; Saimal, Gulshah, Zai Khan, Post Khan, Gul Hamesh.

BADSHA KHEL. -A minor fraction of Babu Khel, Adinzai, Khwazazai Akozai, Yusafzais.

BADU Krel (Mahaban). - A section of Hasan Baz Khel, Mada Khel, Isazai, Yusafzais. Headman; Bara Khan.
BagkzaI (Hazarnao, Kabul River). -One of the three divisions of the Kukkozai, who are one of the affiliated Hohmand clans.

BAEZAI (9,000). - The most powerful of the Mohmand clans. Heac. men; Wahid Khan, Saijid Azam, (xhairat, Sultan Said, Pind Khan, Pavo, Tola, Pirai, Amin Khan, Yad Gul.

BaHadur Baba Kor.-A minor fraction of Kasim Khel, Nusa Khel, Sepah, Baezai, Mohmands.

BAHADER KHEL (Dakka, Girdi, and Peshawar valley in winter, Upper Helmand in summer). - Nomads, a division of Utmanzai, Ruchi Mohmands.

Batadur ShaH KHel.-A subdivision of Nura Khel Samilzai (or Ismailzai) 'Tarkanis.

BAHIOL KHEL. - A minor fraction of Maturizai, Bar Sulizai, Baizai, Akozai, Yusafzais.

BaHRAM-KA-KHEL (800; from Malaliand to Swat River),-A subdivision of Ranizai, Alzozai, Yusafzai Swatis.

BaHRAM KHEL.-A minor fraction of Sherga Khel, Utmanzai, Adinzai, Khwazazai, Akozai, Yusafzai Swatis.

BaHRAM KHEL.-A minor fraction of Bazid Khel, Shamozai, Khwazazai, Akozai, Yusafzais. 
BAI KHEL.-A section of Firozai, Chagarzai, Malizai, Bunerwals.

B AI KoR.-A section of Durba Khel, Hamza Khel. Gasdab Halimzai, Mohmands, Headmen; see "Durba Khel.".

Baizar or BaezaI， $(5,800$;* left bank of Swat River from Kohistan down to and including Thana).One of three clans of the Akozai, Yusafzai Swatis.

BAIZ KHEL.-A sub.division of Mada Khel, Isazai, Yusafzais. Headmen ; Baharal Khan, Saiyid Jamal, Lal Baz, Mrghal, Abdulla, Manzar, Ajab Gul, and others.

BaKHTATAR Kor.-A minor fraction of Hyatai Kor, Shahmansur Khel, Dadu Khel, Tarakzai, Mohmands. Headman; Multan.

BAFBA $K$ HEL. - A minor fraction of Nasrudin Khel, Malizai, Khwazazai, Akozai, Yusafzais.

BALI KHEL.-A minor fraction of Ibrahim Khel, Utmanzai, Bar Ranizai, Akozai, Yusafzai Srratis.

BALI KHEL.-A minor fraction of Sin Khel, Utmanzai, Bar Ranizai, Akozai, Yusafzais.

Balo (Laman). -A sub-division of Asil, Ismailzai, Utman Khels.

BaIOL KHEL.-A minor fraction of Sultan Khel, Aka Khel, Dawat Khel, Khwaezai, Mohmands.
Bami KHeL (8C0).-A section of Babuzai, Baizai, Akozai, Yusafzai Sratis.

BaMr KHeL (780).-A section of Khudu Khel, Saduzai, Utmanzai, Mandan Yusafzais.

BantT Khen (Dir).-A section of Painda Khel, Sesada, Malizai, Yusafzais.

BAO KHEL.-A miror fiaction of Mir Asan Khel, Badu Kbel, Aãinzai, Khwazazai, Akozai, Yusafzai Swatis.

BARA KHEL-A minor fraction of Must Ali, Shekh Khel, Aib Khel, Salarzai, Iliaszai, Bunerwals.

BABA KHEL.-A sub-division of Sepah, Baezai, Mohmanùs. Headmen ; Paind Khan, Shirin, M ujim Khan.

B BRA KHEL (Mahaban).-A section of Hasanbaz Khel, Mada Khel, Isazai, Yusafzais.

$B_{\triangle R A E}$ KHEL.-A minor fraction of Azi Khel, Bar Sulizai, Daizai, Akozai, Yusafzais.

BARAKZAI.-A sub-division of Danlatzai, Malizai, Bunerwals.

BaramigazaI-A sub-division of Wara or Wur, Mamund, Tarklanris (or Tarkanis).

BaRaT KHeL (250; Black Mourtain).-A sub-division of Akazai

- Not including Baizais of the Indus valley. 
Isazai, Ynsafzais, Headmen ; Awal Khan, Wali Shab, Husain Khan, Miro Khan, Bahadur, Badai, and otbers.

BARAT KHEL.-A minor fraction of Alisher Khel, Musa Khel, Nurizai, Malizai, Bunerwals.

Barat KHEL, (1,000).-A section of Babuzai, Baizai, Akozai, Yusufzai Swatis.

BARBAR KHeL.-A section of Aya Khel, Ashazai, Iliaszai, Bunerwals.

Bar DURanis.-A name sometimes applied to the Patban tribes who inhabit the north-eastern part of Yaghistan, enclosed between the range of the Hindu Kush, the Indus, the Salt Range, and the range of Suliman, and first applied to them by Abmad Shah. The name applies to the Yusafzai Utman Khels, Tarkanis, Mohmands, Afridis, Orakzais, Shinwaris, the tribes of the plains of Peshawar, and those of Bangash and Khatak.-(Elphinstone.)

The Duranis are the dominant tribe of Afghans, to which the present ruling family of Kabul belongs.

BarhaN KHeL 180 ; north-east of Baner).-A minor fraction of Ismail Khel, Makhozai, Nasozai, Iliaszai, Yusafzais.

BARI KHEL.-A minor fraction of Aba Khel, Ismailzai, Daulatzai, Malizai, Bunerwals.
BAREHAN KHEL.-A minor fraction of Musa Khel, Kuz Sulizai, Baizai, Akozai, Yusafzai Swatis.

BAR MAKAZAI-A sub-division of Wara, Namund, Tarkanis.

Barozai-A sub-division of Wara, Mamund, Tarkanis.

BARE KHEL.-A sub-division of Hamza Khel, Gandab Halimzai Mohmands; with them go the Taru Khel. Headmen; Lal Dad, Jallat Amir Baz, Fattehullab.

BARU KHEL. - A sub-division of Hamza Khel, Kamali Halimzai, Mobmands.

Bar SulizaI.- $(8,350 *$; North Swat left bank, to Kohistan). - A subdivision of the Baizai, Akozai Yusafzai Swatis, comprising the three sections Azi Kbel, Jinki Khel, and Maturizai.

BaSI KHer.-(Cis-Indus, and Duma mountain). - A sub-division of Chagarzai, Malizai, Yusafzais.

B $_{\triangle Z A}$ KHEL.-A sub-division of Mada Khel, Isazai, Yusafzais. Headmen; Kachkol, Zaidulia, Fakir Shah, Nur Hasan.

$\mathrm{B}_{\triangle Z I D} \mathrm{KHEL}$ - $-\mathrm{A}$ minor fraction of Aba Khel, Babuzai, Baizais Akozai, Yusafzais.

BAzID KHel (450; Mahaban).-A sub-division of Mada Khel, Isazai, Yusafzais. Headmen; Shahdad

* This includes 4,950 men of the Azi Khel and Jinki Khel sections living outside Swat limits. 
Khan, Sarfaraz Khan, Saiyid
Kalam, Shah Mardan, (Alrabi Khel), Muhammad Ali Khan, Baz Khan (Tata Khel).

BAZID KHEL, -A section of Shamozai, Khwazazai, Alkozai, Yusafzais.

BAZID KHEL.-A section of Hasan Khel, Gadaizai, Iliazai, Bunerwals.

BAZI KHEL.-A minor fraction of Khan Khel, Kuz Sulizai, Baizai, Alozai, Tusafzai Swatis.

Beror (100; Black Mountain).-A clan of llesbiwal, Swatis. Headman; Sadur Ali of Kabal.

Biba Kiнel (60; Black Mountain).-A section of Barst Khel, Akazai, Isazai, Yusafzais.

Bibal Thor (770), - A clan of Allaimals.

BIMBABAI (300; Kuz Totai).-One of the eight clans of the Utman Khels.

Bindan Ireme-A minor fraction of Warkam Khel, Aib Khel, Salarzai, lliaszai, Bunerwals.

BIN KHeL (Mahaban).-A section of Hassn Khel, Nada Kibei, Isazai, Yusafzais, Headmen; Sherdad Kihan, Ahwan Khan.

Bostan KHEL. A minor fraction of Alza Maruf, Babuzai, Baizai, Azozai, Yusafzais.
BUcHA KHeL (Bajaur).-A subdivision of Kíalut Khel, Samilzai, Tarkanis.

BECH KHEL - A minor fraction of Ranra Khel, Shati Khol, Wali Beg Kor, Gandab Halimzai, Mohmands. They are closely allied to the Ghunda Khel. Headman; Ghafar.

BUNDI KOR.-A section of Sikandar Khel, Kandai, Isa Khel, Mohmands. Headman; Majlum.

Bunerwals $(7,600$ exclusive of Firozaisj.- The name of Bunerwal strictly applies only to those Iliaszai and Malizai Yusafzais who live in the basin of the Barandu, the principal river of the Buner country. The Firozai section of the Chagarzais may, however, be included in the term.

BURAI KHEL. - A section of the Nahaki Kor, Ibrahim Khel, Kamali Halimzai, Mohmands.

BurHaN KHet.-A minor fraction of Ismail Khel, Makhozai, Nasuzai Iliaszai, Bunerwals.

Burhan KHel (700 ; Pandiali).A clan of Mohmands. Headmen; Saiyid Gal, Badgah, Namdad, Khan Mir, Lal, Saiyi, Dal, Nasim Gul, Ghulam Shah, Muhammad Umar. The Burhan Khel is one of the "Assured" clans.

[ Those Mohmand clans to which the British Government has given 
assurance that they shall not lose or cuffer by the severance of their ancient connection with the Afghan State. The other "Assured" clans are the Dawezai, Halimzai, Isa Khel, Tarakzai and Utmanzai.]

BurHan Kor.-A sub-division of Babazai, Dawezai, Mohmands. Headmen; Kochai, Ghilzai.

Burozar.-A sub-division of Wara, or Wur, Mamund, Tarklanris, or Tarkanis.
BUSA KHEL. - A minor fraction of Pira Khel, Mir Jan Khel, Utmanzai, Adinzai, Khwazazai, Aluzai, Yusafzai Swatis.

BUsHa KHEL (320).-A sub-division of Kamali Halimzai, Mohmands.

Bot KHEL.-A division of Ismailzai, Utman Khels.

Bотков.-A division of Ismailzai, Utman Khels
Chagarzai (7,000; Along both banks of the $I_{i}$ dus ard on the Duma mouatain, and 1,000 in the north-east of Buner).-A division of Malizai, Yusafzais, Pathans. The Firozai sub-division live in Buner; the nther two sub-divisions, viz., Nasrat Khel and Basi Khel, hold land on Duma, and on both sides of the Indus. Headmen; Kudrat Khan, Azim, Mirdad, Bustan, Madar, Nosheri Khan, Kasam Khan, Ghulam Khan, Nuhammad Aban Khan (Akhund Khel), and Hamid Khan. A portion of the Chagarzais (Basi Khel), fighting strength 200, are tenants of the Pariari Saiyids of the Black Mountain.

Chamba Krel (80 Black Mountain).-A section of Barat Khel, Alrazai, Isazai, Yusafzais.
Cenamlawals (1,200).-The name applied to the mixed Mandan clans who inhabit the Chamla valley, south-east of Buner.

Chandan KHec.-A minor fraction of Mir Jan Kbel, Utmanzai, Adinzai, Khwazazai, Akozai, Yusafzai Swatis.

Chandar Kerel (Bajaur).-A subdivision of Ilat Khel, Salarzai, Tarkanis.

Char KHex.-A section of Alishe: Khel, Gadaizai, Iliaszai, Bunerwals.

CHemari Kor (Bar Yakhdand),-A division of Utmanzai, Mohmands. Headmen; Badshah Muhammad, Ali Khan, Shamsai, Muhrmmad Abbas, Amir Baz, Siah Zarin. 
Dabar. - A division of Mandal, Utman K kels.

DAdA KheL (90; Blace Mountain). -A sub-division of Hasanzai Isazai, Yusafzais. Headmen; Habibulla, Saiyid. Ajab, Arsalla, Nur Khamad, Torabaz, Hamza, and Ghulam Haidar.

DADI KEEL.-A section of Sultan Khel, Bar Ranizai, Akozai, Yusafzois.

DADI KHEL.-A minor fraction of Aba Khel, Nekpi Khel, Khwizazai, Alsczai Yusafzais.

DADE KHEL (20:050). - A divipion of Tarakzai, Mohmands. Headmen; Gul Amir, Abdulla, Nabat, Lialo, Khan Kadir, Najai, Achuk.

DALKHA KREL. - A minor fraction of Suitan Khel, Malizai, Khrrazazai, Akozai, Yusafzais.

Dalk of Dadu Khel, Tarakzai, Mohmands. Headmen; Jang, Abdulla, Lalol Nawab, Najai, Achuk.

DALLU KBEL. - A minor fraction of Jalal Khel, Mali (or Muli) Khel, Salarzai, Iliaszai, Bunerwals.

DAORI KHEL.-A section of Samozai, Khwazazai, Aliozai, Yusafzai Swatis.
DARA SHAH Kon. - A minor fraction of Shahbaz Kor, Musa Khej, Supah, Baezai, Mohmands.

DarYazaI-A sub-division of Wara, Mamund, Tarkanis.

Darza KHeL (50; Black Mountain).-A section of Aziz Khel, Alkazai, Isazai, Yusafzais.

DACD KHEL.-A sub-division of Kadai Kor, Halimzai (Gandab), Mohmands. Headmen; Pahlwan, Izzat Shah, Ahmad, and Ato Muhammad.

Dactat Khel (65; Tartara).-A division of Mullagoris, a vassal clan of the Mohmands.

DaULAT KHEL.-A sub-division of Kakazai, Mamund, Tarklanris, or Tarkanis.

Daduat KHaN KHel.-A section of the Ibrahim Khel, Gadaizai, Iliaszai, Bunerwals.

Davlatzai $(1,400$; both banks of the Barandu river, part of the Topdara valley and hills around). -A division of the Malizai, Bunerwals.

Daclatzar (Mahaban).-A subdivision of Amazai, Usmanzai, Mandan Yusafzais. 
Daulazar.-A division of Mansur. Gaduns.

DAWAT, Or DAUD, KHEL,-A sub. division of Kadai Kor, Gandab Halimzai, Mohmands. Headmen; Muhammad Habib, Mirak Suleman.

Dawat, or DaUTA, KHEX (Bohai Dag; a few at Goshta, Kabul river).-A division of Kbwaezai, Mohmands. Headmen; Bara Khan, Muhammad Sharif Khan, Said.

DaWezaI '(700).-One of the affliated Molnmand clans. They are divided into "Kuchi" and "Udredunkai." Headmen; Hazur Khan, Habib Jan.

Dengan.-A tribe inhabiting Kunar, Laghman, and Ningrahar. A few Dehgans are also to be found in Zurmat and Bajaur. The Dehgans are said to be descendants of the Indian races originally inhabiting North-Eastern Afghanistan.

Deshiwals (720; Black Mountain). - A tribe of Swati origin. Headmen; Azad Khan is $K$ han of this tribe; other headmen are Gul Khan, Ahmad Wali, Asghar Ali, and others.

Dilazans.-A people of doubtful origin who in habited the Peshawar valley hefore the Pathan invasion. Scattered families of them are still to be found along the left bank of the Indus in the Hazara and Rawal Pindi districts.
Dodal (Nandihar).-A clan of the Nandihari Swatis. Headman; Ghulam Khan of Batgram.

DodI KHEL - A minor fraction of Barat Khel, Babuzai. Baizai, Akozai, Yusafzais.

Dotial $(1,695)$. - A clan of the Alloiwals.

DULHA KHEL (Dir).-A section of Sultan Khel, Sesada, Malizai, Yusafzais.

DERBA KHEL.-A sub-division of Hamza Khel. Gandab Halimzai, Mohmands. Headmen; Rogh Muhammad, Dauran, Saraf, Sahibroz, Yar Gul Akbar, Gul Ali, Izzat Khan, Amir Khan,

DURBA KHEL. - A sub-division on Hamza Khel, Kamali Halimzai, Mohmands. Headman; Jama Khan.

DURDANI KHEL. - A minor fraction of Musa Khel, Kuz-Snlizai, Baizai, Akozai, Yusafzai Swatis.

DURI KHEL. - A minor fraction of Aziz Khel, Shamozai, Khwazazaj, Akozai, Yusafzais.

Durma Kor (500; Lalpura, Loi Shilman). $\rightarrow A$ section of Shah Mansur Khel, Dadu Khel, Tarak. zai, Mohmands. Headmen; Mubammad Shah Khan and Mubammad Sadiq Khan.

DUSH OR DÜSHA KHes.-A subdivision of Shokb Khel, Auss Khel, Malizii, Yusafzais. 
FaIzelia Kor.-A minor fraction of Ranra Khel, Sbati Khel, Wali Beg Kor, Gandab Halimzai Mohmands. Headınan; Mashki.

Fatirnaya. - A term which covers Gujars, gardeners, ploughmen, tanners, musicians, artizans, menial servants, carriers, pedlars, etc., who live amongst the Yusafzais and are taxed by them.

Farid KHeL, - A minor fraction of Aka Maruf, Babuzai, Baizai, Akozai, Yusafzais.

FATEH IHEL. - A minor fraction of Nasrudin Khel, Malizai, Khwazazai, Akozai Yusafzais.

FATEH KHEL. - A minor fraction of Fiati Khel. Mali (or Muli) Khel, Salarzii, Iliaszai, Bunerwals.

FATEH KHEL.-A minor fraction of Bami Khel, Babuzai, Baizai, A hozai, Yusafzais.
FAter Krel- $-A$ section of $\mathrm{Aba}$ zai, Khwazazai, Akozai, Yusafzai Swatis.

Fateh KHel. A section of Ali Khel, Bar-Ranizai, Akozai, Yusafzai Swatis.

FateH Kor.-A section of Rami Khel, Kadai Kor, Gandab Halimzai, Mohmands. Headman; Sarkai.

FATEH KOR. - A minor fraction of Shahbaz Kor, Musa Khel, Sepah, Baezai, Mobmands. Headman; Ahmab Shah.

FAzIL KHel. - A minor fraction of Babu Khel, Adinzai, Khrazazai, Akozai, Yusafzai Swatis.

FAZIL Kor.-A section of Rasul Kor. Wali Beg Kor, Gandab Halimzai, Mohmands. Headmen; Bahadur, Zulkadar, Nazro.

FinozaI (1,000; extreme north-east of Buner).-A sub-division of Chagarzai, Malizai, Buncrwals.
GaDaizaI (900 ; southern slopes of the Ilam and Dosiri mountains). -A division of Iliaszai, Bunerwals.

GaDo.-A division of Mandal, Ttman Khels.
GADUNS OR JADUNS $(2,000$ Mahaban).-A tritue of Pathans some of whom also live in Britrsh territory in the Hazara district. There are two main clans, i.e., the Mansur and the Salar, who are at enmity with each other. 
$G_{A L I} P_{A O}$ (Bajaur). $\rightarrow A$ section of Kalut Khel, Nar Khel, Samilzai or Ismailzai Tarkanis.

GalzaDA KHeL. - A minor fraction of Aib Kor, Shekh Kbel, Aib Khel, Salarzai, Iliaszai, Bunerwals.

G tribe inhabiting the head of the Swat valley. 'l'bey are probably allied to the Kobistanis.

GazNI.-A section of Khakizai, Ashazai, Iliaszai, Bunerwals.

GHaibI KHeL.-A section of Bahram-ka-Khel, Bar Ranizai, Akozai, Yusafzai Swatis.

Ghaim Kor.-A section of Sroh, Busha Khel, Kamali Halimzai, Mohmands. Headman; Khanizaman.

GHalib Kor, - A minnr fraction of Shahbaz Kor, Musa Khel, Sepah, Baezai, Mohmands.

GHaLI KHeI. - A minor fraction of Aba Khel, Nekpi Khel, Khrazazai, Akozai, Yusafzais.

Grazi Beg Kor (100).- A subdivision of Ibrahim Khel, Kamali Halimzai, Mohmands. Headmen; Abbas, Mudasir, Muhammad Gul, Badsbah, Gul Said.

GHAZI KHAN (50; Black Mountain) -A section of Tasan Khel, Akazai Isazai, Yusafzais.
GHAZI KHEL. - A sub-diviison of Dawat Khel, Khwaezai, Mohmands, Headman: Said, who is the Khan of Lalpura's "Kazi."

GHAZI Krgex.-A section of Mamun Kor, Kandai, Isa Khel, Mohmands. Headmen; see Isa Khel.

GHAZI KOR.-A section of Durba Khel, Hamza Khel, Gandab Halimzai, Mohmands.

GHaZI Kor.-A section of Yardil Kor, Kadai Kor, Gandab Halimzai, Mohmands.

GHaZNI KHeL. - A minor fraction of Ismail Khel, Makhozai, Iliaszai, Bunerwals.

GHilzaI Kor.-A sub-division of Masaud, Safis, a vassal clan of the Mohmands.

GHolam KHeL.-A sub-division of Utmanzai, Mandan Yusafzais. Headmen; Azim Khan, Kasam Khan, Inayat Khan.

GHONDA KHEL.-A minor fraction of Ranra Khel, Shati Khel, Wali Beg Kor, Gandab Halimzai, Mohmands, This fraction goes with the Buch Khel. Headman; Hazrat Shah.

GHUNDI KHEL. -A division of Loi Shilman Halimzai, Mohmands.

Gigiant.-A smill section attached to Ranra Khel, Shatii Khel, Wali Beg Kor, Gandab, Falimzai, 
Mohmauds. Headman ; Mir Bajan.

GilaL (600). - A clan of Allaimals.

Gigianis.-Dee Gugianis.

GoRAI (600; scattered on confines of Bajaur).-One of the eight clans of the Utman Khel.

Gujars.-A scalmart Mussalman pastoral tribe, probably of the same origin as the Jats, scattered in large numbers amongst the Pathan tribes, to whom they are sabject, from the Black Mountain to the Kunar river. 'I'bey own separate villages in or near the lower hills, and till the soil, for which they pay rent. In summer they migrate with their flocks to the mountains. Gujars are also numerous in northwestern India and Kashmir. They speak the language of their winter homes, but have a fer words peculiar to themselves.
They are probably the descendants of the original inbabitants of the country, or at least represent sime earlier wave of invasion than that of the Patbans.

Grgiani.-(Peshawar District).-A tribe who inhabit the Doaba or plain in the angle between the Kabul and swat rivers.

GUL AHMAD KOR-A section of Khalil Khel, Kasim Khel, Tarakzai, Mohmauds. Headman ; Saifal.

Gelo Khel (Yakhdand)-A division of Utmanzai, Mohmands. Headmen; see Utmanzai.

Genda Krel (Mababan), - A section of Hasanbaz Kbul, Mada Khel, Isazai, Yusafzais.

GuRBdz.-One of the four divisions of the Safis, who are a vassal clan of the Mohmands.

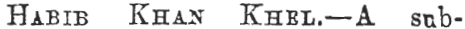
division of Nura Khel, Ismailzai, Tarklanris, or Tarkanis.

HAFIz FoR.-A section of Kan Khel, Kasim Khel, Tarakzai Mohmands. Headman; Abdulla.

HAIAT KHEL.-A minor fraction of Musa Khel, Makhozai, Nasuzaiab Iliaszai, Bunerwals.
$\mathrm{H}_{\text {AIBAT }} \mathrm{KHEL}$ - A minor fraction of Aka Khe1, Ismailzai, Daulatzai, Malizai, Bunerwals.

HAIDAR KoR.-A minor fraction of Asaf Khel, Dalkha Kor, Dadu Khel, Tarakzai, Mobmands. Headmen; see Asaf Khel。

HajaI Kor.-A sub-division of Babazai Kor, Dawezai, Mohmands. 
Headmen; Hazur Khan, Khalik Jan.

HALAL TABAR. - A section of Sikandar Khel, Kandai, Isa Khel of Pandiali Mohmands. For Headmen; see "Isa Khel."

HALIMZAI. - A clan of Mohmands, divided according to location into (i) the Halimzais of Gandab $(2,0 ? 0)$ and (ii) the Halimzais of Kamali $(1,500)$. According to Mer'k they are a branch of the 'larakzais, but for all practical purposes they are now regarded as a separate clan. (i) are divided into the Hamza Khel, Kadai Kor, Wali Beg Kor divisions; (ii) are divided into the Ibrahim Khel, Hamza Khel, and Busha Khel. (For Headmen see above divisions.)

H $\triangle$ LK $\triangle \mathrm{MMAR}$ KoR.-A minor fraction of Rasul Kor, sub-section of Ranra Khe!.

HAMZA KHEL (450).-A division of Gandab Halimzai, Mohmands. For Headmen; see Sultan Khel, Durba Khel, Baru Khel.

Hamza KHeL (3,000 Palai valley and Thana.)-A section of $\mathrm{Kuz}$ Sulizai, Baizai, Akozai, Yusafzai, Swatis. Headmen; Inkab Khan, Bahram Khan, Sarbaland Khan.

HAMZA KHEL of KaMALI (150).-A division of Kamali Halimzai Mohmands. Headmen; Jamal Khan (Durba Khel), Jabbar, Raza Khan, Faiz Talab, Ghani, Tamal Muhabbat, Zarghun, Ghansai,
Jangia, Baz Khan, Zainulla Khan, Sarfaraz Khan, Morcha, Dara Shah, Ajmer.

HAMZA KHRL.-A minor fraction Nasrudin Khel, Malizai. Khwäzazai, Akozai, Yusafzais.

HAMZA KHEL. - A section of arkazai, Daulatzai, Malizai, Sunerwals.

$\mathrm{H}_{\triangle \mathrm{RIF}}$ Kor (Part in Mohmand, part in British territory).-A seotion of Kani Khel, Kasim Khel, Tarakzai, Mohmands. Headmen; Khad Gul, Khadi Gul, Jalal, Zehr Gul.

Hasanbaz KheL (450; Mahaban) -A sub-division of Mada Kbel. Isazai, Yusafzais.

HASAN KHEL.-A division of Udredunkai Dawezai, Mohmands.

Hasan KHel (450 ; Mahaban).-A snb-division of Mada Khel, Isazai, Yusafzais. Headmen; Saiyid Azam, Sherdad, Rashid, Kalandar, and Ziyarat Khan.

HASAN KHEL.-A minor fraction of Jalal Khel, Mali (or Muli) Khel, Salarzai, Iliaszai, Bunerwals.

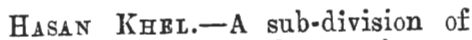
Gadaizai, Iliaszai, Bunerwals.

HASAN KHEL.-A section of Shamerai, Khwazazai, Akozai, Yusafzai Swatis. 
HasaN KHeL (340).-A sub-division of Mada Khel, Isizai, Yusafzais. Headmen ; Sairid Azam, Sherdad, Rashid, Kalandar and Ziarat - Khan.

HASAY KHEL (Ningrahar and Upper Helmand). - A division of Kuchi Dawezai, Hohmands. Headmen; Habib Jan, Haji Islam, Abdul Karim, Abdul Wabab, and others.

HASAN KOR (Loi Shilman).-A section of Sbah Mransur Khel, Dadu Khel, 'Tarakzai, il obmands. Headmen; Kbaista Kban, Gulistan.

HASANI KOR - A sub-division of Nuhammad Khan For, Burhan Khel, Wohmands. Headmen; Said Gul, Shahlai, Badshab Narai, Mralik.

Hasa NaIs $(2,125$; Black Mountain, and both sides of Indus). - A divisiou of Istzai, Yusufzais. Headmen; the $K h$ an of the Isazais is alrays cbosen from the Khan Kl:el sub-division of the Hasanzais. There is at present (191.7) no recognised Khan. Other leading men are--Hamid Khan (Kotwal), Sherdad (Mir Ahmad K'nel), Najim Khan (Zakaria Kihel), Tora Khan, (Lukman Khel), Aladad (Kaka Khel), Saisid Azim Shah.

Hishayr Kor (Utmanzai; Yakhdand).-A division of Utmanzai, cne of the affliated Mohmand clans. Headmen; see Utmanzzai.
HaSHayr Kor (Khwaezai).-A sub-division of Khadi Khel, Khwaezai, Mohmands.

$\mathrm{H}_{\text {ASHIM KOR.-A mincr fracticr of }}$ Shahiuz Kor, Musa Khel, Sepab, Baezai, Mohmands.

HataI Kor.-A sub-division of Nuhammad Khan Kor, Burhan. Khel, Mohmands. Headmen; Mahar Khan, Azam, Kazo, Saiddal, Muhammad Sher.

Hati KHEL.-A section of Mali (or Muli) Khel, Salarzai, Iliaszai, Bunerwals.

Hazar BUz.-Nomadic, a division of Dawezaj, Kuchi Moh. mands. Headmen; Sher Muhammad, Fazl, Fazli Ahmad.

HilaL PaBa Kor.-A minor fraction of Kasim Khel, Musa Khel Sepah, Baezai, Mohmands.

HINDKI.-The name given to the Hindus who inhabit Afghanistan. They are of the Kbatri class, and are found all over the country, eren among the wildest tribes. Bellew estimates their number at about 300,000 souls. The name Hindizi is also loosely used on the Upper Indus, in Dir, Bajaur etc., to denote the speakers of Puniabi or any of its dialects; and it is further sometimes applied, in a historical sense, to the Buddhist inhabitants of the Peshawar valley north of the Kabul river, who were driven thence about the 5 th or 6th century, and settled in the neighbourhood of $\overline{K a n}$ dahare 
HINDEI KoR.-A section of Rasul Kor, Wali Beg Kor, Gandab Halimzai, Mohmands. Headmen; Malikdad, Husain, Gulab Khan.

Hindustani Fanamics.-A band of fanatics recruited from Hindustan, who have inhabited various portions of the Chagarzai, Amazai, Chamlu, and Buner bills. They are now residing at Usmash in Mada Khel territory, and number some 500 men under their leader, Abdul Karim Abdulla.
There are said to be a number of Tanaolis among them.

HUSAIN KHEL.-A division of Salarzai, Tarkanis.

Hosain KHeL.-See Sin KHEL.

Hratar Kor (400), - A section of Shah Mansur Khel, Dadu Khel, Tarakzai, Mohmands. Headmen; Abdulla, Babujan, Saigid Rasul, Dawezai, Sofi, Multan.
IbRatiu KHer (400). -A division of Kamail Halimzai, Mohmands. Headmen; Antar, Arsalla Khan Redai, Nurai, Dmar Din, Dauran Shah. (Lakai Kor and Khwazn Kuhai Kor.)-Abbas Mudassir, Mubammad Gul Badshah, Gul Said. (Ghazi Beg Kor)-Saimal Gul Sbah, Zai Khan, Post Khan, Gul Hamesh. (Nahaki or Yusaf Kor).

IBRAHIM EHEI. (Bajaur).-A division of Salarzai, Tarkanis. This is the "Khan" Khel of the clan. Headmen; Safdar Khan (Nawab of Nawagai). Sardar Khan (of Khar).

IBRAHIM KHEL.- A minor fraction of Musa Khel, Makhozai, Nasuzai, Iliaszai, Bunerwals.

IBRAHIM KHEL.-A sub-division of Gadaizai, Iliaszai, Buuerwala.
IBRAHIM KHEL.A section of Utmanzai, Bar Ranizai, Akozai, Ynsafzai Swatis. Headmen; Alam Khan, Aslam Khan.

Ibratim Kor. (Loi Shilman).A minor fraction of Durma Kor, Shab Miansur Khel, Dadu Khel, Tarakzai, Mohmands.

IBRAHIMI TABAR.-A section of Rajai Khel, Yusaf Khel, Isa Khel, Mohmands. Headmen : see Isa Khel.

IDAr KHEL. A section of Ali Khel, Bar Ranizai, Akozai, Yusafzai Swatis.

IKATIYAR KOR (Loi Shilman).A minor fraction of Durma Kor, Shab Mansur Khel, Dadu Khol, Tarakzai, Mohmands.

Ilac KHer.mA division of Salarzai Tarkanis. 
Iltasza (6,000; Buner valley. Slopes of Dosiri range).- One of the two clans of Bunerwals. Headman; Hastam Khan of Bampokha (Salarzai).

INAM KHOR.-A sub-division of Wara, Mamund, Tarkanis.

ISI EHEL.-A minor fraction of Bami Khel, Babuzai, Baizai Akozai, Iusafzais.

Is A KHEL (700). (Pandiali and Danish Kol).-A clan of Mohmands. Originally an offshoot of the Taralizai clan, hut now distinct from them. This is one of the "assured" clans. Headmen; Ghulam Khan Pri-ud-din, Hakim, Shah Dod, Guldost, Rahmgnl, Kachkol, Chat, Said Khan, Sohbat Zsidullah.

IsA KHEL.-A minor fraction of Jinki Khel, Bar Sulizai, Baizai, Alozai, Yusafzais.

Isa KHEL (Jarobi).-A sub-division of Usman Khel, Baezai, Mohmands. Headmen; Payo, Tola, Gul MIuhammad, Mazid.

IsAzaIS or IsozaIs (Bajaur).-One of the four clans of Tarkanis occupying the Jandol valley. Headman; Said Ahmad Khan.

IsAZAIS. - $\left(\mathrm{On}_{\mathrm{n}}\right.$ the Indus between the Black Mountain and Maha. ban). A clan of Yusafzais.

IsMaIL.-A section of Khadin Khel, Ashazai, Iliaszai, Bunerwals.
IsmaIL KHEL. - A minor fraction of Bai Khel, Firozai, Chagarzai, Malizai, Bunerwals.

IsMaIL KHEL. $-A$ section of Makhozai, Nasuzai, Iliaszai Bunerwals.

IsMaIL KHEL.-A section of Sultan-ka-khel, Bar Ranizai, Akozai, Yusafzai Swatis.

ÍsMAIL KHEL.-A minor fraction of Bai Khel, Kuz Sulizai, Baizai, Akozai, Yusafzais.

IsuraIL Khel. $-A$ minor fraction of Aziz Khel, Shamozai, Khwazazai, Akozai, Yusafzais.

IsMaIL KOR.-A section of Hatai Kor, Muhammad Khan Kor, Burhan Khel, Mohmands. Headman; Muhammad Sher.

Is Amazai, Usmanzai, Mandan Yusafzais.

IsarailzaI. - A sub-division of Daulatzai, Malizai, Bunerwals.

IsMaIlzaI $(8,100)$. - The most powerful of eight clans of the Utman Khel.

Is MAILZAI, or S SMILZAI- $M$ Maidan valley.) One of the four clans of the Tarkanri

IsozaI.-See IsazaI.

IsOZAL-A division of Alizai, Utman Khel. 
$J_{\triangle B A R}$ KHEL. - A section of Musa Khel, Sepah, Baezai, Mohmands. Headmen; Sabir Khan and Saiyid Azim.

$J_{A B I}$ KHEL (Bajaur).-A division of Samilzai, or Ismailzai, Tarka. nis.

$J_{\triangle B I}$ KoR.-A section of Sangar Khel, Yusaf Khel, Isa Khel. Mohmands. Headmen; see Yusaf Khel

J clan of Deshiwal Srvatis. Headmen; Ambul Shahi, Izzatulla.

JaDT NS ; see GADUNS.

JAIAL KHEL.-A section of Mali (or MLuli) Khel, Salarzaj, Iliaszai, Bunerwals.

$J_{\triangle L A L}$ KHEL. - A minor fraction of Azi Khel, Bar Sulizai, Beizai Akozai, Yusafzais.

JALAL KHEL (Dir).,-A section of Painda Khel, Sesada, Malizai, Yusafzais.

Jatangiai Kamoi Badeshi (4.00). -A clan of Allaiwals.

$J_{\triangle L I L}$ KOB.-A minor fraction of Rahmat Kor, Musa Khel, Sepah, Baezai Mobmands.
JALIAL KoR (Kung).-A sab.diri sion of Maimana Khel, $\mathrm{Bhwaezai,}$ Mohmands. Headmen; Khalil, Tabar.

$J_{\triangle M A \bar{L}}$ KHEL (Dir). - A minor frac. tion of Painda Khel, Malizai, Khwazazai, Akozai, Yosafzais.

$J_{A} M_{A L}$ KHEL. $-A$ minor fraction of Macha Khel, Bahram-ka Khel, Ranizai, Akozai, Yusafzais.

JAMI KOB.-A section of Sultan Khel, Hamza Khel, Gandab Halimzai, Mohmauds. Headman ; Ghulam Murad.

$J_{\triangle N}$ BEG Kor. - A section of Sanga: Khel, Yusaf Khel, Isa Khel Mohmands. Headmen; see Isa Khel.

$J_{\triangle N}$ BEG Kon (part in Mohmand, part in British territory).-A section of Kani Khel, Kasim Khel, Tarakzai, Mobmands. Headman; Sheraz.

JANGI TABAB. - A section of $\mathrm{MI}_{2}$. mun Kor, Kandai, Isa Khel, Mohmands. Headmen ; see Isa Khel.

JEWAN Kor.-A sub-division of Dawat or Dauta Khel, Khawaezai, Mohmands. Headman; Bara Khan. 
JIIAN KHEL. - A minor fraction of Kambir (or Kambo) Khel, Aib Khel, salarzai, Iliaszai, Bunerwais.

JIXEI KHEL $\left(4,200^{*}\right)$ - - A section of Bar Sulizai, Baizai, Alzozai, Yusufzais.

JoGA. - A section of Khalizai Ashazai, Iliaszai, Bunerwals.

JoJI KHEL (40; Black Mountain). -A section of Painda Khel, JU NA KHEL. - A section of Sebujni Atazai, Isazai, Tusafzais.
JUGGI KHEL. A minor fraction of Kemal Ǩhel, Abazai, Khwazazai Akozai, Yusafzai Swails.

JULA KHEL.-A minor fraction of Alra Maruf, Babuzai, Baizai, Akozai, Yusufzai Swatis.

JUNA KHEL, - A section of Firozai Chagarzai, Malizai, Bunerwals.
KACHU KEEL. - A minor fraction of Azi Khel, Ali Khel, Bar Ranizai, Alozai, Yusufzai Swatis. This is the Khan Khel of the Ranizais. Headmen; Sharif Khan, Sargand Khan.

KADAI $K_{03}$ (400).-A division of Gandab Halimzai, Mohmands. Headmen; see Yirdil Kor, Rahmatal Kor, Katasar, Daud Khel.

$\mathrm{K}_{\triangle D A R}$ KHEL.-A minor fraction of Nasirudin Khel, Malizai, Khwazazai, Alozai, Yusalzais.

Kadrr Kor.-A sub-division of Khrappawal, Burhan Khel, Moimands.

KADO KOR.-A section of Khalil Khel, Kasim Khel, Tarakzai Mohwands.
KAHMAN KOR.-A division of Gorai Utman Kbel.

Kafi KHEL (300; Black Mountain).-A sub-division of Hasanzai, Isazai, Yusafzais. Headmen; the most influential is Aladaa, who is a friend and relation of the Nanab of Amb). Others areShahzali, Khoidad, and Waidad.

$K_{A K A} K_{O R}-A$ sub-division of the Maimana Khel, Khwaezai, Mohmands.

KaKaZaI (3,100; Bajaur).-A division of Mamund, Tarkauis.

$K_{A \text { LA }} \operatorname{KeET}_{\text {(50 }}$; Black Mountain)-A section of Áziz Khel, Akazai, Isazai, Yusafzais.

Kalar KoB.-A section of Sroh, Busha Khel, Kamali Halimzaie 
Mohmands. Headman; Taza Gul.

KaLAL KoR.-A minor fraction of Ranra Khel, shati Khel, Wali Beg Kor, Gandab Halimzai, Mohmands. Headman; Jamdar.

KaLandar Khel.-A section of Sadin, Ilal Khel, Salarzai, 'Jarkanis.

KaLANDAR KHEL, -A minor fraction of Shabbaz Kor, Musa Khel, Sepah, Baezai, Mohmands.

$\mathrm{K}_{A L U} \mathrm{KHEL}$-A minor fraction of Musa Khel, Makhozai, Nasuzai lliaszai, Bunerwals.

KALUT Kнет (Bajaur).-A division of Samilzai or Ismailzai Tarkanis.

KaMaL KHeL.-A sub-division of the Kandahari Safis, who are a rassal clan of the Mohmands.

KAMALZAI.-A division of Usmanzai, Mandan Yusaf́zais.

KAMAZAI (150).-A sub-division of Utmanzai, Mandan Yusafzais.

KAMBAR KHEL.-A minor fraction of Warkan Khel, Aib Khel, Salarzai, Iliaszai, Bunerwals.

KaMbar Kor.-A section of Sultan Khel, Hamza Khel, Gandab Halimzai, Mohmands. Headman ; Mir Aghajan.
KaMBAR KOR.-A minor fraction of Asaf Khel, Dalkha Kor, Dadu Khel, Tarakzai, Mohmands.

Kambir (or Kambo) Knet.-A section of Aib Khel, Salarzai, Iliaszai, Bunerwals.

KaNAZAI,-A division of Utmanzai, Mandan Yusafzais, Headmen; Kasam and Jamal Khan.

KaNDAHARIS.-A division of the Safis, who are a rassal clan of tho. Mohmands.

KandaI (Pandiali).-A division of Isa Khel, Mohmands. Headmen; Ghulam Khan, Paiuddin.

KANI KHEL (60); part in Mohmand, part in British territory). -A sub-division of Kasim Khel, Tarakzai, Mohmands.

KANZAL KHEL.-A minor fraction. of Alisher Khel, Mrsa Khel, Nurizai, Malizai, Bunerwals.

KARAM KoR.-A section of Hasan Kor, Muhammad Khan Kor, Burhan Khel, Nohmands. Headmen; Badshah, Baz, Malik.

KARI KHEL. A section of Sultanka-Khel, Bar Ranizai, Alkozai, Yusafzai Swatis.

KARIMDAD KHEI.-A minor fraction of Must Ali, Shekh Khel, Aib Khel Salarzai, Iliaszai, Bunerwals. 
FiRIA KHEL. A minor fraction of Fateb Khel, Abazai, Khwazazai, Akozai, Yusafzai Swatis.

KARMO KHEL (Dir territory). - A section of Painda Khel, Sesada, Mralizai, Yusafzais.

KABOI KHEL, -A minor fraction of Painda Khel, Malizai, Khwazazai, Akazai, Yusafzais.

KARE KHEL.-A section of Mali (or IIuli) Khel, Salarzai, Iliaszai, Bunerwals.

KASAM.-A section of Khakizai, Ashazai, Iliaszai, Bunerwals.

KaSAM KHEL. - A clan of Khudu Khel.

KASHT Kor.-A minor fraction of Asaf Khel, Dalkha Kor, Dadu Khel, Tarakzai, Mlohmands.

Fasiar Khel. - A minor fraction of Aib Kor, Shekb Khel, Aib Khel, Salarzai, Iliaszai, Bunerwal.

KasI K KEEL (800; hills north of Michni, part in British territory). -A division of Tarakzai, Mohmands.

KASim Khel (Yakhdand).-A division of Utmanzai, Mohmands. Headmen; see Utmanzai.

$\mathrm{K}_{\triangle \mathrm{SIM}} \mathrm{KHEI}_{\mathrm{H}}-\mathrm{A}$ section of MIusa Khel, Sepah, Baezai, Mohmands. Headmen; Ghairat, Ahmad Nur, Salamat.
KAsI 3 Kon.-A section of Rahmatal Kor, Kadai Kor, Gandab Halimzai, Mohmands. Headmen ; see Rahmatal Kor.

Kata KHeL.-A minor fraction of Aka Maruf, Babuzai, Baizai, Akozai, Yusafzai Swatis.

KataSar. - A sub-division of Kadal Kor, Gandab Halimzai, Mohmands. Headmen ; Jamdad, Abdul Wahid, Jamal, Shamnzai, Ranjak, Charogai, Shah Munir, Bahadur, Samodin, Makaiz, Jallal, Khan Mubammad, Faizullah, Rashatullah, Ghatol, Pir Muhammad, Wahab.

KATKAI KHEL.-A division of Salarzai, Tarkanis.

KatorzaI (Bajanr).-A division of Samilzai Tarkanis.

Katra Khel. -A section of Seni Khel, Gadaizai, Iliaszai, Bunerwals.

KeMaL KeeL. - A section of Abazai, Khwazazsi, Akozai, Iusafzai Swatis.

Kemal Keel.-A minor fracion of Baba Khel, Adinzri, Khrazazai Akozai, Yusafzai Swatis.

Kesama Kor. - A section of Mamun Kor, Kandai, Isa Khel, Mohmands. Headman; Ghulam Khan.

KhadakZaI (2,000).-A sub-division of Khwazazai, Akozai, Yusafzai Swatis.

Note. - The number given includes the Dosha Khel division which is now dependent on the Khan of Dir. 
KHADABZAT. A division of Mansur, Gaduns.

KHADI Khel (Pohai Dag). - A division of Khwaezai, Mohmands. Headmen; Painda Khan, liudai, Muhammad, Akram, Aziz Khan.

KHADI KOR.-A minor fraction of Shohbaz Kor, Musa Khel, Sepah, Baezal, Mohmands.

KHADIN KHEL.-A sub-division of Ashazai, Iliaszai, Bunerwals.

KrHadish KHEL. - A minor fraction of Mir Asan Khel, Babu Khel, Adinzai, Khrazazai, Akozai, Yusaf zai Swatis.

Khatrolla Kor.-A minor fraction of Ranra Khel, Shati Khel, Wali Beg Kor, Gandab Halimzai, Mohmands. Headman ; Sher Mubammad.

KHAISTA Kor (Yakhdand).-A division of Utmanzai, Mohmands. Headmen; see Utmanzai.

KHAKIZAI. - A sub-division of Ashazai, Iliaszai, Bunerwals.

Kralil KHeL (200; Hills north of Michni, part in British territory). - A sub-division of Kasim Khel, Taraszai, Mohmands. Headmen; Jauai, Saifal, Shàzada, Gulfaraz.
KHALIL KoR.-A minor fraction of Rahmat Kor, MIusa Khel, Sepah, Baezai, MTohmands.

FHaLiLs $\{3,600$; Peshwar Dis. trict).-A tribe of the same origin as the Mohmands, who live east of the Khaibar Pass and along the left bank of lower Bara.

KralOZaI.-A sub-division of Kakazai, Mlamund, Tarkanis.

KenaNaZaI. - A sub-division of Utmanzai, Mandan Yusafzais. Headmen ; Kasam, Sadar Khan.

KHaNdA KHEL.-A section of Khan Khel, Kuz sulizai, Baizai, Akozai, Yusafzai Swatis.

Khani Khel.-See Kani Khel.

KHaN Khel (70; Black Mountain). -A section of Barat Khel, Alkazai Isazai, Yusaf zais.

KHaN KHeL $(3,000)$. - A section of Kuz Sulizai, Baizai, Aliozai Yusafzai Swatis. Headmen; Inayat Khan and Bahrane Khan of Thana, Lower Swat.

KHaN KHEL (180； Daggar).-The family of the Khans of Daggar, distinct and very influential in Buner, and not belonging to any clan. Headman; AYub Khan of Daggar.

Khan Kher (120; Black Mountain).-A slan of Deshiwal, Swatis. Headmen; Abdul Ghafur, 
Abu Bakar Khan, Siliandar Khan, Abdul Wahab Khan, and Bahadur Khan.

KHaN KHe (Nandihar). - A clan of Nandihari Swatis.

Kнау Kнel (300; The Black Mountain).-A sub-division of Hasanzai, Isazai, Iusafzais. Headmen; the Khan of the Isazais is chosen from this subdivision, but the Khanship is at present (1907) racant. Other leading men are-Alam Khan, Sabar Khan, Kasam, and Paidad.

KHAN KHEL. -A minor fraction of Bazid Khel, Shamozai, Khwaza. $\mathrm{Z} 3 \mathrm{i}$, Yusafzais.

KrHAMaI TABar.-A section of the Mamun Kor, Kandai, Isa Khel. Mohmands. Headman: Paiuddin.

KHASI KHBL. - A minor fraction of Aba Khel, Kaz Sulizai, Baizai, Akozai, Yusafzais.

BHATCN KHEI. - A minor fraction of Musa Khel, Kaz Sulizai, Baizai, Akozai, Yusafzais.

KHIALI KoR. - A minor fraction of Shahbaz Kor, Musa Khel, Sepab, Baezai, Mohmands.

KHIDARZaI or KeIZarzaI.-A division of Razar, Mandan Yusafzais.

KHIDR KHeL. - A section of Seni Khel, Gadaizai, Iliaszai, Bunerwals.
KHODADAD KHEL.-A minor fraction of Ismail, Khadin Khel, Ashazai, Iliaszai, Bunerwals.

Khordad Kor, or KHUDADAD Kon.-A sub-division of Babazai Kor, Dawezai, Mohmands. Headman; Jafar.

KHOIDAD Kor.-A section of Sultan Khel, Hamza Khel, Gandab Halimzai, Mohmands. Headman : Mnhammad Akram.

Khojawas Kor, or Khwajawas Kon.-A section of Rasal Kor, Wali Beg Kor, Gandab Halimzai, Hohmands. Headmen: Abdul Amir, Ghafar.

Khrappattal. -See Kuz Burhan $\mathrm{KHEL}$.

KमणDU KHEL (1.600; south of Buner).-A sub-division of Saduzai, Utmanzai, Mandan Yusafzais.

KHTGb KHEL.-A sub-division of Usman Khel, Baezai Mohmands. Headmen: Pirai, Shahnam, Izzat, Allahdad Hadi Gul.

KHULozat.-A sub-division of Kakazai, Mamund, Tarklanris, of Tarkanis.

KhoMari. - A minor fraction of Kanzal Khel, Alisher Khel, Musa Khel, Nurizai, Malizai, Bunerwals.

KHUSHal KoR.-A division of Gorai, Utman Khel. 
Khwaezai (2,000; Bohai Dag, Goshta, Kabul River). - One of the Mohmand clans. Headmen : see Dawat Khel, Maimana Khel, Khadi Khel.

KHWAJA KHel. - A minor fraction of Fateh Khel,Abazai, Khwazazi, Akozai, Yusafzai Swatis.

KHWAJA KHEL. - An unimportant sub-division of Bar-Kanizai, Akozai, Yusafzai Swatis.

KHWAJOKUHAI KoR.-A subdivision of Ibrahim Khel, Eamali Halimzai, Mohmands. Headmen (with those of Lakkai Kor) : Antar, Arsalla Khan, Said Fakir, Redai, Narai, Haidar Khan, Umar Din, Dauran Shah, Ghulam Jan.

KHWAZOZAI $(11,150$; right bank of the Swat river, from Kohistan to the Panjkora river).-One of the three divisions of Akozai, Yusaf. zai, Swatis.

They are under the Khan of Dir.

KHWazozaI (Bajaur).-A division of Isazai, Tarkanis.

Said to be of aboriginal stock.

KishranzaI.-A sub-division of Kamalzai, Uswanzai, Mandan Yusufzais.

KodA KHeL (Bohai Dag).-A sub.division of Usman Khel, Baezai, Mohmands. Headmen: Yad Gul, Ghafar, Shad Nam, Gulistan, Almas.
KolI KHex (Dakka, Girdi, Pesh. war, and Upper Helmand).Nomadic, a division of (Kuchi) Utmanzai, Mohmands.

Kotwal (440 ; Black Mountain).A sub-division of $\mathrm{Hasanzai,} \mathrm{Isazai,}$ Yusufzais. Headmen: Hamid Khan, Bostan Khan, Hajat Khan, Ghulam and others.

KotwaL KHEL.-d section of Ara Khel, Ashazai, Iliaszai, Bunerwal.

KUChelai (90; Black Mountain).A clan of Deshiwal Swatis, Headmen : Ahmad, Mir Husain.

F DCHIs (Mohmand country, Upper Helmand, and Ningrahar).-Nomadic, as distinguished from the Udredunkai, Utrianzai, and Dawezai Mohmands.

In winter they leave their families in Ningrahar, and carry merchandize between Kabul and Peshawar. The Dawezai Kuchis are subdivided into Hasan Khel, Mandozai, Hazarbuz, with an associated clan called $\mathrm{Za}$ Khel. Headmen (Utmanzais.) Asim, Abdulla Nar, and Khandad.

KokKOZaI (Right bank of Kabul river).-One of the affliated Mohmand clans.

KUSHAB. A minor fraction of Kanzal Khel, Alisher Khel, is usa. Khei, Nurizai, Malizai, Bunerwals. 
rísH Kon (Kabull river, west of Michni and part in British territor's). A minor fraction of Asaf Khel, Dalkha Kor, Dadu Khel, Tarakzai, MTohmands. For Headmen; see Asat Khel.

KrTA KrEq. - A division of Sanazai. Cis-Swat Utman Khels. Headmen; Saiyid Shah, Mir Alam.

Kez (or Khrappawal) EUrhaN
KHEL.-A division of Burhan Khel, Mohmands.

Kᄃz SulizaI $(6,500$; left bank of Swat river, from Thana to Maniar). - A sub-division of BaizaiAlozai, Insafzai Sivatis, comprising the 3 sections Aba Khel, Khan Khel, and Musa Khel.

KwaJA-A section of Khadin Khel, Ashazai, Iliaszai, Bunerwals.
LAGHMaN KaEL-A minor fraction of Kıru Khel, Malia (or Muli) Khel, Salarzai, lliaszai, Bunerwals.

LAEAI KOR.-A sub-division of Ibrahim Khel, Kamali Halimzai Hohmands.

LaIA KOB.-A minor fraction of Shahbaz Kor, IIusa Khel, Sepah, Baezai, Nohmands.

LaLAT Kor.-A section of Rami Knel, Kadai Kor, Gandab Halimzai, Mohmands. Headman: Aman.

LAL KHEL (60; Black Jountain).-
A section of Painda Khel, Akazai, Isazai, Yussfzais.

LUBA KHEL.-A minor fraction of Musa Khel, Kuz Sulizai, Baizai Akozai, Yusufzais.

LOKMAN KHEL (Right bank of Indus opposite Black Mountain), -A sub-division of Hasanzai, Isazai, Yusafzais. Headmen : Umara Khan. Torab, Niamatulla, Paidad, Nadar Shah, Abdulla and Sain.

LUNDA KHEL.-A section of Usuani Khel, Bar Ranizai, Akozai, Yusafzai Swatis.

IJ ${ }_{A C H A}$ KHEL $-A$ section of $M_{A D A K}$ (Babukarrah valley).-A Bahram-ka-khel, Bar-Ranizai, division of Salarzai, Turkanis. Akozai, Yusafzai Srratis. 
Madak.-A section of Bada, Asil, Ismailzai, Utman Khel.

MADA KHeL (1,500; Mahaban).A division of Isazai, Yusafzais. They are divided territorially into two main branches, called after their two most important villages, Maira and Manjakot. Headmen : see Baza Khel, Hasan Khel, Baiz Khel, and Musa Aba Saivid. Other Headmen are : Sadar Khan, Dad Khan, Najman Nabi (Manjakot) Haidar Khan Halim Gul, Nadir Khan (Naira).

M $\triangle D A K H E L,-A$ minor fraction of Bai Khel, Firozai, Chagarzai, Malizai, Bunerwals.

$M_{\triangle D_{A}} \quad K H E L$ (570). - A clan of the Allaiwals.

$M_{A D A} N_{A M A}(950)$. - A sub-division of Mada Khel, Isazai, Yusafzais.

M Utmanzai. Bar Ranizai, Akozai, Yusafzai, Swatis.

$\mathrm{M}_{\triangle D O}$ or $\mathrm{M}_{\triangle G H D U D}, \mathrm{KHEL}_{\mathrm{H}}-\mathrm{A}$ section of Khadakzai, Khwazazai, Akozai, Yusafzais.

MaDUR KoR.-A sub-division of Masauà, Safis, who are a rassal clan of the Mohmands.

MAGHDUD KHEL.-A sub-division of Kakazai, Mamund, Tarklanris, or Tarkanis.
Maghdod KHel. - A minor fraction of Aba Khel, Babuzai, Baizai, Akozai, Yussfzais.

Maghded KaeI. - See Mado Khel.

MAHBUB RoR.-A section of Rasul Kor, Walibeg Kor, Gandab Halimzai, Mohmands. Headmen; Jamdad, Lllias Khan Tilla.

MAHI KHBL. - A minor frastion of Nasrudin Khel, Malizai, Khwazazai, Akozai, Yusafzais.

MaHMUD KHEL. - A minor fraction of Aib Kor, Shekh Khel, Aib Khel, Salarzai, Iliaszai, Bunerwals.

MАHMOD KHEL.-A minor fraction of Karn Khel, Mali (or Muli) Khel, Salarzai, Iliaszai, Bunerwals.

MaHmod Khec.-A section of Shamizai, Khwazazai, Akozai Yusafzais.

$\mathrm{M}_{A H M U D}$ KHEL.-A sub-division of Kakazai, Matund, Tarklanris or Tarkanis.

$\mathrm{M}_{\text {AHMONZAI }}-\mathrm{A}$ division of Alizai Utman Khel.

MaHSUD KHeL. - A sub-division of Kakazai, Mamund, Tarkanis.

Maimenta KHel (Bohai Dag).-A division of Khwaezai Mohmands. 
MAKH KOR (Hills north-west of Michni, Halli Gandiso).-A A minor fraction of Asaf Krhel, Dalkba Kor, Dadu Khel, Tarakzai, Mohmands.

Manhozar (Part of Puran valley and east slopes of Dosiri mountain).-A sub-division of Nasuzai, Tliaszai, Bunerwals.

Masi KHeL.-A section of Firozai, Chagarzai, Malizai, Bunerwals.

Matiedr EHet.-A section of Panjpai, Nasuzai : Iliaszai, Bunerwals.

MILI (or MrLI) KHEL (Western Buner).-A sub-division of Salarzai, Iliaszai, Eunerwals.

Mili KHEL.-A section of Ali Khel, Bar Ranizai, Akozai, Yusafzai Sratis.

MaLIE KHeL. - A minor fraction of Musa Khel, Kuz Sulizai, Baizai, Akozai, Yusafzai Swatis.

Malie KHeL. - A minor fraction of Aki Mlaruf, Babuziti, Baizai, Akozai, Yusafzais.

MaLinza (Chamla).-A division of Razur, Mandan Tusa fzais.

MaLizaI (3, 700 ; Buner ane northern Chamla).-One of the two clans of the Bunerwals.
MatizaI (26,500; Dir and Panjkora).-A large sub-division of Khwazazai, Akozai, Yusafzais.

Maikats-(North of Agror).Une of the leading clans of the Tikriwals. Headmen;-Lal Khan, Dawat Khan, Akram, Kasam Khan, Abdulla Khan, and others.

MAMA KHeI.-A section of Shamozai, Khwazazai, Alsozai, Yusafzai Swatis.

MamanZaI. --See Muhammadzai.

Mano KHex (Black Mountain).-A sub-division of Hasanzai, Isazai Yusafzais. Headmen; Sai yid Ghulam, Mir Hamza, Khadi Khan, Khoidad.

Mayrond (12,000; Bajaur, principaily in Watelai valley, but they own villages on both sides of the Durand Line).-One of the four clans of 'Tarkanis. Headmen; Muhammad Amin Khan of Inayat Kila, Momin Khan.

MAMON KOR.-A sub-division of Kandai, Isa Khel, Mohmands, Headmen; Ghulam Khan, Paiuddin.

Mamonzar.-A division of Alizai, Utman Khel.

Manezar (Yusafzai Plain).-A division of Razar, Mandanr Yusafzais. 
Maxuzar (80; Black Mountain).A section of Tasan Khel, Akazai, lsazai, Yusafzais.

Mandal $(1,000:$ - One of the eight clans of the Utman Khel.

MaNDAN or MandanR $(25,000-$ 30,000 ; Peshawar District). - A Yusafzai tribe, who hold that portion of the Peshawar district not occupied by Khalils, Daudzais, Gaugianis, Baizais, or $\mathrm{Mr}$ hammadzais.

M $\triangle$ NDAN KHEL.-A minor fraction of Jinki Khel, Bar Sulizai, Baizai, Akozai, Yusafzais.

Mandar (Laman).-A division of Ismailzai, Utman Khel.

M ANDaZAI.-A sub-division of Daulatzai, Malizai, Bunerwals.

Mandezar (Bajaur).-A division of Isazai, Tarkanis.

Said to be of aboriginal stock.

MandozaI (Chardeh, Kabul river, Peshawar Valley and upper Helmand). - Nomadic, a division of Dawezai, Kuchi Mohmands.

Mandrashi Kor.-A section of Sroh, Busha Khel, Kamali Halimzai, Mohmands. Headmen; see Sroh.

MaNGHAI Kor.-A minor fraction of Jabar Khel, Musa Khel, Sepah, Bazeai, Mohmands.
MaNizar.-A division of Razar Mandan Yusafzais.

MANRI KHEL.-A minor fraction of Jinki Khel, Bar Sulizai, Baizai, Aliozai, Yusafzais.

Minsor $(1,50 J) .-A$ clan of the Gaduns.

MarchozaI.-A division of Alizai, Utman Khel.

MARDAN KHEL. -A section of Sultan-ka-Khel, Bar Ranizai, Akozai, Yusafzai Swatis.

MaRr Kor. - A section of Hatai Kor, Nuhammad Khan Kor, Burhan Khel, Mohmands. Headmen ; Nazrai, Khalid, Raz.s.

MaRJan KHeL-A minor fraction of Utmanzai, Adinzai, Khwazazai, Akozai, Yusafzai Swatis.

Marehozar. -A division of Alizai Utman Khel.

Marki Kael KaLan.-A section of Musara Khel, Ashazi, Iliaszai, Bunerwals.

Marki KHeL KHURD.-A section of the Musara Khel, Ashazai, Iliaszai, Bunerwals.

MARUF KHEL.-A minor fraction of Bazid Khel, Shamozai, Khwazazai, Akozai, Yusafzais. 
MASAL KOR (Hills north-west of Michni) - A minor fraction of Asaf Khel, Dalkha Kor, Dadu Khel, Tarakzai, Nohmands. Headmen; see A saf Khel.

MASACD KOR (North-east of the Bedmanai Pass). - A division of Safis, who are a rassal clan of the Mohmands.

MASAUD Kor (Kain Shilman).-A minor fraction of Asaf Khel, Valkha Kor, Dadu Khel, Tarakzai, Mohmands.

MasHTANis (Bajaur).-An adopted sept, or division, of the Isazai, Tarklanris, or Tarkanis. Probably of the same origin as the Mushmanis $(q \cdot v$.

Mastai KOB.-A section of Rrmi Khel, Kadai Kor, Gandab Halimzai, Mohmands. With them live a small section of the Yusaf Khel. Headmau; Kanzal.

Mast KHeL (Bajaur).-A division of Isazai, Tarkanis. Headman; Nuhammad Shah Khan.

Mata.-A division of Mandal, Utman Khel. Mata Kor.-A section of Sroh,
Busha Khel, Kamali Halimzai, Mohmands. Headman; Khanizaman.

MatkhwazaI.-A division of Salar, Gadans.
Maturizai (1,300).-A section of Bar sulizai, Baizai, Akozai, Yrsafzai Swatis.

MAYIN KoR.-A minor fraction of Shahbaz Kor, Musa Khel, Sepab, Baezai, Mohmands.

MaZar Kor (Bohai Dag). - A sabdivision of Maimana Khel, Khwaezai, Mohmands. Headman; Saifuddin.

MaZID KHEL.-A section of Sikan. dar Khel, Kandai, Isa Khel Mohmands.

$\mathrm{M}_{A Z I D}$ KHEL.-A minor fraction of Hati Khel, Mali (or Muli) Khel, Salarzai, Iliaszai Bunerwals。

M AZI KOB.-A minor fraction of Shahbaz Kor, Musa Khel, Sepah, Baezai, Mohmands.

Mihr Din Kor.-A section of Yardil Kor, Kadai Kor, Gandab Halimzai, Nohmands. Headmen: Shah Jehan, Nawab Khan.

Mrr Ahmad Khel (140;' Black Mountain).-A sub-division of Hasanzai, Isazai, Yusafzais. Headmen: Jehandad, Miyandad, Gujar, Mukarab Khan, Ahmad Khan, and Alam Khan.

Mir ahmad Khel.-A minor fraction of Aka Khel, Ismailzai, Daulatzai, Malizai, Bunerwals.

Mir Ahmad Kreel-A section of Ibrahim Khel, Gadaizai, Iliaszai, Bunerwals. 


\section{3}

Mirak KHel Dakka, Girdi, and Peshawar valley and Upper Helmand).-Nomadic, a division of Utmanzai, Kuchi Mohmands.

Mirak Kor.-A section of Daud Khel, Kadai Kor, Gandab Halimzai, Mohmands. Headmen : Mirak, Sulejman, Muhammad Habib.

MiR A LI KHEL.-A minor fraction of Azi Khel, Bar Sulizai, Baizai Alozai, Yusafzais.

Mir Baz Kor.-A section of Rani Khel, Kadai Kor, Gandab Halimzai, Mohmands. Headman : Sarkai.

Mir Hasan KHel (400). -A minor fraction of Babu Khel, Adinzai, Khrrazazai, Akozai, Yusafzai Swatis.

MIR $J_{A N}$ KHEL. - A minor fraction of Utmanzai, Adinzai, Khwazazai, Akozai, Yusafzais.

MIR KHAN KHEL.-A section of Ali Khel, Bar Ranizai, Akozai, Yusafzai Swatis.

Mrr KHeL.-A minor fraction of Aka Maruf, Babuzai, Baizai Akozai, Yusafzais.

Mis KHex.-A minor fraction of Bami Khel, Babuzai, Baizai, Akozai, Yusafzais.

MiRa KHEL. -A section of Shamozai, Khwazazai, Akozai, Yusafzai Swatis
MIRA KHEL.-A minor fraction of Panjpai, Musa Khel, Nurizai, Malizai, Bunerwals.

MIRO KHEL.-A sub-division of Sepah, Baezai, Mohmands. Headmen : Naib Khan and Wahid.

MIR SAIYID Kor (Pipal).-A subdivision of Hasan Khel, Dawezai, Mohmands. Headman: see Dawezai.

Mir WaIs KHEL. -A minor fraction of Panjpai, Musa Khel, Nurizai, Malizai, Bunerwals.

MiRWAS KHEL.-A section of Shamezai, Khwazazai, Akozai, Yusafzai Swatis.

Mirza KHeL.-A sub-division of Kandahari, Safis, who are a vassal clan of the Mohmands.

MishranzaIs.-A sub-division of Kamalzai, Usmanzai, Mandan Yusafzais.

MISHRI KHEL.-A minor fraction of Jalal Khel, Mali (or Muli) Khel, Salarzai, Iliaszai, Bunerwais.

Mishwanis.-See Mushwanis.

M ITta KHeL.-A minor fraction of Aka Maruf, Babuzai, Baizai Akozai, Y usafzais.

Mitta KHer.-A minor fraction of Asha Khel, Nokpi Khel, Khwazazai, Akozai, Yusafzais. 
Mogat Bara KHAN KHEL-A minor fraction of $\mathrm{Khw} a \mathrm{ja}$ Khadin Khel, Ashazai, Iliaszai, Bunerwals.

MoHmands $\{10,550$ in British territory; 11,000 not under British control; hills north-west of Peshawar, between the Swat and Kabul rivers).-A Pathan tribe of pure Afghan descent. They have four main divisions, viz., Tarakzai, Halimzai, Baezai, and Khwaezai. A fringe of affiliated clans (the Kukkozai, Dawezai, and Utmanzai) surrounds the tribe ; it is further hedged in, on the slopes of the Tatara Range, by the vassal clan of the Mullagoris, and towards Bajaur by the Safis. The Isa Khel and Burhan Khel of Pandiali were originally branches of the Tarakzai, but are now quite distinct. The chiefs, who are recognized as Khans of the Mobmands, are those of Lalpura, Goshta, and Pandiali. Of these the most important are the Khans of Lalpura. The holder of the Lalpura Khanship is Akbar Khan, who is at present at Kabul, under surveillance.

Mohmandzai.-See Muhammadzai.

Morcha KнеL (Lalpura Kam Dakka, etc., on the Kabul river) - A minor fraction of Durma Kor, Shah Mansur Khel, Dadu Khel, Tarakzai, Mobmands. They are the Khan (or chief) Khel of the Mohunands, and it is from them that the Khans of Lalpura are invariably selected; see Mohmands. .
MORGaI Kor.-A section of Hatai Kor, Muhammad Khan Kor, or 'Bar' Burhan Khel, Pandiali, Mohmands.

MozADIN TABAR, - A section of Mamun Kor, Kandai, Isa Khel, Mohmands. Headmen: see Kandaj.

MUDAB KHEL. - A section of Khadakzai, Khwazazai, Akozai, Yusafzri Swatis.

MUHAMMAD KHAN KoR (Pandiali). -A division of Burhan Khel Mohmands : they are also known as 'Bar,' Burhan Khel.

MUHam MaD KHan Khel (Goshta). -A sub-division of the Khadi Khel, Khwaezai Mohmands. Headmen: Mir Muhammad Khan, Barka Khan, Yusuf Khan.

MUHAMMAD KHeI.-A minor fraction of Ismail Khel, Makhozai Nasuzai, Iliaszai, Bunerwals.

MUHAMMAD $Y_{A R}$ KoR.-A section of Rami Khel, Kadai Kor, Gandab Halimzai, Mohmands. Headman : Mahba Din.

Munammadzai (Peshawar District). -A tribe who live in Hactnagar; they are also known as Mohmandzai or $M$ amanzai.

MUxa K日EL. - A section of Aya Khel, Ashazai, Iliaszai, Bunerwals. 
Mullagori Kor.-A section of Rajai Khel, Yusuf Khol, Isa Khel, Mohmands.

Mullagoris ( 903 ; Tartara).-A vassal clan of the Mohmands. Headmen : Shah Beg, Hafiz, Mira Jan, Jalat.

MULLA KHEL. - A section of Shamizai, Khwazazai, Akozai, Yusafzais.

MULLa KHEL (Dir).-A minor fraction of Sultan Khel, Malizai, Khwazazai, Akozai, Yusafzais.

MULTA KHEL.-A section of Bahram-ka-Khel, Bar Ranizai, Akozai, Yusafzai Swatis.

MULIA KOR.-A section of Sultan Khel, Hamza Khel, Gandab Halimzai, Mohmands. Headman : Lalajan.

MULLA Kor.-A secticn of Sroh, Busha Khel, Kamali Halimzai, Mohmands. Headman: Khanizaman.

Mtrad KHEL (350), - A section of Dalkha Kor, Dadu Khel, Tarakzai Mohmands. Headmen: Multan, Fajai, Muhammad Hassan (Shahi Kor), Achuk (Takhai Kor), Akbar, Madda Khan Mir Ali.

MURAdU KHEL. - A minor fraction of Azi Khel, Ali Khel Par Ranizai, Akozai, Yusatzai swatss.
MURGHaI Kor.-A section of Hatai Kor, Muhammad Khan Kor, Burhan Khel, Mohmands.

iviosa Abu SaIrid.-A aub-division of Mada Khel, Isazai, Yusafzais. Headmen: Baz Khan and $\mathrm{Yar}_{\mathbf{r}}$ Khan.

Mosa KHEL (Bajaur).-A division of Isazai, Tarkanis.

MUSA KHeL $(2,840)$. - A clan of the Allaiwals.

MUSA KHEL. - A minor fraction of Warkam Khel, Aib Khel, Salarzai, lliaszai, Bunerwals.

MUSA KHEL -A section of Makho zai, Nasuzai, Iliaszai, Bunerwals.

Musa KHeL.-A sub-division of Nurizai, Malizai, Bunerwals.

MUsA KHEL (1,500). -A section of Kuz Sulizai, Baizai, Akozai, Yusafzai Swatis.

MUsa KHeL.-A section of Sen $\mathbf{i}$ Khel, Gadaizai, Iliaszai, Bunerwals.

MUsa KHEL.-A section of Aya Khel, Ashazai, Iliaszai, Bunerwals.

MUSA KHEL, A minor fraotion of Bami Khel, Babuzai, Baizai, Ákozai Yusafzais, 
Mrsı KHEL (3,000 Mitai).-A sub-division of Sepsb, Baezai, Iohmands.

Mcsı Kor (Bohai Dag).-A subdivision of Maimana Khel, Khwaezai, Mohmands. Headman: Saifar.

Mosara KHeL. - A sub-dirision of Astazai, Iliaszai. Bunerwals.

NosazaI.-A division of Mansur Gaduns.

M七sнTaxis.-A few Mushwanis live with the Utmanznis of the Hazara border. The clans, etc., of the Mushwanis are not separately indexed in this Dictionary.

See Mashwari, Part IV.

MosT AII.-A minor fraction of Shekh Khe], Aib Khel, Salarzai Iliazai, Bunerwals.

MUTakaI (500; south of junction of Jandol and Bajaur streams).One of the eight clans of the Utman Khel.
Nadir Kor.-A section of Yardil Kor, Kadai Kor, Gandab Halimzai, Mlohmands.

NAHAKEI, or YTSAF, KoR (80).-A sub-dirision of Ibrahim Khel, Kamali Halimzai, Mohmands.

NATDIHABIS $\quad(1,000 ; \quad$ Nandihar valles, north of Hazara District). - A tribe of Swati origin. Headmen : Samandar Khan, Mozuffar Ehan.

NANU KHEL (70; right bank of the Indus opposite the Black Mountain). $-A$ sub-division of Hasanzai, Isazai, Yusafzais. Headmen: Fakir, Azim, Faruk Sher.
NaraizaI.-A division of Kukkozai, who are a vassal clan of the Mohmands.

NARORS. - A clan of Tikriwal Swatis. Headmen : Saizid Ahmad, Amirulla, Aslam Khan, Ibrahim Khan and other's.

Nasir Kor.-A section of Rasul Kor, Wali Beg Kor, Gandab Halimzai Mohmands. Headmen: Hasan, Ghulam Nabbi, Mehr Gul.

Naskat KeEL (1800; Cis-Indus, and on the north-eastern borders of Buner; -A sub-division of the Chagarzai Malizai, Yusafzais. They do not belong to Buner proper. Headmen : Miandan, Ismail Khan. 
NaSRAT KHet (80; Black Mountain) -A sub-division of Hasanzai, Isazai, Yusafzais. Headmen: Manzar, Hasham, Mansur. The most important man is the Sahibzada of Kanar (Abdul Afoo), a holy man who has a good deal of influence with the surrounding tribes.

NaSRUdiN Khel (1,500, Maidan, Dir).-A section of Malizai,Khwazazai, Akozai, Yusafzais. Headmen: Khans of Robat and Fam, Jan of Bargulai, and Barun.

NASUZAI or $\mathrm{N}_{A \mathrm{SOZ}}$ aI $(1,600$, western siopes of Duma mountain).--One of the four divisions of Iliaszai, Bunerwals, and comprising the two sub-divisions Panjpai and Makhozai.

$\mathbb{N}_{\triangle W}$ AB KoR.-A section of Rahmatal Kor, Kadai Kor, Gandab Halimzai, Mohmands. Headman; Nausher Khan.

NAZAB ROR. - See SADO KOR.

$N_{\triangle Z A R}$ KoR.-A minor fraction of Muradi Khel, Dalkha Kor, Dadu Khel, Tarakzai, Mohmands.

NAZO KHEL-A section of Abazai, Khwazazai, Akozai, Yusafzais.
Nazr ALI KHet. - A minor fraction of Maddi Khel, Utmanzai, Bar Ranizai, Akozai, Y usafzai Swatis.

Negri or Nikbi Khel $(4,000$, a valley of the same name on right bank of Swat). - A sub-division of Khwazazai, Alsozai, Yusafzai Swatis. Headman: Yusaf Khan.

NIAST KheL:-A section of Aya Khel, Ashazai, Iliaszai, Bunerwals.

Nikbi KHel. - See NekPi KHeL.

NURA KHEL (Upper or east end of Talash valley).-A section of (A usa Khel), Malizai, Khwazazai, Akozai, Yusafzais.

NURA KHEL. - A division of Ismailzai, Tarklanris, or Tarkanis.

NURizaI $(1,100$; southern corner of the Buner valley).-One of the three divisions of Malizai, Bunerwals.

NUR MUhamMad Khel. - A minor fraction of Gbaibi Khel, Bahramka-Khel, Bar-Ranizai, Akozai, Yusafzai Swatis.
$P_{A D A I}$ KOR.-A sub-division of the Dawat Khel, Khwaezai, Mohmands. Headman: Bora Khan.
PaDShah KheL. - A minor fraction of Ya Khel, Babu Khel, Ad̄inzai, Khwazazai, Akozai, Yusafzai Swatis. 
PAIG Kor, or KadaI Kor.-A section of Darud Khel, Kadai Kor. Gandab Halimzai, Mohmands. Headmen ; Yakub, Allah Mir.

PaGaI Kor or WaLI Beg Kor.-A section of Rasul Kor, Wali Beg Kor, Gandab Halimzai, Mohmands, Headmen: Sher Zaman, Gul Hasan, Ghulam Jan.

PAH K̈EL (Bohai Jag).-A subdivision of Khadi Khel, Khwaezai Mohmands. Headmen; Gudai, MIuhammad.

PaHLWAN Kor. - A section of Daud Khel, Kadai K or, Gandab Halimzai, Mohmands.

PaIE (350).-A clan of the Allaiwals.

PAINDA.-A minor fraction of Madak, Bada, Asil, Ismailzai, Utman Khel.

PAINDA KHEL (170; Black Mountain).-A sub-division of Akazai, Isazaj, Insafzais. Headmen : Zarif Khan, Abdulla, Sahaid Azim, Hazratulla.

PAINDA KHel.-A section of Alisher Khel, Gadaizai, Iliaszai, Bunerwals.

$P_{\triangle I N D A} K_{H R L}-A$ minor fraction of Macha Khel, Bahram-ka-Khel, Bar Ranizai, Akozai, Yusafzai, Swatis.
PaINDa KHel.-A sub-division of Shamozai, Ismailzai, Utman Khels. Headmen: Ayub Khan, Mir Saijid.

PaINda KHel.-A sub-division of Stamozai, Ismailzai, Utman Khel.

PAINDA KHeL (3,900; left bank of the Panjkora river, Dir).-A section of Malizai, Khwazazai, Akozai Yusafzais. Headmen: Rahmatulla of Barkhand, Mir Afzal of Samkut, Gul Abdulla of Bandai, Abid Khan of Dorial, and Saiyid Kamal of Akhagram.

PAL KHeL.-A section of Mandizai, Daulatzai, Malizai, Bunerwals.

PANJGOL.-A clan of Nandihari, Swatis. Headmen : Hamidulla, Zghawsr Ali, Kudratulla, and others.

Panjmiral.-A clan of Nandihari, Swatis. Headmen : Khan, Khan Wali, Ghulam Khan, Hasham Khan, and Zafar Khan.

PanjPaI.-A section of Musa Khel, Nurizai, Malizai, Bunerwals.

PanjPaI (800; Buner).-A subdivision of Nasuzai, Iliaszai, Bunerwals.

PARDESI Kor.-A section of the Rajai Khel, Yusaf Kbel, Isa Khel, Mohmands. Headmen: see Isa Khel. 
Pariaris (400; Black Mountain).Khel Chagarzais (200), Gujars, etc. (100). Headmen : Mian The headmen are all Saiyids, and the Chagarzais and Gujars are thoir tenants.

$P_{\text {AR KHel (Tartara). }}$-A division of Mullagoris, who are a vassal clan of the Mohmands. Headmen : Adam Khan and Baz.

Parshai-a minor fraction of Divided into Saiyids (100), Bazi Saiyid, Muhammad Ali Shah.

Madak, Bado, Asil, Ismailzai, Utman Khel.

Peghoza (200; Kuz Totai).-One of the eight clans of Utman Khel.

Pesha Kor (Pipal).-A sub-division of Hasan Khel, Dawezai, Mobmands.

PIRA KHEL.-A minor fraction of Mir Jan Khel, Utmanzai, Adinzai, Khwazazai, Akozai, Yusafzai, Swatis.

$\mathbf{R}$

RAHDO Kor.-A minor fraction of Ranra Khel, Shati Khel, Walibeg Kor, Gandab Halimzai, Mohmands. Headman : Gudai.

RAHIMDAD KOR.-A minor fraction of Asaf Khel, Dalkha Kor, Dadu Khel, Tarakzai, Mohmands.

RAHIM KoR.-A section of Sultan Khel, Hamza Khel, Gandab Halimzai, Mohmands. Headman: Mahammad Ghaus.

RABIM KoR.-A minor fraction of Asaf Khel, Dalkha Kor, Dadu Khel, Tarakzai Mohmands.

RAHMAN KOR (confines of Bajaur). -A division of Gorai, Utman Khel.

RAHMAT KoR.-A section of Musa Khel, Sepah, Baezai, Mohmands.
Headmen; Saiyid Azim, Hassim, Alazai, Hadi Gui.

Rahmatal Koz.-A sub-division of Kadai Kor, Gandab Halimzai, Mohmands. Headnien: Nausher Khan, Abdul Kadir, Ghulam Jan, Samo.

$R_{A H M I}$ KHEL. $-A$ sub-division of Kadai Kor, Gandab Halimzai, Mohmands.

JaJAI KHEL (Danish Kol).-A sub-division of Yusuf Khel, Isa Khel, Mobmands. Headmen : Kitch Kol, Chat.

RANIZAI, BAR (6,840; left bank of the Swat river). - One of the three divisions of Akozai, Yusafzai Swatis. 
RAIIZAI, SAME $(3,200$; south of Shalsot and Digar, and north of Mardan).-A heterogenous mixture of Yusafzai Swatis, Utman Khel. etc., formed into a clan. Headman: Ghulam Haidar of Dargai.

Note.-Originally servants of the Bar Ranizai, but now independent.

R $\perp$ NRA KHEL.-A section of Shati Khel, Ali Beg Kor, Gandab Halimzai, Mohmands.

RASUL KHEL ( 80 ; Black Mountain). -A section of Aziz Khel, Akazai, Isazai, Yusafzais.

RASTL KOR.-A sub-division of Wali Beg Kor, Gandab Halimzai, Mohmands.

RAWAL KOR.-A minor fraction of Asaf Khel, Dalkha Kor, Dada Khel, Tarakzai, Molimunds.
$R_{\triangle Z A R}$ (Chamla).-One of the three clans of the Mandan Yusafzais.

Rekhima Kor (Danish Kol).-A section of Rajai Khel, Yusuf Kheî, Isa Khel, Mohmands.

RICHBIN KHEL.-A minor fraction of Kemal Khel, Babu Khel, Adir:zai, Khwazazaj, Alsozai, Yusafzai Swatis.

Rikmin.-See Ricebin Khel.

Restay KHEL.-A section of Hasan Khe], Gadaizai, I liaszai, Bunerwals.

RUSTaM KнEL.-A minor fraction of Azi Khel, Par Sulizai, Baizau, Akozaị, Yusafzais.
SABA KOR.-A section of Kbalil Khel, Kasim Khel, Tarakzai. Mohmands.

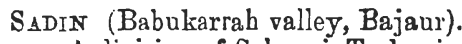
-A division of Salarzai, Tarkanis.

$S_{A D O}$ KOR or NAZAR KOR (Bohai Dag).-A sub-division of Maimana Khel, Khwaezai, Mohmnnds. Headmen: Sado, Ahmad.

SADUZAI (Chamla and British territory)-A division of Utmanzai, Mandan Yusafzais.
SAFIs.-A vassal clan of the Mohmands, and rrobably Kafir converts to Islam. Headmen : Shamsai, Sherdil, Mazim, Musai, Khanpur, Jangrez, Zarapai Mian Khan, Abbas.

$S_{\triangle H A B}$ KoR (Loi Shilman)-A section of Durma Kor, Shah Mansur Khel, Tarakzai, Mohmands.

$S_{A H I B}$ KHAN Kor.-A section of Hatai Kor, Muhammad Khan Kor, Burhan Kbel, Mohmands. 
SAIN KHeL (70; Black Mounta in). -A section of Aziz Khel, Akazai Isazai, Ynsafzais.

SAIYID AlI KHEL (Mahaban).-A section of Hasan Khel, Mada Khel, Isazai, Yusafzais. Head. man : Sher Khan.

SaIYIds (231, Black Mountain, Tili plateau).-A family of Saiyids, living with the Hasanzai, Isazais, Yusafzais. Headmen: There are two factions. Said Azam Shah and Kudrat Shah are the heads of one of these. Said Anwar Shah and Hazrat Shah are heads of the other. Other headmen are:-Pir Mian. Sidki Shah, Maruf Shab, Hazrat Shah, and Akhmad Shah.

SaIyid TirimzaI (580).- - d clan of the Allaiwals.

SaKHaLI KHвL.-A minor fraction of Bai Khel, Firozsi, Chagarza!, Malizai, Bunerwals.

SALAR $(1,300)$.-One of the two clans of the Gaduns.

SalarzaI (1,600; Western Buner). -A division of Iliaszai, Bunerwals. Headman: Hastam Khan, now an old man.

SalarzaIs $(8,000$; Babukarrah and Chaharmung valleys, Bajaur). -One of the four clans of the Tarkanis. Headmen: The Khana of Pashat and Khar have some control over them.
SALIE KOR.-A section of Khani Khel, Kasim Rhel, Tarakzai, Mohmands, Headmen: Lahore and Bahram.

SALIH Kor.-A section of Rahmatal Kor, Kadai Kor, Gandab Halimzai, Mohmands. Headmen : Abdal Kadir, Ghulam Jan.

SALIM KHAN KOR,-A sub-division "Kuz" or "Khrappawal" Burhan Khel, Mohmands. Headman : Gulzar Shah.

Salo Kor.-A section of Sroh, Busha Khel, Kamali Halimzai, Mohmands. Headman : Khanizamau.

Samex (or Ismail) KHeL.-A section of Shamozai, Khwazazai, Akozai, Yusafzai Swatis.

Samizzais. -See Ismarlzat.

SAMKORI (270).-A clan of Allaiwals.

SaNGaR KHEL (Dunish Kol).-A sub-division of the Yusaf Khel, Isa Khel, Mohmands. Headmen : Zuidullah, Guldost.

SaNIZar (300; Bar and Kuz Totai). -One of eight clans of the Utman Khel.

$S_{\triangle P I} K_{H E L}-A$ minor fraction of Aba Kbel, Nekpi Khel, Khwazazai, Akozai, Y usafzais. 
SARBADAL KoR.-A minor fraction of Muradi Khel, Dalkha Kor, Dada Khel, Tarakzai, Mohmands.

SARGAN Kor.-A minor fraction of Ismail, Khadin Khel, Ashazai, Iliaszai, Bunerwals.

Sargarrai Kor (Bohai Dag).-A sub-division of Khadi Khel, Khwaezai, Mohmands. Headmen : Akram, Aziz Khan.

Sarkani KHel.-A sub-division of Shamozai, Ismailzai, Utman Khel. H eadmen : Dost Muhammad, Mohrdil, Mahammad Akram.

SarkaNI KHEL (Arang).-A subdivision of Shamozai, Ismailzai Utman Khel.

SARII KHEL.-A sub-division of Shamozai, Ismailzai, Utman Khel. Headman: Badol.

SEBUJNI $(2,000$; Ningolai to the Harnawai stream).-A sub-division of Khwazazai, Akozai, Yusafzai Swatis. Headman : Jalal Khan.

Nors, -This is an adopted sept, not Yusafzai in origin.

SED KHEL.-A division of Samilzai, Tarkanis.

SEN.-A section of Khakizai, Ashazai, Iliaszai Bunerwals.

Sex KHEL.-See Sin KHeL,
Ser, or Seri, KHeL-A sub-division of Gadaizai, Ilia szai, Bunerwals.

Senzai (Bajaur).-An aboriginal tribe classed as one of the divisions of Isazai, Tarkanis.

SepaH.-A sub-division of Kandahari Safis, who are a rassal clan of the Mohmands.

Separ.-A division of Baezai, Mohmands.

Sergo Khel (or Siyu).-A section of Panjpai, Nasuzai, Iliaszai, Bunermals.

Sesada, or Sersadda.-A name under which the following three branches of the Malizai, Khwazazai, A kozai, Yusafzais are sometimes included, i.e., Sultan Khel, Painda Khel, and Nasrdin Khel.

Sewanai Kor (Bohai Dag). - A sabdivision of Khadi Khel, Khwaezai, Mohmands. Headman: Painda Khan.

Shaba Krel. - A section of Ali Khel, Bar Ranizai, Akozai, Yusafzai Swatis.

ShaDAK Kor.-A minor fraction of Hratai Kor, Shah Mansur Khel, Dadu Khel, Tarakzai, Mohmands. Headman : Sofi.

Shadat For.-A sub-division of Maimana Khel, Kh mands. Headnan: Mira Jan. 
Shambana Kor.-A section of Sultan Khel, Hamza Khel, Gandab Halimzai, Mohmands. Headman : Nurai.

ShaHbaz Kor (Mitai).-A section of Musa Khel, Sepah, Baezai, Mohmands. Headmen: Wahid and Timmar.

Shambaz Kor (Danish Kol).-A section of Rajai Khel, Yusaf Khel, Isa Khel, Mohmands.

SHAH Beg Kor.-A minor fraction of Shabbaz Kor, Musa Khel, Sepah, Baezai, Mohmands.

$\mathrm{SH}_{\mathrm{AHDAD}} \mathrm{KHEL}$-A division of Mutakai, Utman Khel.

Shamgur Kor.-A section of Rasul Kor, Wali Beg Kor, Gandab Halimzai, Mohmands. Headman: Khalid.

Shahi Khel ( 80 ; Black Mountain), -A section of Barat Khel. Akazai, Isazai, Yusafzais.

ShaH Kor.-A minor fraction of Muradi Kbel, Dalkha Kor, I)ada Khel, Tarakzai, Mohmands. Headman: Muhammad Hasan.

SHAH KHEL.-A section of Ibrahim Khel, Gadaizai, Iliaszai, Bunerwals.

Shat Mansdr KHel $(1,300)$ - -A section of Dadu Khel, Tarakzai, Mohmands.
Shatmai Kor.-A section of Rami Khel, Kadai Kor, Gandab Halim. zai, Mohmands. Headmen : Khan Sher, Zainula.

SHaMIZAI $(4,000$; Harnawai stream to Kohistan).-A sub-division of Khwazazai, Akozai, Yusafzai Swatis. Headman : Husain Khan of Asharai.

ShamozaI (Arang, south of Bajaur) -A division of Ismailzai, Utman Khel.

ShamozaI (2,000; Swat river).A sub-division of Khwazazai, Akozai, Yusafzai Swatis.

SHaMso KoR.-A sub-division of Masaud Safis, who are a vassal clan of the Mohmands.

Shargha KHel.-A minor fraction of Abs Khel, Kuz Sulizai, Baizai, Akozai, Yusafzais.

SHARGHA KHEL (500).-A minor fraction of Utmanzai, Adinzai, Khawazai, Akozai, Yusafzais.

SHATI KHEL.-A sub-division of Wali Beg Kor, Gandab Halimzai, Mohmands.

Shato Khel (Pipal).-A subdivision of Babazai Kor, Dawezai, Mohmands. Headman : Mohmandai.

Shere Ali KHel.-A minor fraction of Aba Khel, Kuz Sulizai, Baizai, Akozai, Yusafzais. 
Shrgh Krgu (lower end of Talash valley and Panjkora).-A minor fraction of Ausa Khel, Malizai, Khwazazai, A kazai, Yusafzais.

SHRg KH Krel-A section of Aib Khel, Salarzai, Iliaszai, Bunerwals.

Sher H Kare. - A minor fraction of Kambir (or Kambo) Khel, Aib Kbel, Salarzai, Iliaszai, Bunerwals.

ShвкH KHel (Bajaur).-A division of the Isazai, Tarkanis. They are said to be of aboriginal stock.

ShRRGA KHEL.-A minor fraction of Utmanzai, Adinzai, Khwazazai, Akozai, Y usafzai Swatis.

Sher Khax KHeL. $-A$ minor fraction of Mrsa Khel, Makhozai, Nasuzai, Iliaszai, Bunerwals.

SHER KHEL - A minor fraction of Kambir (or Kambo) Khel, Aib Khel, Salarzai, Iliaszai, Bunerwals.

SHgRPAN KHEL.-A section of Mandazai, Daulatzai, Malizai, Bunerwals.

Sherzai Kret. A section of Hasan Khel, Gadaizai, Iliaszai, Bunerwals.

Shimaraxi MoHmaxds (6C0; Lor and Kam Shilman). - These are really sections of the Shah Mansur Khel and the Masaud Kor, Dadu Khel, Tarakzais, and Halimzai
Mohmands in Loi Shilman; in $\mathrm{Kam}$ Shilman there is a minor fraction of Asaf Khel, Dalkha Kor, Dadu Khel, Tarakzai, Mohmands.

ShINSARAI Kor.-A minor fraction of Hyatai Kor, Shah Mansur Khel, Dadu Khel, Tarakzai, Mobmands. Headman : Saiyid Rasul.

Sibat Keel.-A section of Sebujni (q. v.)

Sikandar KHel.-A sub-division of Kandai Isa Khel, Mohmands.

Sin, or Sen, KHeL (Husain Khel). A section of Utmanzai. Bar Ranizai, Akozai, Yusafzai Swatis.

SkHALI KHel. - A minor fraction of Bai Khel, Firozai, Chagarzai, Malizai, Yusafzais.

Syes Khel.-A minor fraction of Bai Khel, Firozai, Chagarzai, Malizai, Yusafzais.

SROH (120).-A sub-division of Busha Khel, Kamali Halimzai, Mohmands.

Stari.-See SWarai.

StIEMAN KHeL.-A section of Babram-ka-Khel, Bar Ranizai, Akozai, Yusafzai Swat s.

SUleMaNZaI -A division of Salar Gaduus. 
Soriza.-Vide Bar Sulizai and Kuz Salizai.

SULTAN-KA-KHEL (700; east and south of the Swat-Panjkora junction).-A sub-division of Bar Ranizai, Akozai, Yusafzai Swatis.

Sultan KHel (340, Mahaban).-A section of Hasan Khel, Mada Khel, Isazai, Yusafzais. Headmen: Torai Khan, Hamza Khan.

Strtan KHel.-A sub-division of Hamza Khel, Gandab Halimzai, Mohmands.

SUTTaN KHet.-A sub-division of Hamza Khel, Kamali Halimzai, Mohmands. Headman: Ajmir Khan.

SULTAN KHEL. -A minor fraction of Bazid Khel, Shamozai, Kbwazazai, Akozai, Yusafzais.

Sultan KHeL.-A minor fraction of Aka Khel, Ismailzai, Daulatzai, Malizai, Bunerwals.

Sultan Khel $(2,400 ;$ Panjkora, Dir).-A section of Malizai, Khwazazai, Akozai, Yusafzais.

Soltan Merammad.-A section of Musara Khel, Ashazai, Iliaszai, Bunerwals.
Somia KHex (120; Black Mountain). -A clan of Deshiwal

Swatis. Headmen Idhar Ali, Saman.

Strr PAO.-A sub-division of Kalut Khel, Samilzai, Tarkanis.

Surkha Kor (Pandiali).-A sub. division of ' Kuz' or ' Khrappawal,' Burhan Khel, Mobmauds: Hearmen: Salo, Nasim Gul, Baz Mir, Lal Jan.

SWARAI.-A division of Mandal, Utman Khel.

Swatrs. - The original inhabitants of Swat, sometimes called Dehgans, and, according to some authorities, of Indian origin. Driven ont of Swat and Buner by the Alrozai-Yusafzais at the end of the fifteenth century, they emigrated eastwards, under the leadership of the Saigid Jalal Baba, a son of the famous Pir Baba of Buner. Crossing the Indus, they settled in Tikri, Allai, Deshi, Nandihar, Pakli, Konsh, Bogarmang, Agror, Balakot, and Garhi Habibuilla, north of Hazara. of which their descendants are the present inhabitants.

Swatis (15,800*; Swat valley from. Panjkora jrustion to Kohistan).A term loosoly applied to that portion of the Akozai clan of Yusufzais which inhabits Swat. 
TAKHAI KOR.-A minor fraotion of Muradi Kbel, Dalkba Kor, Dadu Khel, Tarakzai, Mohmands. Headman: Acbak.

TAKOR (Laman).-A division of Ismailzai, Utman Khel.

TABAKZAI $(1,600)$. - One of the Mlohmand clans.

TAREANI (or TARKAIANRI 36,000 ). The name of the tribe inbabiting the whole of Bajaur. Headmen: Khans of Nawagai, Jhar, Khar, Pashat, Barwa.

TAB KHel (Tartara).-A division of Mullagoris, a vassal clan of the Mohmands.

$T_{\triangle R U}$ KHEL. $-A$ sub-division of Hamza Khel, Gandab Halimzai, Mohmands, closely allied to the Baru Khel. Headman: Hamid Gal.

TASAN KheL (200; Black Mountain). - A sub-division of A kazai, Isazai, Yusafzais. Headmen: Mauladad, Alaf Khan, Raza Khan, Asim Khan and others.
TaUs KHel.-A section of Seni Khel, Gadaizai, Iliaszai, Bunerwals.

TIkaIwaLs (400; Tikri valley north of Agror).-Malkals and Ashtors are the principal clans of Swatis, in this valley, which also contains Saiyids and Gujars.

TотA KHEL (Mahaban).-A section of Bazid Khel, Madda Khel, Isazai Yusafzais. Headmen: See Bazid Khel and Maúda Khel.

Tsalor Piara. - A section of Shati Khel, Wali Beg Kor, Gandab Halimzai, Mohmands. Headmen : Sherai, Zabat Khan, Gul A hmad Dawezai.

TUghal KHeri. - A division of cisSwat, Sanizai, Utman Khel.

TURA KHeL.-A section of Sadin, Ilal Khel, Salarzai, Tarkanis.

TURI KHEL.-A division of Mutakai, Utman Khel.
UDHI KHEL (Pandiali). -A sabdivision of "Kuz" or Khrappawal Burhan Khel, Mohmands. Headmen: Khan Mir, Mubammad Umar, Gulzar Shah.
UDREDUNKaI (Pipal).-This name is applied to those sections of the Dawezai and Utmanzai Moh. mands who, in contradistinction to the Kuchis, or nomad tribes, have 
fixed habitations in the Mohmand country.

UMar KoR (Pandiali).-A subdivision of Kuz or Khrappawal, Burhan Khel, Mohmands. Headman : Lal.

UMAR. - A section of Musara Khel, Ashazai, Iliaszai, Bunerwals.

UMAR KHAN. - A section of Musara Khel, Ashazai, Iliaszai, Bunerwals.

UMAR KHAN KOR.-A section of Barkazai, Daulatzai, Malizai, Bunerwals.

UMAR KHEL. - A sub-division of Kakazai, Mamund, Tarkanis.

UMAR KHEL.-A minor fraction of the Marjan Khel, Utmanzai, Adinzai, Khwazazai, Akozai, Yusafzai Swatis.

UMAR KHEL.-A minor fraction of Sin Khel, Utmanzai, Ranizai, Akozai, Yusafzais.

UYAR KOB.-A section of Sroh, Busha Khel, Kamali Halimzai, Mohmands. Headman : Buland.

UMARZAI-A minor fraction of Aziz Khel, Shamozai, Khwazazai, Akozai, Yusafzai Swatis.

UMBAR (Laman).-A section of Balo, Asil, Ismailzai, Utman Khel.
UMBARA KHEL.-A section of Sultan-ka Khel, Bar Ranizai, Akozai, Yusafzai Swatis.

UMr KHel (Agra, Chingai Shagai, etc.).-A sub-division of Shamozai, Ismailzai, Utman Khel.

UMR KHEL.-A minor fraction of Mir Asan Khel, Babu Khel, Adinzai, Khwazazai, Akozai, Yasafzai Swatis.

Uma KHEL.-A section of Ibrahima Khel, Utmanzai, Bar Ranizai, A kozai, Yusafzai Swatis.

UMR KOR. - A minor fraction of the Hyatai Kor, Shah Mansur Khel, Dadu Khel, Tarakzai, Mohmands. Headman : Suf and Ismail.

URAI ZAI.-A sub-division of Wara or Wur, Mawund, Tarklanris or Tarkanis.

UraZAI.-A division of Alizai, Ut. mass Khel.

Usman I KHel (500; Swat river, , north-west of Malakand). -A subdivision of Bar Ranizai, Akozai Yusafzai Swatis.

Usmani Kor (Bohai Dag). -A subdivision of Maimana Khel Khwaezai, Mohmands. Headman : Mir Waiz.

Usman Kinex $(1,060)$. - A section of Khud" Khel, Sadazsi. Utmanzai, Mandan Yusafzais. 
Ugman Khel (Upper Bohai Dag). -A division of Baezai, Moh. mands. Headmen : See Isa Khel, Khuga Khel, Koda Khel.

USMaN KHEL. - A section of Hasan Khel, Gadaizai, Iliaszai, Bunerwals.

Usmax KOR.-A minor fraction of Khwaja, Khadin Khel, Ashazai, Iliaszai, Bunerwals.

UsmanzaI (Chamla, Mahaban, and British territory).- One of the 3 clans of Mandan Yusafzais.

USta KHeI.-A minor fraction of Khwaja, Khadin Khel, Ashazai, Ilisszai, Bunerwals.

UTaZAI. -A division of Salar, Gaduns.

UTMAX KHEL $(12,000 ;$ a stretch of country north-west of the Pesbawar border).-A Pathan tribe, inhabiting a large tract of country which extends across the bills bordering the Peshowar valley, and includes the country west and south-west of the junction of the Swat and Panjkora rivers.

Utmanzal (400;* Mahaban).-One of the 3 clans of Mandan Yusafzais. They live both in Independent Territory and in the Hazara District round Torbela. Their sub-divisions are Akazai, Alazai, Ghulam Khel and Khanazai, Headmen: see Akazai, Khanazai, Ghulam Khel, Alazai.

UTMaNZaI (350; 'Rar' and 'Kuz' Yakhdand).-One of the affliated Mohmand cians. They are divided into "Kuchi"; and "Udredunkai." Headmen : Badshah, Muhammud Ali Khan, Shamshai, Mubammad Abbes, Amirbaz (Bar Yakhdand), Umar, Islamdin, Lal Kaim, Wali $\mathrm{Mu}$ hammad, Nasim (Kuz Yalkhdand).

UTMANZAI.-A section of Adinzai, Khwazazai, Akozai, Yusafzai Swatis.

UTMANZAI ( $8 C 0$; left bank of swat river).- $\mathbf{A}$ sub-division of $\mathrm{Bar}$ Ranizai, Akozai, Yusafzai Swatis.

\section{W}

Wader (Kunar river).-A division of the Safis, who are a rassal clan of the Mohmands.

W $\triangle \mathrm{HAB}$ KoR.-A small, broken division of Gandab Halimzai, Mohmands, who are closely allied to the Rasul Kor.
WALAI Kor-A minor fraction of Asaf Khel, Dalkha Kor, Dadu Khel, Tarakzai, Mohmands.

WALI BEG KoR (820;-A dirision of Gandab Halimzai, Mohmands.

WALIDAD KHEL.-A division of Mutakai, Utman Khel. 
WAIIDAD KOR.-A section of Ma. mun Kor, Kandai, Isa Khel, Mohmands.

WaII MUHammad Kor.- (300 Loi Shilman with Wazir Kor and Hasan Kor).-A section of Shah Mansur Khel, Dadu Khel, Tarakzai, Mohmands. Headmen : Ghulam Kadir, Adam, Nasro, Narai, Fazl Din.

W $\triangle R A$ (or WUR) (3,020; Wattelai valley).-A division of the IMamund, Tarkanis.

WABKAN KHEL.-A section of Aib Khel, Salurzai, Iliaszai, Bunerwals.

W
WARO USMAN KHEL.-A section of Usman Khel, Bar Ranizai, Akozai, Yusafzai Swatis.

WAZIR KOR (300).-A section of Shah Mansur Khel, Dadu Khel, Tarakzai, Mohmands Headmen: Kazi, Haji, Shahbaz, Amin Shah Saiyid Muhammad, Daraza, Raza Khan.

WILAYAT KOR.-A section of Sangar Khel, Yusaf Khel, Isa Khel, Mohmands.

\section{$\mathbf{Y}$}

$\mathrm{Y}_{\mathrm{AGHI}}$ KoR.-A section of Sroh, Busha Khel, Kamali Halimzai, Mohmands. Headman : Buland.

$\mathrm{Y}_{\mathrm{A}}$, or ArA, KHEL.-A minor fraction of Babu Khel, Adinzai, Khwazazai, Akozai, Yusafzai Swatis.

TakUbI KHeL (Goshta):-An offshoot of the Surgarrai Kor, Khadi Khel, Khwaezai, Mobmands. Headmen : Jamal, Nadir Shah, Lian Jumma Khan.

YAKUB KHEL.-A minor fraction of Ghaibi. Khel, Bahram-ka-Khel, Bar Ranizai, Alrozai, Yusafzai Swatis.
YAKUB KHEL. - A minor fraction of Nasrdin Khel, Malizui Khwazazai, Akozai, Yusafzais.

YAKUB KOR.-A minor fraction of Ranra Khel, Shati KhelaWali Beg Kor, Gandab Halimzi, Mohmands. Headman : Abmad.

YARDIL KOR.-A sub-division of Kadai Kor, Gandab Halimzai, Mohmands. Headmen : Shah Jehan, Nawab, Musa Khan, Gulai, Yad Muhammad, Niarnot.

Yosaf Khan Khel.-A division of Salarzai, Tarkanis. 
Y USAF KHEL.-A division of Loi Shilman Halimzai, Mohmands.

YUSAF Keer or Isa KHeL (Danish Kol).-A division of Isa Khel, Nohmands.

YUSAF KHRL,-A sub-division of Kakazai, Mamund, Tarkanis.

Y USA KHEL (Dir).-A minor fraction of Painda Khel, Malizai, Khwazazai, Ak ozai, Yusafzais.

YUs $\triangle F$ KOR.-See N NEAKI Kor.

FoSAFZII $(73,000 *)$. - A great group

$\mathrm{Z}_{\triangle \mathrm{B} \triangle \mathrm{B}} \mathrm{KH} \mathrm{HL}$ (North-east of Buner). -A minor fraction of Musa Khel, Makhozai, Nasozai, Iliaszai. Yusafzais.

ZADO.-A minor fraction of Madak, Bada, Asil, Ismailzai, Utman Khel.

$\mathrm{Z}_{\triangle \mathrm{BIF}}$ KOOB.-A minor fraction of Rahmat Kor, Nluss Khel, Sepah, Baezai, Mohmands.

ZarTRAX KOR.-A minor fraction of Hyatai Kor, Shah Mansur Khel, Dadu Khel, Tarakzai, Mohmands. Headman : Abdullah.

ZAKABI KHeI (140; Black Nountain). - A sub-division of of Pathan tribes which include those of the Black Mountain, the Bunerwals, the Yusafzai Swatis, the people of Dir and the Panjkora valley and the inhabitants of the Yusafzai plain in British territory. They all claim descent from nne Mandai, his son Yusaf, and grandson Mandan. From Yusaf's four sons, Isa, Musa, Mail, and Ako are descended, respectively, the Isazais, Iliaszais, Malizais and Akozais: Ako was also the progenitor of the Ranizais. The Utmanzais are descended from Mandan. In this dictionary the descendants of Yusaf are grouped as one tribe and those of Mandan as another.

Hasanzai, Isazai, Yusafzais. Headmen : Najim Khan, Arsalla Khan, Alambaz, Muhammad Zaman, Alam K'ban, Hamid Khan and Ghulam.

$\mathrm{Z}_{\mathrm{A}}$ KHEL (Girdi Kats, Kabul river, Unai pass, Afghanistan).-A subdivision associated with the Dawezai Kuchis of the Mohmands. Headman : Azamdin.

$\mathrm{Z}_{\mathrm{AMAN}} \mathrm{K}_{\mathrm{HA}} \mathrm{KHEL}$ - - A minor frac. tion of Aba Khel, Kaz Sulizai, Baizai, Akozai, Yusafzai Swatis.

Z section of Rajai Khel, Yusaf Khel, Isa Khel, Mohmands. mark.)

- (This number, Bellew's estimate ia probably considerably under the 
ZaNa KHer.-A section of Mali (or Muli) Khel, Salarzai, Iliaszai, Bunerwals.

ZANKA KHEL.-A minor fraction of Barat Khel, Babuzai, Baizai, Akozai, Yusafzais.

$\mathrm{Z}_{\mathrm{ABA}} \mathrm{KHEL}$-A minor fraction of Painda Khel, Maliai, Khwazazai, Akozai, Yusafzais.

ZARIF Kor.-A section of Khani Kbel, Kasim Khel, Tarakzai, Mohmands. Headmen: Nadir Sher, Adaw, Dadshah, Ajun.

Zerdast KHEL. - A minor fraction of Sherga Khel, Utmanzai,
Adinzai, Khwazвzai, Akoza, Yusafzai Srati.

ZER or ZOR KHEL. - A minor frac. tion of Kambir (or Kambo) Khel, Aib Khel, Salarzai, Iliaszai, Bunerwals.

ZIMMU KHEL.-A minor fraction of Aib Kor, Shekb Khel, Aib Khel, Salarzai, Iliaszai, Bunerwals.

ZiNa KHeL.-A minor fraction of Asha Khel, Nekpi Khel, Khwazazai, Akozai, Yusafzais.

ZUBaIR KHEL. - A minor fraction of Musa Khel, Makhozai, Nasuzai, Iliaszai, Bunerwals. 


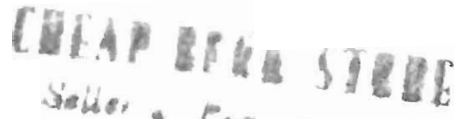

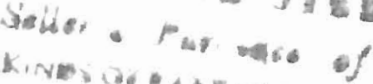

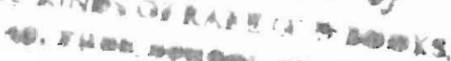

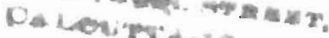




\section{3}

\section{PaRT II.}

Tribes of the Khaibar, Tirah (inoluding Kohat Pass Afridis), Miranzai and Kurram.

\section{A}

Aba BaKar KHeL, - See Kui Khel.

Ава KнEL (left bank of Mastura). -A section of the Fateh Khan Khel, Utman Khel, Daulatzai, Orakzais, Samil. Headman: Rasul.

ABDAL KHEL. - A division of Kuki Khel, Afridis, Gar. Headmen : Mulla Hyat Khan, Saiyid Ali, Mulla Ámir, Gulsam, Sherulla, Budai, Mir Zaman, Mir Shah Gul.

AвDUI Aziz KHeL (80; Mastura valley). - One of the four divisions of the Muhammad Khel, Orakzais ; are called the "Khans of the Muhammad Khel." The present Khan de facto is Aminulla Khan, who is a Sunni and lires mostly in Peshawar, where he is a jagirdar. Gar. Shiah. Headmen: Tor, Hasan Ali, Madat Khan.

ABDUI KHEL (250; north of Kharmana river). - A section of the Mastu Khel, Masuzai, Lashkarzai, Orakzais. Gar. Headman : Ashraf Khan.
ABDUL KमEL. - A sub-division of Urmuz Khel, Sipah, Afridis, Samil. Headmen : Suratai, Sher Mast, Yar Jan, Nulla Firdaus.

Abdul Rahim Khel.-A sub-division of Landi Khel, Sipah, Afridis, Samil. Headmen: Mir Akbar, Gulab Mir.

Abder Rahmań Khel (Tirah).A sub-division of the Bazid Khel, Shekhan, one of the Hamsaycs clans of Orakzai Samil.

Abdul Rahman Khel (200).-A section of the Musa Khel, Mamuzaj, Lashkarzai, Orakzais, Gar.

Abrahim Khel (560; see Mamuzai).-A section of the Ali Karan, Mamuzai, Lasshkarzai, Orakzais. Gar.

ADhr K K R.-A minor fraction of Pehram Kor, Diliar Khel, Mohmànd Khel, Kattia Khel g Hasan Khel, Kitha Khan "Khel, Kukj Khel, Afridis Gow Headmen: Afzal and Madakin 
Aday KHEI (Peshawar Border and Kohat Pass; 5,885. Tirah Adam Khel; 700).-One of the two non-Khaibar Afridi clans. They do not migrate to any extent in summer.

ADILI KHEL.-A minor fraction of Mirghat Khel, Basi Khel, Kamal Khel, Sahib Jan, Aka Kbel, Afridis. Samil.

ADU KHAN KoR.-A section of the Umar Khan Khel, Alisherzai, Lashkarzai, Orakzais. Samil.

ADU KHEL (600). - A section of the - Ali Karan, Mamuzai, Lashkarzai, Orakzais. Gar. Headman : Arsalla Khan.

AFRIDIs $\quad(32,900$; lower and easternmost spurs of the Safed Koh range, west and south of Pesharrar, including the Bazar and Bara valleys, and all the northern part of Tirah).-There are 6 so-called $\mathrm{T}$ baibar clans of Afridis, viz., Kuki Kbel, Kambar Kbel, Kamar Khel, Malikdin Khel, Sipah, and Zakia Khel; also two outside clans, viz., Aka Khel, dwelling on the Orakzai border, and Adam Khel, who occupy a mountainous tract projecting into British territory between Peshawar and Kohat. With the exception of the Adam Khel,* the whole of the Afridi tribe is migratory, remaining in the highlands of Tirab in summer, and descending to the Kajuri, Bazar, and Khaibar valleys in winter. 'The Khaibar' and Kohat passes are commanded by the tribe.

Afzal KHel (Samana range and south side of Khanki valiey).-A sub-division of the Rabia Khel, Ismailzai, Orakzais. Sa mil. Headmen : Rahman Shah and Khalim.

Ammad KHel. - A minor fraction of Nikki Khel, Hasan Khel, Pakhai, Budai, Zakka Khel, Afridis, Samil. Headmen : Gulbadam, Wali, Tirakai, Khairulla-Morad, Ghorzi, Mir Wal.

Ahuad Beg Khel. - A minor fraction of Mohib Khel, Shekhai, Annai, Budai, Zakka Khel. Afridis. Sarnil. Headmen : Akbar Din, Aliakai, Mohinddin, Shahzada, Arsala, Aligul.

AIDU KHEL (left bank of Mastuia). -A section of the Yarkulli Khel, Bazoti, Daulatzai, Orakzais. Samil. Headman : Daim.

Aimal Khan KHel (Mastura river). -A division of the Ali Khel, Hamsayas of the Orakzais. Gar. $\frac{1}{3}$ Shiah. Headmen : Gulbaz and Shiraz.

Aimal Kran Kor.-A section of the Umar Khan Khel, Alisherzai, Lushkarzai, Orakzais. Samil.

AIMAL KHEL.-A minor fraction of Tor Khel, Asad Khel, Mitha

*Certain minor fractions of the Adam Khel, $i$ e., the Mirbash Khel and Bazid Khel Jawakis, and the Kulla Khel section of the Ashu Khel, do, however, migrate to Tirah in 
Khan Khel, Kuki Khel, Afridis. Gar. Headmen : Razai and Islamdin.

AIMAI KHEx. $-\$$ minor fraction of Tashi Khel Sharaki, Galai, Adam Khel, Afridis.

AIMAL KHEL.-A minor fraction of Kasim Khel, Kimat Khel, Jawaki, Adam Khel, Afridis.

Aimat Kran Kor (300).-A minor fraction of the Ali Karan, Sipah, Mamuzai, Lashkarzai, Orakzais, Gar. Headman : Mohibulla.

AKA KHEL $(4,000$; the hills south-west of Peshawar, the Bara and Waran valleys).-One of the two non-Khaibar Afridi clans. Samil.

AKHEL (Ibrahim Khel; 700).-One of the six divisions of the Ismailzai, Orakzais, Samil. Headman : Miran Gul, Subir Shah, and Mir Khan.

AKHEL. - Minor fraction of Sunni Khe1, Zargun Khel, Galai, Adam Khel, Afridis.

AkHoR WaL,-See Tatar Khel.

AKKA KHEL. A section of the Aimal Khan Khel, Zanka Khel, Ali Khel Hamsayas, Orakzais. Gar. $\frac{2}{3}$ Shiah.

AL.AFDIN KHEI.-A minor fraction of Misri Khel, Bosti Khel, Galai, Adam Khel, Afridis.
ALAM KHEL. $\sim$ A minor fraction of Feroz Khel, Tor Sapar, Galai, Adam Khel, Afridis.

ALAM SHer Kor. - i section of Ali Khel, Ashu Khel, Adam Khel, Afridis.

ALI AHMad KHeI.-A minor fraction of Baghdad Khel, Keima Khel, Urmuz Khel, Sipah. Afridis, Samil. Headman : Nabat.

ALIDAD KHEL.-A section of the Dilmarzai, Gar Massuzai, Orakzais.

ALIF KHEL,-A section of the Dilmarzai, Gar Massuzai, Orakzais.

ALI KARAN (head of Khanki rver).-One of the two sabdivisions of the Mamuzai, Lashkarzai, Orakzais. Gar.

AII KHan KHeI.-A section of the Ali Karan, Mamuzai, Lashkarzai, Orakzars. Gar. Headman : Mosadi.

ALI KHAN,KHEL, - - A minor fraction of Bash Khel, Sharaki, Galai, Adam Khel, Afridis.

ALI KHAN KHEI.-A minor fraction of Kasim Khel, Kimat Khel, Jawaki, Adam Khel, Afridis.

$\triangle$ III KHEL $\quad 2,750$; source of Mastura river).-One of the four Hamsaya elans of the Orakzais. 
Gar. $\frac{2}{3} \mathrm{rd}$ Shiah. Headmen: Gulbaz and Shiraz.

ALI KHex (Mastura, Bara, Khanki, and Miranzai valleys).-A subdivision of the Samozai, Shekhan, Hamsayas of the Orakzais. Samil.

ALI KHEI (100). - A sub-division of Ashu Khel, Adam Khel, Afridis. Headman : Fakir.

ALI KBEI.-A minor fraction of Tor Khel, Asad Khel, Mitha Khan Khel, Kabi Khel, Afridis, Gar. Headmen : Razai and Islamdin.

ALI KHEL-A section of Jawakai, Babalri, Sipah, Afridis. Samil. Headman : Ali Shah.

ALI KHEL. A sub-division of Landi Khel, Sipah, Afridis. Samil. Headmen : Mrir Akbar and Gulsb Mir.

ALI KHEL.-A sub-division of Shekhmal, Kambar Khel, $\Lambda$ fridis. Gar. Headmen: Ahmad Shah, Kaipat, Kiramat, Mulla Wali,

AXIY KEAN KoR.-A minor fraction of Sultan Khel, Hasan Khel, Pakhai, Budai, Zakìa Khel, Afridis. Samil. Headmen : see Sultan Khel.

Ali Shgr KHel. - A minor fraction of Babur Khel, Keimal Khel; Trmuz Khel, Sipah, Afridis. Samil. Headman : Ehan Zaman.
Ali SHer KHel (1,240 ; Loargai, Peshawar border). - A clan of Shinwaris. The remaining threo clans of Shinwaris are Afghan subjects. Headmen : Gulistan, Lalgul, Baz Mir, Mir Akbar (Khoga Khel), Timar Shab, Main Haidar Jan (Shekmal Khel), Akbar Khan (Ash Khel).

AlisHerzaI $(3,000$; Khanki and Kurram rivers, and sides of Zawaghar, up to Kharmana stream).-One of the three divisions of the Lashkarzai, Orakzais. Samil.

Alistani (120; Kurram and Cbamkanni Country). - A clan, which is of uncertain origin. It is counected with the Chamkanni tribes and though that clan nas declared that the Alisianis are not their hamsayas, the latter are for political purposs treated as part of the Chamlanni tribe. The headmen of the trans-border portion (1 00 fighting men) of the clan are Misri Khan and Aziz Khan.

ALIZaI (1,000; Kurram). -A subdivision of Landizai, Chardai, Turis.

ALIZAI or STORI KHEL $(500$; about 16 miles from source of Mastura).--One of the divisions of the Daulatzai, Oraizzais, Samil.

Allahdad KHBL (Mastura valley).-A sub-division of the Bar Mabammad Khel, Muhammad Khel, Urakzais, Samil. 
Shiah. Headmen: Ghulam Nabi and Nadir Ali.

Alifa KHel.-A sub-division of Karna Khel, Malikdin Khel, Afridis. Samil. Headmen : Bawal, Mirak.

AMbara KHel (Mastura valley):A sub-division of the Sipab, Muhammad Khel, Orakzais. Gar. Shiah.

AMbara KHEL.-A minor fraction of Sanzal or Sunya! Khel, Kamal Khel, Sahib Jan, Aka Khel, Afridis. Samil.

Ambar KHeL- - A sub-division of Mat Khan Khel, Kambar Khel, Afridis. Gar. Headmen: Sher Khan, Hamid, and Nurai.

AMIN KHAN Kor.-A minor fraction of Durar, Khusrogi, Nasruddin, Zakka Khel, Afridis. Samil. Headman: see Bucha Khel.

AMIR KHAN KHEL.-A section of Azad Khel, Khwaidad Khel, Kamrai, Afridis.

ANAI (1,000).-A sub-division of Budai, Zakka Khel, Afridis. Samil Headmen: see Shekbai, Bash Khel, and Umar Khel.

AND KHeL (25), -A sub-division of the Alizai (or Sturi Khel), Daulatzai, Orakzais, Samil. Shiah. Headman : Akbar.
ANJANi KHeL (25).-A sub-division of the Alizai (Sturi Khel), Daalatzai, Orakzais. Samil. Headman : Zain Khan.

ARA KHEL. - A minor fraction of Ghulam Khel, Haibat Khel, Jawaki, Adam Khel, Afridis.

ASAD KHEL.-A sub-division of Mitha Khan Khel, Kulki Khel, Afridis. Gar.

ASAF KHEL.-A minor fraction of Mawal Khel, Haibat Khel, Jawaki, Adam Khel, Afridis. Headmen : Manadin and Shabadin.

Ashant KHeL,-A division of Kamrai, or Kamar Khel, Afridis. Samil.

AsH KHEJ (500). - A section taking a balf share of the Samil Nasrazai, Masuzai, Lashkarzai, Orakzais. Samil. Headman : Hakim.

AsH KHeL (200; Loargai) - A division of the Ali Sher Khel, Shinwaris. Headman: Akbar Khan.

ASHRAF.-A minor fraction of the Saiyid Khan, Nmasi, Ali Karan, Mamuzai, Lashkarzai, Orakzaiø。 Gar.

AshraF KHEL. -A section of Kamal Khel, Sahib Jan, Aka Khel, Afridis. Samil. 
AsHraf KHeL (Loargi).-A subdivision of Khuga Khel, Alisher Khel, Shinwaris. Headman : Baz Mir.

Asho KHeL $(1,400)$. - A division of Adam Khel, Afridis.

Askari Khel (160).-A minor fraction of the Abrahim Khel, Ali Karan, Mamuzai, Lashkarzai, Orakzais. Gar.

Atal KHeI-A minor fraction of Mawal Khel, Hajbst Khel, Jawaki, Adam Khel, Afridis. (Usually pronounced Aitam Khel.)

ATLAK.-A minor fraction of Nekzam Khel, Tor Sapar, Galai, Adam Khel, Afridis.

ADLI KHeL.-A section of Abdul Khel, Urmuz Khel, Sipah, Afridis. Samil. Headman : Sher Jan.

Arız KHel (Samana and Khanki ralleys).-A sub-division of the Rabia Khel, Ismailzai, Orakzais, Samil. Headmen: Mastan, Sargul, Ghanni, Idat Shah.

AYUB KHEL.-A sub-dirision of Yar Ali Kbel, Kamrai Khel, Afridis. Samil. Headman : Azam Din.

Azad KHEL.-A section of Sultan Khel, Sher Gulla, Aka Khel, Afridis. Samil.

AzAD KHEL or SipaH Daulatzai Sipah)

(Not the $(610),-A$ section of the Ali Karan, Mamuzai, Lashkarzai, Orakzais. Gar.

AZaD KHEL. - A sub-division of Khwaidad Khel, Kamraj, Afridis.

AzAB KHE C.- A section of Durbi Khel, Kambar Khel, Afridis. Gar. Headmen : Muhammad Sher, Khwaja Ali, Yaro, Nurai.

AZIM KHAN KOR. - A section of the Umar Khan Khel, Alisherzai, Lashkarzai, Orakzai, Samil.

AzIz KHEL.-A minor fraction of Bash Khel, Sharaki, Galai, Adam Khel, Afridis.

Aziz KHex (Mastura valley, down to near Hangu). -A subdivision of the Mamozai, Mishtis, Hamsayas of the Orakzais. Samil. Headman: Khani Alam.

AzIz KHEL (near Hangu).A division of the Malla Khel, Hamsayas of the Orakzais. Sanuil. Headmen : Saiyid Akbar and Parangai.

AZIZ KHEL.-A section of Durbi Khel, Kambar Khel, Afridis. Gar. Headmen : Khwaja Ali and Fazal Shah.

AzIz KHEL. - A minor fraction of Ali Sher Khel, Babur Khel, Keimal Khel, Urmuz Khel, Sipah, A fridis. Samil. 
BABADAR KHEL.-A minor fraction of $\mathrm{K}$ uj Khel, Tor Sapar, Galai, Adam Khel, Afridis.

BABAK KHEL.-A section of Ali Khel, Asha Khel, Adam Khel, $\Delta$ fridis.

Babakri.-A division of Sipah, Afridis. Samil. Headmen : see Suran Khel, Ghaibi Khel, and Jawakai.

BaBa Namasi (Mastura valley).-A sub-Jivision of the Bar Muhammad Khel, Nirbammad Khel, Orakzais. They are in reality Ali Khel. Samil. Shiah. Headman : Mir Mian.

BaBAR KHEL.-A section of Kalla Khel, Ashu Khel. Adan Khel, Afridis. Headman : Ilmdin.

BABI KHEL (Samana and Khanki valleys).-One of the six subdivisions of the Rabia Khel, Ismailzai, Orakzais. Samil. Headmen : Abdulla Nur, Palli Shah, Posdil, Baz Gul, Tíwan Shab.

BABUR KHEL.-A section of Keimal Khel, Urmuz Khel, Sipah, Afridis. Samil. Headmen: Suratai and Sher Mast.

$B_{A C H I}$ KHEL. - A minor fraction of Zakho Khel, Janakhori, Hasan Khel, Adam Khel, Afridis.
Bada KHel (200; mouth of Kirman valley).-One of the four claus of Chamkannis. They have left Chamkanni country and settled permanently in the revenuepaying portion of the Kurram, and have adoptad the Shiah tenets of Upper Kurram.

BADDA KHEL (Mastura river).A sub-division of the Mani Khel, Muhammad Khel, Orakzais. Gar, Shiah. Headmen: Sher Naddi and Akbar Ali.

BagHDAD KHEL.-A section of Keimal Khel, Urmuz Khel, Sipah. Afridis. Samil. Headmen : Jumaroz and Arbab.

BagzaI.-A section of the Manatwal Zaimushts.

BaHadur KHEL.-A section of Abdul Khel, Urmuz Khel, Sipah, Afridis. Samil. Headman : Snratai.

BaHadur KHeL (left bank of Mastura river).-A section of the Mir Kulli Khel, Bazoti, Daulatzai, Orakzais. Samil.

BAHRAM KHEX (Samana and Khanki valleys).-A sub-division of the Rabia Khel, Ismailzai, Orakzais, Samil. Headmen: Gul Akhmad and Niaz Gul. 
BaIfAN KHEL.-A minor fraction of Zakho Khel, Janakhori, Hasan Khel, Adam Khel, Afridis.

BAIN KHEL (right bank of Khanki, and Kurram up to Kharmana river.)-A sub-division of the Alisherzai, Lashkarzai, Orakzais, Samil. Headman : Alam Khan.

BAFAR KHEL, - A minor fraction of Bash Khel, Shoraki, Gulai, Adam Khel, Afridis.

BAKHAL KHEL. - A minor fraction of Firoz Khel, Tor Sapar, Galai, Adam Khel, Afridis.

BAKHMALI KHEL.-A section of Kulla Khel, Malikdin Khel, Afridis. Samil. Headmen : Dostai, Sher Gul, Zarif.

BALAJHOI.-A sub-division of Shanai, Zakka Khel, Afridis. Samil. Headmen : Said Khan.

BANAIR KHEL-A section of Kulla Khel, Malikdin Khel Malikdin Thel, Afridis, Samil. Headmen : Shadak, Ayaz Khan, Ghonsamir, Sur Kamand.

BargaSH $(7,500$; Kohat, Miranzai and Kurram valleys).-A great tribe of Pathans, the main clans of which are Miranzai, Baizai and Samalzai. They are both Gar and Sarvil, Sunni and Shian. The divisions, etc., of the Bangash are not indexed in this Dictionary.

BAra Kaddall (lower Mastura river.) -A sub-division of the Abdul Aziz Khel, Muhammad Khel, Orakzais. Gar. Shiah.

Bara KHel (Mastura river).-A minor fraction of the Bazid Khel, Sturi Khel, Alizai, Daulatzai, Orakzais. Samil.

BarAH KHEL. A section of the Khoidad Khel Zaimushts.

BaRANKA KHEL.-A sub-division of Utman Khel, Daulatzai, Orakzais. Samil. Headmen: Musa Kban, Sarmast.

$B A R$ Doranis, vide Section I.

BABID KHEL (Mastura).-A section of the Sturi Khel, Alizai, Daulatzai, Orakzais.

BAREAI KHEL. -A minor fraction of Mian Khel, Janakbori, Hasan Khel, Adam Khel, Afridis.

PaR KHAN KOR (280; Khanki river).-A minor fraction of the Umar Khan Khel, Ali Karan, Mamuzai, Lashkarzai, Orakzais. Gar. Headman: Amir Shah.

BARMI KHEL.-A division of Kamrai, or Kamar Khel, Afridis. Samil. Headmen: Hafiz Samandar and Azam Khan.

\footnotetext{
*Including about 1,100 in Eurram, of whom those in Opper Karram are Slivao and those in Lower Kurram Sandis.
} 
Bar Motamiad KHel (1,200; Mastura valley).-One of the four divisions of the Muhammad Khel, Orakzais. Samil. Shiah. Headmen: Mir Mian, Hasan Ali, Nasir Ali, Band Ali and Ghulam Nabi.

\section{BASHI KHEL.-A section of Kimat Khel, Jawaki, Adam Khel, Afridis.}

BASH KHEL.-A section of Annai Budai, Zakka Kbel, Afridis. Samil. Headmen : Saiyidal Saiyid Amir, Lalbeg.

BasH KHEL (150).-A section of Sharaki, Galai, Adam Khel, Afridis. Headmen : Nazim and Guldin.

BASH KHEL.-A minor fraction of Sber Khan Khel, Umar Khan Khel, Malikdin Khel, Afridis. Samil. Headmen: see Umar Khan Khel.

BASH KHEL.-A sub-division of Mat Khan Khel, Kambar Khel, Afridis, Gar. Headmen: Matu, Babarai.

BasI KHEL ( 600 ; Bara valley).-A section of Kamal Khel, Sahib Jan, Aka Khel, Afridis. Samil.

BASSU KOR.-A minor fraction of Makki Khel, Kattia Khel, Hasan Khel, Mitba Kban Khel, Kuki Khel, Afridis. Gar. Headmen : see Makki Khel.
BatTaI Khel.-A minor fraction of Walli Khel, Ali Khel, Shekhmal Khel, Kambar Khel, Afridis. Gar. Headmen: Muhammad Hasan, Allah Dost.

BATU Kor.-A section of Ali Khel $\mathrm{Ashu}_{i}$ Khel, Adam Khel, Afridis.

BATUKS or KHOIDAD KHEL (EASTERN) ZAIMUKHTS $(1,747)$.One of the two Zaimukht clans.

BAZAR KHAN KHEL (Mastura).-A sub-division of the Utman Khel, Daulatzai, Orakzais. Samil.

B $\triangle$ ZID KHEL.-A minor fraction of Bash Khel, Sharaki, Galai, Adam Khel, Afridis. They really belong to the Jawaki Section of Adam Khel and are exiles from their own country.

BAZID KHEL. - A minor fraction of Mian Khel, Janakhori, Hasan Khel, Adam Khel, Afridis.

BAzID KHEI (Mastura, Khanki, and Miranzai valleys).-A division of the Shekhan, one of the Ham saya clans of Orakzai. Samil Headmen : Pir Mubammad and Sahibulla.

BAZID KHEI (Jawaki country, Kohat Pass, Aimal Chabutra). A sub-division of Jawaki, Adam Khel, Afridis.

B^zoti (400; Mastura).-One of the four divisions of the Daulatzai, Orakzais. Samil. Headmen; Selim, Ghafur, Saiyid Raza. 
Befray Kor.-A minor fraction of Dildar Khel, Mohmand Khel, Kattia Khel, Hasan Khel, Mitha Khan Khel, Kuki Khel, Afridis. Gar.

BETLNI (Mastura).-A section of the Kambar Khel, Bazoti, Danlatzai, Orakzais. Samil.

BILAZAWI ISHBL.-A division of Khanî Khel, Chamkannis.

Bolaki KHeL.-A section of Tatar Khel or Akhorwal, Hasan Khel, Adam Khel, Afridis. Headmen : Sharif, Saiyidan Shah.

Bosti KHeL (200). - A sub-division of Galai, Adam Khel. Afridis.

BUCHA KHEL. - A minor fraction of Lurar, Khusrogi, Nasruddin, Zakla Khel, Afridis. Samil. Headmen: Arsal, Niazai, Mir Hasan.

Chammannis $\quad(3,120$; west of Tirah and east of Kurram).-A small tribe of Pathans of doabtfal origin. Divided in to 4 clans, i.e., Khani Khel, Khwaja Khel, Bada Khel, and Haji (or Para) Khel. The Bada Khel are Sbiabs. The tribe is generally called the Para Chamkannis, but correctly speak. ing this name only applies to the Haji Khel clan.
BUdaI $(2,200)$.-A division of Zakka Khel, Afridis. Samil.

BUDAI KHEL. - A minor fraction of Ali Sher Khel, Babur Khel, Keimal Khel, Urmuz Khel, Sipah, Afridis. Samil. Headman : Khan Zaman.

BUDAL KHEL.-A minor fraction of Maruf Khel, Basi Khel, Kamal Khel, Sahib Jan, Alia Khel Afridis. Samil.

$\mathrm{B}$ СHA KHEx. - A minor fraction of Maddu Khel, Asad Khel, Mitha Khan Khel, Kuki Khel, Afridis Gar.

BubHan Khel (50).-A minor fraction of Drepara, Khusrogi, Nasruddin, Zakika Khel, Afridis. Samil.

PEZR KHeL-A section of Abdul Khel, Urmuz Khel, Sipah, Afridis. Samil. Headman : Jumma.

ChardaI (3,600; Kurram).-The larger of the two clans of the Turis.

Char KHel (Miranzai aud Mastura valley). $-\mathrm{A}$ division of the Malla Khel Ramsayas of the Orakzais. Samil. Headmen : Band Ali, Rasul, and Mal Shah. 
Char KHel. - A section of the Wattizai Zaimushts.

Char K Hex.-A minor fraction of Zak bo Khel, Janakhori, Hasan Khel, Adam Khel, Afridis.
Bazoti, KHeL.-A sub-division of Samil. Headman: Shah.
DaDAR KHeL. - A section of Kalla Khel, Asbu Khel, Adam Khel, Afridis. Headman: Mir Gul.

ADAR KHEL. - One of the sections of the Mir Ahmad Khel (Mir Husain Khel), Firoz Khel, Daulatzai, Orakzais. Samil. Headman: Nazir.

DADI KHEL, - A minor fraction of Durar, Khusrogi, Nasruddin, Zakka Khel, Afridis. Samil. Headmen : see Bucha Khel.

DADO KHEL (40).-A minor fraction of Dreplara, Kh usrogi, Nasruddin, Zakka Khel, Afridis. Samil.

ALAK KHEI (250 commonly known as "Dalak Namasi"). - A sub-division of the Akbel, Ismailzai Orakzais. Gar. Headman : Rasul Khan.

DALEL. - A minor fraction of the Saiyid Khan Namasi, Ali Karan, Mamuzai, Lashkarzai, Orakzais. Gar. Headman: Sher Khan.

Dalel Khel. A minor fraction of Gadia Khel, Tatar Khel or
Akhorwal, Hasan Khel, Adan Khel, Afridis.

DALIL KHEL. A minor fraction of Hasan Khel, Pakhai, Buda, Zakka Khel, Afridis. Samil. Headman : Morad Ali, Orakzai.

DALIL KoR.-A minor fraction of the Umar Khan Khel, Ali Karan, Mamuzai, Lashkarzai, Orakzais. Gar. Headman : Husain Shab.

DARMAI KHEL.-A minor fraction of Tashi Khel, Sharaki, Galai, Adam Khel, Afridis.

DarRe KHeL (500; Chapri and basin of Jalandar stream, living mostly in Kimil Bazar and Arawaz).-A division of Khwajak Khel (Kol), Chamkannis.

DARRI KHEL. - A section of Madda Khel, Sher Gulla, Aka Khel, Afridis. Samil.

D $\triangle$ RWEZ KHEL. - A minor fraction of Rabur Khel, Keimal Khel, Urmuz Khel, Sipah, Afridis. Headman : Khan Zaman. 
DARWI KBEL (Mastura).-One of the four divisions of the Mishti Hamsayas of the Orakzais. Samil. Headmen : Saiyid, Rasul and Baz.

Darya Khan KHel.-A division of Haji Khel, Chamkannis.

DaUdZaI (60).-A division of Mamuzai or Muhammadzai, Zaimukhts.

DatdzaI (Peshawar District).-A tribe of the same origin as the Mohmands, who live along the left bank of the Kabul river to its junction with the Bara.

Dadiat KHeL.-A seotion of the Dilmarzai, Gar Mussuzai Lashkarzai Orakzais.

Dautat KHeL. -A section of the Amar Khan Khel, Alisherzai, Lashkarzai, Orakzais. Samil. Headman : Mirza Hasan.

DadLat KHel. - A section of Ghalib Khan Khel, Malikdin Khel, Malibdin Khel, Afridis. Headman: Hasrat Shah, Muhammad Zaman, Allah Mir.

Daduat KHel.-A minor fraction of Bash Khel, Annai Budai, Zakka Khel, Afridis. Samil.

DatiatzaI (2,100*; Mastura valley) -One of the four clans of the Orak zais. Samil. 100 of them are Shiahs.
DERVEZI KHEL. - A minor fraction of Mohmand Khel, Khattia Khel, Hasan Khel, Mitha Khan Khel, Kuki Khe], Afridis. Gar.

DHONI KHEL. - A minor fraction of Hilal Khel, Keimal Khel, Urmuz Khel, Sipah, Afridis. Samil. Headmen : Gul, Salim.

DILDAR KHEL. - A minor fraction of Mohmand Khel, Khattia Khel, Hasan Khel, Miths Khan Khel Kuki Khel, Afridis Gar. Headmen: Baghi, Saidal, Ghanni, Torbaz.

DirmarzaI (400).-A sub-division of the Gar Massuzai Lashkarzai Crakzais.

DinJaN KHeL. - A minor fraction of Shpalkai Khel, Zargun Khel, Galai, Adam Khel, Afridis.

Dost Mali KHec.-A section of the Bazar Khan Khel, Utman Khel, Daulatzai Orakzais. Samil.

Dreplara (260). - - A section of Khusrogi, Nasruddin, Zakka Khel, Afridis. Samil. Headmen : see Mir Kalan Khel, Dadu Khel, and Barban Khel, sub-sections.

Dreptara. - A section of Paindai, Nasruddin, Zakka Khel, Afridis. Samil. Headmen : Mahbub, Mir Kasim, Gul Badin, Nurbai.

Duparzat $(1,600)$. A division of the Chardai, Turis. 
DU BAR (300).-A section of Khusrogi, Nasruddin, Zakka Khel, Afridis. Samil. Headmen : see Bucha Khel.

DURBI KBEL. -A sub-division of Kambar, Kambar Khel, Afridis. Gar. Headmen : Khwaja Ali,
Yaro, Nar Kban, Fazl Shah Sarfaraz.

DURJI KHEL.-A sub-division of Karna Khel, Malikdin Khel, Afridis. Samil. Headuen: seo Yar Mubammad Khol.

\section{E}

ErAN I KHEL.-A minor fraction of Baghdad Khel, Keimal Khel,
Urmaz Khel, Sipah, Afridis. Samil.

\section{$\mathbf{F}$}

Farakgshah KHex (Samana and Khanki valley).-A sub-division of Rabia Kbel, Ismailzai, Orakzais, Samil. Headmen : Kamar, Ahmad, Saidak, and Makh. mad Zaman.

Farid KHrL (Khanki valley). -A sub-division of Sada Khel, Ismailzai, Orakzais. Samil.

Fateh Khan Khen.-A sub-divisiori of Utman Khel, Daulatzai, Orakzais, Simil, Headman : Khanak.

FATEH KHAN KHEL.-A minor fraction of Maruf $\mathrm{Khel}$, Basi Khel, Kamal Khel, Sahib Jan, Aka Khel, Afridis, Samil.

TATEH KHEL. - A minor fraction of Sahib Khel, Shekhai, Annai,
Budai, Zakka Khel, Afridis. Samil.

FAteH KHeL. - A minor fraction of Sultan Khel, Suran Khel, Babakri, Sipah, Afridis. Samil.

Fateh Krel. - A sub-division of Abdul Khel, Kuki Khel, Afridis. Gar. Headmon : Saiyid Ali, Mir Afzul, Abdul Aziz.

Fater KHBL.-A minor fraction of Miri Khel, Pakhai, Budai, Zakka Khel, Afridis. Samil. Headmen: see Shahbeg and Wallibeg Khel.

Fatehmi в KHeL.-A minor fraction of Ahmad Beg Khel, Mohib Kbel, Shekhai, Annai, Budai, Zakka Khel, Afridis. 
Firoz Khex.-A section of Tor, Sapar, Galai, Adam Khel, Afridis.

Firoz Ëel.-A minor fraction of "l ashi Khel, Mannia Khel, Hasan Khel, Mith Khan Khel, Kuki Khel, Afridis. Headman: see Mashi Khel.

Firoz hHaN Kor.-A minor fraction of Ali Khan Khel, Ali Karan, Mamuzai, Lashkarzai, Orakzais.
Headman : Firoz Khan.

Firoz KHEL (1,COO; IJaulaghar and Mastura ralley). $-\mathbf{A}$ division of the Daulatzai, Orakzais. Samil. Headmen : Sa'adat Khan, Saiyid Khan, Stahzadit, and Asgbar Muhainraad.

Fotter Khel. - A minor fraction of Kattia Khel, Hasan Khel, Nitha Khan Khel, Kuki Khel, Afridis. Gar.
GADAI KHEL.-A section of ! Kambar Khel, Bazoti, Daulatzais, Orakzais. Samil.

GADIA KHEL.-A section of Tatar Khel or Akhorwal, Hasan Khel, Adam Khel, Afridis. Headman : Ajmir.

GAZER KOR.-A section of the Umar Khan Khel, Alisherzai, Lashbarzai, Orakzais. Samil. Headmin : Ali Shekh.

GataI (1,400).-A division of Adam Khel, Afridis.

GAWAR KHEL.-A section of Durbi Khel, Kambar Khel, Kambar Khel, Afridis, Gar. Headmen: Nuhammad Sher, Khwaja Ali. Yaro, Nurai.

GHAIBI $K_{\text {HEL. }}-A$ sub-division of Babakri, Sipah, Afridis. Samil, Headman: Sher Muhammad.
Gralib Kaan KHel.-A sub-division of Malikdin Khel, Malikdin Khel, Afridis. Samil. Headmen : Bazmir, Gholai Jan, Huzrat Gul. Kolkaj, Miran Mir, Zaman, Malla Mancur Payao, Rasul, Salim, Sardar, Akbar, Dostai, Sher Gul, Zaris, shamsuddin.

GHALIB KHAN KHEL.-A section of the Mir Ahmad Khel, Alisherzai, Lashkarzai, Orakzais. Samil. Headman : Ibrahim Khan.

GHaLib K HAN KoR.-A minor fraction of Ali Khan Khel, Ali Karan, Mamuzai, Lashkarzai, Orakzais. Gar. Headman : Arsala.

Gearbina (20).-A section of Orakzais who bave lost their place in the clan owing to their diminished numbers. They are now Hamsayas of the Gar Massuzais. 


\section{7}

GHARU KHEL. - A minor fraction of Ashraf Khel, Kamal Khel, Sahib Jan, Aka Khel, Afridis. Samil.

GHaZI KHEL.-A minor fraction of Baghdad Khel, Keimal Khel, Urmuz Khel, Sipah, Afridis. Samil. Headman : Ahmad Shah.

GHAZI KHEL. - A minor fraction of Mannia Khel, Hasan Khel, Mitha Khan Khel, Kuki Khel, Afridis. Gar. Headmen : see Mashi Khol.

GHULAM ALI KHel.-A minor fraction of Ghuli Khel, Ambar Khel, Mat Khan Khel, Kambar Kłel, Afridis. Gar.

GHOLI KHEL. - A section of Ambar Khel, Mat Khan Khel, Kambar
Khel, Afridis. Gar. Headmen : Mastu, Babrai, Lalgul.

GHULAM KHBL (300).-A section of Haibat Khel, Jawaki, Adam Khel, Afridis. Headman: Moaz Gal.

GHOT KARRA.-A minor fraction of Karra Khel, Ghaibi Khel, Babakri, Sipah, Afridis, Samil. Headmen : see Karra Khel.

GOLI KHEL.-A minor fraction of Kasim Khel, Kimat K hel, Jawaki, Adam Khel, Afridis.

GUNDI KHEL ( 1,000 ; Kurram).-A sub-division of Landizai, Chardai, Turis.
HaBIB.-A section of Paindai, Nasruddin, Zakka Khel, Afridis. Samil. Headmen : Abdulla Mir, Mabbub, Mir Kasim.

Habibian.-A minor fraction of Dreplara, Paindai, Nasruddin, Zakka Khel, Afridis. Samil.

Haibat Kinel $(1,100)-A$ sub-division of Jawaki, Adam Khel, Afridis. Headmen : Maoz Gul, Zarbaz, and Zari Gul.

Haidar Ali KHel.-A sertion of the Fateh Khan Khel, Utman Khel, Daulatzai, Orakzais. Samil.
Haidar KHel (Mastura valley).One of the four divisions of the Mishtis Hamsayas of tho Orakzais. Samil. Headman : Mehrban.

HaIDar KHeL. - A section of the Ali Baran, Mamuzai, Lashkarzai, Orakzais. Gar. Headman: Lal Khan.

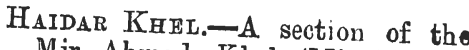
Mir Ahmad Khel (Mir Husain Khel), Firoz Khel, Daulatzai. Orakzair. Samil. Headman: Shirin.

$H_{\triangle J I}$, or $P_{A R A}, K H E L(1,000),-A$ clan of Chambannis. 
These are, correctly speaking, the Para Chamkannis.

H $\triangle J I$ KoR.-A division of Utmanzai Mohmands Headman : see Utmanzais.

HAKIM KHEL.-A minor fraction of Sani Khel, Zargun Khel, Galai, Adariz Khel, Afridis.

HaLIM KoR.-A minor fraction of Bucha Khel, Durar, Khusrogi, Nasruddin, Zakka Khel Afridis. Samil. Headmen: soe Bucha Khel.

H $\triangle M Z_{A}$ K HEL (1,000; Kurram).-A division of Sargalli, Turis.

HASAN BEG KHex.-A section of Kändao Krhel, Ashu Khel, Adam Khel, Afridis.

$\mathrm{H}_{\triangle \mathrm{SAN}} \mathrm{KHEL}(296)$. - A division of Khoidad Khel, Zaimukhts.

$\mathrm{H}_{A S A N} \mathrm{~K}_{\mathrm{H}} \mathrm{EL}$ - A minor fraction of Mlawal Khel, Haibat Khel, Jawaki, Adam Khel, Afridis.

$H_{\triangle S \triangle N}$ KHEL.-A section of the Dilmarzai Landaizai Gar Massuzai, Orakzais.

H $\triangle S A N$ KHEL. - A sub-divirion of Alisherzai, Lashkarzai, Orakzais. Samil. Headman : Shalabaz.

Hasar KHel. - A sub-division of Khabi Khel, Malikdin Khel, Afridis. Samil. Headmen : Janu, Cmaraz, Haidar.
HASAN KHEL.-A section of Pakhai, Budai, Zakika Khel, Afridis. Samil. Headmen : Zarin, Sharabut, Saida. Mirdin, Madrai, Nadir, Golab, Shah.

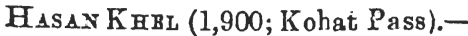
A division of Adam Khel, Afridis.

HASAN KHBL.- A sub-division of Mitha Ǩhan Khel, Kuki Khel, Afridis, Gar, Headmen : Zaman Khan is the chief; see also Kuttia Khel.

HasAT KHEL.-A sub-division of Shekh Ali Khel, Komrai Khel, Afridis. Samil. Headmen : Hafiz Sawandar, Azsm Khan.

HasarzaI (Mastura valley).-One of the four divisions of the Mishtis, one of the Hamsaya clans of Orakzai. Samil. Headman : Abdalla Nar.

HASHMi KHEL. - A section of the Bazar Khan Khel, Utman Khel, Daulatzai, Orakzais. Samil.

HATAY KOR.-A section of Khusrogi, Nasruddin, Zakka Khel, Afridis.

HILAL KнеL.-A section of Keimal Khel, Urmuz Khel, Sipah, Afridis. Samil. Headman: Suratai.

HIMA GHEL. $-A$ section of the Mandan Zaimushts.

HIYMAT Kor.-A minor fraction of Ghazi Khel, Manuia Khel 
Hasan Khel, Mitha Khan Khel, Kaki Khel, Afridis.

HUKDAD KHEL. - A section of Azad Khel, Khwaidad, Kamrai, Afridis.

Hosain Khel. - A sub-division of
Khabi Khel, Malikdin Khel, A fridis. Samil. Headmen : Janu, Ulmaraz, Haidar.

HUSaiN KHEL.-A division of Haji Khel, Chamkannis.
IBRAHIM $\mathrm{K} B E L$ L $-A$ sub-division of Landi Khel, Sipah. Afridis. Samil. Headmen: Niaz Mir, Mir Akbar.

IBRAHIM KHeL. A minor fraction of Tarkial Khel, Mughal Khel, Barmi Khel, Kamrai Khel, Afridis. Samil.

IBRAHIM KHEL-A minor fraction of Kasim Khel, Kimat Khel, Jawaki, Adam Khel, Afridis. Headman : Mushki.

IBRAHIM KHEL. - A minor fraction of Daulat Khel, Ghalib Khan Khel, Malikdin Khel, Malikdin Khel, Afridis. Samil. Headmen : see Daulat Khel.

IBRAHIM KHeL. - A section of the Khoidad Khel, Zaimushts.

IBRAHIM KOR. - A minor fraction of Dildar Khel, Mobmand Khel, Kathia Khel, Hasan Khel, Mitba Khan Khel, Kuki Khel, Afridis. Gar. Headmen: Baghi, Saidal.

IRHTIYAR KHEL. - A minor fraotion of Mohib Khel, Shekhai,
Annai, Budai, Zakiks Khel, Afridis, Samil.

IKHTIYAR KHel. - A subadivision of Yar Ali Khel, Kamrai Kbel, Afridis. Srmil. Headmen : Hafiz Sawandar and Azam Khan.

ISA KHEL - A section of the Umar Khan Khel, Alisherzai, Lashkarzai, Orakzais. Samil. Headwan: Ahmad.

IsA KHEL (120; Samana with Mishtis and All Khels). - A division of the Ismailzai, Orakzais. A religious sect of unarmed beggars. Samil.

IsmaIL KHEL.-A sub-division of the Khwaja Hawas Khel, ali Khel, one of the Hamsaya clars of Orakzai. Gar. One-third Shiah.

IsMAII . KHEL. -A section of the Sturi Khel, Alizai (Sturi Khel), Danlatzai, Orakzais. Samil. Headman : Madak.

IsMAIL KHEL.-A minor fraction of Dildar Khel, Mohmand Khel, Kattia Khel, Hasan Khel, Mitha Khan Khel, Kuki Khel, Afridis. Gar. 
IsMaIL KHEL (150).-A section of Kimat Khel, Jawaki, Adam Khel, Afridis. Headman: Yagin Shah.

IsMAIL KEEL. - A minor fraction of Daulat Khel, Ghalib Khan Khel, Malikdin Khel, Malikdin Khel, Afridis.
IsMAILZAI $(1,800$; Samana and tho Khanki valley).-One of the four clans of the Orakzais ; 600 Gar, remainder Samil. The term Ismailzai strictly speaking comprises the Rabia Khel, Mamazai (Duradar) and Akhel divisions, and its wider sense includes the Mamuzai (Lashkarzai) and the Daulatzai Orakzais.
J $\triangle F \triangle R$ KHEL. - A minor fraction of Daulat Khel, Ghalib Khan Khel, Nalikdin Khel, Malikdin Khel, Afridis. Samil. Headmen : see Daulat Khel.

JALIL KHEL. -A section of Durbi Khel, Kambar Khel, Kambar Khel, Afridis. Gar. Headmen : Khwaja Ali, Shiraz, Gul Hasan, Sarfaraz.

J $\triangle M A L$ KHEL. - A minor fraction of Kaddam Khel, Firoz Khel, Mashi Khel, Mannia Khel, Hasan Khel, Ultha Khan Khel, Kuki Khel, Afridis. Gar. Lieadmen : Amir Sher, Zaman.

JАMAL KHEL. - A minor fraction of Durar, Khusrogi, $\mathbf{N}$ asruddin, Zakka Khel, Afridis. Samil. Headmen : Arsal, Usman, Sher Ahmad.

J $\triangle$ MALI KHEL (right bank of Mastura river).-A sub-division of the Mani Khel, Muhammad Khel, Orakzais, Gar. Shiah.
$J_{\triangle M}$ SHe $\mathrm{K}$ Kов. - A minor fraction of Abdur Rahman Khel, Musa Khel, Mamuzai, Lashkarzai, Orakzais. Gar. Headman: Kammir.

JANAEHOEI (800).-A sub-division of Hasan Khel, Adam Khel, Afridis. Headman: Maizu.

JANAL KHEL. - A minor fraction of Firoz Khel, Tor Sapar, Galai, Adam Khel, Afridis.

J $\triangle N B E G K H E L$ - $A$ sub-division of Pabbi Khel, Kambar Khel, Afridis. Gar. Headman : Jan Baz.

JANO KHEL.-A minor fraction of Khadu Kbel, Mannia Khel, Hasan Khel, Mitba Khan Khel, Kuki Khel, Afridis. Gar. Headmen : Kashmir, Abdulla Khan, Bazai.

JaSBAT KHEL.-A division of Ali Khel, one of the Hamsaya clans of Orakzais. Gar. $\frac{1}{2}$ Shiah. Headmen : Wali and Hawas Khan. 
JAWAKAI-A sub-division of Babakri, Sipah, Afridis. Samil. Headmen : Burai and Fazal.

JAWAKATS (about 2,500; seattered about in British territory in consequence of blood.. feuds. -A divi- sion of Adam Khel, Afridis.

JHANDA KHEL. - A section of Ghalib Khan Khel, Malikdin Khel, Malik din Khel, Afridis. Samil. Headmeu: Yar Muhammad Jehan Izzat.
Kabir KHel (Khanki valley).-A snb-division of the Sada Khel, Ismailzai, Orakzais. Samil. Headman : Fakir.

KADAM KHeL (Mastura river).-A sub-division of Abdul Aziz Khel, Mubammad Khel, Orakzais. Gar. Shiah.

KA DDAM KHEL. -A minor fraction of Firoz Khel, Mashi Khel, Mannia Khel, Hasan Khel, Mitha Khan Khel, Kuki Khel, Afridis. Gar. Headman: Abbas.

KAIM KHEL.-A section of Suran Khel, Babakri, Sipah, Afridis, Samil. Headmen : Niaz Muhammad and Ahmad Gul.

KAJM KHEL.-A section of Shekhmal, Kambar Khel, Kambar Khel, Afridis. Gar. Headmen: Mibrban and Gulistan.

$K_{\triangle K A I}$ Kon.-A section of Ziauddin, Budai, Zakka $\mathrm{K}$ hel, Afridis. Samil.
KAKA KHEL.-A clan of the Khattaks, descended from Shekh Rahim Kar ; they are considered Mian. and are much venerated by other Pathans. They reside near Nowshera, and are great trans-frontie tradere. Headman: Rahim Shah.

KaLt KHEL (300; Trans-frontier). A division of Ali Sher Khel, Shinwaris.

KAILA KHEL (700).-A sub-division of Ashu Khel, Adam Khel Afridis. Headmen: Mir Gal, Alamdin.

KaMaL KHEL.-A sub-division of Sahib Jan, Aka Khel, Afridis. Samil.

KaMaI KHEL.-A minor fraction of Maddu Khel, Asad Khel, Mitha Khan Khel, Kuki Khel, Afridis. Gar.

Kamar KHEL: see KaMrat.

KAMBAR KHEL $(10,287$; Shilobar, Kahu and Kajurai).-One of the 
six Khaibar Afridi clans. Gar. KARRA KHEL.-A section of Ghaibi Headmen: MIehrban, Khair Mu- Khel, Babakri, Sipah, Afridis. hammad, Amaldin, Inzar Khan.

Kaybar KHeL.-A division of the Kambar Khel, Afridis. Gar.

KAMBAR RHEL.-One of the two sub-divisions of the Umarzai Shelihan, one of the Hamsaya clans of Orakzai. Samil. Headman: Misridad.

KAIIBAR KreL.-A sub-division of the Bazciti, Daulatzai, Orakzais. Sami!. Headmen : Saidan Shah and Mir Haidar.

Kuyr KнEт. A minor fraction of Gadia Khel, Tatar Khel or Akhormal. Hasan Khel, Adam Khel, Afridis. Headman: Ajmir.

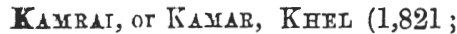
estreme west of Bara valley, next the Sipab and Zakka Khels).One of the six Khaibar Afridi clans. Samil. Headmen : Hafiz Samandar and Azam Khan.

KANDAO KHEL (400).-A subdirision of Asha Khel, Adam Khel, Afridis. Headman : Zarin.

Bariar KOR. - A minor fraction of the Umar Khan Khel, Ali Karan, Mamuzai, Lashkarzai, Orakzais. Grir.

KARNA KHEL. $-A$ division of - Malikdin Khel, Afridis. Samil. Headmen: Bawal, Nawab, Nurak. Samil. Headmen: Shah Murad, Malik Sher Muhammad.

KAron KHeL. - A section of Aaad Khel, Mitha Khan Khel, Kuki Kbel, A fridis. Gar. Headmen : Alim Sher and Mir Zaman.

KAsiar $K$ Hex (250). - A section of Kimat Khel, Jawaki, Adam Khel, Afridis. Headmen: Musa Kran and Sher Bahadur.

KASEM KHEL. - A section of Suran Khel, Babakri, Sipah, Afridis, Samil. Headmen : Turai, Radigul, Niaz Muhammad, Ahmad? Gul.

KASE KHBL. -A section of Pridai, Ashu Khel, Adam Khel, Afridis.

KatTia KHeL.-A section of Hasan Khel, Mitha Khan Khel, Kuki Khel, Afridis. Gar. Headmen : Mir Afzal, Asad Khan, Saman, Biland, Sikandar.

Kateia Mir Khel.-A minor frac. tion of Sahib Khel, Shekhai, Annai, Budai ; Zakba Kbel, Afridis. Samil.

KAZIAN KOR.-A minor fraction of Nekki Khel, Hasan Khel, Pakhai, Budai, Zakka Khel, Af ridis. Samil. Headmen: Saiyid Rasul, Nur Habib.

KeIM $\_$KHEL.-A sub-djvision of Urmuz Khel, Sipah, Afridis. 
Samil. Headmen : see Hilal Khel, Baghdad Khel and Babur Khel.

KHABI KнEL.-A division of Malikdin Khel, Afridis. Samil. Heałmen : Janu and Umaroz.

KHaDak KHeL. -A sub-division of Abdul Khel, Knki Khel, Afridis. Gar. Headmen: Salim, Kadir, Mir Akbar.

KHADI KHEL (north of Kbanki valley). - A sub.division of $\mathrm{Mam}$ uzai Daradar, Ismailzai, Orakzais. samil.

KHADU KHEL, - A minor fraction of Mannia Khel, Hasan Khel, Mitha Kban Khel, Kuki Khel, Afridis. Gar.

KHadizaI (100; Khanki river). -A division of Ismailzai, Orakzais. Samil. Headnan : Dar Khan.

KHADU KHeL (520). - A section of Khoidad Khel, Zaimukhts.

KHAI.-A minor fraction of Kui Khel, Tor Sapar, Galai, Adam Khel, Afridis.

KHaLaN KHeL (310).-A minor fraction of Sipah (Azad Khel), Ali Karan, Mamuzai, Lashkarzai, Orakzais. Gar. Headman: Walidad.

KHALIDAD KoR.-A minor fraction of the Saigid Khan Namasi, Ali Karan, Mnmuzai, Lashkarzai,
Orakzais. Gri. Headman:

Sarandaz.

KHAL KHEL. - A section of Ghaibi Khel, Babakri, Sipah, Afridis. Samil. Headmen : Nakbai.

KHANAKAI KHEL.-A seotion of Ali Khel, Ashu Khel, Adam Khel, Afridis.

KHANI KHEL $(1,200)$.-One of the four clans of Chamkannis.

KHaNI KHEL 60 ; Kharmana river).-A section of the Dilmarzai, far Masuzii, Lashisarazai, Orakzais. Gar.

KHARI KHEL.-A minor fraction of Ismail Khel, Kimat Khe', Jawaki, Adam Khel, Afridis.

KHATtaKS $\quad(24,000$; south-eastern portion of the Peshawar District, and the southern and eastern portions of the Kohat District). The main divisions by which this clan is known to most people are as follows:-The Akor Kbel, i.e., the Chief's family, the Barak, occupying the south and southeastern portions of the district, and the Seni-Khoumu occapying the portions north and north-east and west of Teri. The Tarakki section, which occupies villages west of Teri as far as Dallan, are really Baraks. The divisions, ete., of the Khattaks, with the exception of the Kaka Khel, are not indexed in this Dictionary. 
KHAW $\Delta$ S KHEL. - A minor fraction of Ismail Khel, Kimat Khel, Jawaki, Adam Khel, Afridis.

KhaYABTA KoR.-A minor fraction of Abdur Rahman Kbel, Musa Khel, Mamuzai, Lashkarzai, Orakzais. Gar. Headman : Masaki.

KHesr KHel- - A section of the Yarkuki Khel, Bazati, Daulat. zai, Orakzais. Samil.

KHOIDAD KHeL $(1,500)$. - One of the two and most numeroas clans of the Zaimusht tribe.

Khoidad Khel.-A sub-division of the Mamazai, Mishtis, one of the Hamsaya clans of Orakzai. Samil.

Kнолаг Krez.-A sub-division of Mat Khan Khel, Kambar Khel, A fridis. Gar. Headmen; Miran, Azam, Nor Alam.

KhUGa Khal (410).-A division of Ali Sher Khel, Shinwaris of Loargi. Headmen : Mir Albar, Gulistan, and Bazmir.

KheJal Khel.-A section of Mughal Khel, Barmi Khel, Kamrai Khel, Afridis. Samil. Headman: Ylafiz Samundar.

KHCMARI. - One of the 4 divisions of the llishtis, a Hamsaya clan of Urakzai. Headmen : Narali and Saipid Agghar.
KeUMaBI KHeL.-A section of Jawakai, Babakri. Sipah Afridis. Samil. Headman : Ahmad.

KH USBOGi (560) - A sub-division of Nasruddin, Zakka Khel, Afridis. Samil. Headmen: Madrazar, Jamrez, Gulrez, Mir Hasan, Amir Shah, Lawar, Khan, Sheno, Niazai, Yar Shah, Shiukai.

KHWAIDAD KHEL-A section of the Chawar Khel, Bazoti, Daulatzai, Orakzais. Samil.

$K_{\text {HWAIDAD }} \mathrm{KHEL}$ (between Khank and Mastura valleys).-A subdivision of the Bar Muhammad Khel, IIuhammad Khel, Orakzais. Samil. Shiab.

KHWAIDAD KHEL.-A sub-division of Barmi Khel, Kamrai Khel, Afridis. Samil. Headmen : Azam Khan, Nur Hasan, Guldin, Sher Nam, Kadir, Guldast.

KHWAIDAD KHEL.-A minor fraction of Zamia Khel, Masti Khel, Kambar Khel, Afridis. Gar. Headman : Muhammad Yar.

KHWAJA Ali KeEL. - A minor fraction of Daulat Khel, Ghalib Khan Khel, Malikdin Khel, Malikdin Khel, Afridis. Samil. Headmen : see Daulat Khel.

KHWaJA HaWAS KHEL. division of the Ali Khels, Hamsayas of the Orakzais. Gar. $\frac{1}{3}$ Shiab. Headman : Gal Shah. 
KHWaJA KHeL (450; Kharmana river) - A section taking half of the Samil Masuzai, Lashkarzai, Orakzais. Samil.

KHWAJA KHEI (or KoL) (800).A clan of Chamkannis consisting of the Darre Kbel and Mirza Khel divisions.

KHWAJA KHEL.-A minor fraction of Ismail Khel, Kimat Khel, Jawaki, Adam Khel, Afridis.

KHWAJA KHIDR KHEL.-A section of Mir Kulli Khel, Bazoti, Daulatza, Orakzais. Samil.

KHWAS KHEL (150).-A section of Ali Karan, Mamuzai, Lashkarzai, Orakzais. Gar. Headman : Ibrahim.

KHWAS KHEL. -A sub-division of Mamuzai Daradar, Ismailzai, Orakzais. Samil.

KIMAT KHEI (330).-A sub-division of Jawaki, Adan Khel, Afridis.

KоB KHEI.-A section of Sultan Khel, Sher Gulla, Aka Khel, Afridis. Samil.

KUDA KHEL.-A sub-division of the Umarzai, Shekhans, one of the Hamsaya clans of Orakzais. Samil. Headman : Nurulla.

KUHADAB KHEL.-A minor fraction of Misri Khel, Bosti Khel, Galai, Adam Khel, Afridis.
Kti KueL, or Aba Ba Ka KHeL A section of 'Por, Sapar, Galai, Adam Khel, Afridis. Headmon : Dostai and Yar Khan.

KOI KHEL.-A minor fraction of Durar, Khusrogi, Nasruddin, Zakka Khel, Afridis. Samil.

K UKI KнEL (5,641 ; Bara, Maidan, Rajgal, Gudar, and Lashora valleys).-One of the six Khaibar Afridi clans. Gar. Headmen :

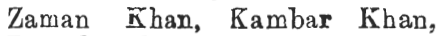
Biland, and Khaista Khan.

KULLa KHEL.-A sub-division of Malikdin Khel, Malikdin Khel, Afridis. Samil. Headmen : Nurali, Mirdast, Umar Gul.

KULLI KHEL. - A minor fraction of Dildar Khel, Mohmand Khel, Kattia Khel, Hasan Khel- Mitha Khan Khel, Kuki Khel, Afridis. Gar. Headman : Mirwal.

KoLLI KHEL.-A sub-division of Shekh Ali Khel, Kamrai Kbel, Afridis. Samil. Headmen : Mulla Amir Shah, Mulla Akhundzada and Sher Walli.

KסRTO KHEL.-A minor fraction of Kui Khel, Tor, Sapar, Galai, Adam Khel, Afridis.

KUSHA KHEL. -A sub-division of the Zakka Khel, Ali Khels Hamsayas of the Orakzais, $\frac{1}{3}$ Shiab. Gar. Headman: Khan Muhammad. 
KUтАв KHeL (Miranzai and Mastara valleys).-A division of Malla Khel, one of the Hamsaya clans of Orakzai. Samil. Headmen : Sarfaraz and Shirak.

Kбтt KHel-A sub-division of Umar Khan Khel, Malikdin Khel, Afridis. Sanil. Headmen : Sher Mast, Wazir, Sayid Gul.
KoZ KHEL. - A minor fraction of Bolaki Khel, Kakar Khel, or Akhorwal, Hassan Khel, Adam Khel, Afridis.

KOZI KHEL.-A sub-division of Shekh Ali Khel, Kamrai Khel, Afridis. Samil. Headmen : Malikdin Khel, Mulla Amir Shah, Malla Akbundzada, and Sher Walli.
$\mathbf{L}_{\triangle \mathrm{DT}}$ KHEL. - A minor fraction of Tashi Khel, Sharaki, Galai, Adam Khel, Afridis.

LAILI.-According to tradition a tribe of Wazirs residing on the rorth-western slopes of the Safed $\mathrm{Kob}$; but they have never been identified.

LAKHARI OR Lashigaki KHEL (Mastura river).-A sub-division of Sipah, Muhammad Khel, Orakzais. Gar. Shiah.

LAEHI KHEL.-A section of Pridai, Ashu Ǩhel, Adam Kbel, Afridis.

LAKKAB FHEL.-A section of Bazid Khe!, Jawaki, Adam Khel, Afridis.

LALBI KHEL.-A section of the Sturi Khel, Alizai, Daulatzai, Orakzais. Samil. Headmen : Aziz Khan, Sheraz.
Lal KHan Kor.-A minor fraction of Saiyid Khan Nmasi, Ali Karan, Mamuzai, Lashkarzai Orakzais. Gar.

LaL KHEL.-A section of Abdul Khel, Urmuz Khel, Sipah, Afridis. Samil. Headmen: Suratai, Sher Mast.

LAL KHEL.-A minor fraction of Nikki Khel, Hasan Khel, Pakhai, Budai, Zakka Khel, Afridis. Samil. Headmen : Zaman, Nasir, Utmanzai, Khawas.

LANDAIZAI* $\quad(2,800 ; \quad$ Kharmana river).-The largest of the subdivisions of Masuzai, Lashkarzai, Orakzaik. $\frac{1}{2}$ Gar (north of the river), $\frac{1}{2}$ Samil (south of the river),

LA NDI KHEL. - A minor fraction of Gadia Khel, Tatar Khel, or Akborwal, Hasan Khel, Adam Khel, Afridis.

- The division is genealogically correct, bat is of no practical use as the Massuzais have accepted the division into Gar and Samil. 
LANDI KHEL.-A division of Sipah Afridis. Namil. Headmen : Nisz Mir, Mir Akbar.

LANDIWAL KHEL.-A minor fraction of Ghulam Khel, Haibat Khel, Jaraki, Adam Khel, Afridis.

CandizaI (2,000; Kurram). - A name by which a coalition formed of the Ghnndai Khel and Alizai Turis is known.

LaNGaR KoR.-A minor fraction of the Umar Khan Khel, Ali Karan, Mamuzai, Lashkarzai, Orakzais. Gar. Headman : Madaki.
Lashrari KHRL.-A minor fraction of Misri Khel, Bosti Khel, Galai, Adam Khel, Afridis.

LASHKaRI KHEL. -A minor fraction of the Abrahim Khel, Ali Karan, Mamuzai, Lashkarzai, Orakzais. Gar. Headman : Mulla Umra.

LASHKABZAI $(7,650$; * Khanki and Kharmana valleys), -The largest and nost important of the four clans of the Orakzais. Gar 6,000; Samil 5,500.
MACHI KHeL (Khanki valley).-A sub-division of the Mamuzai, Daradar, Ismailzai, Orakzais. Samil.

MADAKKI KHEL.-A minor fraction of Bash Khel, Annai, Budai, Zakka Khel. Afridis. Samil. Headmen : Saidab, Lal Baz.

Madar KHeL.-A sub-division of Abdul Khel, Kuki Khel, Afridis. Gar. Headman : Abdul Halim.

MADDA KHEL (480).-A sub-division of Sher Gulla, Aka Khel, Afridis. Samil.

$\mathrm{M}_{\triangle D D U} \mathrm{KHEL}$-A section of Asad Khel, Mitha Khan Khel, Kuki Khel, Afridis. Gar. Headmen : Mehr Jehan and Akbar Khan.
MaHmadai, or MuHammadai.-A sub-division of Ashu Khel, Adam. Khel, Afridis.

MAHMUD KHAN KHEL.-A division of Khani Khel, Chamkannis.

$M_{\triangle K K I}$ KHEL. - A minor fraction of Kattia Khel, Hassan Khel, Mitha Khan Khel, Kuki Khel Afridis. Gar. Headmen: Mir Afzal, Shams-uddin, Zarin.

MaLaM KHoR (Khanki valley).A sub-division of Khadizai, Ismailzai, Orakzais. Samil. Headman : Mian Din.

MALIKDIN KHEL $(6,282$; Maidan, Tirah, Chora, and Kajurai).-One of the 6 Khaibar Afridi olane. Headmarl: Yar Mubammad, Khan Bahadur.

* Inoluding the Masuzai division (1,900), which is, howerer, sometimes classed as a separate clan. 


\section{8}

Malikdin KHEL. -A division of Malikdin Khel, Afridis. Samil. Headmen : Sultan Muhammad Khan, Firoz Khan, Yar Mubammad Khan.

MALI KHEL.-A minor fraction of Kasim Khel, Kimat Khel, Jawaki, Adam Khel, Afridis.

Malia Khel.-A section of Zarghun Khel, Grlai, Adam Khel, Afridis. Headman: Adal Beg.

MaLLa KHeL (800; Miranzai and Mastura vallers).-One of the four Hamsaya clans of Orakzai. Samil. Headmen : Sarfaraz, Daigid Alsbar, and Band Ali.

Matla KHel. -A section of Stari Khel, Alizai, Daulatzai, Orakzais. Samil.

MaLLI KarL. - A section of the Hamza Khel Turis, but so large that it is generaily considered separately, A very large Kuchi commanity.

MAMrL KHeL.-A section of Suran Khel, Babakri, Sipah, Afridis, Samil. Headmen : Amir Shah, Faizu, Kadir Shah, Mir.

MamozaI (foot of Sampagha pass). -One of the four divisions of the Mishtis, one of the Hamsaya clans of Orakzai. They are the -black breep of the Misti clan.

: Samil. Headmen : Nur Muhammad Shah and Nur Gul.
MaMUzar, or MU H A M M D Z A I (WESTERN) ZAIMUKHTS (800). -One of the two clans of Zaimukhts.

Mamozar $(3,600 ;$ sources of Khanki river). - One of the three divisions of the Lashkarzai, Orakzais. Gar.

MamozaI Daradar (300; north of Khanki valley.)-A division of Ismailzai, Orakzais, Samil. Headman: Alam Khan.

Manatumal (300).-A division of Mamuzai, or Muhammadzai, Zaimukhts.

Mandan (150).-A division of Mamuzai or Mabammadzai, Zaimukhts.

MANDRA KHEL. - A section of Ali Khel, Ashu Khel, Adam Khel, Afridis.

MANDRA KHEL. - A minor fraction of Dildar Khel, Mohmand Khel, Kattia Khel, Hasan Khel, Mitha Khan Khel, Kuki Khel, Afridis. Gar.

MandaA KHex.-A sub-section of Darwi Khel Mishtis.

MaNDRaE KHel-A sub-äivision of Firoz Khel, Daulatzai, Orakzais. samil. Headman: Abid Khıı.

MANDU KHEL (400; Kharmana river).-A section of the Khwajah 
Khel Samil Masuzai, Lashkarzai, Orakzais. Headman : Muhammad Shah.

Ml ax Gal. - An Afghan Sunni Tribe. Many of its members are settled as Hamsayas of the Turis, chiefly in the hills above Paiwar and Shilozan.

MaNi KHeL (600; Mastura valley and Landuki pass).-One of the four divisions of the Muhammad Khel, Orakzais. Gar. Shiah. Headmen: Nauroz Ali and Ahmad Mir.

MaNNIA KHEL.-A section of - Hasan Khel, Mitha Khan Khel, Kuki Khel, Afridis. Gar. Headnien : Khaista Khan, Zarin, Mir Alam Khan.

ṀNZ Tzok (415; Loargi, Khargali, and Darband).-A division of Ali Sher Khel, Shinwaris.

MARID KHeL.-A minor fraction of Mian Khel, Janakhori, Hasan Khel, Adam Khel, Afridis.

MaRSID KHeL.-A minor fraction of Kalla Khel, Ashu Khel, Hasan Khel, Adam Khel, Afridis.

MARUF $\mathrm{KHEL}-\mathrm{A}$ minor fraction of Basi Khel, Kamal Khel, Sabii Jan, Aka Khel, Afridi*. Samil.

Marwas KHel.-A sub-division of the Zanka Khel, Ali Khels, one of the Hamsaya clan of
Orakzai, $\frac{1}{3}$ Shiah. Gar. Headman ; Nur Hussain.

Masan KHel.-A sub.division of the Akhel, Ismailzai, Orakzais. Gar. Headman : Baz.

MashakI.-A minor fraction of Shakal Khel, Haibat Khel, Jawaki, Adam Khel, Afridis.

MaSHI KHEL.-A minor fraction of Mannia Khel, Hasan Khel, Mitba Khan Khel, Kuki Khel, Afridis. Gar. Headmen: Musa Khan, Khaista Khan.

Mastal Khel.-A minor fraction of Makki Khel, Kattia Khel, Hasan Khel, Mitha Khan Khel, Kuki Khel, Afridis. Gar. Headmen : see Makki Khel.

MASTI KHEL - A minor fraction of Babur Khel, Keimal Khel, Urmuz Khel, Sipah, Afridis. Samil. Headman: Khan Zaman.

MaSTI KHEL.-A sub-division of Kambar Khel, Kambar Khel, Afridis. Gar. Headmen: Maham. mad Yar, Fakir, Gulistan, Gul Shab, Rahmat.

Masti NaWasr.-A sectioc of the Wattizai Zaimushts.

MASTO KHEL (600; Kharman river). $\cdots$ A section of Gar Masuzai, Lashkarzai, Orakzais. Gar. Headman: Arsala Khan. 
Masto KHeL (1,500; Kurram). -A division of Sargalli, Turis.

MasczaI (1,900; Kharmana river close to Kurram). - The largest of the three divisions of the Lashkarzai, Orałzais. Some authorities, however, regard them ss a separate clan. Gar and Samil.

Matari-A division of the Ali Khel, Hamsayas of Orakzai. Gar. $\frac{1}{3}$ Shiah. Headman : Nurulla Khan.

Mat KHax KHel.-A division of Kambar Khel, Afridis. Gar. Headmen : Mastu and Barbarai.

MaWaL KHEL (760).-Aisection of Haibat Khel, Jawaki, Adam Khel, Afridis. Headmen: Shandi Gul, Ain Shah, and Manadin.

MI $\triangle \mathrm{Z} \triangle H I T \Delta L .-A$ section of the Khoidad Khel Zaimushts.

MIZEx KHEL. - A section of Pridai, Ashu Khel, Adam Khel, Afridis.

Mraxia (Miranzai," Vihowa).-A Trans-Indus tribe, numbers of which are found scattered along the frontier, some living with the Bangash others with the Khetrans, etc.

Mras KHEL. - A minor fraction of Baghdad Khel, Keimal Khel, Trmuz Khel, Sipah, Afridis.
Mias KHEL.-A minor fraction of
Amar Khel, Annai, Khel, Afridis.

MraN KHEL.-A section of Janakhori, Hasan Khel, Adam Khel, Afridis.

Mira Ahmad KHEL.-A minor fraction of Mir Ahmad Khel, Mir Husain Khel, Firoz Khel, Darlatzai, Orakzais. Samil. Headman : Sherbaz.

Mir AHMad Krel. - The Malikdin Khel and $K$ ambar Khel Afridis together are known by this name.

Mir ahmad Keel. A sub-divisior of Alisherzai, Lashk:rzai, Orak. zais. Samil. Headman : Zira

Mir Ahmad KHEl (Husain Khel).-A sub-division of the Firoz Khel, Daulatzai, Orakzais. Samil. Headman: Sherbaz.

Mrrali Khel.-A minor fraction of Mirkalan Khel, Husa Khel, Mamuzai, Lashkarzai, Orakzais. Gar.

Mir Ali Khel (200). - A minor fraction of Abrahim Khel, Ali Karan, Mamuzai, Lasbkarzai, Orakzais. Gar. Headman: Rahman.

Mir Ali KHeL.-A sub-division of the Bazoti, Daulatzai, Orakzais. Samil. Headman : Safarali. 
Misan Krex.-A section of Shekmal Khel, Kambar Khel, Kambar Khel, Afridis. Gar. Headmen : Ajmer and Sber Jan.

Miran KHEL.-A sub-division of Karna Khel, Malikdin Khel, Afridis. Samil. Headmen : see Yar Slubammad Khel.

MiRAS KHEL. - A minor fraction of Ismail Khel, Kimat Kbel, Ja waki, Adam Khel, Afridis.

VIRAZIZ KHEL (near Landuki pass). - A sub-division of the Bar Muhammad Khel, Muhammad Khel, Orakzais. Samil. Shiah.

MIRBASH KHEL-A minor fraction of Shakal Khel, Haibat Khel, Jawaki, Adam Khel, Afridis.

MIrbash KHeL.-A minor fraction of Ismail Khel, Kimat Khel, Jawaki, Adam Khel, Afridis.

MIRBEG KHEL.-A section of the Kambar Khel, Bazoti, Daulatzai, Orakzais. Samil.

MIRBEG KHEI..-A minor fraction of Pirwal Khel, Tatar Khel, or Akhorrval, Hasan Khel, Adam Khel, Afridis.

Mirdad Kor.-A sub-division of the Bazid Khel, Shekhans, one of the Hamsaya clans of Orakzai. Samil. Headman: Alidad.

MireHAT KHEI.-A minor fraction of Basi Khel, Karnal Khel, Sahib Jan, A ka Khel, Afridis. Samil.
MrR Haban KHeL. - A section of the Mir Abmad Khel (Mir Husain Khel), Firoz Khel, Danlatzai, Orakzais. Samil. Headman: Lal Khan.

Mir Husain Khel.-A subdivision of the Firoz Khel, Daulatzai, Orakzais. Samil. Headman : Zain Khan.

Mrrs Kael.-A section of Zingun Khel, Galai, Adam Khel, Afridis.

Mrri Khel (120).--A division of Aka Khel, Afrrdis. Samil.

MIRI KHEL.-A section of Pakhai, Budai, Zakka Khel, Afridis. Samil. Headmen: 'T'aza Gal and Khaista Khan.

MIri KHeL.-A section of Suran Knel, Babakri, Sipah, Afridis. Samil. Headmen: Abdulla Sabib Gul.

M.IR KHAN KHEL-A section of Madda Khel, Sher Gulla, Aka Kbel, Afridis. Samil.

Mir KHAN KHeI. - A minor frrco tion of Durar Khasrogi Nasruddin, Zakka Khel, Afridis. Samil.

MIR KHAN KHEL.-A section of Usinan Khel, sikanda: Khel, Kuki Khel, Afridis. Gar. Headman : Khairai.

Mir Kajan KHet (900), - A section of the Musa Fhel, Mamuzai, 
Lashkarzai, Orakzais. Gar. Headman : NIulla Abdul Kaüir Akhun.

Mir Katax Khei (170).-A minor fraction of Dreplara, Khusrogi, Nasruddin, Zakka Khel, Afridis. Samil. Headmen: Jamrez, Ali, Mast, Zaidullit. Arjumand Shab, Purdil, Mirza Khan, Nurulla.

MIIREHAN TAWASI.-A section of the Wattizai Zaimushts.

Mir Krel (Khanki river).-A subdivision of Thhadizai, Ismailzai, Orakzais. Samil. Hoadman: Gulla.

NIR KULLI KHEL. - A sub•division of Bazoti, Daulatzai, Orakzais. Samil. Headmen : Gulfaraz and Gulzada.

MIIRO KHEL.-A sub-division of NIamuzai, Mishtis, Hamsayas of the Orakzais. Samil. Headman : Hayat Khan.

Miro Khel (Daradar valley).-A sub-division of MIamuzai, Daradar, Ismailzai, Orakzais. Samil.

MIR SAID KHEI.-A minor fraction of Sanzal or Sanyal Khel, Kamal Khel, Sahib Jan, Aka Khel, Afridis. Samil.

MIrac Kor.-A section of Ali Khel, Ashu Khel, Adam Khel, Afridis.

Miswaz Khel (Mastura valley).A sub-dirision of Mani Kbel,
Muhammad Khel, Orakzais. Gar. Shiah.

Mrrzabeg KHel.-A sub-division of Mat Khan Khel, Kambar Kbel, Afridis. Gar. Headmen : Sher Khan, Hamid, and Nurai.

MIRZA KHeL (150).-A division of Khwajak Khel ( $\mathrm{Kol})$, Chambannis.

M ISHAE KHEL. -A minor fraction of Karun Khel, Asad Khel, Mitha Khan Khel, Kuki Khel, Afridis. Gar.

Mishri $\quad(3,000$; Mastura valley down to British territory near Hangu).-One of the four Hamsaya clans of Orakzai. They are a powerful clan and sre looked up to by the others as leaders in important questions. Samil. Headmen : Saiyid Rasul, Abdulla Nur, Mawali, and Nurabaz.

MisRI KHEL. - A minor fraction of Samns Kbel, Ghuli Khel, Ambar Kbel, Mat Khan Khel, Kambar Khel, Afridis. Gar. Headmen : see Khojal Khel.

MisRi KHeL. -A seotion of Bostí. Khel, Galai, Adam Khel, Afridiø. Headman : Dalsher.

MISRI KHEL. - A section of the Umar Khan Khel, Alisherzai, Lashkarzai, Orakzais. Samil. Headman : Madda Shah.

MISRI KHEL.-One of the subdivisions of the Hasanzai, Mishti Hamsaya clan of Orakzais. Samil 
Mitha KhaN KHeL.--A division of Kuki Khel, Afridis. Gar. Headman : Zaman Khan.

Mithe KHer.-A minor fraction of the Barid Khel, Sturi Khel, Alizai (Sturi Khel), Daulatzai, Orakzaîs. Samil. Headman : Badshah Kalandar.

Mitmah KHan KHel (close to Ublan pass).-A sab-division of the Sipah, Muhammad Khel, Urakzais. Gar. Shiab.

Mobara KHeL.-A minor fraction of Bash Khel, Sheraki, Galai. Adam Khel, Afridis.

Mogal KHEL. - A minor fraction of Yunas Khel, Bosti Khel, Galai, Adam Khel, Afridis.

MOGHUL KEEL. - A minor fraction of Usman Khel, Shanai, Budai, Zakia Khel, Afridis. Samil. Headmen: Mihr Din, Bawar, Sultan Vir, Gul Sbah.

Moнabat Krex.-A section of Kandao Khel, Ashu Khel, Adam Khel, Afridis.

MoнIL KнеL.-A minor fraction of Shekhai, Annai, Budai, Zakka Khel, Afridis. Samil.

MoHmand KHeL.-A minor fraction of Daulat Khel, Ghaib Khan Khel, Malikdin Khel, Malikdin Khel, Afridis. Samil. Headmen : see Danlat Khel.
NoHMaNd KHEL-A minor fraction of Kattia Khel, Hasan Khel, Nitha Khan Khel, Kuki Khel, Afridis, Gar.

MUbarak Krec. - A minor fraction of Mirghat Khel, Basi Khel, Kamal Khel, Sahib Jan, Aka Khel, Afridis. Samil.

Mubarak Kael.-A section of Sharaki, Galai, Adam Khel, Afridis.

MUGHणx KHEL. - A sub-division of Barmi Khel, Kamrai or Kamar Khel, Afridis. Samil. Headmen: Hafiz Samandar, Banat, Guldai.

MoHabat KrHan Nawagi.-A section of the Wattizai Zaimushts.

MURABAT $K$ HEL. -1 section of Muhammadai, Asha Khel, Adam Khel, Afridis.

MunammadaI.-See Míamadat.

Munammad Khel (Khanki river). -A sub-division of the Khadizai, Ismailzai, Orakzais. \$amil. Headman : Mirak.

Mugammad Krel (2,400; Masiura. valley and Landuki pass).-One of the four clans of Orakzais. The term Mahammad Khel includes Mani Khel, Sipah, Abdul Aziz Khel and Bar Muhammad Khel, the first three bying Gar and the latter Samil. They zre much under the influence of 
Saiyids. Shiah. Headmen : Mir Mian, Nur Ali, and Mir Raza.

MithamMad KHei. A section of Zargan Khel, Galai, Adam Khel, Afridis. Headman : Firoz.

\section{MithammadzaI.-See MamezaI} ZaIITCEHTS.

Ricula KHel-A section of Zarghan Khel, Galai, Adam Kbel, Afridis.

Melua KHel一One of the two sab-divisinns of the Umarzai Shekhans, nne of the Hamsayas clans of Orakzai. Samil. Headman : Rahman.

NICLIA Kor.-A minor fraction of iIubarak Khel, Sharaki, Gallai, Adam Khel, Afridis.
MULtani KHEL.-A section of Zakku Khel, Sikandar Khel, Kuki Khel, Afridis. Gar. Headmen : Kaim and Yar Sbah.

MoQBIL.-An Afghan Sunni tribe of whom a number are settled in the Kurram as Hamsayas of the Turis, chielly in the low hills above the upper river tract.

MUSA KHEL. A minor fraction of Misri Khel, Bosti Khel, Galai, Adam Khel, Afridis.

MUsa KHEL. - A sub-division of Yar Ali Khel, Kamroi Khel, Afridis. Samil.

MUsa KHEL.-A section of the Manstwal Zaimushts.
Naty Sher Kor (Khanki river).A sub-dirision of Khadizai, Ismailzai, Orakzais. Samil. Headman : Mira Khan.

NaKshbãd KHor (Khanki valley), -A sub-division of Sada Khel, Ismailizai, Orakzais. Samii. Headman: Said Salam.

$N_{\triangle R A T G}$ KHEL. A minor fraction of Bolaki Khel, Tatar Khel or Athonrwal, Hasan Khel, Adam - Kbel. Afridis.
NASAR KHEL. - A minor fraction of Sanni Khel, Zaroun Khel, Galai, Adam Khel, Afridis.

$N_{\text {ASI KOR. - A sub-division of Azim }}$ Khan Kor, Umar Khan Khel, Alisherzai, Orakzais. Samil.

$N_{A S R A T}$ KHEL. - A section of Ghalib Khan Khel, Malikdin Khel, Afridis. Samil. Headmen : see Nathu Khel.

NasraZaI (650 ; Kharmana river).A sub-division of Khwajah Khel, 


\section{5}

Samil Masuzai, Orakzais. Headman : Mir Ahmad Shah.

NASRUDDIN $(1,200$ to 1,500$)$.-A division of Zakka Khel, Afridis. Samil. Headmen : see Habib, Paindai, and Khusrogi.

Nath o KHet-A section of Ghalib Khan Khel, Malikdin Khel, Malikdin Khel. Afridis. Samil. Headmen: Yar Muhammad Khan, Alam Khan, Kasim, Said Ghulam, Mir Alam, Mir Azim, Salim, Gulbaz, Hawas Mir.

NaWAZ Kael- - A minor fraction of Sanni Khel, Zargun Khel, Galai, Adam Khel, Afridis.

$N_{A Z I}$ KreL.-A section of Abdal Khel, Urmuz Khel, Sipab, Afridis. Samil. Headmen: Suratai, Arbab Jamai.

NAZI KHEL. $-A$ minor fraction of Moghul Khel, Usman Khel, Shanai, Zakka Khel, Afridis. Samil. Headmen: Mibr Din, Bawar, Sultan Mir, Gul Sbah.

NAZIR KHEL.-A minor fraction of Sanni Khel, Zargun Khel, Galai, Adam Khel, Afridis.

OrakzaIS $(23,650$; Tirah, the mountainous district north-west of Kohat, and immediately south of the Afridi country, down to the Miranzai valley). - One of the most important of the tribes of
NAzo KHEL.-A sub-division of Aimal Khan Khel, Zanka Khel, Hamsayas of the Orakzais. Gar. $\frac{1}{3}$ Shiah.

$N_{A Z 0}$ KHEL. - A sub-division of the Khwaja Hawas Khel, Ali Khel, Hamsayas of the Orakzais. Gar. $\frac{\mathrm{I}}{3}$ Shiah.

Nerzasi KHeL.-A section of Tor Sapar, Galai, Adam Khel, Afridis. Headmen : Khushal and Habib.

NEKZAMr KHEL_-A minor fraction of Walli Khol, Ali Khel, Shekh. mal Khel, Kambar Khel, Kambar Khel, Afridis. Gar.

NIKkI KHEL.-A minor fraction of Hasan Khel, Palihai Budai, Zakka Thel, Afridis. Samil. Headinen : see Miri Khel, Ahmad Khel, Lal Khel, and Kazian Kor.

Nur MomaMyad Khel.-A minor fraction of Tor Khel, Asad Khel, Mitba Khan Khel, Kuki Khel, Afridis. Gar. Beadmen: Razai, Islamdin.

NORWEZ KHeL.-A sub-division of the Khwaja Hawas Khel, Ali Khel, Hamsayas of the Orakzais. Gar. $\frac{1}{3}$ Shiah.

the North-West Frontier. It may be noted that the Muham. mad Khel clan, as also portions of the Alizais and Ali Khels, are Shiahs. 
PABbi KHBL.-A sub-division of Kambar Khel, Kambar Khel, Afridis. Gar. Headmen: Gul Hasan, Da Khan.

Parari KHrL. - A section of the Mandan Zaimushts.

PAIA KHEL.-A section of Janakhori, Hasan Khel, Adam Khel, Afridis.

PAINDAI (940).-A sub-division of Nasruddin, Zakka Khel, Afridis. Samil. Headmen : Abdulla Mir, Shahbaz, Mir Kasim, Sher Ali, Lal Bar, Niaz Mir, Mahbub.

PatNd KhrL-A sub-division of Barmi Khel, Kamrai Khel, Afridis. Samil. Headman : Knke.

PABHAI $(1,000)$ - - A sub-division of Budsi, Zakka Thel, Afridis. Samil. Headmen : see Wali Khel, Sarddo Khel, Hasan Khel, Shekhwal, Sikandar Khel, and Mir Khel.

PakraI.-A section of Mahmadai, Ashu Khel, Adam Kbel, Afridis.
Paranchas (Kohat and Peshawar districts, Kabul, Bokhara).-A tribe of merchants who are settled in various parts of the frontier districts.

PATC KHEL. - A minor fraction of Mawal Khel, Haibat Khel, Jawaki, Adam Khel, Afridis.

PAYAO KHEL.-A section of the Chawar Khel, Bazoti, Daulatzai, Orakzais. Samil.

Payao KHel (Samana and Khanki valley).-A sub-division of Rabia Khel, Ismailzai, Oralzzais. Samil. Headmen : Maknmad Din, Mir Hawas, Makhmad, and Saiyid Nazir.

Piro Kher (800; Loargai).-A division of Ali Sher Khel, Shinwaris. Headman; Mandezai.

Pirwal KHel. - A section of Tatar Khel or Akhorwal, Hasan Khel, Adam Khel, Afridis. Headman: Hawas.

PrIDAI (100).-A sub-division of Ashu Khel, Adam Khel, Afridis.

$\mathbf{R}$

RABIA KHEL (800: Samana and Khanki valley).-The largest division of the lsmaileai, Oralszais. Samil. Headman : Muhammadin.
RAHIMDAD KHEL. - A minor fraction of Basi Khel, Kamal Khel, Sahib Jan, Aka Khel, Afridis. Samil. 
RAHIMDAD KHEL. - A minor fraction of Bash Khel, Sharaki, Galai, Adam Khel, Afridis.

Rahim KHeL. - A minor fraction of Mohib Khel, Shekhai, Annai, Kudai, Zalika Khel, Afridis. Samil.

RaHim KHel. - Another name for the Sarlii Khel.

RAHMAN KHEL. - A minor fraction of Shakal Khel, Haibat Khel, Jawaki, Adam Khel Afridis.

RAMSHER kiHel.-A section of Uurbi Khal, Kambar Khel, Kambar Khel, Afridis. Gar, Headmen : Muhammad Sher, Khwaja Ali, Yaro, and Nurai.

RANRA KHEL.-A minor fraction of Sher Khan Khel, Umar Khan Khel, Malikdin Khel, Malikdin Khel, A fridis. Samil.
$R_{\triangle Z_{A}} \quad K H E L .-A$ minor fraction of Gadia Khel, Tatar Khel, or Akhorwal, Hasan Khel, Adam Khel, Afridis.

RAZA KHEL.-A section of Kulla Khel, Malikdin Khel, Malikdin Khel, Afridis. Samil. Headman : Ata Muhamirad.

RAZA KHEL.-A minor fraction of Samna thel, Ghuli KheI, Ambar Khel, Mat Khan Khel, Kambar Khel, Afridis. Gar, Headmen: see Khojal Khel.

Rozpa.-A section of the Mandan Zaimushts.

RUKHaN KenEL.-A section of Kandao Khel, Ashu Khel, Adam Khel, Afridis.

RUstam Kor.-A sub.division of Bazid Khel, Shekhans, one of the Hamsaya clans of Orakzai. samil. Herdman: Mustamand.

\section{S}

$S_{A}$ 'ADAT KHEL. - A section of Bazid Khei, Jawaki, Adam Khel, Afridis.

$S_{\triangle B A T}$ KoR.-A minor fraction of Ali Khan Khel, Ali Karan, Mamu. zai, Lashkarzai, Orakzais. Gar. Headman : Firoz Khan.

SABURAJ Khel (Mastura river).-A sub-division of the Mani Kuel,
Muhammad Khel, Orakzai s Gar. Shiah.

$\mathrm{S}_{\triangle \mathrm{DA}} \mathrm{KHEL}(25 ;$ Khanki valley).A division of Ismailzai, Orakzais. Samil.

SADAK KHEL. - A minor fraction of Maruf Khel, Basi Khel, KamaI Khel, Sahib Jan, Aka Khel, Afridis. Samil. 
SADDo KHet.-A section of $P_{\text {akhai, }}$ Budai, Zaklia Khel, Afridis. Samil. Headmen: Hamidnlla and Sher Ghulam.

SADDO KHEL.-A sub-division of Mamuzai, Mishtis, Hamsayas of Oralizai. Samil. Headman: Fakir.

SADO KHEL-A section of the Manatwal Zaimushts.

SAFAR KHEL. - A minor fraction of Ghulam Khel, Haibat Khel, Jamali, Adam Khel, Afridis.

SaHib Jar.-A division of Aka Khel, Afridis. Samil.

SaHib Krel.-A minor fraction of hekhai, Annai, Bndai, Zakka Khel, Afridis. Samil.

Safib KHel. - A section of the Umar Khan Khel, Alisherzai, Lashkarzai, Orakzais. Samil. Headman : Kasim Khan.

SAHIB KHEX.-A minor fraction of Sabib Khel, Shekhai, Annai, Budai, Zakka Khel, Afridis. Samil.

SAIXID AHMAD.-A sub-dirision of Alisherzai, Lashbarzaj, Orakzais. Samil. Headman : Rayaz.

SAIYID KHaN NuisI (320).-A section of the Ali Karan, Mamazai, Irashkarzai, Orakzais. Gar.

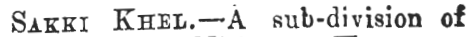
Mamozai, Mishtis, Hamsayas of Orakzai. Samil. Headman : shahzu.

SAMNA KHEL - A minor fraction of Ghuli Khel, Ambar Khel, Mat Khan Khel, Kambar Kbel, Afridi. Gar. Headman: see Khojal Khel.

SamozaI (Mastura, Khanki, and Miranzai valleys).-One of the three divisions of the Shekhans, Hamsayas of the Orakzais. Samil. Headmen : Miram Sher, Ambar Gul, and Tiruh.

SANGARAI (25).-A section of Bazid Khel, Jaraki, Adam Khel, Afridis.

SANYAL KHEL, or SANzaL KHEz. -See SanzaL KHEL.

SaNzal KHel, or SaNral KHEL. -A section of Kamal Khel, Sahib Jan, Aka Khel, Afridis. Samil.

SAPAR KHEL.-A minor fraction of Ghulam Khel, Haibat Khel, Jawaki, Adam Khel, Afridis.

SARBADAR KHEL- -A sub-division of Mat Khan Khel, Kambar Khel, Afridis. Gar. Headmen : Mastu and Barbarai.

SARBAR KHEL $(1,200)$. -A section of Bazid Khel, Jawaki, Adam Khel, Afridis. 
Sarealli. (2,5C0; Kurram).-The smaller of the two clans of the Turis.

SARGOL KHel. - A minor fraction of Pirwal Khel, Tatar Khel, or Alihorwal, Hasan Khel, Adam Khel, Afridis.

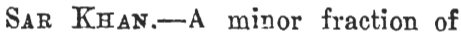
Nekzam Khel, Tor Sapar, Galai, Adam Khel, Afridis.

$\mathrm{S}_{A R} K_{\text {HeL. }}$-A minor fraction of Makki Khel, Kattia Thel, Hasan Khel, Mitha Khan Khel, Kuki Khel, Afridis. Gar.

Sarki KHEL.-A sub-division of Akhel, Ismailzai, Orakzais. Gar. Headmen: Mir Khan and Miram Gul.

SaRMaST ISHEL - A minor fraction of Yunas Khel, Bosti Khel, Galai, Adam Khel, Afridis.

SARMAST KHEL. - A minor fraction of Mian Khel, Janalshori, Hasan Khel, Adam Khel, Afridis.

SARTAR KHEL.-A minor fraction of Nekzam Khel, Tor Sapar, Galai, Adam Khel, Afridis.

Sattal Krel.-A minor fraction of Ghulam Khel, Haibat Khel, Jawaki, Adaw Kbel, Afridis.

SAUR KHEL. - A section of Ali K hel, Ashu Khel, Adam Khel, Afridis.
ShabjL KHeL.-A minor fraction of Uwar Khel, Annai, Budal, Zakka Khel, Afridis. Headmen : Shahaba Din, Bolak. Arab.

SH $\triangle G U$ KOR.-A minor fraction of Ambora Khel, Sanzal Khel, Kamal Khel, Sahib Jan, Aka Khel, Afridis. Samil.

SHAHBaS KHEL. -A minor fraction of Mir Said Khel, SanzaKhel, Kamal Khel, Sahib Jan, Aka Khel, Afridis. Samil.

Shahbeg Krel $\rightarrow$ A minor fraction of Ter Khel, Asad Khel, Mitha Khan Khel, Kuki Khel, Afridis. Gar. Headmen: Razai and Islamdin.

ShaнBeg Kнвг.-A minor fraction of Fateh Khel, Mir Khel, Pakbai, Budai, Zakka Khel, Afridis, Samil. Headmen: Mruhammad Nur, Muhammad Shah, and Kamr Din.

SHAHDAD KHEL.-A section of the Kambar Khel, Bazoti, Daulatzai, Urakzais. Samil.

Shahi KHeL.-A minor fraction of Ghulam Khel, Haibat Khel, Jawaki, Adam Khel, Afridis.

SHAHI KHEL.-A section of the Wattizai Zaimushts.

SHAHMAL KHEL.-A minor fraotion of Firoz Khel, Tor Sapar, Galsi, Adam Khel, Afridis. 
Sha of Zaman Khel, Makli Khel, Kattia Khel, Hasan Khel, Mitha Khan Khel, Kuki Khel, Afridis. Gar.

SHAHWAZ KHEL. -A sub-division of the Khwaja Hawas Khel, Ali Khel, Hamsayas of the Orakzis. Gar. $\frac{1}{3}$ Shiah.

SHAIB KHEL.-A section of the Hir Abmad Rhel, Alisherzai, Lashkarzai, Orakzais. Samil.

SHAKAL KAET (100). - A section of Haibat Khel, Jawaki, Adam Khel, Afridis.

SH $\triangle$ MAL KHEL.-A minor fraction of Pirwal Khel, 'l'atar Khel or Akhorwal, Hasan Khel, Adam Khel, Afridis.

SHAMALI KHEI. - A sub-division of the Akhel, Ismailzai, Orakzais. Gar. Headman: Suba Shah.

SHAMsha KHEL. - A minor fraction of Mawal, Khel Haibat Khel, Jawaki, Adam Khel, Afridis.

Sharat, or Shax, Khel (150). - A division of Zakka Khel, Afridis. Samil. Headmen : Naid Khsn, Mihr Din, Bawar, Saltan Mir, ival Shah, Khanzad, Langur, Khandin, Said Khan.

Sharagh KHel. - A minor fraction of Kaddam Khel, Firoz Khel, Mashi Khel, Mannia' Khel, Hasan
Khel, Mitha Kban Khel, Kuki Khel, Afridis. Gar.

SHaRAKI (200). - A sub-division of Galai, Adam Khel, Afridis.

SHARIF KHEL. - A section of the Chawar Khel, Bazoti, Daulatzai, Orakzais. Samil.

ShekraI (100; Trans-frontier).-A division of the Ali Sher Khel, Shinwaris.

Shekrat.-A section of Annai, Badai, Zakka Khel, Afridis, Samil. Headmen: Dadai and Miraz Khan.

She k ALI KHel.-A division of Kamrai or Kamar Khel, Afridis. Samil. Headmen : Mulla Amir, Shah and Hafiz Samandar Khan.

ShekHaN.-A minor fraction of Kasim Khel, Suran Khel, Babakri, Sipab, Afridis. Samil. Headmen : see Kasim Khel.

SheKHAN.-A minor fraction of Karun Khel, Asad Khel, Mitha Khan Khel, Kuki Khel, Afridis. Gar. Headmen : Gulab, Aiam Sher, Sherai, Ghulam Ali, Khirdad, Alladad Fakir, Abbas.

SHekHaN (2,750; Mastura, Khan$\mathrm{ki}$, and Miranzai valleys).-A Hamsaya clan of Orakzais. Samil. Headmen : Pir Mubammad, Miran Shah, and Baz Gul Khan. 
Shenhmal Khel.- A sub-division of Kambar Khel, Kambar Khel, Afridis. Gar. Headmen : Amal Din, Mihrban, Inzar Khan.

Shekmal Khel (415; Loargai).A division of Ali Sher Khel, Shinwaris. Headmer : Timar Shah, I ain, Haidar Jan.

Shekh MaIt KHeL (200). - A minor fraction of Abrabim Khel, Ali Karan, Mamuzai, Lashkarzai, Urakzais. Gar. Headman: Said A hmad.

SheKWAL.-A section of Palihai, Budai, Zakka Khel, Afridis Samil. Headmen; Sher Ali, Mirza, Samundar, Payao.

SHer.-A sub-division of the Khwaja Hawas Khel, Ali Khel, Hamsayas of Orakzais. Gar. $\frac{1}{3}$ Shiah.

SHERAKAI. - A minor fraction of Dreplara, Paindai, Nasruddin, Zakka Khel, Afridis. Samil.

SHERBA KHEx.-A section of Tor Sapar, Galai, Adam Khel, Afridis.

Shergul KHer. - A minor fraction of Yunas Khel, Bosti Khel, Galai, Adam Khel, Afridis.

SHer Gella.-A division of Aka Khel, Afridis. Samil.

Sher I KHEL. - A minor fraction of Baghdad Khel, Keimal Khel,
Urmuz Khel, Sipab, Afridis. Samil.

Sher KHAN KHeL - A minor fraction of Umar Khan Khel, Mrlikgin Khel, Malikdin Kihel, Afridis. Samil.

Sher Khan Khel.-A minor Eraction of Kasim Khel, Kima, Khel, Jawaki, Adarn Khol, Afridis.

Sher KHaN KHel. - A minor fraotion of Hlonmand Khel, Kattia Khel, Hasan Khel, Mitha Khan Khel, Kuhi Khel, Afridis. Gar.

SHER KHEL.-A minor fraction of Buha Khel, Maddu Khel, Asad Khel, Mitha Khan Khel, Kuki Khol, Afridis. Gar.

SHER KHeL - A minor fraction of Gharu Khel, Ashraf Khel, Kamal Khel, Sahib Jan, Aka Khel, Afridis. Samil.

Ster Khel.-A sub-division of îlat Khan Kbel, Kambar Khel, Afridis. Gar. Headmen: Sher Khan, Hamid, and Nurai.

Sher KHEL. - A minor fraction of Ahmad Beg Khel, Mohib Khel, Shekbui, Annai, Budai, Zakka Khel, Afridis. Samil. Headmen : Shahzada, Arsals, Aligul.

SHINKI inHex.-A section of Sultan Khel, Sher Gulla, Aka Khel, Afridis. Samil. 
Shinwaris. -See ali Sher Kret.

SHIPaLEAI KHEL.-A section of Zargun Khel, Galai, Adam Khel, Afridis. Headman: Saiyid Ali.

SEIRAK KHEL.-A minor fraction of Mawal Khel, Haibat Khel, Jaraki, Adam Khel, Afridis.

Seirak Khel.-A sub-division of the Hasanzai, Mishtis, Hamsayas of Orakzai, Samil. Headman; Langar.

SHIRI KHeI or ALizaI (500; Miastura river).-A division of the Daulatzai, Jrakzais. Samil. $\frac{2}{3}$ Shiah.

SHRENDI KHEL (25; Nastura river). - A sub-division of the Alizai (or Sturi Khel), Paalatzai, Orakzais, Samil. Shiah. Headman : Dalil Khan.

SiKaNDAR KHEI (Daradar valley).A sub-division of Daradar Mamuzai, Ismailzai, Orakzais. Samil.

SIFANDAR KeEt. - A division of Kuki Khel, Afridis. Gar. Headmen: Nir Alam, Rahmatulla, Nazir, Mzarai, Sultan Khhairai.

SigANDAR KHeL.-A section of Pakhai, Budai, Zakka Khel, Afridis. Samil, Headmen : Band Āli, Mubammad Azim.
Bifandar Kor-A minor fraction of Kamal Khel, Maddu Khel, Asad Khel, Mitha Khan Khel, Kuki Khel, Afridis, Gar. Headmen : Muhammad Amin, Gul Jan, Budai, Langar.

SIPAH $(2,969$; Bara valley and Kajurai).-One of the six Khaibar Afridi clans. Samil. Headmen : Sher II uhammad, Shah Murad, Sairid Shah.

Sipar (610).-A section of the Ali Karan, Mamuzai. Lashlkarzai, Orakzais. Gar. See Azad rhel.

Sipara (300); JJastura valley).-A division of the Muhammad Khel, Orakzais. Gar. Shiah. Headmen: Nur Ali and Makhmad Jan.

Stcri Khal (400; Mastura river). -A sub-division of Alizai, or Sturi Khel, Daulatzai, Orakzais. Samil.

Scrausan KHed (Thanki valley). -A sub-division of the sada Khel, Ismailzai, Orakzais. Samil.

Streman Kher.-A section of Shekhmal, Kambar Khel, Kambar Khel, Afridis. Gar. Headmen : Mulla Walli, Kiramat.

SeLtan KHel.-A section of Abdul Khel, Trmuz Khel. Sipah, Afridis. Samil. Headman : Sher Jan.

Sultan Khet.-A section of Suran Khel, Babakri, Sipah, Afridis. 
Samil. Headmen : Niaz Karim, Iram, Gul Muhammad.

Sultax KHel (300).-A subdivision of Sher Culla, Aka Khel, Afridis. Samil.

Sultan KHel.-A section of Annai, Budai, Zakka Khel, Afridis. Samil. Headmen : Afzal, Nekai.

Sultan KHel.-A section of Haibat Khel, Jawaki, Adam Khel, Afridis.

Sultax KHeL.-A minor fraction of Hasan Khel, Pakhai, Budai, Zakka Khel, Afridis. Samil.

Sultan KHel.-A section of the Sipaya, Muhammad Khel, Orakzais. Gar. Shiah.

Sun i KHel. -A section of Zargun Galai, Adam Khel, Afiidis.
SURAB KOR.-A minor fraction of Fatima Kor, Sharagh Khel, Kaddam Khel, Firez Khel, Mashi Khel, Mannia Khel, Hasan Khel, Mitha Khan Khel, Kuki Khel, Afridis. Gar.

Scrax KHeL - A sub-division of Babakri, Sipah, Afridis. Samil. Headmen: Niaz, Muhammad, Turai, Redigul.

Surıt Kor.-A section of Ziauddin, Budai, Zakka Khel, Afridis. Samil. Headmen : Pahlwan, Far Shah, Dauran, sandan, Awal Baz.

Surbar KrygL. - A section of $\mathrm{Kulla}$ Khel, Malikdin Khel, Malikdin Khel, Afridis. Samil. Headmen : see Bakhmali Khel.

SurkHA KHel. A section of Ghaibi Khel, Babakri, Sipah, Afridis. Samil. Headman : Sabib II uhammad Itibarai.
TAIM KHeL.-A section of Bazid Khel, Jawaki, Adam Khel, Afridis.

TAIMUR KHEL.-A minor fraction of Gadia Khel, Tatar or Alhorwal, Hasan Khel, Adam Khel, Afridis.

TALIM K KEL.-A section of Zargun Khel, Galai, Adam Khel, Afridis. Headrnan : Satar.
TANDIW1Ls. - A minor fraction of Ghulam Khel, Haibat Khel, Jawaki, Adim Ehel, Afridis.

TAREIAL KHEL.-A section of Mughul Khel, Barmi Khel, Kamrai Khel, Afridis. Samil. Headmen : Guldar, Banat.

TARKI KHEL.-A section of Usman Khel, Shanai, Budai, Zakks Khel, Afridis. Samil. Head- 
men : Mehr Din, Bawar, Sultan Mir, Gul Shah.

TASHI KHEL.-A section of Sharaki, Galai, Adam Khel, Áfridis.

TATAB KHEL, or AKHORWAL (300; Kohat pass).- A sub-division of Hasan Khel, Adam Khel, Afridis.

TATAB KHEL.-A minor fraction of Mawal Khel, Haibat Khel, Jawaki, Adam Khel, Afridis.

TAZI KHEL (25; Mastura river.) A sub-division of Alizai (or Sturi Khel), Daulatzai, Orakzais. Samil. Sunni. The Lar and Khel section, comprising some 20 men, are Shiahs.

Tiba Sturi Khel (300).-A division of Alizai, Orakzais. Headmen : Aziz Khan, Saiyid Mir, Akbar, and Jafar.

Tor KHex.-A section of the Mir Kulli Khel, Bazoti, Daulatzai, Orakzais. Samil.

Tor KHeL. - A section of Abdul Khel, Urmuz Khel, S i pah, Afridis. Samil. H e a d me n : Suratai and Sher Mast.

TOR KAEL. $-A$ sub-division of Shekh Ali Kbel, Kamrai Khel,
Afridis. Samil. Headmen : Abdul Rahman and Sa Khan.

TOR FHEL. A section of Asad Khel, Mitha Khan Khel, Kuki Khel, Afridis. Gar. Headmen : Islam Din, Ashraf, Ibrahim.

TOR $S_{\triangle P P A R}$, or $\mathrm{Y}_{A G I} K_{H E L}(450$; a valley running from the Kohat road).-A sub- division of Galai, Adam Khel, Afridis. Headmon: Khushal, Habib, Firoz, Umar.

TS $\triangle$ LOR PLARI.-A division of Kuki Khel, Afridis. Headmen : Islam Din and Nurulla.

Tru Kerar.-A division of the Ali Khel Hamsayas of Orakzai. Gar. $\frac{1}{3}$ Shiah. Headman: Nar Gul.

TURIs (6.100; Kurram), - A tribe of Shiahs, inbabiting the Kurram valley. They are divided irto two parties snown as the Drewandai and Mian Muriz.

TUREI KHEL. - A minor fraction of Ghuli Khel, Ambar Khel, Mat Khan Khel, Kambar K h e l, Afridis. Gar.

TuthaI $\mathbf{K}$ HeL, $-\mathrm{A}$ section of Janakhori, Hazan Khel, Adam Khel, Afridis. 
UIOS KHEL, - $A$ section of the Masta Khel, Gar, Mussuzai, Orakzais.

UMa BEg KHEL.-A sub-division of Shanai, Zakika Khel, Afridis. Samil. Headmen: Khanzad, Langur, Khandin, Said Khan.

UMaR KHaN KHeL.-A section of Ali Karan, Mamuzai, Lashkarzai, Orakzais. Gar. Headman: Arsala Khan.

UMaR KHaN KHel-A sub-dirision of Alisherzai, Lashkarzai, Orakzais. Samil. Headman : Abbas Khan.

Umar KHan KHel.-A sub-division of Malikdin Khel, Malikdin Khel, Afridis. Samil. Headmen : Dauran, Gnl Ahmad, Sabz Ali, Aman Gul.

UMAR KHEL. - A section of the Dilmarzii, Gar Mussuzai, Orakzais.

UMAR KHEL,-A sub-division of Abdul Khel, Kuki Khel, Afridis. Gar. Hendmen : Sarbuland and Nasim.

JMAR KHEL.-A section of Masti Khel, Kambar Khel, Afridis. Gar. Headman; Khial Din.
UMAR KHEL. - A section of Annai Budai, Zakka Khoi, Afridis Samil. Headmen. Mir Akbar. Shiraz, Fateh.

UMAR $K_{H E L}-$ A minor fraction of Daulat Khel, Ghaib Khan Khel, Malikdin Khel, Malikdin Khel, Afridis. Samil. Headmen: see Daulat Khel.

UMarza (Mastura, Khanki, and Miranzai valleys).-A division of the Shekhans Hamsayas of Orakzai. samil. Headmen : Baz Gul Khan, Sawar Khan Nazir Shah.

UMIA KOR.-A section of the Mir Ahwad Khel, Alisherzai, Lashkarzai, Orakzais. Samil.

URMUZ KHEL.-A division of Sipah, Afridis. Samil. Headmen : see Keimal Khel and $\mathrm{Abdul} \mathrm{Khel.}$

Usman KHeL.-A sub-division of Shanai, Zakka Khel, Afridis. Samil. Headmen: Mihr Din, Bawar, Sultan Mir, Gul Sbah.

USMaN KHEL.-A sub-division of Sikandar Khel, Kuki Khel, Afridis. Gar. Headmen : Mir Alam, Rahmatalla. 
U'TA K KHEL.-A section of Suitan Khel, Sher Gulla, Aka Khel Afridis. Samil.
UTMaN KHel (400 to 6ijo ; Mastura river and Ublan pass). $\mathbf{A}$ division of Daulatzai, Orakzais. Samil. Headmen : Rasul and Musa Khan.

\section{W}

W Nasruddin, Zakka Khel, Afridis. Headman : Shahbsz.

WALIDAD KHEL. - A minor fraction of Hilal Kbel, Keimal Khel, Urmuz Khel, Sipah, Afridis. Samil. Headman Gul Salim.

$W_{\triangle L I D \triangle E} \mathrm{KHEL}-\mathrm{d}$ minor fraction of Zakho Khel, Janakhori, Hasan Khel, Adam Khel, Afridis.

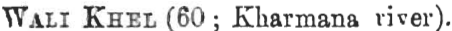
-A minor fraction of the Ash Khel, Samil, Masuzai, Lashkarzai, Orakzais. Samil.

WALLI BEG KHEL.-A minor fraction of Ahmad Beg Khel, Mohib Khel, Shekhai, Annai, Budai, Zakba Khel, Afridis. Samil.

WaLlibeg KHel. - A sab-division of Mat Khan Khel, Kambar Khel, Afridis. Gar. Headmen : Mastu, Barbarai.

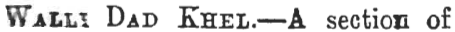
Kruila Khel, Malikdin Khel, Malikdin K.hel, Afridis. Samil. Headmen; see Bakhmali Khel.
WALLI KHEL. - A minor fraction of Ali Khei, Shekhmal Khel, Kambar Khel, Kambar Khel, Afridis. Gar.

WALLI KHEL.-A section of Asad Khel, Mitha Khan Khel, Kuki Khel, Afridis. (iar. Headmen : Wadan.

WaLII Beg KHEL.-A minor fraction of Fateh Khel, Miri Khel, Pakhai, Budai, Zakka Khel, Afridis. Samil.

W $A L L I$ KHEL.-A minor fraction of Miruhat Khel, Basi Khel, Kamal Khel, Sahib Jan, Aka Khel, Afridis. Samil.

WaLLI KefEL-A section of Pakhai, Budai, Zakka Khel, Afridis. Samil. Headmen: Ali Gul and Barkat.

WaND GHaRAI.-A sub-division of Landi Khel, Sipah, Afridis. Samil. Headmen:- Sher Muhammad Khan, Gul Salim.

WAB DURBI KHEL. - A section of Durbi Khel, Kambar Khel, Kambar Khel, Afridis. Gar. Head- 
men : Khwaja Ali, Sarfaraz, Mir Khan.

$W_{\triangle R}$ GHARRA.-A minor fraction of Karra Khel, Ghaibi Khel, Babakri, sipab, Afridis. Samil.

WAR KHEL. - A minor fraction of Dreplara, Paindai, Nasraddin,
Zakka Khel, Afridis. Samil.

WASCL KнвL.-A section of Paindai, Nasruddin, Zakka Khel, A fridis. Samil. Headmen: see Paindai.

WatizaI (300).-A division of Mamczai, or Nibammadzai, Zaimakhts.
Yagi Khei.-See Tor Sapper.

Yaral-Dee Shipalkai Khel, for which it is another name.

$\mathrm{Y}_{\mathrm{AR}}$ ALI KHEL-A division of Kamrai or Kamar Khel, Afridis. Samil. Headman: Abdul Rahman.

$Y_{\triangle R A N} K H E L .-A$ section of Shekhmal, Kambar Khel, Kambar Khel, Afridis. Gar. Headmen; Ghulam Haidar and Rajo.

YARGOL KHEL.-A section of Pabbi Khel, Kambar Khel, Kambar Kbel, Afridis. Gar. Headmen : Gul Hasan, Jan Baz.

YAR KHAN KHEL.-A minor fraction of Kasim Khel, Kimat Khel, Jawaki, Adam Kbel, Afridis.

YaR KHAN 'KHEL.-One of the sub-divisions of the Mamozai.
Mishtis, Hamsayas of Orakzai. Samil.

YAREULLI KHeL.-A sub-division of Bazoti, Daulatzai, Orakzais, Samil. Headmen : Salim, Husan, Raza, Ghafar.

YaR MUHaMmad KHEL. - $A$ subdivision of Karna Khel, Malikdin Khel, Afridis. Samil. Headmen : Narrab and Mir Gul.

YARU KHeL.-A section of tho Yarkulli Khel, Bazoti, Daulatzai, Orakzais. Samil.

$\mathrm{Y}_{A R}$ KHEL.-One of the sub-divisions of the Mamozai, Mishtis, Hamsayas of Orakzai. Samil. Headmen: Ali Sher, Kambar.

YUNAS KHEL.-A section of Bosti Khel, Galsi, Adam Khel, Afridis.

YUSAF KHEL.-A minor fraction of Bash Khel, Annsi, Budai, Zakka Khel, Afridis. Samil. 


\section{Z}

ZAIMUEHTS, Or ZaIMUSHTS (2,310; countrr between the Zawaghsr range, Kurram river, and Miranzai).-A tribe of Pathans, divided into Khoidad Khel, or Eastern Zaimukbts, and Mamozai, or Western Zaimukhts. Samil.

Z A ББ.А KHEL (5,900; Khaibar, Bazar, Bara, and Maidan, i.e., diagonally across the whole Afridi country).-One of the most important of the $6 \mathrm{Khaibar}$ Afridi clans. Samil. Headmen; Jabbar and alir Ahmad.

ZАKHO KHEL.-A section of Janalshori, Hasan Khel, Adam Rhel, Afridis.

ZAKRT KHEL.-A sub-division of Sikandar Khel, Kuki Khel, Afridis. Gar. Headmen: Samandar and Khairai.

Zarani Khel.-A minor fraction of Shipalkai Khel, Zargun Khel, Galai, Adam Khel, Afridis.

ZuYAN KHEL. - A minor fraction of Makki Khel, Kattia Khel, Hasan Khel, Mitha Khan Khel, Kuki Khel, Afridis. Gar. Headmen: see MIakki Khel.

ZarIA KHeL.-A section of Masti Khel, Kanbar Khel, Kambar Khel, Afridis. Gar. Healmen :
Fakir, Gulistan, Gul Shab, Rahmat.

ZAMER KHEL. - A section of the Yarkudi Khel, Bazoti, Danlatzai, Orakzais. Samil.

ZANGI KHEL.-A section of Ghaibi Khel, Babakri, Sipah, Afridis. Samil. Headmen, Salih, Muhanmad, Burai.

ZaNEA KHEL (Mastura river, at its source).-A division of the All Khel (2,750), Pamsayas of the Orakzais. Gar. $\frac{1}{3}$ Shiah. Headman : Mazid Khan.

ZaRGUN KHET (400).-A subdivision of Galai, Adam Khel. Afridis. Headman : Firuz.

Z $\triangle$ RIF KHEL.-A minor fraction of Durar, Khusrogi, Nasruddin, Zakka Khel, Afridis. Samil.

$Z_{\text {ARIN }}$ KHEL.-A minor fraction of Mashi Khel, Mannia Khel, Hasan Khel, Mitha Khan Khel, Kuki Khel, Afridis.

FiARIN KHEL. - A minor fraction of Mian Khel, Janakhori, Hasan Khel, Adam Khel, Afridis.

$Z_{\triangle B O}$ KHeL. - A section of the Ainal Khan Khel, Zanka Khel, 


\section{9}

Ali Khel, Hamsayas of the ( $\mathrm{Z}_{\mathrm{InRYA}} \mathrm{KHEL}$ (Mastara river).-A Orakzais. Gar. $\frac{1}{3}$ Shiah. Head- sub-division of the Mani Khel man : Madar. Muhammad Kbel, Orakzais. Gar. Shiah. Headman : Ali Jan.

ZIAUDIN (200). -A sub-division of Budai, Zakka Khel. Afridis, Samil. Headmen: Pahlwan, $M$ ir Azam. Amir Shah, Sherdan, Yar Ghulam, Awal Baz, Amal Rez.

ZOHRA KOR.-A minor fraction of Zaman Khel, Makki Khel, Kattia Khel, Hasan Khel, Mitha Khan Khel, taki Khel; Afridis. 


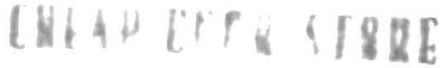

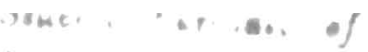

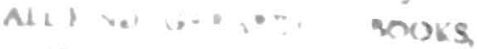

$$
\begin{aligned}
& \text { 4Q, v } \\
& \text { Lialur MTA-16. }
\end{aligned}
$$




\section{1}

\section{Part III.}

ABA KHEL. - (250; winter camping ground raria Mihrban in the Dera Ismail Khan District)Nomadic, a sub-division of Isot Khel, Mian Khel, Lohana Pawindahs. Headman: Ahmad Khan.

ABA KHel. - (Sheratala and Spinwam )--A I minor fraction of Shakba Khel, Khushali, Tori Khel, Ibrahim Khel, Utmanzai, Darwesh Khel Wazirs. Headmen : Argashai and Ghanamrang.

ABA KHeL. - A division of Tatta Bhittanis. Healmaı: Mina Khan (Sen Khel), Zamani.

Abas KHeL (30). - A minor fraction of the Pinza Plara, Abdullai, Aimal Khel, Bahlolzai Mabsuds. Headman : Malik Din.

A Bas KHEL (80).-A section of the Haibat Khel, Nana Khel, Bahlo]zai Mahsuds.

ABAS KHEL (100). - A minor fraction of the Shumi Khel, Palli Khel, Manazai, Alizai, Mahsuds. Headmen : Magri, Imar, and Mirab.

ABas KHEL. - 1 minor fraction of Gita Khel, Muhammad Khel, Malakh, Mallizad, Dawars.
ABBAS KHEL (100).-A minor fraction of the Shamshi Khel, Shekh Hasan, Taji Kbel, Bomai, Nasrai, Ahmadzai, Darwesh Khel Wazirs. Headman : Ghazni Khan.

ABDAL KHEL.-A minor fraction of Bora Khel, Mohmit Khel, Utmanzai, Darwesh Khel Wazirs. Headman: Shekh Abdurrahman.

ABDUL KHEL (30). - A minor fraction of Gangi Khel, Bomai Khel, Nasrai, Kalu Khe], Ahmadzai, Darwesh Khel Wazirs. Headman : Khakim.

ABDOL KHEL (30). - A section of the Kasim Khel, Badinzai, Shaman Khel, Mahsuds. Headman : Jani Khel.

ABDOL KHEL. - A minor fraction of Umarzai, Zira Khel, Amzoni, Mallizad, Dawars.

$A B D U$ L KHRL (270). - A fraction of Eangav Khel, Gidi Khel, Manzai, Alizai, Mahsuds. Headman : Nezam.

$\therefore, 6 \infty$

ABduenar (480).-A súb-division of the Aimal Khel, Bahlolzai Mahsuds. Headman : Fazil. 


\section{2}

Abdul RaHja Khel. A minor fraction of Babar Khel, Khoja Khel, Shodai, Abmadzai, Darwesh Khel Wazirs.

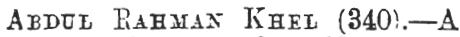
minor fraction of the Sher Khel, Haibat Kahel, Nana Khel, Bahlolzai, Mahsuds. Headmen: Guldad, Jagar.

Abder Rahutan KHel.-A fraction of Nuhammad Khel, Malakh Mallizad, Dawars.

ABDCL WIDANAI (50).-A section of the Malik Dinai, Manzai, Alizai Mahsuds.

ABDER RAHMAN KHEL (210).-A sub-division of the Nana Khel, Bablolzai Mabsuds.

abdor Rabman Khel,-A minor fraction of Idar Khel, Ali Khel, Khiddar Khel, Mohmit Khel, Utmanzai, Darresh Khel Wazirs. Headman : Nur Mrabammad.

ACHA KHer, or ACHA CHAI. $=$ A clan of the small tribe of $\mathrm{Kundi}$ Pawindahs.

ACHARS or ATSARS (240-Kazha Valley, North Waziristan).-A colony of Yusafzai Saiyids, now settled amongst the Madda Khel Wazirs of the Tocbi. Headmen : Mirbaz, Zarak.

ADAB KHeL (Bannu; Chapri, etc., Kurram).-A minor fraction of Saiyid Khel, Umarzai. Sanni Khel, Ahmadzai, Darwesh Khel Wazirs.
ADA FEEx.-A minor fraction of Utman Khel, Zalli Khel, Bomi Khel, Nasradin, Kalu Khel, Ahmadzai, Darwesh Khel Wazirs.

Adair KHeL.-A sub-division of Wargara, Dhana, Bhittanis.

ADDA KERL (100). - A minor fraction of the Utman Khel, Isap Khel, Zalli Khel, Bomai Nasrai, Kalu Khel, Ahmadzai, Darwesh Khel Wazirs. Headman : Kadir.

ADDA KHEL. - Better known as Shamsi Khel (q. r.)

ADIL KHEI (10). - A section of the Birri Khel, Galeshahi, Upper Shaman Khel, Shaman Khel Mahsuds.

AFZAL KHEL.-A minor fraction of Mandi Khel, Mad Khozhai, Khaddar Khel, Mohmit Khel, Utmanzai, Darwesh Khel Wazirs. Headman: Amzulla.

AgA KHEX.-A minor fraction of Pera Khel, Sir Shodiyakai, Bom Khel, Nasradin, Kalu Khel, Ahmadzai, Darresh Kibel Wazirs.

AGHZLN (90).-A section of Zira. Khel, Amzoni, Mallizad, Dawars. Headmen: Pir Ghulam and. Muhammad Alam.

Agzar KHeL.-A sub-division of Niamat Khel, Tatta, Bhittanis. Headman: Al:mad Finan. 


\section{3}

AHMAD KHEL (120). - A section of the Sultanai, Shabi Khel, Alizai Mabsuds. Headmen: Nilgar, Daur.

AHMAD KHEL (30).-A section of the Sherin Khel, Um:r Khel, Giga Khel, Nana Khel, Bahlolzai Hahsuds. Headman : Fauzdar.

A MAD KHEL 138). - A section of Zira Khel, Amzoni, Mallizad, Dawars.

LHMAD KHEL.-A section of 'Jareta, Idak, Tappizad, Dawars. Headmen: Daisal, Halim Shab.

A HMAD KHEL-A division of Kharoti, Gbilzai, Fawindahs. ifleadmen: Ghulam Rasul and Azim Khan.

A HMADZAI $(4,186)$-Left bank of Kurram river and British territory, Wano, Shakai, etc., Mahsud country. A clan of the Darwesh Khel Wazirs. Headman: Mani Khan, Sperkai, is the most inGuential; see also the two diviGions of the A.hmadrais, viz., Kalu Khel and Sain or Shin Khel.

A HMadzaI.- - Winter camping sround Paharpur in the Dera Ismail Khan district).-A large division of the Suleman Khel, Ghilzai Pawindahs. Headman: Haji Gul and Zabardast.

AHMADZAI.-A clan of Dautani Pawindahs.
AIDAL KHEL (50).-A section of the Birri Khel, Galeshahi, Shaman Khel, Mahsuds. Headmen : Alizai, Gul Azad.

Aikali KrHel (80). - A sub-division of the Band Khel, Bahlolzai Mahsuds. Headman: Mehtar.

Armal KHEL $(1,430)$. - A division of the Bahlolzai Mahsuds.

Aishale KHeL (70).-A minor fraction of the Walid Kihel, Mal Khel, Dachi Khel, Palli Khel, Manzai, Alizai Mahsuds.

Aizerachisal (70).-A section of the Malik Dinai, Manzai, Alizai Mahsuds. Headman: Shahabuddin.

AJAB KHEL.-A sub.division of Zerakki, Mallizad, Dawars.

Ara Khel (40).-A minor fraction of the Salimkai, Khalli Khel, Upper Shaman Khel, Sbaman Khel Mabsuds. Headman : Masta Khan.

Aks KHEL (50).-Dera Ismail Khan District.--Nomadic, a subdivision of Isot Khel, Mian Khel, Lohana Pawindabs.

AKA KHEL (45), - A section of the Salimkai, Khalli Khel, Shaman Khel, Mahsuds. Headman Masta Khan. 
Ans KHrL.-( Winter camping ground near Tank in the Dera Ismail Khan district). - A dirision of Suleman Khel, Ghilzai Pawindabs. Headman: Sikandar Krhan.

AGBAR KHEL (20).-A fraction of Zalli Khel, Komai Khel, Nasrai, Kilu Khel, Ahmadzai, Darwesh Kihel Wazirs.

A KBAR KHEL (30).-A minor fraction of the Hassan Beg Khel, Citman Khel, Isan Klel, Z.lli Khel, Bomai, Nasrai, Kila Khel, Ahmadzai, Darwesh Khel Wazirs. Headman: MTianai.

A EHT? KHEL. -A section of Haryam Khel, Darpa Khel, Mallizad, Dawars.

AnHCRDAN. A section of the Tareta, Idak, Tappizad, Dawars.

A Brahim Khel, Zira Khel, Amzoni, Mallizad, Dawars.

Azibai.-(Bannu and Shamal.) A minor fraction of sirdi Kibel, Bakka Khel. Wali Khel, Utmanzai, Darwesh Kiel Wazirs. Headman : Banai.

AERI KHEL. - A minor fraction of Karim Khel, Jamal Ithel, Malik Shahi, Wali Khel, Utmanzai, Darresh Khel Wazirs.

AlaMBEg KHeL. (Winter eamping ground Trimin in the Dera Ismail Khan district).-A division of Narar, Ghilzai Pawindahs. Headman : II ahammad Gul.
Alay KHar Krel (110).-A minor fraction of the Machi Khel. Shumi Khel, Palli Kihel, Manzai, Alizai, Mahsuds. Headman; Khwaja Mubammad Khan.

Arair KHaN KHel.-A section of the Nasar Khel, Haidar Khel, Tappizad, Dawars.

Alay KHAN KHEL.- $A$ section of Alizai, Darpa Khel, Mallizad, Dawars.

Alay KHeL.-A sub-dirision of Ya Khel, Nasar, Ghilzai Pamindahs.

Alay KHEL.-A section of Kanezai Kattagram, Tatta, Bhittanis.

ALI (600).-A section of the Kaks Khel, Bomai, Nasrai, Kalu Khel, Ahmadzai, Darwesh Khel Wazirs, Headinan: Badshab Khan.

Alia KHel (4.0). - A minor fraction of the Salimkai, Khalli Khel, Upper Shaman Kbel, Shaman K hel Mahsuds. Headman : Shahzad.

Alinharai. - A minor fraction of Khushalai, Tori Khel; Ibrahim Khel, Utmanzai, Darwesh Khel Wazirs, Headmen : Azalmir, Salom, and Shabak.

Alikhanai (60). - A section of the Kikrai, Nana Kbel, Bahlolzai, Mahsuds. 
Alikhanai (56).-A fraction of Bomai Khel, Nasrai, Kalu Khel, Ahmadzai, Darwesh Khel Wazirs. Headman: Jindai.

ALI KH $\triangle$ KN KHeL (30). - Á minor fraction of the Brond Khel, Chahar Khel, Upper Shaman Kluel, Shaman Khel, Mahsuds. Headman : Zari Khan.

ALI KHAN KHEL (1,130),-A minor fraction of Sarki Khei, Madda Khel, Ibrahim Khel, Utmanzai, Darresh Khei Wazirs. Headmen : Dande, Sadda Khan, Alambe Khan. See also Star Ali Khan Khel, and Waruka Ali Khan Thel. The latter are frequently alluded to as the "Ali Khan Khel" simply.

ALI KHEL (20). - A minor fraction of the Shami Khel, Jalal Khel, Nana Thel, Bahlolzai, Mahsuds.

ALI KHEL (10). - A minor fraction of the Shiraz Khel, Jalal Kbel, Nana Khel, Bahlolzai, Mahsuds.

ALI KHEL (26).-A sub-division of the Khalli Khel, Shaman Khel, Mahsuds.

ALI KHEL.-A sub-division of Bobak, Dhana, Bhittanis. Heałmen: Baist Khan, and Bazza Khan.

ALI KHEL.-A minor fraction of Idia Khel, Jani Khel, Wali Khel, Utwanzai, Darwesh Khel Wazirs.
AlI KHEL - A section of Khaddar Khel, Mohmit Khel, Utmanzai, Darwesh Khel Wazirs. Headmen : Nur Mubammad, Hakach, Sakhemin, Akhmad, Salih Din, Nazarka, Gul Samid.

ALI KHEL (30). - A section of the Kaka Khel, Ghaleshahi, Upper Shaman Khel, Shaman Khel, Mahsuds. Headman: Mir Akbar.

ALI KHEL (300). - A minor fraction of Sbogai, Tori Khel, Ibrahim Khel, Utmanzai, Darwesh Khel Wazirs. Headmen: Dashatnir and Kasim.

ALI KHEL.-A section of Manzar Khel, Ibrahim Khel, Utmanzai, Darwesh Khel Wazirs. Headmen : Mihrab Khan, Kabal, Nawaz Khau, Mad Azam and others.

Ali Kнel (Bannu District). -A section of Musa Khel, Shin or Sain Khel, Ahmadzai, Darwesh Khel Wazirs.

ALI KHEL (40). - A fraction of the Kharmach Khel, Shingi, Bablolzai, Mabsuds. Headman : A ta. mir.

ALI KHEL (178).-One of the five sub-divisions of the Haidar Khel, Tappizad, Dawars. Headmen : Alif Khan, Abassamand.

ALI KHEL.-A section of Malli Khel, Idak, Tappizad, Dawars.

ALI KHRL. - A clan of Niazi Pawindahs. 
ALI KHEL (64). - A minor fraction of Brahim Khel, Zira Kbel, Amzoni, Mallizad, Dawars.

ALIK KHEL (90). - A section of the Mamia Khel, Shingi, Bahlolzai, Mahsuds. Headman: Gulpir.

Acrur Krel.-A minor fraction of Alikhani, Bomi Khel, Nasradin, Kalu Khel, Ahmadzai, Darwesh Khel Wazirs.

Aft Merandrad KeEl (120).-A fraction of the Langar K'hel, Gidi Khel, Hanzai, Alizai Mahsads. Headman : Wreshmin.

AlisHo KHEL ( $\mathrm{\Omega O})$. - A minor fraction of the Sandra Khel, Sbami Khel, Jalal Khol, Nana Khel, Bahlolzai, Mahsuds. Headman: Zanjir.

Alizar $(4,5 \mathrm{CO})$ - - One of three clans of the Mahsud Wazir tribe. Headmen : Badar Din, Mrbammad Afzal, Badshah Khan, Shah Salim.

AlIZAI.-A sub-division of Darpa Khel, Mallizad Dawars. Beadmen: Najib and Amal Khan.

AltahDAD KHel.-A section of Sen Rhel, Aba Khel, Tatta, Bhittanis. Headmen : Mina Khan, Katawaz.

ALLAHDAD KHEL-A sub-division of Shan Ehel, Tatta, Bhittanis.

ALMaR KHEL (20). - A minor fraction of the Khoidadai, Malikshai, Aimal Khel, Bablolzai, Mahsuds.
AMAX KHEL (40). - A minor fraction of the Langar $\mathbf{K}$ hel, Khoedadis. Malikshahi, Aimal Krhel, Bablolzai Mahsuds.

A MIZAL KHEL (40). - A minor fraction of the Furidai, Khamar Khel, Gidi Krbel, Manzai, Alizai, Mahsuds.

Ayzoni (738).-One of the eight divisions of Mallizad, Dawars. See also Zira Khel and Taib Khel.

ANa KHEL (20). -A section of the Ibrahim Khel, Astanai, Shabi Khel, Alizai, Mahsuds.

ANDAE KHEL (40). - A minor fraction of the Nekzan Khel, Sher Khel, Haibat Khel, Nana Khel, Bahlolzai, Mahsuds.

Ardars (1,000; Ghazni, Kalat-i-. Ghilzai).-One of the Pawindah trading clans of Ghilzais.

Aramisa KHel.-A minor fraction of Mir Khan Khel, Asat Khel, Wuzi Khel, Utmanzai, Darwesh Khel Wazirs. Headnan: Kaim Shab.

Aram KHel (Khaisora and Shawal valleys).-A minor fraction of Bachagai, Tor, Jani Khel, Wa]i Kbel, Utmanzai, Darwesh Khel Wazirs. Headman : Shadamir.

ARGHUND (56).-One of the ejgbt divisions of Mallizad, Dawars。 Headman : Hakim Khan. 
AzGIUND.-A sub-division of 'itMAN KHRL.-A section of Resu, Arghund, Mallizad, Dawars.

ASAT, OR: ASAD, KHEL.-A section Waruki, Dhana, Bhittanis.

Atsars.-See Achars. of Wuzi Khel, Mohmit Khel, Utmanzai, Darwesh Khel Wazirs. Headmen: Juma Gul and Gulba. din.

AgGHR KHBI. (Winter camping ground at Paniala in the Dera Ismail Khan district). - A division of Nasar, Ghilzai Pawindahs. Headman: Mian Gul.

AsHA KHEL.-A sub-division of Aba Khel, Tatta, Bhittanis. Headman : Kakar.

ASHRAF KHRL. - A minor fraction of Ismail Khel, Bozi Khel, Madda Khel, Ibrahim Khel, Utmanzai, Darwesh Khel Wazirs.

ASEANDI KHEL. A minor fraction of Ali Khel, Manzar Khel, Ibrahim Khel Utmanzai, Darwesh Khel Wazirs. Headman: Baz Mubammad and Niaz Gul.

ASEANDI KHEL (Bannu and Shawal).-A minor fraction of Morib Khel, Usman Khel, Takhti Khel, Bakka Khel, Wali Khel, Utmanzai, Darwesh Khel Wazirs. Headman : Mozalmir.

AstanaI (460).-A sub-division of the Shabi Khel, Alizai, Mahsuds. Headmen : Shahzur, Mawal, Lalgul, Alif Sbab, Khari.

AUdaK KHeL (40).-A minor frac. tion of the Nebzan Khel, Nana Khel, Bahlolzai, Mabsuds, Headman : Karamai.

AODI KHEL. - A minor fraction of Shogai, Tori Khel, Ibrahim Khel, Utmanzai, Dar'wesh Khel Wazirs. Headmen: Kotanai, Sammat, and Ghalba!.

AvZar KHel. - A minor fraction of Umar Khel, Ali Khel, Khaddar Khel, Mohmit Khel, Utmanzai, Darwesh Khel Wazirs. Headman : Nazir Khan.

AWAD KHEL. A section of Adizai Boba, Dhana, Bhittanis.

AWAD KHE L (40). - A section of Taru Kbel, Boba, Dhana Bhittanis.

AWAR KaEL. - A minor fraction of Mira Khel, Jad Khozhai, Khaldar Khel, Mohmit Khel, Utmanzai, Darwesh Khel Wazirs.

Arob KHsL (140). - A section of the Hakim Khel, Band Khel, Buhlolzai, Mabsuds. Headman : Sakin.

AzAD KHEL (120). - A section of Tara Khel', Boba, Dhana, Phittanis. 


\section{8}

AzAD KHEL (30).-A minor fraction of the Babal Khel, Khoedadi, Malik Shahi, Aimal Khel, Bablolzai Mahsuds.

Azay KHeL.-A sub-division of Khaddi, Mallizad, Narrars.

Azar Mir hHEL. - A minor fraction of Sikandar Khel, Abdul Khel, Bora Khel, Mnhmit Khel, Utmanzai, Darwesi Kbel Wazirs.

$\triangle Z D I$ KHEL (50). - A fraction of the Shamak Khel, Abdullai, Aimal Khel, Bahlolzai, Mahsuds, Headman : Abdulla Khan.

AzDI KHEL (20), - A minor fraction of the Saddan Khel, Khoedadi, Malik Shahi, Aimal Khel, Bahlolzai Mahsuds. Headman Paio.
AZDI KH BL (10). - A minor fraction of the Shahi Khel, Manzar Khel, Aziz Khel, Nazrr Khel, Aimal Khel, Bahlolzai, Mabsud s.

AZIZ FHEI (230).-A section of the Nazar Khel, Aimal Khel, Bahlolzai, Mahsuds. Headman: Jalati.

Aztz KHeL.-A minor fraction of Shadi Khel, Bora Khel, Mohmit Khel, Utmanzai, Darwesh Khel Wazirs. Headmar : Ghulami.

Azmat KHeL.-A sub-division of Zerakki, Mallizad, Dawars. Headmen : Bandi and Saiyid Akbar.
BABAEAR KHEL.-A section of the Shadi Khel, Bobak, Dhaua, Bhittanis.

BABA KHEL (20). - A minor fraction of the Hiral Khel, Shahar Khel, Upper Shaman Khel, Shaman Khel, Mahsuds. Headman : Serai.

BABA KमEL (240).-The principal section of the Galeshabi, Upper Shaman Khel, Mahsuds.

BABA KHEL.-A fakir section of Khiddar Khẹl, Mohmit Khel, Utmauzai, Darwesh Khel Wazirs. Headman : Idagai.
BABa KHEL (20). - A minor fraction of the Shiraz Khel, Jalal KheI, Nana Khel, Bahlolzai, Mahsuds. Headman : Darpa Khel.

BAPA KHEL (30). - A minor section of the Boyi Khel, Mamadis, Shingi, Bablolzai Mahsuds.

BABA KHEL. - A minor fraction of Malik Khel, Mir Khel, Land, Malakh, Mallizad Dawars.

BABAKB and TAJI KHEL (10).-A minor fraction of the Landi Kbel, Saddan Khel, Khoedadi, Malik Shahi, Aimal Khel, Bahlolzai, Mahsuds. 
Babal KHel (80). - A minor frace tion of the Khoidadi, Malikshai Aımal Khel, Bahlolzai, Mahsuds.

BABAR KHEL. - A minor fraction of Abmad Khel, Zira Khel, Amzoni, Mallizad, Dawars.

Babat KHeL (10). - A minor fraction of the Mirdad Khel. Abdul Rahman Khel, Nana Khel, Bahlolzai Mahsuds.

BabBarsara.-A section of Wuzi Khel, Mohmit Khel, Ctmanzai, Darwesh Khel Wazirs.

BABI KHEL. (Winter camping ground, Kulachi, in the Dera Ismail Khan district). A division of Suleman Khel, Ghilzai Pawindahs. Headman : Bazid.

BABRI KHeL (25).-A section of the Pir Muhammad Kbel, Haidrai, Chahar Khel, Shaman Shel, Mabsads.

BACHAGAI.-A minor fraction of Tor, Jani Khel, Wali Khel, Utmanzai, Darwesh Khel Wazirs. Headmen: Mirbosh, Shadamir, Kaimal, Gulbaz.

BACHA KHEL (55).-A section of the Pathanai, Shabi Khel, Alizai, Mahsuds.

Badaszai (313).-A division of the Shaman Khel, Mahsuds. Headman: Saiyid Akbar Shah.
$B_{\triangle D A R} \mathrm{~K}$ HEL $(60)$ - $-\mathrm{A}$ minor fraction of the Walidad Khel, Lalli Khel, Ábdullai, Aimal Khel, Bablolzai, Mahsuds.

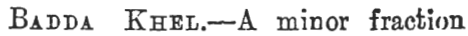
of Saifaì, Kabul Khel, Wali Khel, Utmanzai, Darwesh Khel Wazirs.

B^DDA KHEL. - A section of Utman Miram Shah, Tappizad, Dawars.

BADDAR KHEL.-A minor fraction of Khan Khel Bar Khozhai, Khaddar Khel, Mohmit Khel, Utmanzai, Darwesh Khel Wazirs. Headman: Saiyid Ali.

BADI KHEL.-A minor fraction of Umarzai, Zira Kbel, Amzoni, Mallizad, Dawars.

BADIN KHeL, -A clan of Dautani Pawindahs. Headman: Zala Khan.

Badinzar (200).-A division of the Upper Shaman Khel, Mahsuds.

BadiwaI (186).-A sub-division of the Khalli Khel, Shaman Khel, Mahsude.

BADN KHEL, - A minor fraction of Karim Khel, Jama! Khel, Malik Shabi, Jani Khel, Wali Khel, Utmanzai, Darwesh Khel Wazirs.

Ba.DzaI.-A sub-division of Kattagram, Tatta, Bhittanis. Head men : Shahbaz (Kaland Khel) Said Anin. 
BAGHBAN KHEL - A minor fraction of Sudan Khel, Isperka, Kalu Khel, Ahınadzai, Darwesb Khel Wazirs. Headmen : Jalandar Shah, Jani Khan.

BaHader KHel (10).-A minor fraction of Khojal Khel, Shadai Khel. Nasrai, Kalu Ǩheỉ, Ábmadzai, Darwesh Khel Wazirs. Headman: Madi.

Bafader Kerel (T0), -A minor fraction of the Garerai, Shumi Trhel, Palli Krhel, Mranzai, Alizai Mahsuds. Headman : Awal Ǩban.

$\mathrm{B}_{\mathrm{AHLOLZ}}$ (5,000).-One of the three srreat clans of the Mabsuds.

Bıik Inel (600; Banuu District). A minor fraction of Krbandar Khan Khel, Hatui Khel, Shin Khel, Ahmadzai, Darresh Khel Wazirs. Healmen : Nazardin and Bazgul.

BAIE Khel (10). - A minor fraction of the Trhali Khel, Bangish Khel, Jbrahim Khel, Astanai, Shabi Khel, Alizis, Mahsuds.

B $_{1 \text { JI KHEI (10).-A minor fraction }}$ of the Makhal Kihel, Patanai, Shabi Khel, Alizai, Mahsuds.

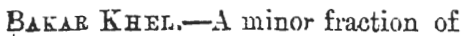
Bukar Khel, Idal Khel, Irathi Khel, Shin or Sain Khel, Alymadzai, Darwesh Klyel Wazirs.
BAKAR KH HEL ( 100 ; Bannu Dintrict, Shakai, Birmal and (Vano).-A minor fraction of Idal $\mathrm{K}$ hel, Hathi Khel, Shin or Sain Khel, Ahmad-

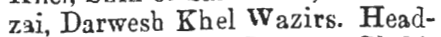
men : Bander Khan, Shekh Piṿa, Landai, Kasim Shab.

BAEAR KHEL.-A minor fraction of MIalik Khel, Miri Khel, Laud, Malakh, Malizad, Dawars.

BakHSHAI.-A minor fraction of Natta Khel, abdul Khel, Bora Khel, Nrohmit Khel, Utmanzai, Darwesh Khel Wazirs.

Bahrshar.-A minor fraction of Mandi Khel, Wuzi Khel, Mohmit Khel, Utmanzai, Darwesh Khel Wazirs.

BAKHSH KHEL (200).--A section of Madda Khel, Ibrahim Khel Utmanzai, Darwesh Khel Wazirs. Headmen: Gulli, Lair, and Gulab.

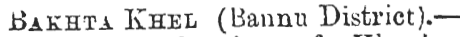
A minor fraction of Khanbeg Khel, Tori Khel, Musa Khel, Hathi Khel, Shin or Sain Khel, Ahmadzai, Darwesh Khel Wazirs.

BathrisR. (Their winter camping ground is at Tirimin in the Dera Ismail Khan district). - A division of Mian Krhel, Lohana, Pawinaabs. Headmen: Hassan Khau, Ali Muhammad and Musa Khan.

BAKHTI KHeL (70).-A minor fraction of the Baba Khel, Galeshabi, Shaman Khel, Mas'ade. Hesàman : Saranai. 
BAKHTI KHeL (60). - A section of the Umar Khel, Nana Khel, Bahlolzai, Mahsuds. Headman : Suma Khan.

BARI KHEL -A section of Ipi, Haidar Khel, Tappizad, Dawars, Headmen: Fateh Khan and Shekh Jimal.

BAKI KHEL.-A section of the Ali Khel, Haidar Khel, Tappizad, Dawars.

BAEI KHEx (30), - A minor fraction of the Momin Khel, Manzar Khel, Aziz Khel, Nazar Khel, Aimal Khel, Bahlolzai, Mahsuds. Headman : Yusaf.

BaKI KEEL (10). - A minor fraction of the Baba Khel, Galeshahi, Upper Shaman Khel, Shaman Khel, Mahsuds. Headman: Walishab.

BAFKA KHEL 11,000; Shawa and Bannu Districts).-A sub-division of Wali Khel, Utmanzai, Darwesh Khel Wazirs. Headmen : see Takhti Kbel, Sardi Khel, and Narmi Khel; 6,000 within British territory.

BAKKA KHEL.-A section of Ipi, Haidar Khel, Tappizad, Dawars.

EATOL $\mathrm{K}$ HEL.-A minor fraction of Sudan Khel, Isperka, Kalu Khel, Abmadzai, Darwesh Khel Wazirs. Headmen: Jalandar Shab, Mani Khan.
BAKSHAI (60).-A section of the Ozbakai, Shingi, Bahlolzai, Mahsuds. Headman Rahim Khan.

BaLAL KHEL.-A section of Hasan Khel, Mohmit Khel, Utmanzai, Darwesh Khel Wazirs. Headmen: Ghulam Jan, Khan Ghazab, Jan, Gul Shirin, Kakai.

BALEL KHEL, -A minor fraction of Aghzan, Zira Khel, Amzoni, Mallizad, Dawars, Headmen: Mubammad Alam, Pir Gholam.

BALI KHEL. - A minor fraction of Poi Khel, Muhammad Khel, Malakb, Mallizad, Dawars.

BAIIL KHEL. -A minor fraction of Chiton, Zira Khel, Amzoni, Mallizad, Dawars.

BaILa KHEL (Bannu District).-A minor fraction of Taos Khel, Pirba Khel, Hathi Khel, Shin Khel, Ahmadzai, Darwesh Khel Wazirs.

BALLI KHEL, - A minor fraction of Shadi Khel, Bora Khel, Mohmit Khel, Utmanzai, Darwesh Khel Wazirs. Headman : Kipat Khan.

BatoCH $(2,000)$-Paniala in the Dera Ismail Khan district. A Pathan tribe of Turko-Iranian origin, allied to the Lodis 


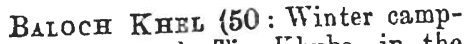
ing gronnd, Tir Khuba, in the Dera Ismail Khan District).Nomadic, a sub-division of the Isot Kihel, Xian Khel, Lohaua Pawindabs. Headman: Mlauladad Khan.

BALOL KHEL.-A minor fraction of the Ipi, Haidar Khel, Tappizad, Dawars.

BANDA (77).-A division of Tappizad, Dawars. Headman : Shabal.

BAND KHEL (710).-The smallest of the four divisions of the Bablolzai, Mahsuds.

Baxga $K$ HeL (30). - A minor fraction of the Kharmanz Khel, Nazar Khel, Aimal Khel, Bahlolzai, Mahsuds. Headman: Nikarrab.

Baxgali Kagl. - A section of Sen Kbel, Aba Khel, Tatta, Bhittanis.

Baygal Khel (20).-A section of the Kasim Khel, Chabar Khel, Shaman Khel, Mahsuds. Headman: Sbyar Khan.

Baxgash TrHel (80). - A section of Ibrahim Khel Astanai, Shabi Khel, Alizai, Mahsuds, Headmen : Lalgul, Mirabat Khan.

BANgasH KHEL (60).-A section of the Taru Khel, Bobak, Dhana, Bhittanis.

Batgase KHel.-A sub-dirision of Tapiai, Tappizad, Dawars. Headman : Zarar.
BaxNUCHI (כ0,000).-An Afghan tribe of Turko-Iranian origin : inhabit the area between the Kurram, and Tochi in British territory.

BANUN KHEL. (Their winter camping ground is at Draband in the Dera Ismail Khan district).-A division of Nasar, Chilzai Pawindahs. Heaâman : Ima and Subibdad.

Baxzar. - A division of Kharoti, Ghilzai, Pawindahs. Headman : Arnir Khan.

Baoua KHeL.-A sub-division of Sarsa, Tatta, Bhittanis.

$\mathbf{B}_{\triangle \mathrm{B} \triangle \mathrm{K}} \quad(40,000)$.-An important branch of the Khataks and live south of the Teri Toi, and west of the Saghris and Bangi $\mathbf{K}$ hel in the Bannu district.

Bana KHozar. - A section of Khaddar Khel, Mohmit Khel, Utmanzai, Darwesh $\mathrm{K}$ hel Wazirs. Headmen : Garrarai, Amin Khan and Khanzaman.

BARA FHONAI.-A minor fraction of Muhammad Khel, Dirdoni, Wuzi Khel, Mohmit Khel, Utmanzai, Darwesh Khel Wazirs.

BARAM KHEL.-A minor fraction of Ali Khel, Manzar Khel, Ibrahim Khel, Darwesh Khei Wazirs. 


\section{3}

BABAM KHEL (Bannu District).-A minor fraction of Khanbeg Khel, Tori Khel, Musa Khel, Hathi Khel, Shir Khel, Ahmadzai, Darwesh Khel. Wazirs. Headmen : Salak and Wadin.

Barayr KHet.-A section of Hakim Khel, Mubarak Shahi Mallizad, Dawars.

Barat Khel (Baunu District).-A minor fraction of Baik Khel, Khandar Khan Khel, Hathi Khel, Shin or Sain Khel, Ahmadzai, Darwesh Khel Wazirs. Headman: Nazardin.

Barat KHEL. - A minor fraction of Sudan Khel. Isperka, Kalu Khel. Ahmadzai, Darwesh Khel Wazirs. Headman: Mama Khan.

BABE KHEL (30). - A minor fraction of the Maka Khel, Malli Khel, Shelih Hassen, Taji Khel, Bomai, Nasrai, Ahmadzai, Darwesh Khel Wazirs.

Barga KHel (Bannu, Chapri, and Gurang in Kurram). - A minor fraction of Kundai, Tor Khel, Saiyid Khel, Umarzai, Shin or Sain Khel, Abmadzai, Darwesh Khel Wazirs. Headman : Niazye.

BARIAM KHEL (60).-A section of the Patanai, Sbabi Khel, Alizai Mahsuds, Headman : Khila Jan.

BARI KHEL. - A minor fraction of Sogi Khel, Muhammad Khel, Malakh, Mallizad, Darars.
BARI $K_{H E L .-A}$ minor fraction of the Ali Khel, Haidar Khel Tappizad, Dawars.

BARIMI KHEL. - A minor fraction of Pai Khel, Muhammad KLal Mallizad, Lawars.

BABITAL.-A sub-division of Zerakki, Mallizad, Dawars.

BAR KAEM. - A sub-division of Hassu Khel, Mallizad, Dawars. Headman : Baki Khan.

$\mathrm{B}_{\mathrm{AR}}$ KHEL $-\mathrm{A}$ division of the Nasar, Ghilzai Pawindahs. Tbeir winter camping ground is at Rara in the Dera Ismail Khan district. Headman: Alumad Kban.

BAREI KHEL. A minor fraction of Dur Khel, Babakki, Has\%u Khel, Mallizad, Dawars.

$\mathrm{B} \triangle \mathrm{B}$ KILIA. A fakir section of Saivid origin living with the Muhammad Khel, Malakb, Mallizad, Dawars.

BarMast KHEL - A section of the Shakhi, Waraspun, Bhittanís.

BARMI KHEL (Bannu District). -A minor fraction of Sardi Kbel Bakka Khel, Wali Khel, Utmanzai, Jarwesh Khel Wazirs. Headman : Landak. 
Barmi Kene (Bannu District).-A minor fraction of Khandar Khel, Hathi Khel, Shin, or Sain Khel, Ahmadzai, Darwesh Khel Wazirs. Headman : Shah Tamoz.

BARYIT KHEL.-A minor fraction of MIushakki, Macha, Madda Khel, Ibrahim Khel, Utmanzai, Darwesh Khel Wazirs. Headman: TVarre Kban.

BARYI THEL. A section of Manderi, Idak, Tappizad, Dawars, Headman : Kutab.

BARO KHEL (60).-A sub-division of the Haidar Khel, Tappizad, Dawars. Headman : Khan Sahib.

BAROMAI (100).-A sub-division of the Sbabi Khel, Alizai, Mahsuds. Headman : Muhammad Ayaz.

BAROND KHEL (85). -A sub-division of the Chahar Khel, Shaman triel, Mausuds. Headman: Belá.

BARBA KHEL.-A division of Tharoti, Ghilzai Pawindahs. Headman : Alam Khar.

BaReMr KHeL (110).-A section of the Gidi Kbel, Manzai, Alizai, Mabsuds. Headman: Mad Akblos.

Baegayr (45). -A section of the Patbrnai, Shabl Khel, Alizai, Mahsuds.
B ASHAR Khel (Banuu District).A minor fraction of Rozi Khel, Ali Khel, Musa Khel, Hathi Khel, Shin Khel, Ahmadzai, Darwesh Khel Wazirs. Headman: Miraband.

Basralir (Bannu District).-A minor fraction of Tori Khel, Musa Khel, Hathi Khel, Shin, or Sain Khel, Ahmadzai, Darwesh Khel Wazirs. Headman : Gul Khan.

BASSIA KHEL.-A sub-division of Niamat Khel, Tatta, Bhittanis. Headman: Marwat.

Bassi KHel.-A minor fraction of Painda Khel, Shadi Khel, Nasradin, Kalu Khel, Ahmadzai, Darwesh Khel Wazirs. Headman : Sawar Khan.

BASSI KHEL ( 30 ). -A minor fraction of the Khan Khel, Kharmaz Khel, Nazar Khel. Aimal Khel Bablolzai Mahsuds. Headman: Ashiq.

BaTA KHEL.-A section of Zhao Khel, 'Tappi, Tappizad, Dawars.

Batar KHel (40).-A minor fraction of the Nelizam Khel, Sher Khel, Haibat Khel, Nana Khel, Bahlolzai, Mahsuds.

BATIE KHEL (30).-A section of the Nekzan Khel, Nana Khel, Bahlolza: Mahsuds. Headman: Guladad. 
BATKAI (70).-A sub-division of the Gidi Khel, Manzaj, Alizai, Mabsuds. Headman : Sarfaraz.

Batri KHex (40).-A minor fraction of the Faridai, K hamar Khel, Gidi Khel, Manzai, Mahsuds.

BAWIAI.-A minor fraction of Dani Khel, Matkai, Maliz Shahi, Jani Khel, Wali Khel, Utmanzai, Darwesh Khel, Wazirs.

BAWLA KHEL (Bannu, Wano, and Birmal).-A section of Sirki Khel [800 (400 in Wano)], Shiv, or Sain Khel, Ahmadzai, Darwesh Khel Wazirs. Headmen: see Sirki Khel.

BAYA KHEL.-A minor fraction of Malli Khel, Topiya Kbel, Bomi Khel, Nasradin, Kalu Khel, Abmadzai, Dar'wesh Khel Wazirs.

$B_{A Y A}$ KHEL (20). - A section of the Bomai, shabi Khel, Alizai Mahstuas. Headman : Bitai.

BAZID KHEL (10).-A minor fraction of the Khali Khel, Bangish Khel, Itrabim Khel, Astanai, Shabi Khel, Alizai Mahsuds. Headman: Mirabat Khan.

Bazid Krei.-See Tor Khel.

BAZI Krex.-A section of the Badzai, Kattagram, Tatta, Bhittanis. Headman : Saiyid Amin.
BEGAI (30).-A minor fraction of the Ghulam Khel Ali Kana Khel, Bomai, Nasrai, Kalu Khel, Ahnuadzai, Darwesh Kbel, Wazirs.

BEJaL. - A minor fraction of Bar Kaum, Hassu Kbel, Mallizad, Dawars.

BenHoNaI KeEL (10).-A section of the Daria Khel, Bibizai, Shabi Khel, Alizai, Mahsuds. Headman : Deronai.

Befi Khel (30).-A minor fraction of the Hassan Khel, Kharmaz Khel, Nazar Khel Aimal Khel, Bahlolzai Mahsuds.

Bhalol KHel (15). - A minor fraction of the Bizodai, Malikshai Aimal Khel, Bahlol zai, MFabsuds.

BHaNgi Khel $(10,000)$. - A branch of the Khataks, inhabiting the mountain tract north of Kalabagh in the Mianwali district.

BhangI KHEL - A micor fraction of Kutti Khel, Umar Khel, Ali Khel, Khaddar Khel, Mobmit Khel, Utmanzai, Darwesh Khel Wazirs. Headmen : Salih Din, Gul Samid, Zarbat Khar.

Bhita Khel (20). - A minor fraction of the Boyi Khel, Manadis, Shingi, Bablolzai Mahsuds.

Bhitranis $(4,060$; country between Waziristan and Dera Ismail Khan District).-A Pathan tribe, some of whom also live in British territory. Headmen: see Tatta, Dhana, and Waraspun. 


\section{6}

Bianzat.-A sub-division of Bath. tiar Mian Khel, Lohana Pawindahs.

Bibaz zal-A sub-division of $\mathrm{H}_{\text {assu }}$ Khe!, Mallizad, Dawars, Headmen : Mad Afzal, Raibat Khan.

BIBAN KHEL $(20)$. - A minor fraction of the Darai, Chabar Khel, Upper Shaman Khel, Shaman Khel, Mahsuds. Headnan : Dadak.

Bibizal (160).-A sub-division of the Shabi . K hel, Alizai, M ahsuds, Headman : Mastapa.

Bibla (40).-A section of the Malai, Shingi, Rahlolzai, Mahsuds.

Bicha KHeL (40). - A section of the Patanai, Shabi Khel, Alizai Niahsuds. Headman: Rakham Din.

BidaI KHEL (220).-A minor fraction of Gangi Khbel, Bomai, Nasri, Kalu Khel, Ahmadzai, Darwesh Khel Wazirs. Headman : Chokbai.

Bijal KHel. - A minor fraction of Ali K' hel, Manzar Khel, Ibráim Khel, Utmanzai, Darwesh Khel Wazirs.

Bisal KHEx (8).-A minor fraction of Khojal Khel, Shadai Khel, Nasrai, Kalu Khel, Abmadzai, Darwesh Khel Wazirs. Headman : Mlach.
Bijjal KHel (13).-A section of the Zarri Khel, Chahar Khel, Shaman Khel. Mahsuds.

BIJjI KHEL (\%0).-A section of the Malai, Shingi, Bahlolzai, Miahsuds. Headmen : Salelim Khan Zaman, Nasajaso.

RII $\triangle$ L FHEL.-A sub-division of Shan Kbel Tatta, Bhittanis. Peadman: Azim.

Bilal KHeL (20).-A minor fraction of the Bezodi, Malik ShahiAimal Khel, Bablolzai, Mahsuds.

Biland Khel (35).-A minor fraction of the Gurri Khel, Dachi Khel, Palli Khel, Manzai, Alizai, Mahsuds.

Birifast KhBL. -See Masti KHeL.

BirRI KHEL (100).-One of the subdivisions of the Galeshahi, Upper Shaman Khel, Mahsuds. Headman : Piya Shah.

Bizan Khel and Moghal KHeL (80) British territory and Badar. -A minor fraction of Shadai Khel, Nasrai, Kalu Khel, Ahmadzai, Darwesh Khel Wazirs. Headman : Shawal.

Bizodar (240).-A section of the Malikshai, Aimal Khel, Bahlolzai, Mahsuds. 
Boba (980). - A division of Dhana, Bhittanis. Headmen : Arsala, Mir Nasar, Akbar, Adam Khan ('Taru Khel), Raza Khan, Muhd. Khan (Idezai).

Bobar.-A section of Hakim Khel, Mubarak Shahi, Mallizad, Datwars.

B OBAE (650) - -A division of Dhana, Bhittanis. Headmen : Barra Khan, Ali Khel, Baist Kbau (Shadi Khel).

BobalaI. - A minor fraction of Dreplarai, Tori Khel, Ibrahim Khel, Utmauzai, llarwesh Khel Wazirs. Headman : Mian Din Khan.

Bobarai (160).-A sub-division of Shingi, Bahlolzai, Mahsuds.

Bobar KHel (90).-A minor fraction of Khojal Khel, Shadai Khel, Nasrai Khel, Kalu Khel Ahmadzai Darwesh Khel Wazirs. Headman : Baghdad, Khidar Khan.

Bobar Kaeter (Bannu District).A minor fracrion of Waligai, Musa Khel, Hathi Khel, Shin Khel, Ahmadzai, Darwesh Khel Wazirs. Headman : Adam Khan.

Bobi KHEL (60). - A fraction of the Surat Khel, Sultanai, Shabi, Khel, Alizai, Mahsuds. Headman : Chiri Khan.

BobLaI KHeL (30).- - A minor fraction of Gangi Khel, Bomai, Nasrai, Kalu Kbel, Ahmadzai; Darwesh Khel Wazirs. Headman : Nambi Khan.
BODAR (100).-A section of doubtful origin living with the Tori Khel, Wazirs.

BODAR KHEL. - A minor fraction of the Dreplarai, Sarki Khel, Madda Khel, Ibrahim Khel, Utmanzai, Darresh Khel Wazirs.

Bodar kHEL-A minor fraction of Khojal Khel, shadi Khel, Nasradin, Kalu Khel, Ahmadzai, Darwesh Khel Wazirs.

BoI KHEL.-A minor fraction of Bakar Khel, Idal Khel, Hathi Khel, Shin, or Sain Kbel, Ahmadzai, Darwosh Khel Wazirs, Headman : Nasim Shah.

Bor or Bora KHex (60). - A minor fraction of the Garerai, Shumi Khel, Palli Khel, Manzai, Alizal, Mahsuds, Headman : Mira Khel.

BoI KHEI.-A sub-division of the Issuri, Tappizad, Dawars. Headmen: Khraja Muhammad Khan, Auladin.

Bor KHEL (140). - A section of the Mamdai, Shingi, Bahlolzai, Mahsuds, Headmen : Muha mmad Yar, Libas.

BoI KHex (28).-A section of Brahim Khel, Amzoni, Mallizad, Dawars.

BOJIA KHEL (150).-A sub-division of Shingi, Bahlolzai, Mahsuds. 
BonI KHEL. (Bannu District).A minor fraction of Rozi Khel, Ali Khel, Musa Khel, Hathi Khel, Shin Khel, Ahmadzii, Darwesh Khel Wazirs.

BorI KHeL (30).-A fraction of the Kharmach Khel, Shingi, Bablolzai, Mabsuds.

Bolsk.-One of the three primasy branches of the Khatak tribe.

BOMAI KHEL (3,346). - A section of Nasrai, Kalu Khel, Abmadzai Darresh Khel Wazirs.

BoNIYA KHEL (Bannu District).A minor fraction of Barmi Khel, Khandar Khan Khel, Hathi Khel, Shin Khel, Ahmadzai, Darwesh Khel Wazirs. Headman: Shah Tamoz.

BorA KHEL ( 20 ). - A section of the Birri Khel, Galeshahi, Upper Shaman Khel, Stlaman Kbel, Mabsuds. Headman : Thalim shah.

BORА KHEL (1,000), - A sub. division of Nohmit Khel, Utmanzai, Darwesh Khel Wazirs. Headmen: Kipat is the chief ; others are Shekh, Khwaja Mir.

Borr KHEL (10). - A minor fraction of the Adda Khel, Utman Khel, Isop Khel, Zrelli Khel, Bomai Nasrai, Kala Khel, Abmadzai, Darwesh Khel, Wazirs.
Bora (78).-A division of Tappizad. Dawars.

BOYAKAI (12).-A section of the Tappi Khel, Badanzai, Shaman Khel, Mahsuds.

Bora KHFL ( 180 ). - A minor fraction of the Malli Khel, Shekb Hassan, Taji Khel, Bomai, Nasrai Ahmadzai, Darwesh Khel, Wazirs.

Bozs KHel (Bannu, Chapri and Garang in Kurram).-A minor fraction of Tor Khel, Umarzai, Shin Khel, Ahmadzai, Darwesh Khel Wazirs.

BozIA KHEL. -A minor fraction of the Misakki, Wuzi Khel Mohmit Khel, Urmanzai, Darwesh Khel Wazirs.

Bozr KHel (400), - $\mathbf{A}$ section of Madda Khel, Ibrahim Khel, Utmanzai, Darwesh Khel Wazirs. Headmen : Namwar (Khoji Khel) and Zara n: (Ismail Knel).

BozI KHel.-A section of Shujawa Mubarak Shahi, Mallizad Dawars.

Brahiar Khel (190).-A section of Zira Khel, Amzoni, Mallizad, Dawars. Headmen : Shaghadin and Abdal Khalik.

BsOND KEEL ( 120 ). - A section of the Chabar Khel, Upper Shaman Khel, Mabsuds. 
BUdin KHex (5) Britisl terri-|Buri KheI (Winter camping tory.-A minor fraction of Shadai, Nasrai, Kalu Bhel, Ahmadzai, Darwesh Khel Wazirs. Headman: Shab Nawaz.

Buland KHel (130\%). A fraction of the Gurri Khel, Dachi Khel, Palli Kbel, Manzai, Alizai Mahsuds. Headman : Saidal. ground near Chaudhwan in the Dera Ismail Kiban district). $-\mathbf{A}$ division of Nasar, Ghilzai Pawindahs. Headman: Ali Khan.

Busharat KHEL. - A minor fraction of shamsi Khel, Topira Khel, Bomi Khel, Nasradin, Kalu Khel, Ahmadzai, Darwesh Khel Wazirs.

Chagal-A minor fraction of $\mathbf{C H a n n i - A ~ s e c t i o n ~ o f ~ B a r ~ K a u r e ~}$ Janbeg Khel, Ali Khan Khel, Hassu Khel, Mallizad, Dawass. sarki Ǩbel, Madda Khel, Ibrahim Kíbel, Utmanzai, Darwesh KheI Wazirs.

Chanar Kens (30).-One of the three sections of the Kikarai Nana Khel, Bahlolzai, Mabisuds.

CHaHar Krel $(380)$. - One of the forx divisions of the Upper Shaman Khel, Mabsuds.

Chalak KHel,-A section of Turaki Khel, Shakbi, Waraspun Bhittanis.

CHatas Khel.-A minor fraction of Dre Nami, Bala] Khel, Hasan Khel, Mlohmit Khel, Utmanzai, Darwesh Khel Wazirs.

Chand Keer (50).-A section of the Bojia Khel, Shingi, Bahlolzai, Mrahsads. Headman: Tarmisa.

ChaplaI (400).-A sub-division of Muia, Waraspun, Bbittanis. Headmen : Dowiat, Toti, Gbaza (Mandi Khel), Pir Khan, Samarzai, Amo, Jangi, Dino (Umr. Thel).

Charghal Khel. - A minor fraction of Shinki Khel, Babakli, Hassu Khel, Mallizad, Dawars.

Chargur. - A clan of the small tribe of Kunbi Pawindahs. Headman : Mahammad Akbar.

Chari KHet (40). - A minor frace tion of the Langar Khel. Khoedadi, Malikshahi, Aimal Khel, Baholzaj, Mrahsuds.

CharkHeL. - $A$ section of Maryam Khel, Darpa Khel, Mallizad Dawars. 
Chabrhil (40).-A section of Land Mralakb, JIallizad, Dawars.

Chutor (48). - A section of Zira Khel, Amzoni, Mlallizad, Dswars. Headmen : Zewar, Ghulam.
ChеND KHel (40). - A minor fraction of the Gidi Khel, Manzai, Alizai, Mahsuds. Headman : Ali.
DichI KHEL $(1,2 \pi 0)$. - A section of the Palli Khel, Mranzai, Alizai, Mshsud:. Headman; Badshah Khan.

Dadi KHeL (160).-A section of Taru Khel, Boba, Dhana, Bhittanis.

DADORA.-A sub-division of $\mathrm{Wa}$ ruki, Dhana, Bhittanis. Headman : Ghazi.

Dalat Khel (20).-A sub-dirision of Tappizad, Dawars.

Dalil Krel (3i)) - A minor section of the Sher Khel, Haibat Khel, Nana Khel, Bahlolzai, Mahsuds. Headman : Ma'ang.

DaLLI KHEL ( 70$)$. - A section of the Malik Dinai, Manzai, Alizai, Mahsuds. Headman: Shewagar.

DAYGAR KHEL (150).-A fakirsection of Saiyids living with $\mathrm{Mu}$ hammad Khel, Nalakh, Mallizad, Dawars.
DaNGaRzi.-A sub-division of Banda, Tappizad, Dawars.

DANI KHEL. - A minor fraction of Matkai, Malik Shahi, Wali Khool, Utmanzai, Darwesh Khel Wazirs.

DaraI or Idarai (90).-A section of the Chahar Kbel, Upper Shaman Khel, Mahsuds.

$D_{A R A K}$ KHEL. - A minor fraction of Mandi Khel, Wuzi Khel, Mohmit Khel, Utmanzai, Darwesh Khel Wazirs. Headman : Dig.

DARIA KHEL (120).-A section of the Bibizai, Shabi Khel, Alizai Mabsuds.

DARI KHEL.-A section of :Chaplai Muia, Waraspun, Bhittanis.

DaRI KHEL (30).-A section of the Kasim Khe!, Badinzai, Upper Shaman Khel, Shaman Khel, Mabsuds. Headman : Khadrai. 
DAREAI (30). - A minor fraction of Dochi Khel, Palli Khel, Manzai Alizai, Mahsuds.

DaRMaL KHeL.-A minor fraction of Shadi Khel, Balal K hel, Hasan Khel, Nohmit Khel Utmanzai Darwesh Khel Wazirs.

DARPA KHEL (235).-A division of Mallizad, Dawars. Headmen : Sliahzada, Gulpir, Najib, and Mire.

Darae KHeL (90).-A minor fraction of the Kamal Din, Shekh Bazid Khel, Isap Khel, Zalli Khel, Bomai, Nasrai, Kaln Khel, Abwadzai, Darwesh Kinel Wazirs.

DARRI KHEL.-A section of Wuzi Khel, Mobmit Khel, Utmanzai, Darwesh Khel Trazirs. Head. man: Gulabat.

DARB I KHEL (30) - A section of the Kasim Khel, Badanzai, Shaman Khel, Mabsuds.

DARBI KHeI.-A minor fraction of Madda Khel, Miamai, Kabul Tihel, Utmanzai, Darwesh Khel Wazirs.

Darmesh KHet Wazirs $(30,000)$. - The name given to the Utmanzai and Abuadzai clans of Wazirs Headmen: see Ahmadzai and Utmanzai.

DARTESH KHeL.-A minor fraction of Hehtar Khel, Muhammad Khel, Hasan Khel, Mohmit Khel, Utmanzai, Darwesh Khel Wazirs.
DARWESH KHEL (10).-A minor fraction of the Ali Khanai Kikraj, Nana Khel, Bahlolzai Mahsuds. Headman : Galop.

Dáwesh KHeL ( 30 ). - A minor fraction of the Kaka Kbel, Galishahi, Upper Shaman Khe], Shaman Khel, Mahsuds. Headman : Momindar.

DARTA KHEL.-A section of Alizai Darpa Khel, Mallizad, Dawars.

DARIA KHEL (100). - A minor frac. tion of the Kotar Khel, Abdul Khel, Lang:3r Khel, Khoidad Khel, Gidi Khel, Manzai, Alizai, Mabsuds. Headman : Bola Gulaim.

Darta Kert, Darwesh KHeL, A minor fraction of Bizen Khel, Shadi Knel, Nasradin, Kolu Khel, Abmadzai, Darwesh Khel. Wazirs. Headman: Sahib Khan.

Dastkgex (80). -A minor fraction of the Hussen Beg Khel, Utman Khel, Isap Khel, Zalli Khel, Bomai, Nasrai, Kali Khel, Ahmadzai, Darwesh Khel Wazirs. Headman : Mianai.

DASTA KHEL.-A minor fraction of Ali Khel, Brahim Khel, Amzoni, Mallizad, Dawars.

DATAE KHEL (British territory).A minor fraction of Painda Khel, Shadi Khel, Narsadin, Kalu Khel, Ahmadzai, Darwesh KheI Wazirs. 
1) $\triangle$ TUBAI (60).-A fraction of the Badinai, Khalli Khel, Upper Shaman Khel, Shaman Khel, Mabsuds.

Datoват (20).- - A minor fraction of the Datorai (proper), Badiwai Khalli Khel, Upper Shaman Khel, Shaman Khel, Mahsud. Koadman: Zardal.

DATTA KHEL, - A section of the original Datta Khel branch of Utmanzai, Darresh Khel Wazirs who, haring lands among the Khaddar Khel, are regarded as a section thereof for purposes of administration. Headman: Pimbal.

Datta KHel.-A section of the same branch of the tribe as the last entry but living with the Abdul Khel, Bora Khel. Nohmit Khel, Ctmanzai, Darwesh Khel Wazirs. Headman : Zamu Kban.

Datra KHEL - A section of the same tribe as last entry but living with the Dreplari, Tori Khel, Ibrahim Khel, Utmanzai, Darwesh Khel. Wazirs. Headman : Amaldar.

DatTA KHEL-A sub-division of Zeraksi, Mallizad, Dawars.

D $D_{\triangle T A R_{A}}$ - A section of Badiwai, Khalli Khel, Shaman Khel, Mahsuds.

DatTi KHex (jl5).- The chief subdivision of the Galeshahi, Shaman Khel, Mabsuds.

Datro KHel. -A section of Shadi Khel, Bobak, Dhana, Blittanis.
DACD.-A minor fraction of Brohim Khel, Zari Khel A : 1zJ Mallizad, Dawars.

DAUDI KHEL (40).-A section of the Astanai, Shabi Khel, Alizai, Mahsuds.

DAUD KHEL. - A sub-rection of the Jangi Khel, Umar Khel, Chaplai, Muia, Waraspun, Bhittanis. Headman : Kotal.

DAUD KHEL. (Winter camping ground at Gomab bazar in the Dera Ismail Khan district).-A division of Nasar, Ghilrai Pawindahs. Headmen : see Manjar Khe! and Sarwan Khel.

Datratan KHeL.-A section of Manzar Khel, Ibrahim Khel, Utmanzai, Darwesh Khel Wazirs.

DadLat KHEL. - A minor fraction of Sikandar Khel, Abdul Khel, Bora Khel MIohmit Khel, Utmanzai, Darwesh Khel Wazirs.

Daulat Khel (Bannu District).A minor fraction of Ali Kbel, Musa Kbel, Hatbi Khel, Shin Khel, Ahmadzai, Darwesh Khel Wazirs.

Daulat Khel (40).-A minor fraction of the Barumi Khel, Khoidad Khel, Gidi Khel, Manzai, Alizai Mahsuds.

Dadiatzais (500, Ghazni and $\mathrm{Ka}_{\mathbf{a}}$ Jat-i-Ghilzai).-One of the Ghilzai Pawindah trading clans. 
Datr $K$ het (45).-A minor fraction of the Nekzan Khel, Sber Khel, Haibat Khel, Nana Khel, Bahlolzai, Mabsuds.

Datenass $(700)$ Wano.-Their winter camping grounds are on the banks of the Indus between Kat Malana and Parca in the Dera Ismail Khan District.-One of the leading Pawindah trading tribes of similar oxigin to the Lobana Pawindahs. They originally possessed Wano, but were almost completely ousted by Ahmadzai Wazirs. In their efforts to recorer the ralley, they were assisted by their allies the Suleman Knel Pawindahs. They are divided into the following clans;-Badin Khel, Madar Khel, Sirkezi, Nasu Khel, Wazir Khel, Ahmadzai. Headmen;-see above clans.

DAFAR KaEL.-A minor fraction of Machi Khel, Ismail Khel, Bozi Khel, Madda Khel, Ibrahim Khel, Utmanzai, Darresh Khel Wazirs.

DaWARs (6,C00, Tochi Valley).'The Dawar's are divided into two min fractions called Mallizad or Malia, and Tappizad. They are priest-ridden and fanatical, and those of Lower Dawar bear the repatation of being cowardly. The Upper Dawar, howerer, approximates closely to the Wazir. They are industrions and skilful cultivators. Dawar villages are strongly walled and flanked, whilo towers are found scattered among the fields to protect the cultivators and their crops from Wazir raids.
DeganN.-A Falir section living with the Muhammad Khel Malakh, Mallizad, Dawars. Headmen: Ghanam Shab and Badrang.

Drana $(2,080$; Banuu and Dera Ismail Kban districts). - A clan. of Bhittanis. Headman : Arsala, Adam Khan, Bara Khan, Laisar and Raza Khan.

Dhanni KHel (60). - A minor fraction of the Shumi Khel, Palli. Khel, Manzai, Alizai, Mahsuds. Headman : Tate.

Dhanji Kret (130).-A minor fraction of the Gurri Khel, Dachi Khel, Palli Kbel, Manzai, Alizai, Mabsuds. Headman: Azam.

DrDAB (30).-A minor fraction of the Mouda Khel, Kilirai, Nana Khel, Bablol zai. Mahsuds. Headman: Didar.

DigaN KHEL.-A minor fraction of Datta Khel, living with the Abdul Khel, Bora Khel, Mohmit Khel, Utmanzai, Darresh Khel Wazirs. Headman : Zamma Khan.

Digar KHBL.-A minor fraction. of Morib Kbel, Utman Khel, Takhti Khel, Bakka Khel, Wali. Khel, Utmanzai, Dartwesh Khel Wazirs. Headman: Islam Khan.

Dinas.-A small tribe of doubtful origin, who although not Wazira. are fonnd in various parts of the 
Wazir country living with the following :-

(i) [10] Khaddar Khel, Mohmit Khel, Utmanzai, Darwesh Ḱluel.

(ii) [200] Tori Khel, Ibrahim Khel, Utmanzai, Darwesh Khel.

(iii) [40] Arghund, Mallizad, Dasvars.

Dinams (40).-A mizor fraction of the Band Khel, Bahlolzai, Mah. subs. Headman: Tagbal.

Dis (10).-A minor fraction of the mixed Khel, Michi Khel, Shumi, Khel, Palli Khel, Manzai, Alizai Mahsuds.

Dirdoni.-A section of Wuzi Khel. Mohmit Khel, Utmanzai, Darwesh Khel Wazirs. Headmen: Wazir Khan, Nakir Khan, Shadià Khan, Khangul, Alam.

Joday KREL. (Rannu District). -A minor fraction of Ali Khel, Musa Khel, Hathi Khel, Shin or Sain Khel, Ahmadzai, Darwesh Khel Wazirs.

DoDra KHEL (60).-A sub-division of the Astanai, Shabi Khel, Mahsuds. Headman: Wreshmin.

DoDI KHEL. - A minor fraction of Titar . Khel, Khan Khel, Takinti Khel, Bakka Kbel, Wali Khel, Utmanzai, Darwesh Kuel Wazirs.
Dodi KнвL (Bamu District).-A minor fraction of Khandar Khan Khel, Hathi Khel, Shin Khel, Ahmedzai, Darwesh Khel Wazirs.

DODI KHEL.-A sub-division of Khaddi, Mallizad, Dawars. Headman; Shahmaddi.

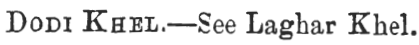

DOD KHEL. - A minor fraction of Mir Hasani. Macha, Madda Kbel, Iorahim Khel, Utmanzai, Darwesh Kbel Wazirs.

Dosalui.-A sectinn of Wuzi Khel, Mohmit Khel, Utmanzai, Darwesh Kbel Wazirs. Headman, Nisaz Gul.

Dotannis.-See Dautanis.

Dba Monal.-A minor fraction of Musakki, Wuri Khel, Mohmit Khel, Utmanzai. Darwesh Khel Wazirs.

DRELZARI (200). - A minor fraction of Ali Khel Shogai, Tori Khel, Jbrahim Khel, Utmanzai, Darwesh Khel Wazirs.

DRE-NAMI.-A minor fraction of Balal Khel, Hasan Khel, Mohmit Khel, Utmanzai, Darwesh Kbel Wazirs.

Dreprara.-A sub-division of Shakhai, Waraspun, Bhittavis. Headman; Charakki (Ghurburu). 
Dreptarat. - A minor fraction of Asad Khel, Wuzi Khel, Mobmit Khel, Utmanzai, Darwesh Khel Wazirs.

Dreplarai (30).-A minor fraction of the Ali Khanai, Kikrai, Nana Khel, Bablolzai, Mahouds. Headraan: Ali Mabammad.

DreplaraI.-A minor fraction of Muhammad Khel, Hasan Khel, Mohnit Khel, Utmanzai, Darwesh Khel Wazirs.

Drepiarai (800). - A section of Tori Khel, Ibrabim Khel, Utmanzai, Darwesh Khel Wazirs. Headmen : Miandin Khan, Khari Mukhmad, But, etc.

Drepiarai (275).-A minor fraction of Sarki Khel, Madda Khel, Ibrahim Kbel, Utmanzai, Darwesh Khel Wazirs. Headmen :
Umar Khan, Nur Muhammad Sarwar Khan.

DBEIAI KHL (20).-A minor fraction of the Ghulam Khel. Ali, Kaka Khel, Bomai, Nasrai, Kalu Khel, Ahmadzai, Darmesh Khel, Wazirs.

DUR (30)-A section of the Nekzan Khel, Nana Khel, Bahlolzai, Mabsuds. Headman : Zamonai.

Dor.-See Madi Khel and Dur.

DOR KHBL.-A section of Bibalki Hassu Khel. Mallizad, Nawars. Headmen: Muhammad Afzal, Raibat Chan, Tawan Shah.

DURuTrR KHel (60̃).-A section of Umar Khel, Nana Khel, Bahlolzai, Mahsuds. Headman : Tawakal.

Dotranis.-See Dautanis.
FAIIRAN.-A fakir rection living with the Brahim Khel, Amzoni, Mallizad, Dawars.

FAKIRAN (12)-A fakir section living with the Khatti, Taib Khel Amzoni, Mallizad Dawars.
FARIDAI (80).-A minor fraction of Ehamar Khel, Gidi Khel, Manzai, Alizai, Mahsuds.

Fatea Kher.-A minor fraction of Aziz Khel, Nazar Khel, Aimal Khol, Bablolzai, Mabsuds. 


\section{6}

Fater KHel. - A section of 'Turaki Khel, Shakhai, Waraspun Bhittanis.

Fatima $K$ Het (50). - A section of the Umar Khel, Astanai, Shabi Khel, Mahsuds, Headman : Nomit Khan.

Fatura KHel. - A minor fraction of Muhammad Khel, Isperka, Kalu Khel, Ahmadzai, Darwesh Kuel, Wazirs. Headman : Habib Gul.
Fattre Khel (20).-A minor fraction of the MIonda Khel, Kikrai, Nana Khel, Bahlolzai Mahsuds. Headman : Nazemir.

Firoz KHel (20; Dera Ismail Khan District).-Nomadic, a section of Baluch Khel, Isot Khel, Miau Khel, Lohana, Pawindaks.

Eiroz KHer.-A sub-division of Niamat Khel, Tatta, Bhittani. Headman : Bakhman.
G $\triangle D A I$ BHBL (110).-A ninor fraction of the Bidai, Gangi Khel, Bomai, Nasrai, Kalu Khel, Ahmadzai, Darwesh Khel Wazirs. Headman : Tut.

Gad KHEL (50; Dera Ismail Khan District).-Nomadic, a section of Umarzai, Sen Khel, Mian Khel, Lohana, Pawindahs.

GaJJI KHEL (30).-A minor fraction of Salimi Khel, Dachi Khel, Palli Khel, Manzai, Alizai, Mahsuds.

GaleshaHi (590).-A division of Upper Shaman Khel, Alizai, Mahsuds.

GALLA KHEL (7).-A sub-division of Boya, Tappizad, Dawars.

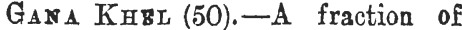
Shamak Khel, Abdullai, Aimal Khel, Bohlolzai, Mabsuds, Headman : Mamak.

GaNDAPURs. - (Dera Ismail Khan, District east of Tank).-A tribe of Saiyid origin similar to the Ustaranas (Pt. IV). They appear to have descended into the plains with the Lohana $\mathrm{Pawindahs}$ in the 17th century. Headmen: Nawab Muhammad Afzal Khan. The clans, etc., of the Gandapurs are not separately indesed in this dictionary.

GaN DI KHEL (20). - A minor fraction of the Mirat Khel, Shami Khel, Jalal Khel, Nana Khel, . Bahlolzai, Mahsuds.

GANGI KHEL $(460)-A$ minor fraction of Bomai Khel, Nasrai, Kalu Ahmadzaj, Darwesh Khel Wazirs. Headmen : Chokhai. 
GABAI FHEL (30). - A section of Brond Khel, Chahar Khel, Shaman Kbel, Mahsuds. Headman : Bilak.

GARA KHEL. - A minor fraction of Kundai, Tor Khel, Umarzai Shin or Sain Khel, Ahmadzai, Darwesh Khel Wazirs. Headman : Fazal.

Garerar (640).-A minor fraction of the Shumi Khel, Palli Khel, Nlanzai, Alizai Mabsuds. Headman : Kabul.

Gega OB GioA KHEL (200).-A Nana Khel, Bahlolzai, Mahsuds. Headman : Mohammad Afzal.

Ghairat Khel. - A minor fraction of Bakar Khel, Ida Khel, Hath Khel, Shin or Sain, Khel, Ahmadzai, Darwesh Khel Wazirs, Headman: Abdul Ghafur.

GEAL. - A minor fraction of Karim Khel, Jamal Kbel, Malik Shahi, Wali Khel, Utmanzai, Darwesh Khel Wazirs.

GOD KHEL (20), - A minor fraction of the Shami Khel, Jalal Khel, Nana Khel, Bahlolzai, Mahsuds.

GOLA KHEL. - $A$ minor fraction of Pira Khel, Mir Hasani, Macha, Madda Khel Jbrahim Khel, Utmanzai, Darwesh Khel Wazirs.

Gora Kael (70).-A minor fraction of Walidad Khel, Lalli Khel, Abdallai, Aimal Khel, Bahlolzai, Mahsuds.
Gecdar hHel (20).-A minor fraction of the Datorai, Badiwai, Khalli Khel, Upper Shaman Khel, Shaman Khel, Mahsuds. Headman : Narmi Khan.

GHALAT Z BeL (Banna District).A minor fraction of Kundi, Pirba Khel, Hathi Khel, Shin or Saba Khel, Ahmadzai, Darwesh Khel Wazirs.

GHalib KHEL (15). - A sub-division of the Badanzai, Shaman Khel, Mahsuds.

GHANI KHEL (110).-A minor fraction of the Karval Iin, Sbekh Bazid, Isap Khel, Zalli Khel Bomai, Nasrai, Kalu Khel Ahmadzai, Darwesh Knel Wazir. Headman : Dour.

GHANI KHEL.-A minor fraction of Mir Hasani, Macha, Madda Khel, Ibrahim Khel, Utmanzai, Darwesh Khel Wazirs. Headman : Dandi.

GHaranaI.- (Winter camping ground at Kalagarh in the Dera Ismail Khan district). - One of the lesser Pawindah trading clans. Headman : Muhammad Husain.

GHARIzAI. - (Winter camping ground at Panarpur).-One of the lesser Pawindah trading claas. Headman : Mir Alam.

GHARRI KHAN.-A section of the Ismail, Gulzai, Barak Khstaks of Teri in the Bannu district. 
GHaRTaz KHeL. - A minor fraction of Nlitha Khel, Badiwai K halli Khel, Shaman Khel, MIabsuds.

Ghazal yai (35). - A minor Eraction of Piran Ilangar Khel, who are a Faki section living with the Muhammad Khel, Jalakb, Mallizad, Dawars.

GHazir aI (30).-A minor fraction of the Pinzo Plarai, Abdullai, Aimal Kreel, Bahlolzai, Mabsuds. Headman : Ghulghai.

GHazikar (10). - A minor fraction of the Pinzaplara, Abdullai, Aima] Kbel, Bahlolzai, Habsuds.

GHazI $\mathrm{KHEL}$ (10).-A minor fraction of the Kasim Khel, Chahar Khel, Upper Shaman Khel. Shaman Khel, Mahsads. Headman: Amin Khan.

GuIlzıIs.-See Ghilzais. Part IT, and $\mathrm{Pawindahs,} \mathrm{Part} \mathrm{III.}$

Ghozi KHel ( 60$)$. - A minor fraction of the Shah Alam Khel, Krsim Khel, Chahar Khel, Shaman Khel, Mahsuds.

Gнгвгк.-A section of Dreplara, Shakhi, Maraspun, Bhittanis.

GHelay Krex - -A minor fraction of Kratti, 'Jaib Khel, Amzoni, Mallizad, Duwars.
GHelay Irhel-A sectiou of Alizai, Darpa Khel, Mallizad Dawars.

GhएLAנr Khel. -A minor fraction of Balla Khel, Shadi Kbel, Bora Khel, Utmanzai, Darwesh Khel, Wazirs. Headman : Kipat.

Gнuгay KHeL (300). - A fraction of the Ali Khel, Kaka Khel, Eomai, Nasrai, Kalu Khel, A hmadzai, Darwesh Khel, Wazirs Headman : Akhund.

GHelay KнеL. - A minor fraction of Umar Khel, Sada Khel, Isperlsa. Kalu Khel, Ahmadzai, Darwesh Khel Wazirs.

GHCLOP KHel. - A minor fraction of the Dosalii, Wazi Khel, Mobmis Krel, Utmanzai, Darwesh Khel Wazirs.

GHCxDI. - A section of Brabim Khel, Amzoni, Mallizad, Dawars.

GhWarazais (150; Gumal),-A clan of Kakars, living apart from the bulk of the tribe.

Gidi KHEL (1,590).-A sub-division of the Manzai, Alizai, Mahsuds. Headmen : Muhammad Afzal and Badrdin.

GIDI KHEL (650).-A section of the Gidi. Khel, Manzai, Alizai Mahsuds. 
GIRANI $K$ Hel. - A minor fraction of Muhammad Khel, Isperka, Kalu Khel, Ahmadzai, Darwesh Khel Wazirs.

GITA KHEL, -A section of Muhammad Khel, Malakh, Mallizad, Dawars.

Gogar.-A minor fraotion of Mandi Khel, Wuzi Khel, Mohmit Khel Utmanzai, Darwesh Khel Wazirs.

GorI KHEL. - A minor fraction of Thoji Khel, Bozi Khel, Madda Khel, Jbrahim Khel, Utmanza:s Darwesh Khel Wazirs.

GraN KHeL (30).-A minor fraction of the Hassan Khel, Khar marz, Nazar Khel, Aimal Khel Bahlolzai, Mahsuds. Headman : Par Mahammad.

GUDI KHEL.-A section of the Manzai division of the Barak Khataks. They inhabit the soutbern portion of the Lowaghar or Maidani range in British territory.

G $\mathrm{D}$ KHEL (20). - A minor fraction of the Shain i Khel, Jalal Khei Nana Khel, Bablolzai, Mabsuds.

Gula KHel (40). -A minor fraction of the Babal Khel, Khoedadi, Malikshahi, Aimal Khel, Pablolzai, Mabsuds.

GULAPIR.-A section of Brahim Khel, Amzoni, Mallizad, Dawars.
GOLI KHEL.-A section of Bobak, 1) hana, Bhittanis.

GULI KHEL. (Winter camping ground, Darabin in the Dera Ismail Khan District). - A division of Suleman Khel, Ghilzai Pawindahs. Headman: Sarwar

Gou KHan KHex.-A minor fraction of Karkatai, Kaka Ki hel, Bomi Khel, Nasradin, Kalv Khel, Ahmadzai, Darwesh Khel Wazirs.

Gella KHeL (Wano).-A minor fraction of Zalli Khel, Bomi Khel, Nasradin, Kalu Khel, Ahmadzai, Darwesh Khel Wazirs.

Goll KHel (Bannu District). - A minor fraction of Waligai, Musa Khel, Hathi Khel. Shin or Sain Khel. Ahmadzai Darwesh Khel Wazirs.

GolMaHoMED KHeL. - A section of Ali Khel, Lobak, Dbana, Bhittanis.

GuL Mis KHeI (10).-A minor fraction of the Mirat Khel Shami Khel, Jalal Khel, Nana Ki hel, Bahlolzai, Mahsuds.

GULNAM KHEL.-A minor fraction of Poi Khel, Mahammad. Khel, Malak, Mallizad, Dawars.

GULOB KHEL. - A minor fraction of Karkatai, Kaka Khel, Bomi Khel, Nasradin, Kalu iThel, Ahmadzai, Darwesh Khel Wazirs. 


\section{0}

Gol Sher KHed (10). - A minor fraction of the Bariam Khol, Patanai, Sbabi Khel, Alizai Mahsuds. Headman : Haji Mubammad.

GoLZaI or KHaLFaD.-One of the main divisions of the Barak Khataks inbabiting the country round Teri in the Bannu district.

GoNNA KHEL (60),-A minor fraction of the Shamak Khel, Abdullai Aimal Khel, Bahlolzai, Mahsuds.

Gorbaz $(1,000 *$ southern border of Khost).-Originally a clan of Wazir origin who have since lost all connection with the parent tribe. A few families, however, still reside in Showal. Headmen : Khan Sahib and Paidil in the Tochi near Saidgi and on the Khost border near Miranshah; at Spin Nimal Khel in Mahsud country and at Mirian in Bannu District.
GoRBUZ.-A minor fraction of Khan Khel, Tashto Khel, Bakka Khel, Wali Khel, Utmanzai Darwesh Khel Wazirs.

GorbUzar.-A sub-division of Darpa Khel, Mallizad, Dawars. Headman : Shabzada, Shadi Khel.

GORRI KHEL (400). - A minor fraction of the Dachi Khel, Palli Khel, Manzai, Alizai, Mah:uds. Headman : Azam.

GURBI KHEL (190).-A fraction of the Shamerai, Palli Khei, Manzai Alizai Mahsuds. Headman: Ala Mir.
Haibach Kres (40). - A fraction of the Kharmach Khel, Shingi, Bahlolza: Mahsuds. Headman: Karamai.

HaIbat KHEL. -A minor fraction of Dardoni, Wazj Khel, Mohmi Khel, Utmanzai, Darwesh Khel, Wazirs.
HaIBAT KHEL (180):-The most important sub-division of the Nana Khel, Bahlolzai. Mahsuds. Heacman : Mir Ajal.

HaIB.atTaI (1,000)...-A section of Tori Khel, Ibrahim Kbel, Utmanzai, Darwesh h hel Wabirs. Headmon: Miandad, Muhammad Akbar, Gulaim. 
HAIDABI (60).-A sub-division of Chahar Khel, Shabur Shaman Khel, Mahsuds. Headnan : Isap.

$\mathrm{H}_{A I D A R}$ KHEL (8อ̃2). -A division of the Tappizad, Dawars. Headmen: Alif Khan, Gul Khan, Nasar Khan, Abussamaud, Zakke- mir.

HAIDAR KHEL.-A minor fraction of Khiddar Khel, Mehtar Khel, Mubammad Khel, Hasan Khel, Mohmit Khel, Utmanzai, Darwesh Khel Wazirs.

HaIdAR KHeL (20).-A minor fraction of the Makbal Khel, Patanai, Shabi Khel, Alizai Mabsuds. Headman : Shawal.

H $_{\text {AIRAL }}(80$ ). - A section of Chahar Khel, Upper Shaman Khel, Mahsuds.

HaJi KHeL. - A minor fraction of Pai Kbel, Mubammad Khel Malakh, Mallizad, Dawars.

HaKiM KHeL (220).-A sub-division of the Band Khel, Bahlolzai Mabsuds.

HAKIM KHEL. - A minor fraction of Machi Khel, Abdul Khel, Bora Khel, Mohmit Khel, Utmanzai, Darwesh Khel Wazirs.

HAKIM KHEL. - A minor fraction of Pira Khel, Jamal Khel, Malik Shahi, Wali Khel, Utmanzai, Darwesh Khel Wazirs.
Hakim Khel (99).-A sub-division of Mubarak Shahi, Mallizad, Dawars. Headman : Khansamand.

Havgo KHeL (300; Bannu District). - A minor fraction of Dodi Khel, Khandar Khan Khel, Häthi Khel, Shin, or Sain, Khel, Ahmadzai, Darwesh Khel Wazirs. Headmen: dimal Khan and Wadin.

$\mathrm{H}_{A S A N} K_{H E L}$ - A sub-division of Aba Khel, Pala Khel, Tatta, Bhittanis. Headman : Zamani.

$\mathrm{H}_{\triangle \mathrm{SAN}} \mathrm{K}$ HEL-CA sub-division of Taru Khel, Boba, Bhittanis.

HASAN KHEL (30).-A section of Shamerai, Manzai, Alizai, Mah. suds.

HaSan KHeL (60).-A minor fraction of the Kharmanz Khel, Naza Khel, Aimal Khel, Bahlolzai Mahsuds.

$H_{\triangle S A N}$ KHeL (400; Kaitu and Laram). - A sub-division of Mohmit Khel, Utmanzai, Darwesh Khel Wazirs. Headmen : Jan Gulshirin, Kakai, Idgul and other.

HASAN KHEL.-A sub-division of Urmuz, Mallizad, Dawars.

Hassan Beg KHel (450). - A minor fraction of the Utman Khel, Isap Khel, Zalli Khel, Bomai, Nasrai, Khalu Khel, Abmadzai, Darwesh Khel Wazirs. Headman: Sher Jan. 


\section{2}

Hassax KHeL (30).-A section of the Birri Khel, Gales bahi, Upper shaman Kibel, Shaman I'hel, Mahsuds. Headman : Alibaz.

Hassax Khel. - See TaJi KHeL.

H $\Delta S S U$ KHEL (808). - A division of Mallizad, Dawars. Headmen : Mrad Afzal, Tawan Shab, and others.

HATHI(or ItTr) KHEL (3,000; Bannu District, Thal, Shakai, Birmal and Wano). -A sub-division of Shin, or Sain Khel, Ahmadzai, Darwesh Khel Wazirs. Headmen: see Khandar Khan Khel, Idal Khel, Pirba Khel, and Kusa Kkel.

HAWAS KHEL (20). - a minor fraction of the Haibat Khel, Nana Khel, Bahlolzai, Mrahsuils.

H $\triangle$ WAZ KHEL (10).-A minor fraction of the Nebzan Khel, Nana Khel, Bahlolzai, Mahsuds.

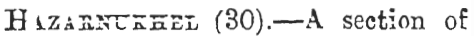
the Mirdad Khel, Abdurrahman Khel, Nana Khel, Bahlolzai, Mahsuds. Headman: Shawar Pin.

IBA KHEL.-A section of Tareta, Idak, Tappizad, Dawars.

Ibrahiar KHel (160).-A section of the Astanai, Shali Khel, Alizai, Mahsuds.
HrdaRzaI.-A division of Kharoti, (ihilzai, Pawindahs. Headman: Hayat Khan.

HINDI KHEL. - A minor fraction of Tor Jani Khel, Wali Khel, Utmanzai, Darwesh Thel Wazirs. Headmen: Malkun, $\mathrm{Pir}$ Makhmad.

Hiśdol KHEL (60). $-\mathrm{A}$ minol fraction of the Makhi Khel, Karim Khel, Alj, Kaka Khel, Bomai, Nasrai, Kalu Khel, Ahmadzai, Darrests Khel Wazirs.

Hozi KHeL.-A section of Gurbuzai, Darpa Khel, Mallizad, Dawars.

Hervaz (180).-A division of Mallizad, Dawars. Headman : Nazim halim.

Fĩsain hHeL. -A sub-division of Khaddi, Mallizad, Dawars. 
IDAK (615).-A division of the Tappizad, Dawars. Some authorities, however, say they are a separate clan belonging neither to 'Tappizad, nor Mallizad. Headmen : Bakbt Jamal, Daisal, aød Mir Salak.

IDAL KHEL. - A minor fraction of Chitton, Zira Khel, Amzoni, Mallizad, Dawars.

Idal KHex ( 1,000 ; Bannu, Shakaj, Birmal, and Wano).-A section of Hathi Khel, Shin, or Sain Khel, Ahmadzai, Darwesh Khel Wazirs. Headmen : Bandar Khan, Sbekh Piyao, Landai, Nasim Shah.

IDAL KHEL. (72)-A section of Muhammad Khel, Malakh, Mallizad Dawars. Headmen: Payodin, Soil Khan.

IDAR KHEL. Ali Khel, Khaddar Khel, Mohmit Khel, Utmanzai, Darwesh Khel Wazirs. Headmen : Nur Muhammad, Makhach, Sakheman, Akhmad.

IDIA KHEL. - A section of Jani Khel, Wali Khel, Utmanzai, Darwesh Khel Wazirs. Headmen : Nazam Khan, Mir Birjan, Zurghun Sbah, Gul Ghafar, Akaldin, Zargai, Shekh Majid.

IDU KHEL. - A section of Ali Khel, Bobak, Dhana, Bhittanis.
Iretiyar (90). - A minor fraction of the Ghulam Khel, Ali, Kaka Khel, Bomai, Nasrai, Kalu Khel, Ahmadzai, Darwesh Khel Wazirs. Headman: Alshund.

IkHtifar KHeL (60).-A minor fraction of the Maka Khel, Malli Khel, Shekh Hassan, Taji Khel, Bomai, Nasrai, Kalu Khel, Ahmadzai, Darwesh Khel Wazirs. Headman : Mirzagul.

IkHtifar Khel.-A minor fraction of Dirdoni, Wuzi Khel, Mohmit Khel, Utmanzai, Darwesh Khel Wazirs.

Jual KHel. See Inas Khel.

INAS, or ILAL KHEL-A minor fraction of Painda Khel, Manaka Khel, Bakhshi Khel, Madda Khel, Ibrabim Khel, Utmanzai, Darwesh Kbel Wazirs.

INDAS KHEL.-A minor fraction of Bizen Khel, Shadi Khel, Nasradin, Kalu Kbel, Ahmadzai, Darwesh Khel Wazirs. Headman : Nazir Khan.

INDAS KHEL. - A minor fraction of Dreplarai, Sarki Khel, Madda Khel, Ibrabim Khel, Utmanzai, Darwesh Khel Wazirs.

IPI (186). - A sub-division of Haidar Khel, Tappizad, Dawars. Headmen: Fatteh Khan, Kashmir, Ibrahim Gul. Sheikh Jamal. 
Is $\triangle B$ KHEL (40). - A section of Tappi Khel, Badinzai, Shaman Khel, Mabsuds.

IsAB Khel.-A minor fraction of Shadi Khel, Bora Khel, Mohmit Khel, Utmanzai, Darresh Khel Wazirs. Headman: Gul Ahmad Khan.

ISAB KHEL.-A minor fraction of Nasr Khel, Haidar Khel, Tappizad, Dawars.

IsAGAI KHEL (20).-A section of the Langar Khel, Gidi Khel, Manzai, Alizai, Nahsuds.

ISAK (10). - A minor fraction of the Karim Khel, Ali Khel, ñake Khel, Bomai, Nasrai, Kalu Khel, Abmadzai, Darwesh Khel Wazirs.

Is KHEL (21)-A section of the Birr: Khel, Galeshahi, Shaman Khel, MIahsuds.

IsA KHBL.-A minor fraction of Bakar Khel, Idal Khel, Hathi Khel, Shin, or Sain, Khel Ahmadzai, Darwesh Khel Wazirs. Headraan: Shekh Piyao.

IsA KHEL. - A minor fraction of Walak Khel, Dosalli, Wuzi Khel, Mohmit Khel, Utmanzai, Darwesh Khel, Wazirs. Headman: Zarmi Khel.

IsA KHeL.-A minor fraction of Saifali, Kabul Khel, Wali Khel, Utmanzai, Darwesh Khel Wazirs.
IsAP KHEL (1,1n0). - A fraction of Zalli Khel, Bomai Khel, Nasrai, Kalu Khel, Ahmadzai, Darwesh Khel Wazirs.

IsMaIL.-A sub-divis:on of the Gulzai, Barak Khataks of Teri, in the Bannu district.

Isminask.-A section of Dreplara, Shakhdi, Waraspun, Bhittanıs.

IsMAIL KHEL (160). - A minor fraction of Bozi Khel, Madda Khel, Ibrahim Khel, Utmanzai, Darwesh Khel Wazirs. Headman: Zarib and Nazim.

IsMAIL KHEL (60). - A section of Ozbaki, Shingi, Bablolzai, Mabsuds. Headman : Najib.

Ismaitzai-A' section of Brahim Khel, Amzoni, Mallizad. Dawars.

Iso KHEL. - A minor fraction of Masti Khel, 'Tojiya Khel, Bomi Khel, Nasradin, Kalu Khel, Ahmadzai, Darwesh Khel Wazirs.

Isот KrEL.-See Sot Khel.

IsPERKAI (160). - A sub-division of the Kalu Khel, Ahmadzai, Darwesh Rhel Wazirs. Headman: Lias.

IssURI (135). - $A$ division of Tappizad, Dawars. Headmen : Samand Khan, Khwaja M uhammad Khan, Auladin, and Talat.

ItTr KEEL. -See Hathi KHEL. 
JABAR KHEL (30):-A minor fraction of the Bojia Khel, Shingi, Bahlolzai, Mahsuds. Headman: Khan Zaman.

Jabar KHeL (70). -A minor fraction of the Walid Khel, Mal Khel, Dachi Khel, Palli Khel, Manzai, Alizai, Mahsuds.

$J_{\triangle B A R} K_{H E L}-A$ minor fraction of Bakhshi Khel, Madda Khel, Ibrabim Khel, Utmanzai, Darwesh IKhel Wazirs.

$J_{\triangle D R A N S .-A}$ tribe, occupying the east slopes of the Suleman range, east of Zurmat.

J tion of the Sikandar Khel, Badiwai, Kalli Khe], Upper Shamau Khel, SLamau Khel, llabsuds.

JALAL DiN (100). - A minor fraction of the Shekh Bazid Khel, Isap Khel, Zalli Khel, Bomai, Nasrai, Kalu Khel, Ahmadzai, Darwesh Khel Wazirs.

JaMALDIN KHEL.-A minor frac. tion of Wodiu Khel, Khazzar Khel, Ali Khan, Saski Khel, Madda Khel, Ibrahim Khel, Utmanzai, Darwesh Khel Warirs.

$J_{\triangle L A L}$ KHEL. - A minor fraction of Khoji Khel, Bozi Khel, Madda Khel, Ibrabim Khel, Utmanzai, Darwesh Khel Wazirs.
JALAL KHEL (Winter camping ground Saggu in the Dera Ismail Khan district). A division of Nasar, Ghilzai, Pawindahs. Headmen: Saiyid Ahmad and Sabu Jan.

JALAL KHEL (80).-A section of the Bobalai, Shingi, Bahlolzai, Mahsuds. Headman: Gul Muhammad.

Jaxal KHel (250). - A sub-division of the Nana Khel, Bahlolzai, Mahsuds. Headman: Karim Khan.

JALAL KHEL. - A sub-division of Sara, Tatta, Bhittanis. Headman: Darya Khan.

JALAL KHEL.-A minor fraction of Shadi Khel, Bora Khe?, Mohmit Khel, Utmanzai, Darwesh Khel Wazirs. Headman : Latak.

JALAL KHEL.-A minor fraction of Khan Khel, Takht Khel, Bakka Khel, Wuli Khel, Utmanzai, Darwesh Khel Wazirs. Headman Mîrza.

J AM $\triangle \mathrm{L}$ KHE L. - A minor fraction of Ali Krel, Brahim Khel, Amzoni, Mallizad, Dawars.

JAMAL KHEL.-A section of Malik Shaini, Wali Khel, Utmanzai, Darwesh Khel Wazirs. Headmen: Jumazan Khan, Muhammad, Taghar, Urmur, Hnsaini, Gulla Khan, Sulemzui. 
JAIILL KHEL (30).-A section of the Shalil Khej, Badinzai, Upper Shaman Khel, Shaman Kbel Mrahsuds. Headman : Lali Khan.

JAMAL KEEL. - A section of the Haidrai, Chahar Khel, Shaman Khel, MIabsuds.

JA IAL THEL (Bannu District).A minor fraction of Ali Khe], IIusa Khel, Hathi Khel, Shin, or Sain, Khel, Abmadzai, Darwesh Khel Wazirs.

JAMAL KHEL. - A minor fraction of Muhaminad Khel, Dardoni, Wuzi Khel, Mohmit Khel, Utmanzai, Darwesh Khel Wazirs. Headman : Gul Sahib.

J AMIL KHEL (20).-A minor fraction of shadj Khel, Lar Larai, Land, MIalakh, Mallizad, Dawars. Headman : Malikdin.

JAXII KHEL. - A minor fraction of Usman Khel, Takhti Khel, Bakka Khel, Wali Khel, Utmanzai, Darwesh Thel Wazirs. Headwan : Akmad Din.

$J_{\Delta x \perp S}(290) .-A$ minor fraction of the Karim Khel, Ali Khel, Kaka Khel, Bomai, Nasrai, Kalu Khel, Ahmaảzai, Narwesh Khel Wazirs. Headman : Minabat.

JATBEG KHEL (220).-A minor fraction of Ali Khan Khel, Sarki Khel, Madda Khel, Ibrahim Khel, Utmanzai, Darwesh Khel Wazirs. Headmen : Madi and Nazardin.
JANDI KHEL (30). - A section of the Khalli Khel, Shahur Shaman Khel, Shaman K Kel, Mahsuds. Heaảman : Sardan Shah.

J $\triangle$ NGI KHEL (10). - A fraction of the Surat Khel, Sultanai, Shabi Khel, Alizai, Mahsuds. Headman: Dawar.

JANGI KHEL.-A minor fraction of Machi Khel, Abdul Khel, Bora Khel, Mohmit Khel, Otmanzaii Darwesh Khel Wazirs.

JANGIR KHEL. - A minor fraction of Saiyid Khel, Umarzai, Shin, or Sain, Khel, Ahmadzai, Darwesh Khel Waz:rs. Headman : Naurang.

JANI KHEL (1,000; Khasora and Wano).-A sub-division of Wali Khel, Utmanzai, Darwesh Khel Wazirs, Htadmen : see ldia Khel, Tor, and Malik Shabi.

Jax KHAN KHEL.-A mincr fraction of Sogi Khel, Muhammad Khel, Malakh, Mallizad, Dawars.

JAN KHAN KHEL. - A sub-division of Boya, Tappizad, Dawars.

$J_{A W A L}$ KHEL. - A sub-division of Aba Khel, Tatta, Bhittanis. Headman : Zarif.

JiRAKI (Bannu District).-A minor fraction of Pirba Khel, Hathi Khel, Shin, or Sain, Khel, Abmadzai, Darwesh Khel Wazirs. Headmen : Musharab Khan, Gulbagh.

JUMALAT.-A minor fraction of Datta Khel (Abdul Khel), q.v. Headman : Virghal. 


\section{K}

KaBIR KHEL. -A section of the Teri (or Tori) Khel, Tapiai, Tappizad, Dawars. Headman: Gulal Shah.

Kabtu KHEL $(2,600$; Kurram, Shawal, and Birmal).-A sub-division of Wali Khel, Utmanzai, Darwesh Khel Wazirs. Headmen : Landai of the Saifali section and Galbat Khan of the Miama section.

KaDAM KHEL. - A section of the Ali Khel, Haidar Khel, 'Tappizad, Dawars.

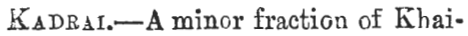
rak Khel, Wodin Khel, Khazzar Khel, Ali Khan Khel, Sarki Khel, Madda Khel, Ibrahim Khel Otmanzai, 1)arwesh Khel Wazirs.

KADIR KHEL (30).-A minor fraction of the Abas Khel, Raibat Rhel, Nana Khel, Bahlolzai, Mahsuds. Headman: Shaurang.

KAFSHI KHEL.-A section of the Nasar Khel, Haidar Khel, 'Iappizad, Dawars.

KAHI KHEL (120).-A minor frac. tion of the Khoidad Khel, Gidi Khel, Manzai, Alizai, Mahsuds. Headman : Said Akbar.

KAI KHEL (150).-A section of the Gidi Khel, Manzai, Alizai, Ma:h. suds. Headman : Saiyid Äkkar.
KAIM KHEL.-A minor fraction of I smail Khel, Bozi Khel. Madda Khel, Ibrahim Kbel, Darwesh Khel Wazirs.

$K_{A J I} K_{H E L}(50)$. - A minor fraction of the Karaki Khel, Bidai, Gangi Khel, Bomai, Nasrai, Kalu Khel, Alumadzai, Darwesh Khel Wazirs.

KAII KHEL-A minor fraction of Paipali, Kabul Khel, Wali Khel, Utmanzai, Darwesh Khel Wazirs. Headmen : Kattai and Sarwar Khan.

KaJi KEeL (60). - A minor fraction of Karim Khel, Guri Khel, Dachi Khel, Palli Khel, Manzai, Alizai, Mahsuds. Headman : Tor.

KaJRAI (70).-A fraction of the Poi Khel, Shanirai, Palli Khel, Manzai, Alizai, Mahsuds.

$K_{A K A}$ KHEL.-A minor fraction of Idar Khel, Ali Khel, Khaddar Kbel, Mohmit Khel, Utmanzai, Darwesh Khel Wazirs. Headman : Akhmad.

$K_{A K A}$ KHEL. $-A$ section of Turaki Khel, Shakndi, Waraspun, Bhittanis.

KAKA KHEL-A sub-division of Niamat Khel, Tatta, Bhittanis. Headman: Ahmad Khan. 
KAKA KHEL (20). -A minor fraction of the Hiral Khel, Chahar Khel, Upper Shaman Khel, Shaman Khel, Mahsuds. Headman : Gingrai.

KAKA KHEL.-A minor fraction of Khare, Taib Khel, Amzoni, Mallizad, Dawars.

KAKA KHEL (630) - A fraction of Bomai Kbel, Nasrai, Kalu Khe!, Ahmadzai, Darresh Khel Fazirs. Headman:Badshain Khan.

TAKHAI (60).-A section of the Baba Khel, Galeshahi, Upper Shaman Khel, Mahsuds. Headman : Ḱatamir.

Kalaxdar KHel.-A minor fraction of Ali Khel, Manzar Khei, Ibrahim Khel, Ttmanzai, Darwesh Thel Tazirs. Headmen: Mihrib Than, Kabal, Namaz Ḱtian.

Káladar Khel (Bannu District). - A minor fraction of Taos Khel, Pirba Khel, Hathi Khel, Shin, or Sain, Khel, Almadzai, Darwesh Khel Wazirs.

KAIANDAE KHEL.-A minor fraction of the Bakhshi Khel, Madda Khel, Jbrahim Thel, Utmanzai, Darwesh Kbel Tazirs.

KILASDAR KHEL.-A section of the Badzai, Kattagram, Tattz, Bbittanis. Headman : Shatbaz.
KaLAT KHeL. - A minor fraction of Mubammad Khel, Isperka, Kalu Thel, Ahmadzai, Darwesh Khel Wazirs. Headman : Muhammad Jan.

KaLI KHEL (15). - A minor fraction of the Adda Khel, Utman Khel, Isap Kibel, Zalli Khel, Bomai, Nasrai, Kalu Khel, Ahmadzai, Darwesh Khel, Wazirs. Headman: Saidin.

KALI KHEL. A minor fraction of Morib Khel, Usman Khel, 'Takhti Khel, Baklza Khel, Wali Khel, Utmanzai, Darwesh Khel Wazirs.

Kalli Keel. - A minor fraction of Bachagai, Tor, Jani Khel, Wali Khel, Utmanzai, Darwesh Khel Wazirs. Headmen : Kaimal and Shadimir.

KALU KHEL - A minor fraction of Siliandar Khel, Abdul Khel, Bora Khel, Mohmit Khel, Utmanzai, Darwesh Khel Wazirs.

KaLU KHeL (3,906).-A division of Ahmadzai, Darwesh Khel Wazirs. Mani Khan, Isperka, is the leading man; for other Headmen; see Isperka and Nasradin.

Kuyial Din (440). - A minor fraction of the Shekh Bazid Khel, Isap Khel, Zalli Khel, Bomai, Nasrai, Kalu Khel, Ahmadzai, Darwesh Khel Wazirs. 
TAMAI KHEI (10).-A section of the Daria Kbel, Bibizai, Shabi Kbel, Alizai, Mabsuds. Headman : Jumak.

KaMaI KHEL.-A minor fraction of Bakar Khel, Idal Khel, Hathi Khel, Shin, or Sain: Khel, Ahmadzai, Darwesh Khel Wazirs. Headman : Laudai.

KaMaI KHEL (60).-A section of Ozbakai, Shingi, Bahlolzai, Mainsuds. Headman: Sari Gul.

KaMaL KHeL (Winter camping ground at Drabin in the Dera Ismail Khan district).-A division of Nasar, Ghilzai Pawindahs. Headman : Bura Khan.

$\mathbb{R}_{A M A B} K_{H E i}(35)$. $-A$ minor fraction of the Karmach Khel, Malai, Shingi, Bahlolzaj, Mahsuds.

KanezaI.-A sub-division of Kattagram, Tatta, Bhitannis. Headmen: Tor, Isap, Gulsalam.

KanjRaI (90).-A minor fraction of the Dachi Khel, Palli Khel, Manzai, Alizai, Mahsuds. Head. mas : Umarzai.

KanRoN KHEL (140).-A section of the Mamdai, Shingi, Bahlolzai, Mahsuds. Headmen : Kandhar, Baghdad, Mirza.

KARAKI KHEL (60). - A minor fraction of the Bidai, Gangi Khel, Bomai, Nasrai, Kalü Khel, Ahmadzai, Darwesh Khel Wazirs. Headman : Janai.
KARACH KHEL (20).-A minor fraction of the Ali Khanaj, Kikrai, Nana Khel, Mahsuds. Headman. Paste Khan.

KARA KHEL.-A section of Shadi Khel, Bobak, Dhana, Bhittanis.

KARA KHEL (160).-A minor fraction of the Hassau Beg Kabel, Utman Khel, Isap Khel, Zalli Khel, Boinai Nasiaj, Kalu Khe], Ahinadzai, Darwash Khel Wazirs Headman : Pir Khan.

Kariar KHeL (3CO). - A fraction of Ali Khel, Kaka Krel, Bomai Khel, Nasrai, Kalu Kbel, Ahmadzai, Darmesh Khel Wazirs.

KaRIM KHEL - A minor fraction of Jamal Khel, Malik Shahi, Wali Khel, Utmanzai, Darwesh Khel Wazirs.

KARIMDAD KERI (50).-A section of Abdul Rabman Khel, Nana Khel, Bablolzai, Mahsuds.

Karkata (20).-A section of the Kaka Khel, Iiomai, Nasrai, Kalu Kbel, A hmadzai, Darwesh Khel Wazirs.

KaRKaTaI.-A minor fraction of Kaka Khel, Bomi Khel, Nasradiu, Kalu Khel, Ahmadzai, Darresh Khel Wazirs.

Kar KHEL (18). - A minor fraction of Ahmad Khel, Zira Khel, Amzoni, Mallizad, Darrars. 
KABMANDI FiHAN-A minor fraction of Madda Kihel, Miamai, Kabul Khel, Wali Khel, Utmanzai Darwesh Kbel Wazirs.

KARYATZ KHEL-A minor fraction of Marsi Trhel, Abdul Khel, Bora Khel, Nohmit Thol, Cirnan. zai, Darwesh Khel Wazirs.

TARMI KHEL.-A minor fraction of the Gurri thel, Dacsi Thel, Palli Inhel, Mlanzai, Alizai, Mahsuds.

FAROX (140). -A section of the IIamdai, shingi, Bablulzai, Matasuds.

TARORI KHEL. - A minor fraction of Karkatai, Kalia Khel, Bomi Thel, Nasradin, Kalu Khel, Ahmadzai, Darwesh Khel Wazirs.

FARRAMr KHEL. - A minor fraction of Khan Khel, Bar Khozhai, Khaddar Khel, Nobmit Khel, Utmanzai, Darwesh Khel Wazirs. Headman Kinan Zaman, and Ainir Tihan.

KaRRI KHEL.-A section of the Manderi, Idak, Tappizad, Dawars. Headmen : Nazarband, Khwaja Nubammad.

TARRI KHEL. - A sub-division of Mullagan, Mallizad, Dawars.

KAREI KHEI (60). - A sub division of Urmuz, Ilailizad, Dawars.
KASAM KHEL.-A section of the Al: Khel, Haidar Khel, Tappizad, Dawars.

KASAII KHEL.-A minor fraction of Dur Khel, Babalki, Hassu Khel, Nallizad, Dawars.

Kashaitri KHei (30). - A minor fraction of the Makhi Khel, Janas, Karim Khel, Ali, Kaka Khel, Bomai, Nasrai, Kalu Khel, Ahmadzai, Darwesh Khel Wazirs. Hesdman: Budshah Khan.

Fasim KHEL (70).-A fraction of Sheri Khel, Umar Khel, Nans Khel, Bahlolzai, Mahsuds. Headwan : Namári.

FASIXI KHEL (60).-A sub-division of Badanzai, Shaman Khel, Mahsuds.

$\mathrm{K}_{\mathrm{ASI}} \mathrm{Kr}$ KaEI $(70)$. - A fraction of Sherin Khel, Umar Khel, Nana Khel, Bahlolzai, Mahsuds.

KaSIMI KHEI (20).-A sub-3ivision of Chahar Khel, Shahur Sharuan Thel, Mahsuds. Headman: Fattehroz.

KaTAGBAMI $(100)$. - A section of doubtful origin living with the 'Tori Kbel, Ibrahim Khel, Utmanzai, Darwesh Khel Wazirs. Headman : Khonamir. They are blacksmiths by trade.

KaTA KHEL.-A section of Manderi, Idak, Tappizad, Dawars. Headman : Sahib Khan. 
K ${ }_{\triangle T L L} K_{H E L}(60)$. - A minor fraction of the Karaki Khel, Bidai, Gangi Khel, Bomai, Nasrai, Kalu Thel, Ahmadzai, Darwesh Khel Wazirs. Headman : Razim.

Katal Khel (50).-A minor fraction of Walidad Khel, Lalli Khel, Abdullai, Aimal Khel, Bahlolzai, Mahsuds.

KatTagRaII (260).-A division of 'Tatta, Bhittanis. Headmen: Shabaz (Kallandar Khel); Saiyid A min, Eazi Khel.

FatTi KHel (10).-A minor fraction of the Saddar Khel, Khoidadai, Maliksbahi, Aimal Khel, Bah!olzai, Mahsuds. Headman : Akbte Jan.

KaZI KHEL.-A minor fraction of Muhammad Khel Isperka, Kalu, Khel, Ahmadzai, Da:wesh Khel, Wazirs. Headman : Pir Muhammad.

Tiemal Krees (12).-A section of the Ali Khel, Khalli Khel, Shaman Khel, Mahsuds. Headman: Mir Alam.

KeMat KHeL (50). - A minor fraction of the Pinzaplara, Abdullai, Aimal Khel, Bahlolzai, Mahsuds.

Kest.-A sub-division of Waraki, Dhana, Bhittanis. Headman: Laisar Khan.

Keadar KheL, - See Mirman Kbel.
KEIDAR KHEL (100).-A section of the Astanai, Shabi Khel, Alizai, Mahsuds. Headman : Mlawal.

KhaDdar KHeI (750; Tochi Valler). - A sub-division of Mohmit Khel,Utmanzai, Darwesh Khel Wazirs. Headmen; see Ali Kbe], Mad Kozai, and Bar Kiozaj.

KHadi (21\%). - A division of Mallirad, Darrars. Headmen: Shah Madi and Janai.

KHADI KHEL (30).-A section of the Bromai, Shabi Khel, Alizai, Mahsuds. Headman : II uhammad, Ayaz.

KHATRAE KHEL.-A minor fraction of Wodin Khel, Khazzar Khel, Ali Khan Khel, Sarki Khel, Madda Khel, lbrahim Khel, Ut. manzai, Darwesh Khel Wazirs.

Khatrae KHeL.-A minor fraction of Pira Khel. Mir Hasani, Macha, Madda Khel, Ibrahim Khel, Utmanzai, Narwesh Khel Wazirs.

KhatrgaN.-A section of Nana Khel, 'Tapiai, Tappizad, Dawars.

KHALE (10) - -A minor fraction of the Sherh Bazid Khel, Isap Khel, Zalli Khel, Bomai, Nasrai, Kalu Khel, Abmadzai, Dorwesh Khel, Wazirs.

Khalif Khel. - A minor fraction of Usman Khel, Takhti Kbel, Bakka Khel, Wali Khel, Utmanzai, Darwesh Khel Wazirs. Headman : Sakam. 
$\mathrm{K}_{H \perp L I} \mathrm{KHEI}$ (40), - $A$ section of the Bangish Khel, Ibrahim Khel Astanai, Shabi Kbel Alizai, Mahsuds.

KнаL KBEL (20).-A minor fraction of the Shahi Khel, Manzar Khel, Aziz Khel Nazar Khel, Aimal Khel, Bahlolzai, MIahsuds.

KHaLIL KHeL. - A minor fraction of Idar Ǩbel, Ali Khel, Khaddar Khel, Nohmit Khel, Utmanzai, Darwesh Khel Wazirs. Headmen : Makhach and Akhmad.

KHaLli KHeL (340).-A division of Lpper Shaman Khel, Mahsuds. Also a division (90) of the Shahpur. Shaman Khel, Mahsuds.

KHAMAR Krex (240).-A section of Gidi Khel, Manzai, Alizai, Mahsuds.

KHANAI KHEL (70).-A fraction of the Karon, Manadi, Shingi, Bablclzai, Mahsuds. Headman: Kandhar.

Khanbeg Khex (Bannu District). - A minor fraction of Tori Khel, Nasa Khel, Hathi Khel, Shin, or Sain, Khel, A.hunadzai, Darwesh Khel Tazirs.

KHan Bibi KHel. - A minor fraction of Khairak Khel, Wodin Khel, Khazzar Khel, Ali Khan Khel, Sarki Kbel, Madda Khel, Ibrahim Khel. Utmanzai, Darmesh Khel Wazirs.
Kraxdar Khax KHex (Bannu District). $-A$ section of Hathi Khel, Shin, or Sain. Khel, Ahuadzai, Darwesh Khel Wazirs. Headmen : Nizam Ḱhan, Landai, Shah Tamoz.

Khavdar Khel. - minor fraction of Paipaii, Kabul Khel, Tali KThel, Utmanzai, Darwesh Khel Vazirs. Headmau: Gulbat.

Khaxd KHEL (80). - A fraction of Zalli Khel, Bomai Khel, Nasrai, Kalu Khel, Ahmadzai, Jarresh Khel Wazirs.

KHAXTI FHEL.-A minor fraction of Maka Khel, Tujisa Khel, Bomi Khel, Nasradin, Kalu Khel, Ahmadzai Darwesh Khel Wazirs.

KHAX KHEL, - A minor fraction of Matzai, Nialik Shahi. Wali Khel, Utmanzai, Darwesh Khel Wazirs.

KHAx Kreu (25).-A section of Khan Khel, Shaji Khel, Alizai, Mlahsuds.

KHAN KHEL (60).-A sub-division of Shabi Khel, Alizai, Mahsuds. Headman: Sukhel.

KHAN KHEL. -A minor fraction of Takhti Khel, Bakka Kihel, Wali Khel, Utmanzai, Darwesh Khel Wazirs. Headmen: Khan Bads!lah, Khazam Khan, Miyan Khel, Gulazamir, Zamma Mir, Mirza, Gul Khatin, and Paidal. 
KHAN KHEL (60).-A fraction of the Kharmanz Khel, Nazar Khel, Aimal Khel, Bablolzai Mahsuds.

KHAN KHEL (2j0), - A fraction of the Garerai, Shumi Khel, Palli Khel, Manzai, Alizai, Mabsuds. Headman : Mir Jamal Khan.

$\mathrm{KH}_{\mathrm{ARE}}$ (90).-A业 section of Tuib Khel, Amzoni, Mallizad, Dawars.

KHARE KHEL.-A minor fraction of Mandi Khel, Mad Khozhai, Khaddar Khel, Mohmit Khel, Utmanzai, Darwesh Khel Wazirs.

KHARMACH KHEL (190),-A fraction of the Shamerai, Palli Khel, Mauzai, Alizai, Mabsuds. Headman : Boshai.

KHaR MaCH or KHaRManz KHeL (24:0). - A section of Nazar Khel, Aimal Krel, Bahlolzai, Mahsuds.

Kharmach KHeL (150).-A subdivision of Shingi, Bablolzai, Mahsuds.

Kenarmanji Khel. - A miror fraction of Madda Khel, Miamai, Kabul Khel, Wali Khel, Utmanzai Darwesh Khel Wazirs. Headman : Gulbat Khan.

KHaRotis $(l, 710$; between Khorasan and India. Their winter camping grounds are situated between Mandra and Paharpur in the Dera Is:nail Khan district).-One of the Ghilzai Pawindah trading clans.
KharRI KHex (70). - A section of the Kilarai, Nana Khel, Pahlolzai, Mahsuds. Headmen: Fateh Mamindar.

KHARSIN (200;Upper Tochi Valley). -A small tribe claiming to be Saiyids from Abyssinia, settled on the northern border of upper Dawar. Headmen : Rahim Gul, Pirgul, and Saidgul. a larger branch of the same tribe resides in Sabarai, a district of Khost, east of Matun.

KHAsons. $-A$ tribe of uncertain nrigin inbabiting the south-east portion of the Khasor range in British Territory.

KHaTaks.-A Pathan tribe belonging to the 'Turko-Iranian group. They are divided into two main branches : the Eastern or Alzora and Western or Teri Khataks. They inkabit the Kohat district.

KHatr KHEL (30).-A minor fraction of the Ghulam Khel, Ali, Kaka Khel, Bomai, Nasrai, Kalu Khel Ahmadzai, Darwesh Khel Wazirs.

KHatex (87).-A section of Taib Khel, Amzoni, Mallizad, Dawars.

KHAUS KHEL (20).- A fraction of the Makhal Khel, Patanai, Shabi Khel, Alizaj, Mahsuds. Headman : Shahzad. 
KABYAZ KHEL (120).-A minor fraction of the Has:an Beg Khel, Utman Khel, Isap Khel, Zulli Khel, Bomai, Nasrai, Kalu $\mathbf{K}$ bel, Ahmadzai, Darwesh Khel Wazirs. Headman : Sherjan.

KHaWAS KHeL (18).-A section of the Haibat Kbel, Nana Khel, Fablolzai, Máhsuds.

KHAWAT KHEL.A section of Tarai Khel, Muia, Waraspun, Bhittanis.

KHAWAZKHAT.-A section of the Ismail, Gulzai, Barak Khatak of Teri in the Bannu District.

Krazzar KHel (480).-A minor fraction of Ali Khan Khel, Sarki Khel, Nadda Khel, Ibrahim Khel, Utmanzai, Darwesh Khel Wazirs. Headmen : Sadda Khan, Alambai, Dande, Zer Nuhammad Khan, Habib, and others.

KHeche.-A sub-division of Pala Khel, Tatta, Bhittanis.

Khiddar Ketel (110).-A section of Astanai, Sbabi Khel, Alizai, Mabsads. Headman: Miawal.

KHidDar KHeL. - A minor fraction of Mehtar Khel, Muhammad Khel, Hasan Khel, Mohmit Khel, Utmanzai, Darwesh K Thel Wazirs.

KHADDI KHEL (25).-A section of Baromai, Shabi Khel, Alizai, Hahsuds.
KHIDRI (100). -A section of Manderi, Idak, 'Jappizad, Dawars. Headman : Saleh Kban.

KHOA KHEL.-A minor fraction of Ali Khel, Manzar Khel, Ibrahim Khel, Utmanzai, Darwesh Khel Wazirs.

KHOIDADaI (240).-A section of Malikshai, Aimal Kñel, Bahlolzai, Mahsuds.

KHOIDAD KHEL (777).-A section of the Gidi Khel, Manzai, Alizai, Mahsuds.

KHosa Kret (Gumatti and Wano).-A minor fraction of Ali Khel, Bomi Kbel, Nasradin, Kalu Khel, Abmadzai, Darwesh Khel Wazirs.

KвлтA KнеL. - A minor fraction of Shoji Tor Khel, Ibrahim Khel, Utmanzai, Darwesh Khel Wazirs. Headmen : Kutanai, Sammat, Landon, A bmad Gul.

КнојА KнеL (20). - A minor fraction of the Karimdad Khel, Abdur Rahrnan Khel, Nana Khel, Bahlolzai, Mahsuds. Headman : Ghulamai.

KнолА KHez. - A minor fraction. of Marsi Khel, Abdul Khel, Bora Khel, Mohmit Khel, Utmanzis, Darwesh Khel Wazirs. Headman : Momazzi. 
KHOJA KHEL. - A'minor fraction of Masti Khel, Tojiya Khel, Bomi Khel, Nasradin, Kalu Khel, Abmadzai, Darwesh Khel Wazirs.

II.tojal Khel (170; Wano).-A minor fraction of Shadai Khel, Nasrai, Kalu Kbel, Ahmadzai, Darwesh Khel Wazirs Headmen: Baghdad, Khidar Khan.

Kнол KHEL (210).-A minor fraction of Bozi Khel, Madda Khel, Ibrahim Khel, Utmanzai, Darwesh Khel Wazirs. Headmen: Namwar and Kor.

荭нолг KHEL(20). - A minor fraction of the Hiral Khel, Chahar Khel, Upper Shaman Khel, Shaman Khel, Mahsuds. Headman : Bilo:.

Ireoj Krel (Bannu District).-A minor fraction of Daulat Khel, Ali Khel, Musa Khel, Hathi Khel, Shin, or Sain, Khel, Ahmadzai, Darwesh Khel Wazirs.

KHоJкаI (50).-A section of Khon Khel, Shabi Khel, Alizai, Mahsuds.

InhojRaI (20).-A section of Shamerai, Manzai, Alizai, Mabsuds.

KhojRaI (60).-A subdivision of Darpa Khel, Mallizad, Dawars. Headman : Shah Husain.

KHONI KHEL. A minor fraction of Dad Khel, Mjr Hasani, Macha, Nadda Khel, Ibrahim Khel, Utmanzai, Darwesh Khel Wazis.
KHRONIA KHEL (140).-A minor fraction of the shodai, Nasrai, Kalu Khel, Ahmadzai, Darwesh Khel Wazirs. Headman: Niazai.

Khojbay Khei.-A minor frac. tion of Shinki Khel, Bibrikai, Hassu Khel, Mallizad, Dawars.

KHUNDA KHeL.-A minor fraction of Warrukai, Idia Thel, Jani Khel, Wali Khel, Utmanzai, Darwesh Khel Wazirs. Headman : Shekh Majid.

Kheni KHeL (2') .- -A minor fraction of the Krarmach Khel, Nazar Khel, Aimal Khel, Bahlolzai, Mabsuds.

Khonifa KHeL (200; Gumatti temporarily). -A minor fraction of Shadi Khel, Nasradin, Kalu Khel, Ahmadzai, Darwesh Khel Wazirs. Headman : Bhittani.

KHUN KHeL (20).-A minor fraction of the Shumi Khel, Palli Khel, Manzai, Alizai, Mahsuds.

KhUShataI (700). - A section of Tori Kbel, I bra'aim Khel, Utmanzai, Darwesh Khel Wazirs. Headmen: Ghazim Shah, Tawanir, Mattigai, and Salom.

KHWaJA AHMad KHEL (45).-A minor fraction of Ali Khan Khel, Sarki Khel, Madda Khel, Ibrabim Khel, Utmanzai, Darwesh Khel Wazirs. 
KhwaJA Dere KHaN.-A migor fraction of Idia Khel, Jani Khel, Wali Khel, Utmanzai, Darwesh Khel Wazirs. Headmau : Mir Bir Birjan.

KHWAJA KHEL.-A minor fraction of Miamai, Kabul Khel, Wali Khel, Utmanzai, Darwesh Khel Wazirs. Headmen : Surkam and Gulbat Khan, Mehr Ali.

KHWAJA NIADI $_{\text {A }}(70)$. - A minor fraction of Gangi Thel, Bomai, Nasrai, Kìlu Khel, Abmadzai, Darwesh Khel Wazirs. Headman: Khakim.

$\mathrm{KHWAS} \mathrm{KHEL}$-A mincr fraction of Madda Khel, Miamai, Kabul Khel, Wali Khel, Utmanzai, Darwesh Khel Wazirs.

KHWAZI KHEL (10).-A minor fraction of the Sandra Khel, Shami Khel, Jalal Khel, Nana Khel, Bahlolzai, Mahsuds.

KImaRaI (150). -A sub-division of Nana Khel, Bahlolzai, Mabsuds. Headman : Fateh Khan.

KIn⿴ar (105).-A section of Datti Khel, Galeshahi, Shaman Khel, Mahsuds. Headmen : Id Akbar, Sawan, Amzun, Saifal. KinI KHEL-A section of Mallizad, Darars. Headman : Atim Khan.
Kimar KHel (140). - A sub-divrsion of Haidar Khel, Tappizad, Dawars. Headman : Nasar Khan.

KiMat KHEL (20). - A minor fraction of the Pinzo, PlarajAbdullai, Aimal Khel, Bahlolzai, Mahsuds. Headman : Kalam Din.

KINI KHEL.-A sub-division of Khaddi, Mallizad, Dawars.

KIRA KHEL (60). -A section of the Malik Dinai, Manzsi, Alizai, Mabsuds.

KIRCH KHEL.-A section of Hakim Khel, Mubarak Shahi, Mallizad, Dawars.

KissadiN KHeL (40). - A minor fraction of Salimi $K$ hel, Dachi Khel, Palli Khel, Manzai, Alizai Mahsuds.

Kiz Parez KHel.-A section of Tapiai, 'Tappizad, Dawars.

KODA KHEL. - A minor fraction of Muhammad Khel, Isperisa, Kalu Khel, Alimadzai, Darwesh Khel Wazirs. Headmen: Wasila Khan, Bakhtamir, and Jan.

KOI KHEL (15).-A section of Malla Khel, Chahar Khel, Shamau Khel, Mabsuds.

Kotar KHeI (160).-A minor fraction of the Abdul Khel, Langar Khel, Khoidad Khel, Gidi Khel, Manzai, Alizai, Mahsuds. 
KUKI, or RAHMAז, KHEL.-A minor fraction of Manaka Bakhshi Khel, Madda Khel, Ibrahim Khel, Utmanzai, Darwesh Khel Wazirs.

KuLI KHeL (20). - A minor fraction of the Shiraz Khel, JalaKbel, Nana Khel, Bahlolzail Mahsuds.

IKENDAI.-A minor fraction of $J_{\text {an- }}$ beg Khel, Ali Khan Khel, Sarki Khel, Madda Khel, I brahim Khel, Utmanzai, Darwesh Khel Wazirs.

KONDAI. - A minor fraction of Tor Khel, Umarzai,Shin, or Sain, Khel, Ahmadzai, Darwesh Khel Wazirs. Headmen : Niazi, Fazal, Zaid Gal, Ghallai.

KUNDAI.-A minor fraction of Bizen Khel, Shadi Khel, Nasradin, Kalu Khel, Ahmadzai, Darwesh Khel Wazirs. Headman : Jalal Khan.

KUNDEZAr (30). 一A minor fraction of the Hassan Beg, Utman Kihel, Isap Khel, Zalli Khel, Bomai Nasrai, Kalu Khel, Ahmadzai, Darwesh Khel Wazirs, Headman: Pir Khan.

KONDI.-A minor fraction of Su\}.m Khel. Isperka Kal a Khel, Ahmadzai, Darwesh Khel Wazirs. Headmen : Pirdost and 'Taib Khan.

KUNDr (Bannu District).-A minor fraction of Pirba Khel, Hatbi Khel, Shin, or Sain, Khel, Abmad- zai, Darwesh Khel $W_{\text {azirs. Head- }}$ man : Dangir Khan.

KCNDIS (200 ; Mandra, north-west of Dera Ismail Khan District).One of the lesser Pawindah trading tribes. They are divided as follows :-Acha Kbel, Clargul, Mala Khel. Headmen: see above clans.

KURESH (i0). - A minor fraction of the Mixed Khel, Michi Khel, Shumi Khel, Palli Khel, ManzaiAlizai, Mabsads.

KᄃRWAT - A section of Taib Kbel, Amzoni, Mallizad, Dawars.

KटTAB KHel.-A section of the Badzai, Kattagram, Tatta, Bhittanis.

KUTAв KHeL.-A minor fraction of Balla Khel, Shadi Khel, Bora Khel, Mohmit Khel, Utmanzai, Darwesh Khel Wazirs.

KUTAR KHEL.-A minor fracticn of Hindi Khel, Tor, Jani Khel, Wali Khel, Utmanzai, Darwesh Khel Wazirs. Headmen : P'ir Makhmad and Khushal.

KUTTI KHEL.-A minor fraction of Mir Ali Kbel, Iảia Khe], Jani Khe\}, Wali Khel, Ưtmanzai, Darwesh Khel Wauirs. Headman : Gul Ghafar.

KUtmi KHeL. A section of Nawnr Khel, Miran Shah, Tappizad, Dawars. 
LADDA5. - A section of Tareta Idak, Tappizad, Dawars.

LADDI KHeL (30).-A minor fraction of the Nelzan Khel, Nana Khel, Bahlolzai Nahsuds. Headman: Draz Khan.

$L_{A D I}$ KHEL. $-A$ sub-dirision of Mlusakki, UJallizad Dawars. Headman : Vilband.

LAD THEL. A minor fraction of Khan Khel, Takhti Khel, Bakka Thel, Wali Khei, Jtmanzai, Darwesh Khel Wazirs. Headman : Traridin.

Lighar (or Dodi) Kael.-A minor fraction of Khazzar Khel, Ali Ǩhan Khel, Sarki Khel, Madda Thel, Ibrahim Khel, Utmanzai, Darwesh Kinel ivazirs.

LAIQ KHEL. - A minor fraction of Mira Khel, MIad Khozhai, Khaddar Khel, Jlohmit Khel, Utmanzai, Darresh Khel Wazirs. Headman : Sanobar.

Latar KHel. - A sub-division of Khaddi, Nallizad, Dawars.

L.ALI KHEL.-A minor fraction of the Raji Kbel, Rahimdad Khel, Abdurrahman Khel, Nana Khel, Bah!olzai, Mahsuds. Headman: Gandapir,
LALI KHEL. - A minor fraction of $\tilde{T}_{0} l$ Khel, Abdul Khel, Bora Khel, Mohmit Khel, Utmanzai, Darwesh Khel Wazirs.

LALI KHEL (160). - A section of Abdullai, Aimal Khel, Bahlolzai, Mahsuds. Headman : Fazil.

LAIIA KHEL (British territorr). A minor fraction of Painda Kbel, Shadi Khel, Nasradin, Kalu Khel, Ahmadzai, Darwesh Khel Wazirs. Headmen: Gulbaz and Sawan.

Lamar. - A section of Kesu, Waruki, Dhana, Bhittanis.

Lama Khel. - A section of Maryam Khel, Darpa Khel, Mallizad, Dawars. Headman: Mire.

LAND.-A sub-division of Urmuz, Mallizad, Dawars.

LAND.-One of the principal dirisions of the Barak Khataks inhabiting the plain portion of the Iiobat district.

LAND (300).-A sub-division of Malakh, Mallizad, Dawars. Headmen : Nazar Din and Akib.

LANDI KHEL (40).-A section of the Saddan Khel, Khoedadi, Malikshahi, Aimal Khel, Bahlo!zai, Mahruds. 
LANDI KHEL, - A minor fraction of Janbeg Khel Ali Khan Khel, Sarki Khel, Madda Khel, Ibrahim Khel, Utmanzai, Darwesh Khel Wazirs.

LANDI KHEL.-A minor fraction of Alikhani, Bomi Khel, Nasradin, Kalu Khel, Ahmadzai, Darwesh Khel Wazirs.

LANDI KHEL. - A minor fraction of Saigid Khel, Umarzai, Shin, or Sain, Khel, Ahmadzai, Darwesh Khel Wazirs.

LANDI KHEL (14).-A section of the Ali Khel, Khalli Khel, Shaman Khel, Mahsuds.

LANGar KHEL (80).-A section of the Khoidadi, Malik Shahi, Aimal Khel, Bahlolzai, Mahsuds. Headman : Bitai.

LANGAR KHEL.-A minor fraction of Aziz Khel, Shadi Khel, Bora Khel, II ohmit Khe, Utmanzai, Darwesh Khel Wazirs.

LANGAR KHEL (650).-A section of the Gidi Khel, Manzai, Alizai, Mahsuds. Headmen: Muhammad Afzul and Badr Din.

LANGAR KHEL.-A minor fraction of Masti Khel, Tojiya Khel, Bomi Khel, Nasradin, Kalu Khel, Ahmadzai, Darwesh Khel Wazirs.

LANGI KHEL. - A division of Kharoti, Ghilzai Pawindahs. Headman : Ataga, Musa $\mathbf{K}$ han.
LAR LoRAI.-A section of Land, Malakh, Mallizad, Darrars. Headmen : Nazirdin, Akib, Balyain.

LASHKARI. - A section of Utman Miram Shah, Tappizad Dawars.

LAWAL KHEL.-A minor fraction of Idar Khel, Ali Khel, Khaddar Khel, Mohmit Khel, Utmanza i, Darwesh Trhel Wazirs.

Lati $K_{H}$ L (100). - A minor frac. tion of the Makhi Khel, Janas, Karim Khel, Ali, Kalia Khel, Bomai, Nasrai, Kalu Khel, Ahmadzai, Darwesh Khel. Wazirs. Headman : Badshah Khan.

LatKI KHEL.-A minor fraction of Marsi Khel, Abdul Khel, Bora Khel, Mohmit Khel, Utmanzai, Darwesh Khel Wazirs.

LAOS or Lios KHeL (60). - A section of the Ozbakai, Shingi, Bahlolzai, Mahsuds. Headman: Balai i.

LEKHI KHEL (90). -A section of the Umar Khel, Astanai, Shabi Khel, Mahsuds. Headman: Alif Khan.

LEWA KHEL - A minor fraction of Umar 登hel, Sada Khel, Sperkai, Kalu Khel, Ahmadzaj, Darwesh Khel Wazirs.

LIWANNI KHEL.-A minor fraction of Pai Khel, Mubammad Khel, Malatsh, Mallizad, Dawars. 


\section{0}

LOCHI KHEL -A minor fraction of Dosalli, Wuzi Khel, Mohmit Khel, Utmanzai, Darwesh Khel Wazirs.

LoHaxa or LoHant. - A term often loosely applied to all Porrindah claus. Correctly speaking it is held to apply only to those clans that are descended from Nuharnae, or Luhanae, great grandson of Ibrahim (Loedai) and brother to Ghalzoe, the su pposed ancestor of the Ghilzais.

LOIIA KHBL.-A miror fraction of Mrusakki, Wuzi Khel, Mohmit Khel, Ctmanzai, Narwesh Khel Wazirs. Heaảman: Kaloni.

LoLI KKHBL (70). - A minor fraction of the $\mathbf{M l a k h i}$ Khel, Janas.
Karim Khel, Ali , Kalia Khel Bomai, Nasrai, Kalu Khel, Ahmadzai, Darwesh Khei Waziris. Headman : Janai.

Ions.-A division of Mlian Khel Lohana Pawindahs.

LUDANA. - A minor fraction of Nlanzur Khel, Tor Khel, Umarzai: Shin, or Sain, Khel, Abmadzai, Darwesh Khel Wazirs. Headman : Alam Khan.

LU $\mathrm{K}$ US $\mathrm{N}$ HeL. - A minor fraction of Karim Ǩhel, Jamal Knhel, Malik Shahi, Wali Khel, Utmanzai, Darwesh Khel Wazirs.

Lenc.-A section of Taib Khel, Amzoni, Mallizad, Dawars.
MICHa (900). - A section of Madda Khel, Ibrahim Khel, Utmanzai, Darwesh Khel Wazir. Headmen: Ware Khan, Raja, Gulrez, Mashagal, Shekar.

$\mathrm{BraCHA} \mathrm{KHEL}$ - A minor fraction of Sir Shodivalai, Bomi Khel, Nasradin, Kilu Khel, Ahmadzai, Darwesh Khel Wazirs.

MACHI KHEL. - A section of Bor: Khel, Nohmit JShel, Utmanzii Darresh Khel Wazirs. Headmen : Abdurraliman and Nabot.
MaCHI KHEL (640). - The largeat and most iwportant minor fraction of the Shumi Khel, Palli Khel, Manzzi, Alizai, MIahsud:. Headmen: Shah Salim, Khraja Jl ubammad Khan.

1 ${ }_{A C H I} \mathrm{KHBL}_{\text {H. }}-\mathrm{A}$ minor fraction of Mlasti Khel, Tojiya Khel, Fomi Khel, Nasradin, Kalu Khel Ahmadzai, Darwesh Kbel Wazirs.

Mradar KHel.-A clan of Dautani Pawindahs. Headman: Ghulam Haidar. 


\section{1}

Madda Khel (3,500; Tochi and Sharal valleys).-A sub-àivision of the Ibrabim Khel, Utmanzaj, Darwesh Khel Wazirs. Headmen : see Sarki Khel, Rakhshi Khel, Bozi Khel, Mächa, Khazzar Khel.

MADDA $K_{H E L}(25) .-A$ minor fraction of the Jalal Din, Shekh Bazid Khel, Isap Khel, Zalli Khel, Bomai, Nasrai, Kalu Khel, Ahmadzai, Darwesh Khel Wazirs. Headman: Tila Khan.

$M_{\triangle D D A} K_{H E L}-\mathrm{A}$ minor fraction of Miamai, Kabul Khel, Wali Khel, Utmanzai, Darwesh Khel Wazirs. Headman : Mezhai.

$M_{\triangle D D A} \mathrm{KHEL}(40)$. - A minor fraction of the Salimi Khel, Dachi Khel, Palli Khel, Manzai, Alizai, Mahsuds.

$M_{A D D A} K_{H E L}(30)$. - A minor fraction of the Maka Khel, Malli Thel, Shekh Hassen, Taji Khel, Bomai, Nasrai, Ahmadzai, Darwesh Khel Wazirs. Headman: Pir Afzal.

MADDI KHEL.-A ninor fraction of Haibatai, Tori Khel, Ibrahim Khel, Utmanzai. Darwesh Khel Wazirs. Headman : Mabammad Atbar.

$\mathrm{M}_{A D D J} K_{\text {GEL }}(34)$. - A section of Zarri Khel, Chahar Khel, Shaman Khel, Mahsuds.

MADI KHEL and Dor.-A minor fraction of Bizen Khel, Shadi Khel, Nasradin, Kalu Khel,
Abmadzai, Darwesh KLel Wazirs. Headman: Gal Adam.

$\mathrm{M}_{A D T} \mathrm{KHEI}$ - A miner fraction of Aziz Khel, Shadi Khel, Bora Khel, Mohmit Khel, Utmanzai, Darwesh Khel Wazirs. Headman: Gulami.

M $\triangle D I$ KHeL (Bannd District),-A minor fraction of Jiraki, Pirba Khel, Hathi Khel, Shin, or Sain, Khel, Ahmadzai, Darwesh Khel Wazirs. Headman : Musharrab Khan.

MADI KHEL - A sub-section of Malik Khel, Miri Khel, Land, Malakh, Mallizad, Dawars.

Mad KHozar.-A section of Khaddar Khel, Mohmit Khel. Utmanzai, Darwesh Khel Wazirs Headmen: Sanobar, Amzalla, Wayulli, Watanai, Rakhim Shab, Pir Muhammad.

MaghaL KHEL.-A section of Shadi Khel, Bobak, Dhana, Bhittanis.

MAGHZAI.-A section of Tarai Thel Muia. Waraspun, Bhittanis. Heado men: Raza Khan, Mian Khel.

MaGi KHeL.-A minor fraction of Malik Khol, Kalia Khel, Bomi Khel, Nasradin, Kalu Khel Ahmadzai, Darwesh Khel, Wazirs.

MaHMOD KHeL.-A division of Suleman Khel, Ghilzai Pawirdahs. 
MaAsed or MAHSED WAZIBS $(11,400)$.- An important tribe of Pathans, occupying the hills north of the Ganal Pass. They ure an extremely barbarous and warlike tribe, of the same origin as the Darwesh Khel Wazirs.

IIAI KHEI. (Winter camping ground, Kalagarh in the lera Ismail $\mathrm{E}$ han district.)-A clan of Niazi Parrindahs. Headman : Sadar.

Mati KHEL (120).-A minor fraction of Malli Khel, Tazi Khei, Bomai, Nasrai, Kalu Thel, Ahmadzai, Darwesh Khel Wazirs.

MAKHAL - A minor fraction of the Kimat Ehel, Haidar Khel, Tappizad, Dawars.

Makhal ThHel (50).-A section of the Patanai, shabi Khel, Alizai II absads. Headman: Shahzad.

Mahiax Khel.-A minor fraction of Jad Khel, Mir Hasani, Mracha, Iradda Thel, Ibrahim Khel, Utmanzai, Darwesh Khel Wazirs.

MAEHI.-A minor fraction of Ipi, Haidar Kel, Tappizad, Daw. ars.

MIAKI (260). - A minor fraction of the Janas, Karim Khel, Ali, Kaks Khel, Pomai, Nasrai, Kalu
Khel, Ahmadari, Earwesh Khel Wazirs. Headman: Padshah Khan.

MaKHI KHEL (160).-A fraction of the Wrzirgai, Gidi Khel, Manzai, Alizai Mahsuds. Headwen : Amar Din.

Malar or MIal Kabl (390'-A sub-section of the Dachi Khel Palli Khel, Manzai, Alizai Mahsuds. Headman: Mehr Lil.

MIALAI (294).-A sub-division of Shingi, Bahlolzai, Mahsuds.

MaLA KHEL (40*).- A small colony of Hamsayas of the Bhittanis living near the Larzan Pass. Headmen: Zafar Khan, Fateh Khan.

MaLA KHEL.-See Mala Kbel.

M $A$ I A KEEL - A clan of the small tribe of Kundi Pawindahs. Headmen: Amir Khan and Gana Khan.

MALAK KHEL.-A minor fraction of Taos Khel. Sogi Khel, Mnhammad Khel, Malakh, Mallizad, Dawars.

MALAK KHEL. - A minor fraction of Sikandar Khel, Abdul Khel, Bora Khe!, Mohmit Khel, Utmanzai, Darwesh Khel Wazirs. 


\section{3}

MataNg KHeL (80).-A minor fraction of Torang Khel, Lalli Khel, Abdullai, Aimal Khel, Bahiolzai Mahsuds.

Malifdad Krel (20). - $\Lambda$ minor fraction of the Pirdad Kbel, Abdurrahman Khel, Nana Khel, Bahlolzai, Nahsuds. Headman: Mawi.

Malte Dinai (190).-A sub-dirision of Manzai, Alizai, Mabsuds. Headman : Kasim Gul.

MALIK KHEL.-A minor fraction of Miri Khel, Land, Malakh Mallizad, Dawars.

Marih KHEL (60).-A section of Kaka Khel, Bowai Khel, Nasrai Kalu Kbel, Ahmadzai, Darwesh Khel, Wazirs.

M AIIESHAHI (480).-A sub-division of dimal Ḱbel, Bablolzai, Mahsuds.

MaLIE SHAHI (4to; Siah Koh and Kurram). - Nomadic, a small subdivision of Wali Khel, Utmanzai, Darwesh Khel Wazirs. Head. men :Marot, Babri, and Ghaffar.

MaIIK SHaHI. - A section of Jani Khel, Wali Khel, Utmanzai, Darwesh Khel Wazirs. Hoadmen : Pawindah Khan, Piyao Khan, Sabib Gul.

MatLaEH $(1,000)$.- One of the eight divisions of Mallizad, Dawars. Headmen: see Char- khel, Miri Thbel, Lar Lorai, A bdul Rahman Khel, Gita Khel, Kriki Khel, Sogi Khel, Idal Khel, Paj Khel, Piran Dangar Ḱbel, Oji Khel.

MaLl: Krel (3I).-A sub-division of Chaha Khel, Shaman Khel, Mahsuds.

$\mathrm{M}_{\triangle \mathrm{LLI}}$ KeEL (18).-A minor fraction of Yir Muhammad! Khel, Haidrai, Chahar Khel, Shaman Khel, MIahsuds.

MALLI KHEL. - A sub-division of Idak, Tappizad, Dawars. Headmen: Walli Hueain and Mir Salali.

MaLI KHEL (300).-A fraction of the Stekh Hassan, 'Paji Khel, Bornai, Nasrai, Kalu Khel, Abmadzai, Darwesh Khel Wazirs. Headmen : Salim Khan and Mirza Gul.

MalitZad (4,008).-One of the two main clans (viz., Tappizad and MIallizad) of Dawars. Headmen : see Mallakh, Amzoni,Darpa Krel, Mubarak Shabi, Khaddi, Zerrakk Argund Muskli, Hakim Kkel, Hasan Khel.

MaMADI (30).-A minor fraction of the Janas, Kerim Khel, Ali, Kaka Khel, Bomai, Nasrai, Kalu Khe!, Ahwadzai, Darwesh Khel Wazirs. Headman : Juma Kuan.

MaMa KHeL.-A section of Malli Khel, Idak, 'lappizad, Dawars. Headwan: Mir Salak. 
MAMA KHEL.-A section of Tareta, Idak, Tappizad. Dawars.

MAMA KERL (50). - A minor fraction of the Gbulam Khel, Ali, Kaka Khel, Bomai, Nasrai, Kalu Kbel, A hmadzai, Darwesh Khel Wazir's.

MaMaL KHEL (20). - A minor fraction of the Darai, Chahar Khel, Upper Shawan Khel, Shaman Khel, Mahsuds. Headman : Babawal.

NI AMANZI (16; Dera Ismail Khan District).--Nomadec, a minor fraction of Musazai, Sein Khel, Mian Khel, Lohana, Pawindahs.

MAMARAS KHEL (17).-A section of the Kikarai, Nana Khel, Bahlolzai, Mahsude.

AraMdaI or MaMADAI (280).-A sub-division of Shingi, Bahlolzai, Mahsuds.

Namia KHel (30)-A minor traction of Kharmarz $\mathbf{K}$ hel, Nazar Khel, Aimal Khel, Bablolzai, Mahsuds. Headman: Amir Shadai.

Mami or Mamia Khel (150).-A sub-division of the Shingi, Bahlolzai, Mahsuds. Headmen : Rahimdad, Gulpir, Mubammad Ali.

$M_{\triangle M I T} K_{H E L}(110),-A$ minor fraction of Machi Khel, Shumi
Khel Palli Khel, Manzai, Alizai Mahsuds. Headman : Jim.

Mamit KHeL.-A sub-division of Umar Khel, I'atta, Bhittanis. Headman : Fateh Khan.

Mamrez Khel (Bannu District). -A minor fraction of Barim Khel, Khandar Khan Khel, Hathi Khel, Shin, or Sain, Khel, Ahmadzai, Larwesh Khel Wazirs. Headman : Shah Tamoz.

MaMrez KHEL (Winter camping ground, Mandra in the Dera Ismail Khan district). -A clan of Niazi Pawindahs. Headman : Haji Habibulla Khan.

MaMU KHEL-A minor fraction of Malik Shahi, Jani Khel, Wali Khel, Utmanzai, Marwesh Khel Wazirs. Headman : Powindah Khan.

Manaka.-A minor fraction of Bakhshi Khel, Madda Khel, Ibra* him Khel, Utmanzai, Darwesh Khel Wazir's.

MaNdan.-One of the principal divisions of the Barak Khataks inbabiting the Teri valley in British territory.

MANDAN.-A suh-division of the Gulzai, Barak Khataks of 'leri in the Bannu district.

Mandar Khel.-A sub-division of Isut Khel, Mian Khel, Lohana, Pawindahs. 
Manderi (460).-A sub-division of the Idak, Tappizad, Dawars. Headmen : Salib Kban, Nazarband, Bakht Jamal.

M $\triangle N D I$ KHEL. - A minor fraction of sadda Khel, Isperka, Kalu Khel, Ahmadzai, Darwesh Khel Wazirs.

Mandr KHeL.-A section of Wuzi Khel, Mohmit Khel, Otmanzai, Darwesh Khel Wazirs. Headwan : Dig.

MANDI KeEL.-A minor fraction of Mad Khozhai, nhaddar Khel, Mohmit Khel, Utmanzai, Darwesh Khel Wazirs. Heaumen : Amzalla, Wagulli.

MANDI KHEL-A section of Chaplai, Muia, Waraspun, Bhittinis. Headman: Daulat.

MANDI KHEL. - A section of Nana Khel, Tapiai, Iappizad, Dawars.

MANGAT KHEL.-A minor fraction of Sardi Khel, Bakka Khel, Wali Kbel, Utmanzai, Darwesh Khel Wazirs. Headman : Mauladad Khan.

Mangi KHel (90).-A fraction of Baba Khel, Galeshahi, Upper Shaman Khel, Mahsuds. Headmen : Shamdai .

MANJ $\triangle R$ KHeI.-A sub-division of Dand Khel, Nasar, Ghilzai Pawindahs. Headman: Mamat.
MansarI (20).-A fraction of the Sibandar Khel, Badiwai, Khalli Kbel, Upper Shaman Khel, Shaman Khel, Mahsuds. Headman: Saidak.

$\mathrm{M}_{\triangle \mathrm{NSOM}} \mathrm{KHEL}$ (Bannu District).A minor fraction of Barmi Khel, Khandar Khan Khel, Hathi Khel, Shin, or Sain, Khel, Ahmadzai, Darwesh Khel Wazirs. Headman: Rakhmal.

MaNzat.-A division of the Barak Khataks living near Teri in the Banuu District.

M two divisions of Alizai, Mahsuds.

$\mathrm{M}_{\mathrm{ANZARI}}$ KHEA.-A minor fraction of Mitha Khel, Badiwai, Khalli Khel, Shaman Khel, Mahsuds.

Manzar KHEL (120).-A minor fraction of the Aziz Khel, Nazar Khel, Aimal Khel, Bahlolzai; Mahsuds. Headmen: Maman, Kadir Shah.

Manzar KheL (500; Tochi and Khaisora).-A sub-division of Ibrahim Khel, Utmanzai,Darwes h Khel Wazirs. Headmen : see Ali Khel, Dalatan Khel, and Si andar Khel.

MaNzor KHEL, - A minor fraction of Tor Khel, Umarzai, Shin, or Sain, Khel, Ahmadzai, Darwesh Khel, Wazirs. Headmen : Jamal Din, Adal Khan, Alam Khan, Senian. 
II ABAMr KHeL (30). - A minor fraction of the Hassen Beg Khel, Ctman Kbel, Isop Khel, Zalli Khel, Bomai, Nasrai, Kalı Khel, Ahmadzai, Darwesh Khel Wazirs. Headran: Pir Khan.

Maresar (40).-A section of the Garrarai, Shumi KThel, Palli Trhel, Manzai, Alizai, II absuds. Headman : Asti.

MaRI KHEL (30). - A minor section of the Nomin Khel, Hanzar Khel, Aziz Khel, Nazar Khel, Aimal Khe], Bahlolzai Mahsuds.

MAREI KHEL (80) - A section of Matti Khel, Galeshabi, Shaman Kihel, Mahsuds. Headmen : Azam, Shah Zaman.

II ROBI (110).-A section of Sultanai, Shabi Khel, Alizai, Mahsuds. Headman : the MIulia Pawinliah, Kaisar K han.

MIROR KHEL - A minor fraction of Pira Khel, Jamal Ehel, Malik Shahi, Wali Khel, Utmanzai, Darwesh Khel Wazirs.

$I_{\triangle R S A I}(30)$. - A minor fraction of the Garerai, Shumi Khel, Palli Khel, MIanzai, Alizai, Mahsuds.

Inassk. - $\lambda$ division of Kharoti, Ghilzai Pawindahs. Headman : Baba.

MARSI KHEL. - A minor fraction of Abdul Khel, Bora Khel, Ifohmit Khel, Utmanzai, Darwesh Khel Wazirs. Headman: Momazzi.
MAREF KHEL.-A sub-dirision of Wargara, Dhana, Bhittanis.

Marya KHeL.-A sub-division. of Darpa Khel, Mallizad, Dawars Head man : Mirai.

Martan KHet (3อ๊.--A section of Ghalib Khel, Badanzai, Shaman Khel, Mahsuds.

MIAWATS.-A branch of the Pathan tribe of Lodi. Their. principal divisions are the Musa Khel, Achu Kbel, Khuda Khel Bahram, Tappi. They inbabit the south-eastern portion of the Bannu district.

Masha Khel (25; Dera Ismail Khan District). -Nomadic, a sub-division of Sen Khel, Mian Khel, Lohana Pawindahs.

Mashangar.-A minor fraction of Sir Shodizyakai, Bomi Khel, Nasradin, Kalu Khel, Alumadzai, Darwesh Khel Wazirs.

Mashi KHan. - A section of the Ismail, Gulzai, Barak Khataks of Teri in the Bannu district.

MasSar KHex (50). - A sub-division of Boba, Dhana, Bhittanis.

Masti KHel (20). - A minor section of the Boyi Khel, Mamadis, Shingi, Bahlolzai, Mahsuds.

MASTI KHEL. - A minor fraction of Karmandi Khel, Khwaja Khel, Miamai, Kabul Kbel, Wali Khel, Utmanzai, Darwesh $\mathrm{K}$ hel Wazirs. Headman : Mikr Ali. 


\section{7}

Masti Khel (350). - A fraction of liomai, Nasrai, Kalu Khel, Ahmadzai, Darwesh Khel Wazairs. Headman : Shergul.

Masti Khen alias Birmast Khel. -A section of 'Turak Khel, Shakhai, Waraspun, Bhittanis. Headman: Mahomed.

Matr KHel. - A minor fraction of Dreplarai, Sarki Khel. Madda Khel, Ibrahim Khel, Utmanzai, Darwesh Khel Wazirs.

MatiwaL (45 ; Dera Ismail Khan District).-Nomadic. a section of Waruki, Sen Khel, Mian Khel, Lohana Powindahs.

MatraI.-A section of Malik Shahi, Wali Khel, Utmanzai, Darrvesb Khel Wazirs. Headmen : 'Torabas, Marota, Pirwal, Umar Kbel, Achegul and Negham.

Mat Krel (140), - A sub-division of Galeshahi, Upper Shaman Khel Mahsuds. Headman : Motabar.

$M_{\text {तULI I KHEL (30). - A minor }}$ fraction of Sharri Khel, Kasim Khel, Chahar Khel, Shaman Khel, Mahsuds.

MaWar KHel (20). - A minor fraction of the Kamal Din, Shekb Bazid Khel, Isap Khel, Zalli Khel, Bomai, Nasrai, Kalu Khel, Ahmadzai, Darwesh Khe] Wazirs. Headman : Banocha.

MATAN KHEL.-A minor fraction of Dod Khel, Mir Hasani, Macha, Madda Khel, Ibrahim Khel, Utmanzai, Dar'wesh Khel Viazirs.
Maycb KHer.-A minor fraction of Saadat Khel, Dreplarai, Sarki Khel, Nadda Khel, Ibrabimzai, Darwesh Khel Wazirs.

Mehtar Kinel. - A minor fraction of Muhammad Khel, Hasan Khel, Mohmit Krhel, Utmanzai, Darwesh Khel Wazirs.

Mewa Krel (25).-A section of Palali, Tapiai, Tappizar Dawars.

Miagr Krel (60).-A minor fraction of the Walid Khel, Wal Khel Dachi Khel, Palli Khe!, Manzai Alizai, Mabsuds.

Mraki Keel (15).-A rainor fraction of the Jala! Din, Shekh Bazid Khel, Isap Khel, Izh i Khel, Bomai, Nasrai, Kralu Khel, Ahmadzai, Darwesh Khel Wazirs. Headman : Tila Than.

MiamaI.-A section of Kabul Khel, Wali Khel, Utmanzai, Darwesh Thel Wazirs. Headmen: Gulbat Khan and Mad Alam.

MIANDAK KHEL - A minor fraction of Miandi Khel, (Langi), Mad Khozhai, Khaddar Khel, Mohmit Khel, Utmanzai, Darwesh Ǩluel Wazirs. Headman : Wagali.

Mian Gul Khel (Bannu Distriot). -A minor fraction of Kiundi, Pirba Khel, Hathi Khel, Shin, or Sain, Khel, Ahmadzai, Darwesh Kbel Wazirs. Headmen : Muin Shah and Jinas K̄han. 
Miax KH RL.-A minor fraction of Bora Khoezai, Khaddar Khel, Motmit Khel, Ctmanzai, Darwesh Khel Fazirs. Headman: Garrarai.

Misnr.-A section of Dreplara; Shakhi, Waraspun, Bhittanis.

Mraxib Khel (60).-A minor fraction of the Walidad Khel, Lalli Khel, Abdullai, Aimal Khel, Bahlolzai, Mrhsuds. Headman: Saleh Shab.

Mraxis (390 ; Gumal Winter cainping grounds near Pata and Hathala in the Dera Ismail Khan district).-One of the lesser Pawindah trading tribes. Headmen: Ghulam, Ustura, and 'Tur.

Miax Khay KHeI (Bannu Distriet).-A miner fraction of Jiraki, Firba Khel, Hathi Khel, Shin, or Sain. Khel, Ahmadzai, Darwesh Khel Wazirs. Headman : Gulbagh.

MiAN KHEL (80).-A minor fraction of Bizodi, Malikshahi, Aimal Khel, Hahlolzai, Mabsuds. Headman : Khatkai.

MIAN KHEL (1,400; Ghazni and Derajat). - A clan of the Lohana Pawindahs. Headman : Mir Alam Khan.

Misnwali.-A minor fraction of Dod Khel, Mir Hasani, Macha Madda Khel, Ibrahim Khel, Ut. manzai, Darwesh Khel Wazirs.
MICHAN KHEL.-Practically identical with the Marwats in British territory.

MrCHaN KHEL.-One of the lesser Pawindah trading clans. 'l'hey have no separate $K$ irrois of their own but are found living with other Pawindahs.

MIHR KHAN KHEL.-A minor fraction of Balli Khel, shadi Khel, Bora Khel, Mohmit Khel Utmanzai, Darwesh Khel Wazirs. Headman: Kippat Khan.

MINA KHEL(10).-A minor fraction of Sikandar Khel, Badiwai, Khall Khel, Sbaman Khel, Mahsuds. Headman : Madakki.

MINA KHEL.-A minor fraction of Malik Shahi, Jani Khel, Wali Khel, Utmanzai, Darwesh Khel Wazirs. Headman : Piyao Khan.

MiNd KHEL.-A section of Gurbuzai, Darpa Khel, Mallizad, Dawars. Headmen: Shahzada (Shadi Khel).

MiNGI KHBL(20).-A minor section of the Shabi Khel, Manzar Khel, Aziz Khel, Nazar Khel, Aimal Khel, Bahlolzai, Mahsuds.

MIRA KHEL (60). - A minor fraction of Ali Khel, Shogai, Tori Khel, Ibrahim Khel, Otmanzai, Darwesb Khel Warirs.

MiRA KHEL.-A minor fraction of Balli Khel, Shadi Khel, Bora Khel, Mohmit Khel, Utmanzai, Darwesh Khel Wazirs. 
Mira KHel.-A minor fraction of Mad Khozhai, Khaddar Khel, Mohmit Khel, Utmanzai, Darwesh Khel IVazirs, Headmen: Watanrai, Sanobar. Rabhim Shah.

Mira KHEL (10).-A minor fraction of Charkhil, Land, Malakh, Mallizad, Dawars.

MiRa KHEL (20), -A section of the Birri Khel, Galishahi, Upper Shaman Khel, shaman Khel, Mahsuds. Headman : Muhammad Anir Khan.

Mir Alar.-A minor fraction of Dreplarai, 'Tori Khel, Ibrahim Khel, Utmanzai, Darwesh Khel Wazirs.

Mir Ali KHec.-A minor fraction of Idia Khel, Jani Khel, Wali Khel, Utmanzai, Darwosh Khel Vazirs. Headmen: Zarghun Shah, Gul Ghafar, Akaldin.

Mirax KHer.-A section of Zhao Khel, Tapiz̄i, Tappizad, Dawars.

Miram Shat (179).--A division of Tappizad, Dawars. Headmen : akar, Mongul, Sharop, Mir Khitab.

Miran KHel.-A minor fraction of Karim Khel, Jamal Khel, Malik Shahi, Wali Khel, Utmanzai, Darwesh Khel Wazirs.

Mirat (or Mirab) KHel (50).-A fraction of the Shami Khel, Jalal Khel, Nana Khel, Bahlolzai, Mahsuds. Headman: Gangari.
Mibbeg Kefel (Bannu District).A minor fraction of Tori Khel, Nusa Khel, Hathi Khel, Shin, or Sain, Khel, Ahmadzai. Darwesh Khel Wazirs. Headman: Shah Tamoz.

MIRDAD KHEL (40).-A minor fraction of the Abdurrabman Khel, Nana Kbel, Bablolzisi, Mahsuds.

Mirgol KHel (70).-A minor fraction of sikandar Khel, Badiwai, Khalli Khel, Shaman Khel, Mahsuds. Headman : MIarwat.

Mir Hasani. - A minor fraction of Macha, Madda Khel, Ibrabim Khel, Utmanzai, Darwesh Khel Wazirs.

MIRIa MI KreE $(30)$. - A minor fraction of the Stali] Kbel, Badiuzai, Upper Shaman Khel, Shaman Khel, Nahsuds. Headman : Kaftar.

MIRI KнEL.-A section of Land, Malakh, Mallizad, Dawars. Headmen : KLoji.

Mirkel KHeL (50). - A section of Baromai, Shabi Khel, Alizai, Mahsuds. Headman : Gul Khan.

MiB KHANaI (40).-A section of the Kikrai, Naı K Kel, Bahlolzai, Mahsuds, Headuan: Gul Din.

Mir KHaN KHeL (10).-A minor fraction of Saduar Khel Khoidadai, Maliksbahi, Aimal Khe], Bahlolzai Mrhsuds. Headman : Mian Khan. 
MiR KHAN KHeL (25).-A minor fraction of the Pirdad Khel, Abdul Rabman Khel, Sher Khel, Haibat Khel, Nana Khel, Bahlol. zai, Mabsuds.

MIR KHAN KHel-A minor fractjon of Asat Khel, Wuzi Khel, Mohmit Khel, Utmanzai, Darwesh Khel Wazirs. Headman : Jama G̀ul.

NIR KHAN KBgL.-A minor fractios of Khushali, Tori Khel, Ibrahim Khel, Utmanzai, Darwesh Khel Wazirs.

irr than Ither (10). - A minor fracion of the Shahi Khel, Manzar Khel, Aziz Khe!, Nazar Khel, Airal Khel, Kahlolzai, Mahsuds.

Min FHoNI.-A sub-division of Khadi, Mallizad, Dawars.

Mirmax KHel (Better known as Khadar Khel). -A minor fraction (f) Dosalli, Wuzi Khel, Mohmit Khel, Utmanzai, Darwesh Khel Wazirs.

Miró KHeL (Banna District).-A minor fraction of 'Taos Khel, Pirba Khel, Hathi Khel, shin, or Sinin, Khel, dbmadzai, Darwesh Khel Wazirs. Headman : Pilawar Khan.

Miror.-A section of Nawar Rhel, Miran Shah, Tappizad, Lawars.

MIROSH KHEL.-A minor fraction of shammal, Hassu Khel, Inallizad, Vawars.
Mirsan KHEL.-A minor fraction of the Bakhshi Khel, Madda K hel, Ibralium Khel, Ctmanzai, Darwesh Khel Wazirs.

Mirwash Kreed (40).-A section of the Kaka Kbel, Galishahi. Tpper Shaman Khel, Shaman Khel, Mabsuds. Headman : Nezam.

Mirwase Kanel (20).-A fraction of the Sikandar Khel, Badiwai, Kballi Khel, Upper Shaman Kbel, Shaman Khel, MI isuảs.

MIRZA KHEL. - A minor fraction of Mir Khan Khel, Asat Khel, Wuzi Khel, Mohmit Thel, Utmanzai, Darwesh Khel $W_{\text {azirs. }}$

MrRZa KEEL (20).-A section of the Sultrinai, Sbabi KLel, Alizai Mahsuds. Headman : Tap.

MrRza KHeL.-A minor fraction of Saiyid Khel, Umarzai, Shin, or Sain. Khel, Ahmadzai, Darresh Kuel Wazirs.

MIRZA KHEL. - A minor fraction of Muhammad Khel. Isperka, Kalu Khel, Ahmadzai, Darwesh Khel Wazirs. Headman: Daulat Khan.

Mirza Khel. A branch of the Thatals and Ttman Kheis, bat now identical with the Mal'wats in British territory.

MISAEKI.-A section of Wuzi Khel, Mobmit Khel, Utmanzai, Darwesh Kbel, Wazirs. Headmen : Kaloni, Alam Gul. Sarrar. 
MIsHi KHEL. - A minor fraction of Khatti, Taib Khel, Amzoni, Mallizad, Dawars.

Misr I Khel.-A minor fraction, of Shadi Khel, Lar Lorai, Land Malakn, Halliztd, Dawars.

Mrta KHEL.-A minor fraction of Bizan Khel, Shadi Khel, Nasradin, Kala Khel, Ahmadzai, Darwesh Kibel Wazirs.

Mita KHel.-A sub-division of Issuri, Tappizad, Dawars.

MItha KHeL. - A minor fraction of Kharmmi Khel, Khwaja Kbel, Miamai, Kabul Khel, Wali Khel, Utmanzai, Darwesh Khel Wazirs.

MItha KHeL (186).-A section of the Badiwai, Khalli Khel, Shaman Khel, Mabsuds.

Mitha Khel.-A section of Shammal, Hassa Khel, Mallizad, Dawars.

Mithis (300; winter camping ground, Pabarpur, in the northwest of Dera Ismail Khan District).-One of the lesser Pawindah tribes. Headmen : Akhtar and Sher Muhammad.

MItTI KHeL.-A minor fraction of the Khamar Khel, Gidi Khel, Manzai, Alizai, Mahsuds.

Mised KHel (110):- A sub-dirision of the Michi Khel, Shumi Khe], Palli Khel, Manzai, Alizai, Mabsuds.
MIYAMI KHEL.-A minor fraction of Abdul Rahman Khel, Muhammad Khel, Malakh, Mallizad, Dawars.

Miran KHeL - A minor fraction of Malik Shahi, Jani Khel, Wali Khel, Utmanzai, Darwesh Khel Wazirs, Headman : Sahib Gul.

Mifan KHeL.-A section of Mal Khel, Idak, Tappizad, Dawars.

ModiR KHeL (50).-A minor frac. tion of the Adda Khel, Utman Khel, Isap Khel, Zalli Khel, Bomai, Nasrai, Kalu Khel, Ahmadzai, Darwesh Khel Wazirs. Headman : Kadir.

MOD KBEL - A minor fraction of Shadi Kbel, Bora Khel, Mohmit Khel, Utmanzai, Darwesh Khel, Wazirs.

Moghatgal (40).-A section of Bibizai, Shabi Khel, Alizai Mausuds. Headman: Khwaja Gul.

Moghal Khel (100).-A section of Pathanai, Shabi Khel, Alizai, Mahsuds. Headman: Shahzad.

Moghat Khel.-A minor fraction of Manzar Khel, Tor Kbel, Umarzai, Shin, or Sain, Khel, Ahmadzai, Darwesh Khel Wazirs.

Moghal KheL,-A minor fraction of Pira Khel, Mir Hasani, Macha, Madda Khel, Ibrahim Khel, Utmanzai, Darwesh Khel Wazirs. 
MOGHAL KHEL. - A minor fraction of Dani Khel, Matkai, Malik «hahi, Wali Khel, Utmanzai, Darwesh Khel Wazirs.

Mloghal KheL (Bannu District). A minor fraction of Daulat $\mathrm{K}$ bel, Ali Khel, Musa Kbel, Hathi Khel. Shin, or Sain, Khel, Ahmadzai. Darwesh Khel, Wazirs. Headman: Zabta Khan.

MIOGI KHEL (30).-A section of the Garrarai, Shumi Khel, Pall Khel, Manzai Alizai, Hahsuds. Headman : Muhammad Akbar.

MOHMIT KHAN KHEL. - A minor fraction of Tor, Jani Khel, $W_{\mathrm{ali}}$ Khel, Utmanzai, Darwesh Khel Wazirs. Headman: Amaldad.

Monmit Krei $(3,000)$. - One of the three great divisions of the Utmanzai clan of the Darwesh Khel Wazirs, the other two dirisions being the Ibrahim Kbel and the Wali Khel. Headman : Kipat Khan.

MomaDDI (35).-A sub.division of Zerakki, Mallizađ, Dawars.

MoMrN KBres (60). - A minor fraction of Sher Khel, Hibat Kbel, Nana Khel, Bablolzai, Mahsuds. Headmen : Mir Ajal, Bare Kban, Nialang Khan.

Momiv $\mathbf{n}$ в (60). - A fraction of the Manzar Khel, Aziz Khel, Nazar Khel, Aimal Khel, Bahlo]zai, Mahsuds.
MoNdA KHel (60). - A section of the Kikrai. Nanakbel, Bablolzai, Mahsuds.

Monemes (6?)). - A section of the Malik Dinai, Manzai dlizà, Jiahsuds. Headman : Kasim Gul.

Morib Krel.-A minor fraction of Usman Khel, Takti Khel, Bakka Khel, Wali Khel, Ut. manzai, Darwesh Khel Wazirs. Headmen : Khojamir, Mazalmir, Islam Khan, and Gulroz.

Morib Kael.-A minor fraction of Sarmast Khel, Dardoni, Wazi Kbel, Mohmit Kbel, Utmanzai, Darwesh Khel Wazirs.

Mrbabat Shahi (22.j).-A divisiou of Mallizad, Dawars. Headman : Shekh Mansur.

UITGHAL KHEL. - A minor fraction of Bizan Khel, Shadi Khel, Nasradin, Kalu Khel, Ahmadzai, Darwesh Khel Wazirs.

MUHANMAD KHEL (110).-A minor fraction of the MIachi Khel, Stumi Khel, Palli Khel, Manzai, Alizai, MIahsuds. Headman: Shah Salim.

Mreamad KHet (20; migratorv).--A section of IsperkaKaln Khel, Ahmadzai, Darwesh Khel Wazirs.

MTHAMJAD KHEL. -A section of Hassan Khel, Wohmit Khel, Ut. manzai, Darwesh Khel Wazirs. Headrnen: Fazal Shah, Muhammad Jan, etc. 
Munammad KhrL (18),-A subdivision of Khadi, Mallizad, Dawars.

MUнaMmad Khel (12).-A section of Nana Khel, Tapiai, Tappizad, Dawars.

MUHaMMAD KHEL (700).-A subdivision of Malakb, Mallizad, Dawars, Headmen : Khan Muhammad Khqn, Fazal Din, Makhmad, Shad Azam, alias Bich.

Mugammad Pro.-A section of Alizai, Darpa Khel, Mallizad, Dawars.

MUkRI (Winter" camping ground Rode in the Dera Ismail Khan district).-A sub-division of Bakhtiar, Mian Khel, Lohans Pawindahs. Headman: Ghulam Sarwar Khan.

Mros (800).-One of the divisions of Waraspun, Bhittanis. Headmen : Daulat, Toti (Mandi Khel), Dorran Samarzai ( $\mathrm{Omr} \mathrm{Kh} \boldsymbol{\theta}]$ ).

MUXA OR MALA. KHEL (520; winter camping grounds Panial in the north-west of Dera Ismail Khan District).-One of the lesser Pawindah trading tribes. Headmen : Khushdil and Jahan Khan.

MUTA KnEL.-A division of the Marwats in British territory.
Mullagar (80).-A division of Mallizad, Dawars. Headman: Madali.

MUllagan.-A section of IpiHaidar Khel, Tappizad, Dawars.

MURGa KHeL (20).-A minor fraction of the Mixed Khel, Michi Khel, Shumi Khel, Palli Khel, Manzai, Alizai, Mahsads.

MUSA KHEL.-A minor fraction of Narmi Khel, Bakka Khel, Wali Khel, Utwanzai, Darwesh Khel Wazirs. Headman : Banai Khan.

MUSA KHEL (30).-A minor fraction of the Bobalis, Shingi, Bablolzai Mahsuds. Headman : Mir Dutih.

Mosa Kehel (1,000; Bannu District).-A section of Hathi Khel Shin, or Sain, Khel, Abmadzai, Warwesh Khel Wazirs. Headmen : Adam Khan, Shah Tamoz.

MUsa KHeL.-A sub-division of Khadi, Mallizad, Dawars.

MUSAKKI (260).-A division of Mallizad, Dawars.

MUsam KHEL. - A minor fraction of sikandar Kbel, M[anzar Khel, Ibrahim Khel, Utmanzai, Darwesh Khel Wazirs.

MUgazaI (85; Dera Ismail Khan District), - Nomadic, a sub-division of Sen Khel, Mian Khel, Lohana Pawindahs. 
MESAZAI (Winter camping ground Drabin in the Dera Ismail Khan district). - A division of the Nasar, Ghilzai, Parindahs. Headman : Zaman.
MrsHAKEI. A minor fraction of Nacha, Madda Khel, Ibrahim Khel, Otmanzai, Darwesh Khel Wazirs. Headman : Tare Krban.
$N_{\triangle B R I}$ KHEL. - A sub-division of Boya, Tappizad, Dawars.

N $\triangle$ HAR $_{\text {(Dera Ghazi Khan District }}$ and Khetran Hills).-A Pathan tribe. Headman: Khan Mubammad.

$N_{\triangle Y M R I}$ KHEL (100), - A minor fraction of the Boya Khel, Malli Khel, She kh Hassan, Taji Khel, Bomai, Nasrai, A bmadzai, 1)arwesh Khel Wazirs. Headman : Nandir.

$N_{\triangle M \triangle B I} K_{H E L}(30)$. - A minor fraction of the Darai, Chahar Khel, Upper Shaman Khel, Sharnan Khel, Nahsuds. Headman: Aurang.

$N_{\triangle N A} K_{H E L}(1,430)$. - A division of Bablolzai, Mahsuds.

$N_{\triangle N A} K_{H E L}-A$ minor fraction of Balli Khel, Shadi Khel, Bora Khel, Mohmit Khel, Utmanzai, Darwesh Khel Wazirs.

N $\triangle N$ I KHEL. - A minor fraction of Idar Khel, Ali Khel, Khaddar
Khel, Mnhmit Kkel, Vimátizai, Darwash Khel Wazirs.

$N_{A N \Delta} K H E L .-A$ minor f $f_{1}$ astion of Manzar Khel, 'Tor K hel, Umarzzi, Shin, or Sain, Khel, Ahmadzaj, J)arwesh Khel Wazirs. Headman : Adal Khan.

NANA KHEL. - A minir fraction of Mir Khan Khel, Asat Khel, Wuzi Khel, Nohmit Khel, Ctmanzai, Darwesh Khel Wazirs.

NANA KHEL. - A sub-division of 'Tapiai, 'Lappizad, Dawars.

NANDAR KHEL.-A minor fraction of Paipali, Kabul Khel, Wali Khel, Utmanzai, Darwes's Khel Wazirs.

NANI KHEL. - A section of Alizili Darpa Khel, Mlallizad, Darrars.

$N_{\triangle N I}$ KHEL. $-\Delta$ minor fraction of Lar Lorai, Land, Malakh, Mallizad, Dswars. 


\section{5}

NARMr KHer (Bannu and Shawal) -A section ot Bakka Khel, Wali Khel, Utmanzii, Darwesh Khel Wazirs. Headmen : Banai Khan, Shah Nawaz, Ghainadin, Pilod Khan.

$\mathrm{N}_{\text {ASAR }}$ KHEI. - A minor fraction of Musakki, Macha, Nadda Khel, Ibrahim Khel, Utmanzai, Darwesb Khel Wazirs.

Nasar KHeL.-A section of Zhao Khel, 'Tapiai, Tappizad, Dawar's.

N ASARS $(7,500$; move yearly from Khorasan into Derajat). - A trading clan of Ghilzais, one of the wealthiest of the Pawindah tribe.

$N_{A S I R}$ KHEL.-A section of Umar Khel, Nana Khel, Bablolzai, Irabsuds.

$\mathrm{N}_{\text {ASRADIN }}(7,210 ;$ Wana and British territory). -A sub-division of Kalu Khel, Ahmadzai, Darwesh Khel Wazirs. Headinen: see Shadi Khel and Bomi Khe!.

$N_{\triangle S R A I}(3,746)$ - $A$ sub-division of the Kalu Khel, Amadzai, Darwesh Khe], Wazirs.

NASBAKI KHEL (40).-A minor fraction of the Gadai Khel, Bidai, Gangi Khel, Bomai, Nasrai, Kalu Khel, Ahmadzai, Darwesh Khel Wazirs.

NasRaOTIS.-A sab-division of the Khataks inhabiting the narrow valley at the foot of the Shinghar range in British territory.
$N_{A S R I}$ or $N_{A R S I}$ KHEL (130).-A sub-division of Band Khel, Bahlolzai, Mahsuds.

NaSri KHel (50). - A minor fraction of Pinzaplara, Abdullai, Aimal Khe', Bahlolzai, Mahsuds. Headman : Akin Khan.

NASR I KHEL. - A minor fraction of Bachagai, Tor, Jani Khel, Wali Khel, Utmanzai, Darwesh Khel Wazirs. Headman: Gulbaz.

NASRI KHEL. - A minor fraction of Bar Kaum, Hassu Khel, Tor, Mallizad, Dawars.

NASR KHEL (302). -A sub-division of Haidar Khel, Tappizad, Dawars. Headmen: Gul Khan, Zakhamir.

NASU KHEL.-A clan of Dautani Pawindahs. Headman: Sad Rahmat.

NAURANG KHEL (80). - A section of the Hakim Khel, Band Khel, Bahlolzai, Mahsuds. Headman: Iaar Khan.

NAWAR KHEL. - A minor fraction of Salimi Khel, Dachi Khel, Palli Khel, Manzai, Alizai, Mahsuds.

NaWAR KHel.-A sub-division of Miram Shah, Tappizad, Darrars. Headm€n : Mir Khitab Sharop.

NaWAR KHeL. - A section of Nawar Khel, Miram Shab, Tappizad, Dawars. 
NAWdR KreL.-A section of Zira Khel, Amzoni, Mallizad Dawars.

- Nazal KHeL - A minor fraction of Marsi Khel, Abdul Khel, Bora Khel, Nohmit Khel, Utmanzai; Darwesh Khel Wazirs. Headman : Momazzi.

NIZABBEG KaEL (Britich territory). - A minor fraction of Budin Khel, Shadi Khel, Nasradin Khel, Kaln Khel, Abmadzai, Darwesh Khel Wazirs. Headman : Mir Alaw.

$N_{A Z A B}$ KHeI ( 470$)$. - A sub-division of Aimal Khel, Bahlulzai, Mrabsuds.

$\mathrm{N}_{A Z_{A R}} \mathrm{~K}_{H E L}$ - $-\mathrm{A}$ minor fraction of Aziz Khel, Shadi Khel, Bora Khel, Mohmit Khel, Utmanzai, Darwesh Khel Wazirs.

NAZAR $K_{H E L}(340)$. - A minor frac. tion of Ali Khan Khel, Sark Krhel, Nadda Khel, Ibrahim Khel, Utmanzai, Darwesh Khel, Wrazirs. Headmen: Nabbi Khan, Khadirn.

NAZTA KHEL. - A minor fraction of Pira Khel, Mir Hasani, Macha, Madda Khel, Ibrahim Khel. Utmanzai, Darwesh Khel Wazirs.

NAZIK KHEX (20).-A section of the Pirdad Khel, Abdurrahman Thel, Nana Kbel, Bahlolzai Mahsads. Headman : Mache.

NAZIMI KHEL (10).-A minor fraction of the Kasim Khel Chahar
Khel, Upper Shaman Khel, Shaman Khel, Mabsuds.

NeFAM KHEL. - A minor fraction of Bizan Khel, Shadi Khel, Nasradin, Kalu Khel, Ahmadzai, Dar. wesh Khel Wazirs. Headman : Timar Khan.

NeESAN KHEL. -A minor fraction of Sher Khel, Haibat Khel, Nana Khel, Bahlolzai, Mahsuds.

Netisan Krel (190). - $\mathrm{A}$ subdirision of the Nana Khel, Bahlolzai Mahsuds.

NezaM KHEL. - A section of Hakim Khel, Mubarak Shahi, Mallizad, Dawars.

NEZAMr KHEL. - A section of Fasim Khel, Chahar Khel, Shaman Khel, Mahsuds.

Niamat KHeL (150).-A division of Tatta, Bhittanis. Headmen: Ahmad Khan (Kaka Khel), Marwat (Bassia Khel) Rakhman (Firoz Khel), Ahmad Khan, Mahabbat (Asghar Khel), Lewat (Shahgul), Juma Khan (Firoz Khel).

NIAIAT KHEL (Winter camping ground Draband in the Dera Ismail Khan District).-A division of Nasar, Gbilzai Pawindahs. Headman : Mala Mir.

NiAMAT KHEL (45). - A minor fraotion of Ali Khan Khel, Sarki Khel, Madda Khel, Ibrabim Khel, Utmanzai, Darwesh Khel Wazirs. 
NIAZTS (980); Rhorasan and the Derajat).-Migratory, a Pawindah tribe of similar origin to the Lobana Pawindahs. They are divided as follows:-11) Mamrez Khel, (200), (2); Nur Khan Khel, (170) (3) Mahsud Khel, (230); (4) Ali Khel, (120); (5) Mala Khel, (260). There are four other clans of this tribe, viz. Isa Khel, (1,600), Kamar Mesban (30), Kundi (360), and Sarhan $(1,200)$, who are settled in British territory in Isa Khel, Kalabagh, Mianwali, Bannu, etc.

NIK $\triangle B_{A B} \quad K_{H}$ HI $\quad(240)$. - A fraction of the Langar Khel, Gidi Khel, Manzai, Alizai, Mabsuds. Headman : Badrdin.
Nikbal.-A section of unknown origin living with the Shograi, Tori Khel, Utmanzai, Darwesh Khel Wazirs.

NOR KHEL.-A minor fraction of Balal Khel, Hasan Khel, Mohmit Khel, Utmanzai, Darwesh Khel Wazirs. Headman: Jan.

NUMBRI KHEL. - A minor fraction of Wuji Khel, Haidrai, Chahar Khel, Shaman Khel, Mahsuds.

NURI Kret.-A sub-division of Sara. Tatta, Bhittanis. Headman : Guldad.

NoRI KHel. - A section of Utman, Miram Shah, lappizad, Dawirs.

0

Shaman Khel, Shaman Krhel, Mahsuds. Headman: Abdulla Jan.

OzBakaI (240).-A sub-division of Shingi, Bahlulzai, Mahsuds.

Osak KHet (10). -A minor fraction of the Sikandar Khel, Badiwai, Kalli Khel, Upper

OJI KHEL.-A section of Muhammad Khel, Malakh, Mallizad, Dawars.

Badiwai, Kall Khel, Upper OzI.-A sub-division of Zerakki,
Mallizad, Dawars.

$\mathbf{P}$
PAdMI (33).-A section of Taib Khel, Amzoni, Mallizad, Dawars.

Pahar KHex.-A minor fraction of Dre Nami, Balal Khel, Hasan Khel, Mohmit Khel, Utmazzi, Darwesh Khel Wazirs.
PaHar KHel. - A section of Gha. lil Khel, Badanzai, shaman Khel Mahsud.

PAI KHeL.-A minor fraction of Kundai, Tor Khel, Umarzai, Shin, or Sain, Khel, Ahmadzai, Darwesh Khel Wazirs. Headman: Ghallai. 


\section{8}

PaI KHel (60; Dera Ismail Khan District).-Nomadic, a section of Urnarzai, Sen Khel, Mian Ehel, Lohana Pawindabs.

PAI KHeL (81).-A section of Muhammad Thel, Malakh, Mallizad, Nawars.

PaLTDA Khel.-A minor fraction of Manaka, Fakhshi Khel, Madda Khel, Ibrahim Khel, Utmanzai, Darwesh Khel Wazirs.

PaINDs Freel (5; British territorr). -A minor fraction of Shadai Kbel, Nasrai, Kalu Khel, Ahmadzai, Darwesh Khel Wazirs.

PAINDI KHEL.-A division of Kharoti, Ghilzai Pawindabs.

PaINd KHel.-A sub-division of $\mathrm{Y}_{\mathrm{a}}$ Khel, Nasar, Ghilzai, Pawindahs.

PAINJI KHEI (20).-A minor section of the Bezodi, Malik Shahi, Aimal Khel, Bablolzai, Mahsuds.

PaIo KHeL.-A minor fraction of Khazzar Khel, Ali Khan Khel, Sarki Khel, Madda Khel, Ibrahim Khel, Utmanzai, Darwesh Khel Wazirs.

PaIPALI.-A section of Kabul Khel, Wali Khel, Utmanzai, Darwesh Khel Wazirs. Headman : Gulzada.

Paipali-A sub-division of Banda, Tappizod. Dawars.
PaIs Kere (80). - A section of the Daria Khel, Bibizai Shabi Khel Mahsuds. Headman : Nazar Din.

Pakan Khel.-A sub-division of Urmuz, Mallizad, Dawars.

Pa Khex (200).- A section of Taru Khel, Boba, Dbana, Bhittanis.

$P_{A K I B}$ KHEL. - A minor fraction of Malik Khel, Kaka Khel, Bomi Khel, Nasradin, Kalu Khel, Ahmadzai, Darwesh Kbei Wazirs.

Para KHEL.-One of the three divisions of the Tatta, Bhittanis. Headman : Fateh Khan.

Note.-[Profe:ly speaking the Pala Khel division includes the Toran, Khecha, Niamat Khel, Umar Khel, Aha Khel, and Shan Khel. The name, however, is not much used; and it is more convenient to treat the Umar Khel, Niamat Khe?, Aba Khel, and Shan Khel as indepen dent divisions.]

Palali (76).-A sub-division of Tapiai, Tappizad, Dawars. Headman: Baz.

PALLI KreL $(1,590)$. - The most important of the four eub-divisions of the Manzai, Alizai, Mahsuds. Headman : Eadshah Khan.

PANAEZAI. A minor fraction of Sikandar Khel, Abdul Khel, Bora Khel, Mohmit Khel, Utmanzai, Darwesh Khel Wazirs. 
Panji Khel (10).-A minor fraction of Bizodai, Malikshahi, Aimal Khel, Bablolzai, Mahsuds.

PANRI, or Parin.-A division of Mian Khel, Lohana Pawindahs. Headman: Ata Gul.

Parate of Moddr Khel, Miamai, Kabul Khel, Utmanzai, Darwesh Rhel Wazirs. Headman : Sbindibagh.

Parez KHeL.-A-A section of the Manderi, Id̄ak, Tappizad Dawars. Headman : Zarwak.

Parez KHel.-A sub-division of Tapiai, Tappizad, Dawars. Headmen : Abdulla, Zarar.

PARIDaI (210).-A section of the Gidi Khel, Manzai, Alizai Mahsuds. Headman : Gulamir.

Pari Khel (110) -A minor fraction of the Shumi Khel, Palli Khel, Manzai, Alizai, Mahsud. Headman : Gulaband.

PAR KHEI (20). - A minor fraction of the Shalil Khel, Badinzai, Upper Shaman Khel, Shaman Thel, Mahsuds. Headman: Shawaz Khan.

Parin.-See Panri.

Parwate, or Parwat Khel.-A division of Kharoti, Ghilzai Pawindahs. Headman: Hasat Kban.
PARTAT KHEL.-A sub-division of Tallal Khel, Nasr, Ghilzai Pawindahs. Headwan: Tatal.

Pasani (115; Dera Ismail Khan District).-Nomadic, a sub-division of Isot Kłel, NIian Khel, Lohana, Pawindabs. Headman : Abdulla Khan.

Pasali (Winter camping gruand Chote in the Dera Ghazi Khan District). - A division of Nasar Ghilzai, Pawindahs.

Pasart.-A division of Kharoti Ghilzai, Pawindabs. Headman : Aulad Khan.

PasH (20).-A section of the Nekzan Khel, Nana Khel, Bablolzai, Mahsuds. Headman: Pate.

Pashmis Khel.-A minor fraction of Paipali, Kabul Khel, Wali Thel, Utmanzai, Darwesh Khel Wazirs. Headman: Gulzada.

Pastranis. - A tribe said to inhabit the northernmost hills of the Dera Ghazi Kban District. No other information available.

Patanai (350).-A sub-division of Shabi Khel, Alizai, Mahsuds. Headman : Shahzad.

PAT KHEL (i10).-A section of the Aziz Khel, Nazur Kbel, A imal Khel, Bahlolzai, Nahsuds. Headman : Jalotai. 


\section{0}

Pator Krel (500; Shakai).-A minor fraction of Khanda Khan Khel, Hathi Khel, Shin, or Sain, Khel, Aimadzai, Darwesh Khel Wa irs. Headman : Landai.

PatTi KHeL.-A section of Brahim Khel, Amzoni, Mallizad, Dawars.

Pawindahs (30,000; between Kborasan and India). - The name applied in the Derajat to all those migratory Pathan clans, who come down to British territory in winter, returning as summer approaches, to Afghanistan. The leading Pawindah clans are :Nasirs, Suleman Khels, Kharotis, Mian Khels, and Dautanis. Of less importance are :-Niazis, Mula Khels, Mithis, Kundis, Michan Khels, Mianis, Ghazizai, Gharanai, and Pumranis. Of the above the first three are Ghilzais. the Mian Khels are Lohanas Or Lohanis ; the Niazis and Dautanis are allied to the Lohanas in origin; and the remainder are small Pawindab clans that are often spoken of as Lohanas, but whose origin is doubtful. The Andars, Tokhis and Tarakis are also Ghilzai Pawindahs who come down with kafilas and leave their families behind. The others bring their families and bave fixed encampments, or Kirri's in British territors. See Ghilzai, Pt. IV, and Lobana, Pt. III.

Pajamir KHel (10).-A minor fraction of the Babal Khoedadi, Malik Shahi, Aimal Khel, ahlolzai, TMahsuds.
Pila KHel (150). - $\dot{A}$ minor fraction of Shogai, Tori Khel, Ibrahim Khel, Utmanzai, Darwesh Khel Wazirs. Headmen: Pir Hasan.

Pindake Khel (15). -A minor fraction of the Jalal Din, Shekh. Bazid Khel, Isap, Zalli Khel, Bomai, Nasrai, Kalu Khel, Ahmadzai, Darwesh Khel Wazirs.

Pinzaplara (160).-A section of Abdullai, Aimal Khel, Bablolzai, Mahsuds.

PipaI KHEL (20). -A minor fraction of the Adda Khel, Otman Khel, Isap Khel, Zalli Khel, Bomsi, Nasrai, Kalu Khel, Ahmadzai, Darwesh Khel Hazirs. Headman : Kadir.

PIRA KeEL.-A minor fraction of Eoza Khel, Tor Khel, Umarzai, Shin, or Sain, Khel, Abmadzai Darwesh Khel Wazirs.

PrRA KHEL.-A minor fraction of Jamal Khel, Malak Shahi, Wali Khel, Utmanzai, Darwesh Khel Wazirs. Headmen: Husain Zariband, Gulla Khan, Pergai, Sulemani.

PiRA Kent.-A section of Kanozai, Kattagram, Tatta, Bhittanis.

Pira KHax.-A section of the Ali Kbel, Bobaik, Dbana, Bhittanis.

PIRA KHEL:-A minor fraction of Sir shodiyakai, Bomi Khel, Nasradio, Kalu Khel, Ahmadzai, Darwesh Khel Wazirs. 
Pira KHET. - A minor fraction of Mir Hasani, Macha, Madda Khel, Ibrahim Kbel, Utmanzai, Darwesh Khel Wazirs. Pirali-A sub-division of Bapda,
Tappizad, Dawars.

Prral Kret.-A secticn of Ipi Haidar Khel, Tappizad Dawars.

Piran.-A sub-aivision of Zerakizi, Nallizad, Dawars.

Piran Dafgar Khel (150).-A fatir section living with the Nubammad Khel, Malakh, Mallizad, Drwars. Headmen: Badrang, Ghanam Shah.

Prrea Keel (700; Banna District). - A section of Hathi Kbel, Shin, or Sain, Khel, Abmadzai, Darwesh Khel Wazirs. Headman: Pilwar Khan, La Shah.

PIRDAd KHeL (60).-A section of Abdul Rahman Khel, Nana Khel, Bahlolzai, Mahsuds. Headman: Arsaliki.

גi,

Ali

of

hel,
Khaniya Khel, Shadi Khel, Nasradin, Kalu Khel, Ahmadzai, Darwesh Khel Wazirs. Headman: Lalo Khan.

\section{section of the Haidrai, Chahar Khel, Shaman Khel, Mahsuds. \\ Pir Muhaurad Kenel (43).-A}

Pir Ntrhamad KHeL.-A minor fraction of Ismail Khel, Bozl Khel, Madda Khel, Ibrahim Khel, Utmanzai, Darwesh Khel Wazirs.

Por KHeL (180).-A fraction of the Shamerai, Palli Khel, Manzai, Alizai, Mibsuds. Headman: Pais.

Poliya KHeL.-A minor fraction of Titar Khel, Khan Khel, 'Takhti Khel, Bakk: Khel, Wali Khel, Utmanzai, Darwesh Khel Wazirs. Headman : Mian Khel.

FOR KrHL.-A minor fraction of Sir Shodiyakai, Bomi Khel, Nasradin, Kralu Thel, Ahmadaai, Darwesh Kbel, Wazirs.

Pos KHeL.-A minor fraction of Padmi, Taib Khel, Amzoni, Nallizad, Dawars.

Pos Kinta.-A section of Khoza, Darpa Khel, Mallizad, Dawars.

Pos Parez Khel.-A section of Tapiai, Tappizad, Dawars.

Potia $K_{H E L}(70)$. - A minor fraction of the Khonia Khel, Shodai Nasari, Kalu Kuel, Ahmadzai, Darwesh Khel Wazirs. Headman : Mirwal.

Potia KHeL.-Another name for the Alizai $i_{8}$ Mahsuds.

Potra KaEr (20). - A section of the Daria Khel, Bibizai, Shabi Khel, Álizai, Mahsuds. Heałman: Shari. 
PotiyA Khel.-A minor fraction of Khuniya Khel, Shadi Khel, Nasradin, Kalu Khel, Ahmadzai, Darwesh Khel Wazirs. Headmen: Bhittani Khan, Mihrwal.
Per henc.-A minor fraction of Pai Khel, Muharmmad Khel Malakh, Mallizad, Dawars. Headmen: Shadazam, alias Bich.
RAD KEEL (70;.-A minor fraction of the Gadai Khel, Bidai, Gangi Khel, Bomai, Nasrai, Kala Khel, Ahamadzai, Darwesh Khel, Wazirs. Headman : Gholamai.

R.Aggr Kael (Bannu District).-A minor fraction of Baik Khel, Khandar Khan Khel, Bathi Khel, Shin, or Sain, Thel, Ahmadzai, Darresh Khel Wazirs. Headman : Razgul.

RighzaI (60).-A section of Taib Thel, Amzoni, Mallizad, Dawars. Heacimen : Said Akbar Mokhsein.

Ratiudad Khel (E்0).-A section of Abdul Rahman Thel, Nana Khel, Bahlolzai, Nahsuds.

RaHiurda KHEL (40).-A minor section of the Shalil Khel, Badinzai, Lpper Shaman Khel, Shaman Khel, Mahsuds. Headman : Zarpaio.

RaHuat KHer.-See KrKI KHBL.

RAHMax KHEL (20).-A minor fraction of the Datorgi, Badimai, Khalh Khel, Upper Shaman
Khel, Shaman Khel, Mahsuds. Headman : Irok.

RaIbat KHel (Bannu District). - A minor fraction of Ali Khel, Musa Khel, Hathi Khel, Shiv, or Sain, Khel, Ahmadzai, Darwesh Khel Wazirs. Headman: Shom K han.

RAJ $\bar{E}$ KHEL. - A minor fraction of Khan Khel, Bara Khozai, Khaddar Khel, Mohmit Khel, Utmanzai, Darwesh Khel Wazirs.

RAJI KHEL (20). - A section of the Rahimdad Kbel, Abdurrahman Khel, Nana Kíbel, Bablolzai, Mahsuds.

RajJi KHex (190).-A minor fraction of Halai, (or Mal Khel) Dacbi Khel, Palli Khel, Manzai, Alizai, Mahsuds.

RAJJI KHeL.-A section of Rana Kbe!, Tapiai, Tappizad, Darrars.

RAKH KHEL. A minor fraction of Mir Ali Khel, Idia Khel, Jani Khel, Waii Khel, Utmanzsi, Darwesh Khel Wazirs. Headmen: A kaldin. 
RaNa KHeL (70; Dera Ismail Khan District).-Nomadic, a section of Umarzai, Sen Khel, Mian Khel, Lohana Pawindahs.

RANGI KHEL.-A minor fraction of Idar Khel, Ali Khel, Khaddar Khel, Mobmit Khel, Utmanzai, Darwesh Khel Wazirs.

RASHID KHEL (10).-A minor fraction of the Khali Khel, Bangish Khel, Tbrahim Khe?, Astanai, Shabi Khel, Alizai, Mahsuds. Headman : Sakhidar.

Rasman KHex.-A minor fraction of Charkhil, Charkhil Land, Malakh, Mallizad, Dawars.

RASUL KHEL. - A minor fraction of Haibatti, Tori Khel, Ibrahim Khel, Utmanzai, Darwesh Khel Wazirs.

Rasul KHEL. - A section of Taru Khel, Boba, Dhana, Bhittanis.

Razo KHeL (10).-A sub-division of Khaddi, Mallizad Dawars.

Razoni.-A section attached to the Asad Khel, Wuzi Khel, Mohmit
Khel, Utmanzai, Darwesh Khel Wazirs. Headmen: Qoyam and Mir Khali.

Reshmin KHet.-A minor fraction of Madda Khel, Miamai, Kabul Khel, Utmanzai, Darwesh Khel Wazirs. Headman : Mezhai.

RESH IIN KHEI. - A minor fraction of Sikandar Khel, Abdul Khel, Bora Khel, Mobmit Khel, Utmanzai, Darwesh Khel Wazirs.

Resharin KHeL.-A minor fraction of Bar Kaum, Hassu Khel Mallizad, Dawars.

Rozi KHEL.-A section of Zhao Khel, Tapiai, Tappizad, Dawars.

Rozi KHEL. - A minor fraction of Ali Kbel, Musa Khel, Hathi Khel, Shin, or Sain, Khel, Abmadzai', Darwesh Khel, Wazirs. Head' man: Miraband.

RUSTAM KHEL (50). - A fraction of the Abas Khel, Haibat Khel, Nana Khel, Banlol zai Mahsuds. Headman : Shabdad.

\section{S}

SABA KHEL (70) - A minor fraction of the Karim Khel, Guri Khel, 1)achi Khel, Palli Khel, Manzai, Alizai Mahsuds. Headman : Na. zar Khan.
SABAK KHEL.-A section of Shadi Kbel, Bobak, Dhana, Bhittanis. 


\section{4}

SABOGAI. - A minor fractinn of Sada Khel, Isperka, Kalu Kbel, Ahmadzai, Darwesh Khel Wazirs. Htadwan: Ahmad Gul.

SABO KHEL. -A miner fraction of the Bakhshi Khel, Madda Khel, Ibrahim Khel, Utmanzai, Darwesh Kibel Wazirs.

SaDA KeEL (300; Bannu and Shakai).-A section of Isperka, Kalu Khel, Ahmadzai, Darwesi Khel Wazirs. Headmen: Zalim Kban, Ahmad Gul.

SaDax KHEL ( 80$)$. - A iraction of the Khoidadi, Malikshahi, Aimal Khel, Bablolzai, Mahsuds.

SADAN KHEL (35); Bannu to Shakai, and Birmal).-A section of Isperka, Kalu Khel, Ahmadzai, Darwesh Khel Wazirs. Headmen: Jalandar Shah and Mani Khan.

SADDA KHEL (35).-A minor fraction of Mirdad Khel, Abdul Rahman Khel, Sher Khel, Haibat Khel, Nana Khel, Bahlolzai Mahsuds.

SADDAN KHEL (80).-A section of the Khoedadi, Maliksłaahi, Aimal inhel, Bahlolzai Mahsuds.

SaDDar Kene (40).-A section of the Saddan Khel proper, Khoedadi, Malikshahi, Aimal Khel, Bablolzai, Mahsads.

SADDAN KHEL (8C).- a section of Isper'sai, Kala Khel, Aimadzai, 1)arwesh Thel Wazirs. Headman : Azati.

SADDr KHEL (60).-A fraction of Isperkai, Kaln Khel, A hmadzai, Darwesh Khel, Wazirs. Headman : Iiras.

SaHib KaEl (10). A minor fraction of the $\mathbf{K}$ hali Khel, Bangish Khel, Ibrahim Khel, Astanai Shabi Khel, Alizai, IIahsuds.

SAHNI KHEL. - A minor fraction of Kundai, Tor Khel, Unarzai, Shin, or Saiu, Khel, Ahmadzai Darwesh Khel Wazirs. Headmau : Zaid Gu:.

SıHOGI. - A minor fraction of the Kimat Khe?, Haidar Khel, Tor, Tappizad, Dawars.

SaIfali.-A section of Kabul Knel Waii Khel, Utmanzai, Darwesh Khel Wazirs. Headman: Kotan Khan, Ilmuddin, Landai, and Nazr Din.

SaIfali Kreer (Bannu District).A minor fraction of Dodi Khel Khandar Khan Khel, Hathi Khel Shin, or Sain, Khel, Abmadrai Darwesh Khel Wazirs.

SAINI KHEL. - A mincr fraction of Narmi Khel, Bailia hihel, W iali Thel, Utmanzii, Darwesh Krel, Wazirs. Headman: Shah Narz.

SAINI KHEL - A minor fraction of Titar Khel, Khan Khel, Takhti Khel, Baika Khel, Wali Khei, Utmanzi, Darwe-h Khel Warirs. Headmen : Khan Badsbah, Khazan Khan. 
Sain KHzL, or Shin KheL (280).A sab-division of the Almadzai, Darwesh Khel Warirs. Headmen: Khemor and Bado.

SaIridgai.-A minor fraction of Khan Khel, Takhti Khel, Bakka Khel, Wali Khel, Utmanzai, Darwesb Khel Wazirs. Headman: Gul Kbatin.

SAIYIDGIS or SAIDgIS ( 430 ; Waziristan).-A clan of Saiyids who inhabit Zowe, Shawal and the Tochi, Dawarghar, Kanibogh and the Dandi plain, north of Miram Shah. There are also some saiyidgis across the frontier in Birmal, of whom little is known. The divisions of the Saiyidgis are known by the names of the localities they inhabit, as above. Those of Kanibogh and of Shawal are pastoral in their habits, and all are on good terms with the Darwesh Khel. Headmen: Pai Muhammad and Shagai (Dandi Plain) Juma Khan (Zowe), and Aghamir.

SAIYIDI KHEL. - A section of Troan Pala Khel, Tatta, Bhittanus.

SaIyid Keel (Bannu, Kurram).A section of Umarzai, Shin, or Sain, Khel, Ahmadzai, Darwesh Khel Wazirs. Headman : Pirmal Khan.

SaIYID KHet (120; winter camping ground, Gandi Umar Khan in the Dera Ismail Khan District).-Nomadic, a sub-division of Isot Khel, Mian Khel, Lohana, Pawindahs. Headman: Sikandar Khan.
SAKA KHEL (30).-A section of Salimkai, Khalli Khel, Shaman Khel, Mahsuds.

SaLEMI KHeL.-A sub-division of Urnar Khel, Tatta Bhittanis. Headman : Gulbagh.

$\mathrm{S}_{\text {dIIH }} \mathrm{K}_{\mathrm{H}} \mathrm{EL}$ - $\mathrm{A}$ minor fraction of Shinki Khel, Bibakki, Hassu Khel, Mallizad, Dawars.

Salim Kres (30).-A minor fraction of the Jalal Din, Shek Bazid Khel, Isap Khel, Zalli Khel Bonai, Nasrai, Kala Khel, Ahmadzai, Darwesh Khel, Wazirs. Headman : Tila Khan.

SaliMI KHeL (390).-A minor fraction of the Dachi Khel, Palli Khel, Manzai, Alizai, Mahsuds. Headman : Badshah Khan.

SALIM KAI (125).-A sub-division of Khalli Khel, Shaman Khel, Mahsuds.

SALIM KAI (30).-A minor fraction of Pinzaplarai, Abdullai, Aimal Khel, Bahlolzai, Mahsuds. Headman : Tari Makhmad.

SaLimkaI (130).-A fraction of the Khalli Khel, Upper Shaman Khel, Shaman Khel, Mahsuds.

SALIMONAI (35) - - A minor fraction of the Abdul Khel, Langar Khel, Khoildad Khel, Gidi Kbel, Manzai, Alizai, Mabsuds. 


\section{6}

SALWA KHEL. - A sub-division of Mullagan, Nallizad, Dawars. Headman : Mad Ali.

SATDRA KHEL (60). - A fraction of the Shami Khel, Jalal Khel, Nana Khel, Bahlolzai, MIahsuds. Headman : Karim Khan.

SATGI KHel (15).-A miror fraction of the Jalal Din, Shekh l'asid Khel, Isap Kbel, Zalli Khel, Bomai, Nasrai, rali Khel, Ahmadzai, Darwesn Khel Wazirs, Headman : Kbakim.

SANJAR KHEL.-A miner fraction of Sada K hel, Sperkai, Kalu Khel, Ahmadzai, Darwesh Khel Wazirs.

SAXZAR KHEL (50). - A section of the Bobalai, Shingi, Bahlolzai, Mahsuds. Headman : Gulzadin.

SARDARI KHEL (40).-A minor fraction of Pirdad Khel, Abdu! Puhman Khel, Sher Khel, Haibat Khel, Nana Khel, Bahlolzai, Mahsuds. Headuen: Allahdad, Shahzai.

SABDI KHEL (Pannu and Shawal) - A section of Bakka Khel, Wali Fhel, Utmanzai, Uarmesh Khel Wazirs. Headmen: Ashraf Khan, Khak i Shah, Gulak Khan, Rasul Shah, Landak, Mauladad Khan, Banai.

SABGABA KBEL.-A minor fraction of Alikhani, Bomi Khel, Nasradir, Kalu Khel, Ahmadzai, Darwesh Khel Wazirs.
SARIE KHEL ( 20$)$.-A section of the Birri Kbei, Galeshabi, Upper Shaman Khel, Shaman Khel, Mahsuds. Headman : ajam Gul.

SarkI KHeL. - A minor fraction of Mira Khel, Mad Khozhai Khaddar Khel, Mohmit Khel, Utmanzai, Darwesh Khel Wazirs. Headman: Rakhm Sbah.

SAREI KHEI $(1,400)$. - A section of Madda Ṫheî, Ibrahim Khel, Utmanzai, Darresh Khel Wazirs. Headmen : Sadda Khan, Alambe and Shildam Khan.

SARMASHAI (50).-A section of Salimkai, Khalli Khel, Shaman Khel, Mabsuds.

SerMast KHEL. - A minor fraction of Nachi Khel, Ahdul Khel, Bora Khel, Mohmit Khel, Utmanzai, Darwesh Khel Wazirs. Headman : Shalım.

SARMAST KHEL $\rightarrow$ A mino: fraction of Darḋoni, Wuzi Khel, Mohmit Khel, Utmanzai, Darwesh Khel Wazirs.

SaRMaSt KHEL (120).-A fraction of the Gega Khel, Nana Khel, Bahlolzai, Mahsuds. Headman : Muhaminad Afzal.

SARMAST KHEL. - A section of Umar Khel, Chaplai, Muia, Waraspan, Bhittanis. Headman : Isap. 
SAB PAREFI. (Winter camping ground, Choti, in the Dera Ghazi Khan Districti.-A division of Nasar, Ghilzai, Parindahs.

SARA (100).-A division of Tatta, Bhittanis. Headmen : Sher Khan, (Jalal Khel), Lawat (Nurab Khel).

SABTAN KHEL. - A sub-division of Daud Khel, Nasir, Ghilzai, Pawindahs. Headman: Gul Khan.

SATAK FHEL (Winter camping ground, Zarkani in the Dera Ismail Khau District).-A division of Nasur, Ghilzai, Pawindabs. Headman : Perak.

SAWAKAI (30).-A minor fraction of the Landi Khel, Saddan Kbel, Khoedadi, Malik Shahi, Aimal Khel, Bablolzai, Mahsuds.

SEN KneL (600; Dera Ismail Khan District). - Nomadic, a division of Mian Khel, Lohana Pawindahs. Headman: Azim Khan.

Sen Krel.-A suh-division of Aba Khel, Tatta, Bhittanis. Head. man: Miua Krlian.

Serzar.-A section of Kanezai, Kattagram, Tatta, Bhittanis. Headman: Tor.

SENZaI.-A section of Kesu Waruki Dhana, Bhittanis, Headman: Sher Mahmud.
Shabadin Krel.-A section of Palali Tapiai, Tappizad, Dawars.

SHabar KHel (10). - A minor frac. tion of Rharmach Khel, Malai, Shingi, Bahlolzai, Mahsuds.

Shabar Khel. - A minor fraction of Sarmast Khel, Badi Khel, Dardoni, Wuzi Khel, Mohmit K'hel. Utmanzai, Darwesh Khel Wazirs.

Seabar KHel.-A minor fraction of Kharmanj Khel, Kbwaja Khel Miamai, Kabui Khel, Wali Khel, Utmanzat, Darwesh Khel Wazirs. Headman: Gulbat Khan.

Shabaz KHeL.-A minor fraction of Idal Khel, Nínbammad Khel, Malakh, Mallizad, Dawars.

SHabra KHEL (70).-A fraction of the Karon, Mamadi, Shingi, Bahlolzai, iíah suds. Headman: Kasei.

Shabia KHEL (40). - A minor fraction of the Krarmach Khel, Shingi, Bahlolzai, Mahsuds. Headman: Fatteh Khan.

SHabi KHeL (60).-A fraction of the Manzar Khel, Aziz Khel, Nazar Khel, Aimal Khel, Bahlolzai, Malsuds. Headman: Mian Dod.

Shabi Krel (1130). - A division of the Alizai, Mahsıds.

The Mulla Povindah is the leading man in this division. 
ShaBCDIN (30.-A section of the Garrarai, Shumi Khel, Palli Khel, Manzai, Alizai, Mahsuds. Headman : Jafri.

SHADAFEA.-A minor fraction of Muhammad Khel, Isperka, Kalu K.bel, Abmadzai, Darwesh Khel, Wazirs. Headman : Katamir.

Shadar (400).-A section of Nasrai, Kalu Khel, Ahmadzai, Darwesh Khel Wizirs.

SHADAK KHEL.-A section of Boya, 'T'appizad, Dawars.

Shad Krel (200).-A sub-division of Bobak, Dhana, Bhittanis. Headman: Mansur.

Shad KHeL ( 75 ; winter camping ground, Mriali in the Dera Ismail Khan District).-Nomadic, a subdivision of Isut Khel, Nian Khel, Lobana, Pawindahs. Headman: Haji Paind.

Shad Krec - A minor fraction of Siliander Khel, MIanzar Khel, Ibrahim Khel, Utmanzai, Darwesh Khel Wazirs.

SHAD: KHEL, - A section of Bora Khel, Mohmit Khel, Etmanzai, Darwesh Khel Wazirs. Headman : Kippat Khan.

SHADI KHEL.-A minor fraction of Boza Khel, Tor Khel, Umarzai, Shin ,rr Sair, Khel, Ahmadzai, Darwesh Khel Wazirs.
Shad K KeL (10\%-A minor fraction of the Shalil Khel, Badinzai, Upper Shaman Khel, Shaman. Khel, Mahsuds.

Shadr KHeL. -A minor fraction of Ba!al Khel, Hasan Khel, Nohmit Khel, Utmanzai, Darwesh Kbel Wazirs.

SHaDI KHEL. - A sub-division of Banda, Tappizad, Dawars. Headmen: Shabol, Nazr Mubammad.

Shadi KHel.-A section of Ipi Haidar Khel, Tappizad, Dawar's.

SHADI KHEL.-A minor frac. tion of Lar Lerai, Land, Malakh, Mallizad, Dawars.

SHADIZaI (Winter camping ground, Mnsazai in the Dera Ismail Khan District). -A division of Nasar, Ghilzai, Pawindahs. Headman : Bai Khan.

SHa Hab DIN KHEL.-A sub-division of Musakki, Mallizad, Darrars. Headman : Ahsan.

ShaHaB Krel- $-A$ minor fraction of Manzar Khel, Tor Khel, Um. arzai Shin, or Sain, Khel, Ahmadzai, Darwesh Khel Wazirs. Headman: Jamal Din.

ShataBudDiN KHeL (90).-A minor fraction of Garerai, Shumi Khel, Palli Khel, Manzai, Alizai, Mahsods. Headmen: Zafar, Kabul. 
ShaH Alam Kiger (128).-A section of the Kasim Khel, Chabar Khel, Shaman Khel, Mahsuds.

Shatrbaz KHer (20).-A minor frac. tion of Bizodai, Malikshai, Aimal Khel, Bahlolzai, Mahsuds. Headman : Sila Khan.

S̈A GBEg KHeL (40).-A minor fraction of the Rahimdad Khel, Abdurrahman Khel, Nana Khel, Bahlolzai, Mahsuds. Headman: shaizal.

Shahgul KHel.-A sub-division of Niamat Khel, Tatta, Bhittanis. Headmen : Lewat.

Shati Kher.-A sub-division of lvi usakai, Mallizad, Dawars.

Shaнx Kнex.-A minor fraction of Padmi, Taib Khel, Amzoni, Mallizad, Dawars.

SHAH JAHAN KHEL.-A minor fraction of Jan Beg Khel, Ali Khan Khel, Sarki Khel, Madda Khel, Ibrahim Khel, Utmanzai, Darwesh Khel Wazirs.

S耳AB MrRaI. - A minor fraction of Dreplarai, Tori Khel, Ibrabim Khel, Utmanzai, Darwesh Knel Wazirs. Headman: Khari.

Shat MUframmad KHeL.--A minor fraction of Pira Khel, Janal Khel, Malik Shahi, Wali Khel, Utmanzai, Darwesh Khel Wazirs.
SHAHTALI KHEL.-A minor fraction of Sikandar Khel, Abdul Khel, Bora Khel, Mohmit Khel, Utmanzai, Darwesh Khel Wazirs.

Shaib KHel.-A minor fraction of Dani K hel, Matkai, Malikshahi Wali Khel, Utmanzai, Darwesh Khel Wazirs. Headman: Marota.

SHAEBA KHEL (20). - A fraction of the Khalli Khel, Shahur Shaman Khel, Shawan Khel, Mahsuds. Headman: Namar Khan.

SHAKHA KHEL. - A minor fraction of Khushalai, Tori Khel, Ibrahim Khel, Utmanzai, Darwesh Khel Wazirs. Headmen : Ghazim Shah, Mattigai, and Tawannir.

Shatra Khel.-Aba Khel, Pala Khel, Tatta, Bbittanis. Headman : Bhawul.

SHAFA KHEL (50).-A fraction of the Salimkai, Khalli Khel. Upper Shaman Khel, MIahsuds. Headman : Ilal.

Shatralat.-A minor fraction or Macha, Madda Khel, Ibrahim Khel, Utmanzai, Darwesh Khel Wazirs.

ShakHaL Krel (70).-A fraction of the Boi Khel, Namadi, Shingi Bahlolzai, Mahsads. Headman : Rasil Khan.

Shakharia Khel (60). fraction of Khojal Khel, shadai. Nasrai, Kalu Khel, Ahnadzai, Uarwesh KhtI Warirs. Headroan : Zardak. 
SHAKHAR KHEL. - A minor fraction of IIusikki, Wuzi Khe, rolohmit Khe!, ¿tmanzai, Darresh Kuel Wazirs.

Seatear KeEl (Bannu District). - A minor traction of Kundi, Pirba Khel, Hathi Tíhel, Shin, or Sain, Khel, Ahmadzai, Darwesh Khel Wuzirs. Headman : Dangir Khan.

SHAKHI (230).-A division of Waraspun, Bhittanis. Headmen : Pazid, (Maziana). Mabomed Turahi Khel), Charakki (Dreplara).

SHAELI K̈HEL (60). - A sub-division of the Band Khel, Bahlolzai, Mahsads. Headman : Rahimdad.

Shali. KHEL (130).-A section of the Badinzai, Lipper Sbaman Khel, II aheuds.

SEdjLI (30). - A nizor fraction of the Erond Khel, Chahar Khel, Upper Shaman Khel, Shaman Khel, Maisuds. Headman: Panai.

SFAMAK KHEL (160).-A section of the Abdullai, Aimal Krhel, Bahlolzai, Malsuds.

SHAus hHer.-A minor fraction of Shadi Khel, Balal Khel, Hasar Khel, Inhmit Khel, Utmanzai, Darwesh Khel Wazirs.

Sgamas Khel (10).-A minor fraction of the Mirah Khel, Shami Khel, Jalal Khel, Nana Khel, Bablolzai, Mabsuds.
SHAMAN KHEL (1,900).-A clan of Mahsuds -divided into (1) Upper Shaman Khel (1,560), and Shah Shaman Khel (340).

Shauerai (140).-A fraction of the Palli Khel Manzai, Alizal, Mahsuds. Headman: Karim Khan.

Shavi KHre (50). - A minor fraction of the Shogai, Tori Khel, Ibrahim Khel, Utmanzai, Darwesh Khel Wazir's.

Shami Khel (140). A minor faction of Shamsk: Khel, Shek Hassan, Tazi Khel, Bumai, Nas rai Abmadzai, Darkesh Khel, Wazirs. Headmen: Dost Muhammad and Niraband.

SHAMI KHEL (150).-A fraction of Jalal Khel, Nana Khel, Bahlolzai Wahsuds.

Shamir Krent. - A section of Nana. Khel, Tapiai, Tappizad, Dawars,

Shavir Krel. - A minor fraction of the Raji Khel, Rahimdad Khel Abdurrahman Khel, Nana Khel Bablolzai, Mabsids. Headman : Gandapir.

Shampic. - A sub-division of Hasu Khel, Mallizad, Dawars. Headman: Raibat Khan.

Shamsher KHel.-A minor fraction of Idia Khel, Jari Khel, Wali Khel, Utmanzai, Darwesh Khel Wazirs. Headman : Zarghun Shah. 


\section{1}

Shamser KHel.-A sub-division of Khaddi, Mallizad, 'awars.

SHaMSI, or ADDA, KHEL.-d minor fraction of amaldin Khel, $\mathrm{W}$ adin Khel, Khazzar Khel, Ali Khan Khel, Sarki Khel, Madda Khel, I brahim Khel, Utmanzai, Darwesh Khel Wazirs.

SHAMSI KHEL (300).-A fraction of the Shekh Hassan, Taji Khel, Bomai, Nasrai, Kalu Khel, Ahmadzai, Darwesh Khel, Wazirs. Ileadman: Ghazni Khan.

Shamsi KHEL (100).-A minor fraction of the Jalal Khel, Sher Khel, Haibat Khel, Nana Khel, Bablolzai, Mabsuds. Headman : Karim.

Shavsi Krel.-A section of the Ali Khel, Haidar Khel, Tappizad, Dawars.

ShaN KHEL (80).-A division of Tatta, Bhittanis. Headman : Azim.

Sharbat Khel. - A minor fraction of Paipali, Kabul Khel, Wali Khel, Utmanzai, Darwesh Khel Wazirs.

SHARIF KHEL (10).-A section of Hakim Khel, Mubarak shahi, Mallizad, Dawars.

SHARRI KHEL (55).-A section of Kasim Khel. Chahar Khel, Shaman Khel, Mahsuds.

Shatrai (60)-A section of Malik Jinai, Manzai, Alizai, Mahsuds. Headman : Bazals.
SHEI LEAI (30). - A section of the Garrarai, Shami Khel, Paili Khel, Manzai, Alizai, Mahsuds. Headman : Tilai.

Shen AbDcl Khel (110) (Wano). -A minor fraction of Gangi Khel, Bomai, Nasrai, Kalu Khel, A hmadzai, Darwesh Khel Wazirs. Headman : Nambi Khan.

SHekr ALI.-A minor fraction of Narmi K'hel, Bakka Khe!, Wali Khel, Utmonzai, Darwesh Khel Wazirs. Heaāmen : Ghainadin and Pilod Krhan.

SHekHax.-A sub-division of Khaddi, Mallizad, Dawars.

Shene Barid Khel (70).-A minor fraction of the Niliarrab Khel, Khoidad Khel, Gidi Kinel, Manzai, Alizai, Míahsuds.

Selert. bazid (Tano).-A minor fraction of Zalli Khel, Bumi Khel, Nasradin, Kalu Khel, Abmadzai, Darwesh Khel Wazirs.

Saekt Bazid KHel (כอ̃o).-A minor fraction of the Isap Khel, Zalli Khel, Bomai, Nasrai, Kalu Khel, Abmadzaj, Darwesh $\bar{K}$ hel Wazirs.

SHEKH BUdiN, - A minor fraction of Sardi Khel, Bakka Khel, Wali Khel, Utzanzai. Darwesh Khel Wazirs. Headmen : Ashraf Khan a.ki Shab, Gulak Khan. 
Shekrbodin Krey.-A minor fraction of Wadin Khel, Khazzar Khel, Ali Khan Khel, Sarki Khel, Madda Krel, Ibrahim Khel, Utmanzai, Darwesh Khel Wazirs.

Shent Hassax (600).-A section of the Taji Khel, Bomai, Nasrai, Kalu Khel, Ahmadzai, Darwesh Khel, Wazirs.

SHEKHUIr KHEL.-A minor fraction of Jan Beg Khel, Ali Khan Khel, Sarki Khei, Madda Khəl, Ibrahim Khel, Utmonzai, Darwesh Khel Wazirs.

Seterg UMray.-A minor fraction of Pira Khel, Jamal Khel, Malik Shahi, Wali Khel, Utmanzai, Dartresh Khel Wazirs. Headman : Sulemani.

SHEKHWADI.-A minor fraction of Shadi Khel, Bora Khel, Mohmit Khel, Utmanzai, Darwesh Khel Wazirs.

Sher Ahuad Kenel-A minor fraction of Sifili, Kabul Khel, Wali Khel, Utwanzai, Darwesh Kuel Wazirs.

Sher Ali helel $(30\rangle$. - A minor fraction of the Nelzan Khel, Nana Khel, Bahlolzai, Nahsuds. Headman : Biland.

Sherbeg KHeL (20).-A section of the Pirdad Khel, Abdurrahman Khel, Nana Khel, Bahlolzai, Mahsuds. Headrnan: Allahdad.
Sherin KHel (90). - A section of the Umar Khel, Nana Khel, Bahlolzai, Mahsuds.

Sher Dari Krel (150). - A minor fraction of the Jalal Khel, Shér Khel, Haibat Khel, Nana Khel, Bahlolzai, Mahsuds.

Sher KHAN KHeL. - A minor frac. tion of Kharmanj Khel, Khwaja Khel, Miamai, Kabul Khel, Wali Kinel, Utmanzai, Darwesh Khel Wazirs.

SHER KHAN KHeL (16),-One of the two sections of the Nialla Khel, Chuhar Khel, Shaman Khel, Mabsuds. Headmen: Shahid Khan, Zarpiyao.

Sher KHEL (80).-A section of the Hoibat Khel, Nana Khel, Bahlolzai, Mahsuds.

SHeR KHEL.-A minor fraction of Fateh Khel, Muhammad Khel, Hasan Khel, Mohmit Khel, Utmanzai, Darwesh Khel Wazirs.

SHER KHEL.-A minor fraction of Dre Nami, Balal Khel, Hasan Khel, Mohmit Kbel, Utmanzai, Darwesh Khel Wazirs.

SHE R KHEL (50). - A fraction of the Bariam Khel, Patanai, Shabi Khel, Alizai, Mabsuds. Headman : Khila Jan.

SHeR KHeL.-A section of Kimat Khel, Haidar Khel, Tappizad, Dawars. 


\section{3}

Sher M chanmad Krel. -A minor fraction of Mir Hasari, Macha, Madda Khel, Ibrahim Khel, Ut. manzai, Darwesh Khel Wazirs.

Shingi (1,430).-A division of the Bahlolzai, Mahsuds. Headmen: Fateh $\mathrm{K}$ han and Gul Pir.

SHINEI KHEL.-A section of Habakini, Hassu Khel, Mallizad, Dawars. Headman : Mad Afzul.

ShIRAK KHel. - A minor fraction of Sada Khel, Isperka. Kalu Khel, A hmadzai, Darwesh Khel Wazirs. Headman: Zalim Khan.

Shiranis.-See Part IV for this tribe and all its clans, etc.

Shinaz KHeL (100).-A fraction of Jalal Kbel, Nana Khel, Bablolzai, Mahsuds.

Shir Kenc. - A sub-division of Zerakki, Mallizad, Dawars.

ShITA KHex.-A sub-division of Issuri, 'Tappizad, Dawars.

SHobaraI (30). - A section of the Garrarai, Shumi Khel, Palli Khel, Manzai, Alizai, Mahsuds. Headman : Nejam.

Shobak KHEL (20).-A minor fraction of the Rahimdad Khel, Abdul Rahman Khel, Sher Khel, Haibat Khel, Nana Khel, Bahlolzai, Mahsuds.
Shodal. - See Shad Krgl.

Shod KHEL (80). - A ninor fraction of the Ghulam Khel, Ali, Kaka Khel, Bomai, Nasrai, Irala Khel, Abmndzai, Darwesh Khe], Wazirs. Headman : Khoshal.

Shod KHeL · (16).--One of the fire sections of the Ghalib Khel, Badanzai, Shaman Kibel, Mahsuds.

SHODIYAEAI. - A min or fraction of Bomi Khel, Nasradin, Kaln Khel, Ahwadzai, Darwesh K bel Wazirs.

ShOEBAI (10). - A minor fraction of the Baba Khe], Galeshahi, Upyer Shaman Khel, Shaman Khel, Mahsuds. Headman : Hazrat.

Shogal (700). - A section of Tori Khel, Ibrahim Khel, Utmanzai, Darwesh Khel Wazirs. Headmen: Kotanai, Sammat, ete.

Shogr KHeL - A minor fraction of Kutti Khe!, Umar Khel, Ali Khel, Khaddar Khel, Nlohmit Khel, Utmanzai, Darwesh Khel Wazirs.

SHOI KHEL (30). - A minor fraction of the Bojia Khel, Shingi, Bahlolzai, Mahsuds. Headman : Salenin.

SHoliaI (25).-A minor fraction of the Garri Khel, Baran Khel, Chahar Rhel, Shaman Khel, Mahsuds. 
Shomar Krel (14).-A minor fraction of the Rahimdad Khel, Abdul Rahman Khel, Sher Kibel, Haibat Khel, Nana Khel, Brhlolzai, Mabsuds.

SHour Kred (50). - A minor fiacof Shogai, Tori Khel, Iorahim Khel, Utmanzai, Darwesh Khel Tazirs.

Sho Mchamud KHel (16).-A minor fraction of the Barumi Thel, Khoidad Khel, Gidi Khel, Manzai, Alizai, Mahsuds. Headman : Aligul.

SHCDAFEA. - A minor fraction of Gita Khel, Muhammad Khel, Malakh, Mallizad, Dawars.

DHC KHEL.-.A minor fraction of Narni Khel, Bakla Khel, Taii Thel, Utmanzai, Darwesh Thel Wazirs. Headmen : Pilod Khan and Mirgul.

SнблАTaL.-A sestion of Shujawal, Mubarak Shahi, MIallizad, Dawars. Headman : Shekh Mansur.

Shгуг Kнег $(1,280)$. - A section of Palli Khel, Manzai, Alizai Nabsuds.

SHWATAx.-A minor fraction of the Sikandar Thel, Badiwai, Khalli Khel, Vpper shaman Khel, Shaman Khel, Mabsuds.

S:KANDAR KHEL.-A section of Manzar Khel, Ibrahim Khel, Utmanzai, Darw ish Khel Wazirs.
Headmen : Lal Khen, Ayaz Kihan, Maddi Khan.

SIFANDAR KHEL (150).-A section of the Badiwai, Khalli Khel, Upper Shanan Khel, Mahsuds.

Sigandar KHeL.-A section of Palali, Tapiai, Tappizad, Uawars.

SthaNdar KHEL (20).-A minor fraction of Khoonia Khel, Shadai Khel, Nasrai, Kalu Khel, Ahmadzai, Varresh Khel Wazirs. Headman : Nazim.

Siman.-A section of Malli Ǩhel, Idak, Tappizad, Dawars.

SIMAN KHEL, - A section of Palali, Tapiai, Tappizad, Dawars.

SINI KHEL.-A minor fraction of Khiddar Khel, Mihtar Khel, Mruhammad Khel, Hasan Khel, Mohmit Khel, Utmanzai, Darresh Khel Wazirs.

SINI KHEL (10).-A minor fraction of the Ibrahim Kihel, Astanai, Shabi Khel, Alizai, Mahsuds.

SINI KHEL.-A section of Khuniya Khel, Shadi Khel, Nasradin, Kalu Khel, Alumadzai, Darwesh Khel Wazirs.

SIN KileL,-A minor fraction of Khatti, Taib Khel, Amzoni, Mallizad, Dawars.

Sint KHEL -A minor fraction of Lar Lerai, Land, Malakh Mallizad, Dawars. 


\section{5}

Sire NASAR (Winter camping ground, Choti, in the Dera Ghazi Khan District).-A division of Nasar, Gbjlzai Pawindahs.

Sirisezi.-A clan of Dautani Pawiudahs. Headman: Ghulam Sadiq.

SiRkI KeEL. - A branch of the Sani Khel, Division of the Ahmadzai Wazirs.

SiRti KHeL [800; (400 in Wano. and 400 in Bannu and Birmal)?, - A sub-division of Shin, or Saiu Khel, Ahmadzai, Darwesh Khel Wazirs : Headmen : Lajmir Khan, Band Khan, Madazan, Zargar Khan. These maliks are responsible for the Gumal.

Sirki Khel. - A minor fraction of Gita Khel, Muhammad Khel, Malakh, Mallizad, Dawars.

Sirki KHel, -A minor frac. tion of Taos Khel, Sogri Khel, Mubammad Khel, Malakh, Mallizad, Vawars.

Sir Shoditakai, - A minor fräction of Shodiyakai, Bumi Khel, Nasradin, Kalu Khel Ahmadzai, Darmesh Khel Wazirs.

SODA KHEL (20). - A minor fraction of the Mirdad Khel, Abdur Rahman Khel, Nina Khel, Bahlolzai Mahsuds. Headman : Samandar.

SogI KHEx.-A seetion of Mabammad Khel, Malakh, Mallizad,
Dawars. Headmen: Flan Mubammad Than, Makhmad.

SoP KHEL. $\rightarrow$ A minor fraction of Janbeg Khel, Ali Than Kihel, Sarki Khel, Madda Knel, Ibrahim. Khel, Utmanzai, Darwesh Kihel, Wazirs.

SorA KHEx (70.-A minor fraction of the Gegrs Khel, Siser Krhel, Haibat Khel, Xana Khel, Bahlol, zai, Mahsuds. Headman : Shahid Khan.

SOT, Or ISOT KHEL. - A divjeion of Mian Kuel, Lohana Parvindabs.

SPAIGI.-A minor fraction of Abdul Rahman Khel, lluhammal Khel, Malakh, Mallizad, Dawars.

SPe EIS; see Spalgi, for which it is another name.

SPIN KHeI.-A section of Zhao Khel, Tapiai, Tappizad, Dawars.

Star Ali Krhav Khel (820).-A name applied to the Khazzar Khel and Nazar Khel, minor fractions of the Ali Khan Khel, Sarki Khel, Madda Khel, Ibrahim Khel, Utmanzai, Darwesh Khel Wazirs. Headmen : Sadda Khan, Alambe, and Shadam Khan.

SolmMani.-Sometimes said to be a section of Khaddar Khel, but in reality a section of Wuzi Khel, Mohmit Khel, having land among the Kbaddar Khel. 


\section{6}

Solemax KHel $(9,220$; between Krlat-i-Ghilzai and Jalalabad).The most numerous and powerful of the Ghilzai Pawindah trading clans.

SeltanaI (200).-A sub-division of Shabi Khel, Alizai, Mahsuds. Headman : Fakir Muhammad.

Seltax Khel (40). - A minor fraction of the Bojia Khel, Shingi, Bahlolzaj, Mahsuds. Headman : Sirat Khan.

StLTAN KHEL. - A minor fraction of Kharmanj Khel, Khwaja Khel, Miamai, Kabul Khel, Wali Khel, Utmanzai, Darwesh Khel Wazirs. Headmen: Surkam and Gulbat Khan.

Scltas KHel (Winter camping ground, Janeli in the Dera Ismail Khan District).-A division of Suleman Khel, "Ghilzai Pawindahs. Headman : Aurang.
SorA KH8I (80).-A section of the Giga Khel, Nana Khel, Bahlolzai Mahsuds. Headman: Shahid Khan.

SURAN KHEL. A dirision of Kharote, Ghilzai Pawindahs. Headman : Aulad Khan.

SURAr.-A section of Tarai Muia, Waraspun, Bhittanis.

Sorat KHEL (70).-A section of the Snltanai, Shabi Khel, Alizai Mahsuds. Headman : Darar.

Str Dodi Khel (Bannu District). - A minor fraction of Dodi Khel, Khandar Khan Khel, Hathi Khe!, Ahmadzai, Darwesh Khel Wazirs.

SER SARMASHAI (20).-A fraction of the Khalli Khel, Shahur Shaman Khel, Shaman Khel, Mahsuds. Headman : Adil.
TABBI KHEI.-A minor fraction of Hindi Khel, Tor, Jani Khel, Whil Khel, Utmanzai, Darwesb Khel Hazirs. Headwan: Mal. kun.

TAGHAL KHEL $(20)$. - A minor fraction of the Rahimdad Khel, Abdul Rahman Khel, Sher Khel, Haibat Khel, Nana Khel, Bahlolzai, Mahsuds.

$\mathrm{T}_{A G H I} \mathrm{~K}_{A I}(50)$. - A section of $\mathrm{Ma}$ lik Dinai, Manzai, Alizai, Mah. suds. Headman : Sahibgul.

TAGOL KHEL (10). - A minor fraction of the Ragi $\mathbf{K}$ hel, Rahimdad Khel, Abdurrahman Khel, Nana Khel, Bahlolzai, Mabsuds. Headman : Baray.

Tahir ShaH.-A section of Brahim Khel, Amzoni, Mallizad, Dawars.

TAIB KHEL (300).-A sub-division of Amzoni, Mallizad, Dawars. Headmen: Hathi Khol, Panak, Said Akbar, Mokhsein. 
TaJaL KHeL (50).-A section of Ibrahim Khel, Astanai, Shabi Khel, Alizai, Mahsuds. Headman : Shabnir.

TAJBI KHEL (150).-A section of the Taru Khel, Boba, Uhana Bhittanis.

'YAJI KHEL (600). - A fraction of the Bomai, Nasrai, Kalu Khel, Ahmadzai, Darwesh Khel, Wazirs. Headman : Mirzagul.

TaJi KHeL ( 20 ). - A minor fraction of the Hiral Khel, Chahar Khel, Upper Shaman Khel, Shaman Khel, Mahsuds.

TAJI KHEI (20).-A minor section of the Mamia Khel, Kharmarz Khel, Nazar Khel, Ainal Khel, Bahlolzai, Mahsuds. Headman : Salebin.

TAJI KHEL and BABAKR (10).-A minor fraction of the Landi Khel, Sadian Khel, Khoedadi, Malik Shahi, Aimal Khel, Bahlolzai, Mahsuds.

TAJI and Hassan KHeL (30).-A minor fraction of the Shiraz Khel, Jalal K hel, Nana Khel, Bahlolzai, Mahsuds. Headman : Alimon.

TaJU KHeL (50); winter camping ground, Musazai in the Dera Ismail Khan District).-Nomadic, a mivor fraction of the Umarzai,
Sen Khel, Mian Khel, Lohana Pawindahs. Herdmen : Rab กิawaz Khan, Khan Bahadur.

TAKHMaL KHEL.-A minor frartion of Nazar Khel, Ali Khan Khel, Sarizi Khel, Madda Khel, Ibrahim Khel, Utmanzai, Darwesh Khel Wazirs.

Taketi Keel (Bannn and Shawal).-A section of Bakka Khel, Wali Khel, Urmanzai, Darwesh Khel Wazirs. Headmen: see Usman Khel and Khan Khel.

TAKHTI KHez (British territory).A minor fraction of Burin Khel, Shadi Khel, Nasradin, Kalu Khel, Ahmadzai, Darwesh Khel Wazirs. Headman: Hasham Khan.

TAKHTI KHEL-A sub-division of Umar Khel, Tatta, Bhittanis.

TALIB KHPI (50).-A-fraction of the Sher Khel, Haibat Khel, Nana. Khel, Bahlolzai Mashuds. Headman : Mir Ajal.

TaL Khan KHeL (20), - A minor fraction of the Darai, Chahar Khel, Upper Shaman Khel, Shaman Khel, Mahsuds. Headman Mawal.

TANI KHBT. - A minor fraction of (ihani Khel, Mir Hasani, Macha, Madda Khel, Ibrahim Khel, Utmanzai, Darwesh Khel Wazirs. 
Tanis $\{3,000$, southern border of Khost).-A tribe living between the Zadrans on the west, and the Gurbaz on east. Headman : Khan Badshah. Chief village, Dargi. About 100 families (Headman : Than Shirin) are settled amongst Madda Khel Wazirs of the Kazha.

TAN KUSHI.-A section of Tareta, Idak, Tappizad, Dawars. Headman: Ghulam Rasul.

TAOS KHex (Bannu District).-A minor fraction of Pirba Khel, Hathi Khel, Shin, or Sain, Khel, Ahmadzai, Darresh Khel Wazirs. Headman: Dilawar Khan.

TAOS KHEL.- A minor fraction of Sogi Khel, Muhammad Khel, Malakh, Mallizad, Dawars. Headman: Khan Muhammad Khan.

TaOS KHeL.-A sub-division of Haidar Khel, Tappizad, Dawars. Headman : Panai.

TAPI oR TAPI KHeL (60). - A subdivision of Badanzai, Shaman Khel, Mahsuds.

TAPIAI (504).-A division of TappiZad, Dawars. Headmen: Baz, Abdulla, Gula! Shah, Mir Kalam, Zarar, Dawagar.

TAPPAR KHEL (501.-A minor iraction of the Khoon ia Khel, Shodai, Nasrai, Kalu Khel, Ahmadzai, Darwesh Khel Wazirs. Headman: Niazai.
TAPPI - Another name given to the Tapiai Tappized Dawars.

TAPPIZAD $(2,333)-$ One of the two clans of Dawars. Headmen: Naztrband Gulab Shah, Mir Khitab.

Tara Khel (400)-A sub-dirision of Muia, Waraspun, Bhittanis. Headman : Isof Kh:n (Khrad).

Taba Kabe (20). - A minor fraction of the Sandra Khel, Shami Khel, Jalal Khel, Nana Khel, Bahlolzai, Mahsuds.

TARAKI.-One of the three primary branches of the Khataks in British territory.

TaRAEIS $(3,000$; Ghazni and Kalatj-Ghilzai).-One of the Ghilzai Pawindsh trading clans.

Taran KHec,-A sub-division of Sara, Tatta, Bhittanis. Hea'man: Minak.

Taneta.-A sub-division of Idak, Tappizad, Dawars. Headman : Daisal.

TargadaI (70).-A fraction of the Gidi Khel, Manzai, Alizai Mahsuds. Headman : Barlai.

TARI.-One of the three primary branches of the Khatak tribe in the Bannu District. 
TABI KHRL-A minor fraction of Tol Khel, Abdal Khel, Bora Khel, Utmanzai, Darwesh Khel Wazirs. Headmen: Allabdad and Sherma.

TARI KHEL. (Winter camping ground, Dir Khana in the Dera Ismail Khan District).-A clan of the Niazi Parindahs. Headman: Shahbaz Khan.

TAREAI (80).-A section of Shamerai, Manzai, Alizai, Mahsuds. Headman. Pira Kbel.

TARKA KHEL.-A minor fraction of Charkhil, Land, Malakb, Mallizad, Dawars.

TAR KHEL.-A minor fraction of the Mussakli, Wuzi Khel, Mohmit Khel, Utmanzai, Darwesh Khel Wazirs. Headman : Sarwar.

TAR KHeL.-A section of Pira Knel, Kanizai, Kattagram, Tatta, Bhittanis.

TAREI KHAN -A sention of the Ismail, Gulzai, Barak Khataks of Ter in the Bannu District.

TAREI KHEL (30). - A section of Natti Khel, Galeshahi, Shaman Khel, Mabsuds.

TARKI KHEL (20).-A section of Bibizai, Shabi Khel, Alizai, Mahsuds.

TARO KHeL (730). - A sub-division of Boba, isana, Bbittanis. Headmen: Nasar, Mir Akior, Adam Khan.
Tatar Khel (10). - A minor section of the Mired Khel, Michi Khel, Shumi Khel, Palli Khel, Manzai, Alizai Mabsuds.

Tatta (890)-A clan of the Hhittanis. Headmen: Fateh Khan, Umar Khel, Abmad Khan, (Niamat Khel), Shahbaz, sred Amin (Badzai), Mina Irban (Ảba Krael) Tor (Kanezai).

TATTA KHEL. - A minor fraction of Madda Khel, Miamai, Kabul Khel, Utmanzai, Darwesh Khel Wazirs.

Tattar Khel, - A minor fraction of Idal Khel, Muhammad. Khel, MIalakh, Mallizad, Dawars.

Tattar Thes (30), - A minor fraction of the Brond IThel, Chahar Khel, Upper: Shaman Khel, Shaman Khel, Mahsuds. Headman : Ila.

Tats KHEL (35; Dera Ismail Khan District). - Nomadic, a section of Waruli, Sen Khel, Mian Khel, Lohana Pawindahs.

TaW as Irex. - A minor fraction of Bakhshi Khel, Madda Khel, Ibrahim Khel, Utmanzai, Darwesh Khel Wazirs. Headman : Gulli. 


\section{0}

Tawas KHer (Bannu, Wano, and Birmal).- $-A$ section of Sirki Khel, Shin, or Sain, Khel, Ahmad. zai, Uarwesh Khel Wazirs. Head. men : see Sirki Khel.

TERI KHBL.-A sub-division of Tapiai, Tappizad, Dawars. Headman: Gulal Shah.

TILA KHEL. - A minor fraction of Mir Hasani, Macha, Madda Khel, Ibrahim Khel, Utmanzai, Darwesh Khel Wazirs.

TIMAB KHeL.-A section of Gurbuzai, Darpa Khel, Mallizad, Dawars. Headman : Gul Nam.

Tirhi Kंrec.-A section of the Ali Khel. Haidar Khel, 'Tappizad, Dawars. Herdmen : Alif Khan, Amal Khan, Abu Samand.

Tirsaur $K$ Hel. - A minor fraction of Nazar Khel, Ali Khan Khel, Sarki Khel, Madda Khel, Ibrabim Khel, Utwanzai, Darwesh $\mathrm{K}$ bel Wazirs.

TiRsay KrHeL.-A minor fraction of Masti Khel, Tojiya Khel, Bomi Khel, Nasradin, Kalu Khel Ahmadzai, Darwesb Khel, Wazirs.

TITAR KHEL.-A minor fraction of Khan Khel, T'skhti Khel, Bakka Khel, Wali Khel, Utmanzai, Darwesh Khel Wazirs. Headmen : Khan Badshh, Khazan Khan, Mian Kbel, Galzamir.
Titar KHel (30).--A section of Baran Khel, Chahar Khel, Shaman Khel, Mrabsuds.

Titi IR Hes (160). -A sub-division of Band Khel, Bahlolzai, Mah. suds. Headman : Tarder Khan.

TOCHI KHEL.-A minor fraction of Kiki Khel, MIuhammad Khel, Malakh, Mallizad, Dawars.

TOgHLA KнEL. - A minor fraction of Dani Khel, Matkai, Malik Shahi, Wali Khel, Utmanzai, Darwesh Khel Wazirs.

TOIA $K$ HEL. - A minor fraction of Bachagai, Tor, Jani Khel, Wali Fhel, Utmanzai, Darwesb Khel Wazirs. Headman: Mirbosh.

Torb KHeL (55). - A minor fraction of the Sher Khel, Haibat Khel, Nana Khel, Bablolrai, Mahsuds. Headmen : Mir Ajal, Bare Khan, Malang Khan.

ToJi $\mathrm{K}$ Hex. $-\mathrm{A}$ minor fraction of Pira Khel, Jamal Khel, Malik Shahi, Wali Khel, Utmanzai, Darwesh Khel Wazirs.

ToJira KHEL $(1,600$, - of whom 1,000 are in Wano). - A minor fraction of Bomi Khel, Nasradin, Kalu Khel, Ahmadzai, Darresh Khel Wazirs.

TokHISs $(1,500$; Ghazni and Kalati-Ghilzai)--One of the Ghilzai Pavindah trading clans. 
Tor $\triangle B$ KHex (30)-A minor fraction of the Kotar Khel, Abdul Khel, Laugar Khel, Khoidad Khel, Gidi Khel, Manzai, Alizai, Mahsuds.

Tora KHEL. - A minor fraction of Mir Khan Khel, Asat Khel, Wuzi Khel, Mohmit Khel, Utmanzai. Darwesh Khel Wazirs.

ToL KHEL.-A minor fraction of A bdul Khel, Bora Khel, Molumit Khel, Utmanzai, Darwesh Khel Wazirs. Headman: Mirsahib.

Torang KHet (60).-A minor fraction of the Lalli Khe?, Abdullai, Aimal Khel, Bahlolzai, Mahsuds.

Torang Krel (80).-A minor fraction of the Torang Khel, Lali Khel, Abdullai, Aimal Khel Bahlolzai, Mahsuds. Headman : Kharaja Muhammad.

Toran KHer. -A sub-division of Pala Khel, Tatta, Bhittanis.

TORLaLI.-A sub-division of Khaddi, Mallizad, Dawars.

"Yon DoI Khel (Bannu District). - A minor fraction of Dodi Khel, Khandar Khan Khel, Hathi Kbel, Shin, or Sain, Khel, Amadzai, Darwesh Khel Wazirs. Headman: Nezam Khan.

TorI Khel $(3,500$; a continuous belt of country outside, but parallel to our frontier from the shakttu to the Kurram river and the Kaitu stream).-A sub-division of Ibrahim Knel. Utmanzai, Darwesh Khel Wazirs. Headman : Kotanai and Madd (Muhammad) Akbar are the leading men; for other's see Shugai, Khushalei Haibattai, and Dreplarai.

TORI KHEL (20). - A minor fraction of the Kasim Khel, Chahar Khel, Shaman Khel, Mahsuds. Headman : Amir Khan.

TORI KHEL. - A minor fraction of Idal Khel, Muhammad Khel, Malakh, Jlallizad, Dawars.

Tcri Krel (Bannu District).-A minor fraction of liusa $\mathrm{Khel}$, Hathi Kbel, Shin, or Sain, Khel Ahmadzai, Darwesh Khel Wazirs. Headman : Shah Tamoz.

TorI KHen.-Anotber name for Teri Khel, Tapiai, 'Tappizad Dawars.

TORI KHEL.-A minor fraction of Cuarlibil, Land, Malakh, Mailizad, Dawars.

TORI KHEL. - A minor fraction of Dod Khel, Mir Hasani, Macha Madda Khel, Ibrahim Khel, Utmanzai, Darwesh Khel Frazirs.

ToR KHEL (30). - A minor fraction of the Khan Khel, Kharmarx Khel, Nazar Kbel Aimal Khel, Bahlolzai, Mlahsuds. 
TOR KHEL.-A minor fraction of Aziz Khel, Shas i Ḱbel, Bora Khel, Mohmit Khel, Utmanzai, Darresh Khel Wazirs. Headman : Ida Khisn.

ToB KHEL.-A section of Jan Kbel, Wali Khel, Utmanzai, Darwesh Khel IIazirs. Headmen: Malkun, Pir Makhmad Amaldad, Mirbosh, Shadamir, Traimal, and Gulbaz.

TOR (or B BzID) KHEL.-A minor fraction of Thazzar Khel, Ali Khan Khe!, rarki Khel, Madda Khel, Ibrahim Khel, Utmanzai, Darmesil Khol Wazirs.

TOR KHEL.-A minor fraction of saiyid Khel, Cmarzai, Sain Khol, Ahmadzai, Darwesh Khel Wazirs.

Tor Krex-1 minor fraction of Alikbani, Bomi li hel, Nasradin, Talu Ehel, Ahmadzai, Darwesh Thel Trazirs.

Tor KHel. (Bannu and Kurran).A section of Umarzai, Sain Khel, Ahmadzai, Darwesh Trhel Wazirs. Headmen : Jamal Din, Adal Khan, Alim Khan, Senian, Niazi, Fazal, Zaid Gul, Gballai.

TOR IKHEL.-A section of Alizai, Darpa Khel, Mallizad, Dawars.

TOR SaRMashar (20).-A section of the Khalli Kbel, Shahur Shaman Khel, Shaman Khel, Mahsuds. Headman : Mastikai.

Tozia KHec.-A minor fraction of Mir Hasani, Macha, Madda Khel, Ibrahim líhel, Utmanzai, Darwesh Krbel Wazirs.

Toz KHEL.-A

Haidar Khel, Tection of ars. Headmen : Gul Fin, DawKhan.

TOKAR KHEL.-A sub-division of Musakki, Mallizad, Dawars. Headman: Hibib Khan.

Tor (Winter camping ground, Panir ala, in the Dera Ismail Khan District). - A division of Nasar Ghilzai Pawindahs. Headman : Piràil.

T'URaki Krec.-A sub-division of Shakbi, Waraspun. Bhittanis. Headınen: Zarif (Chalak Khel). Mohamed (Birm Mast-Khel.)

Trastagi-A section of Alizai Darpa Khel, Mallizad, Dawars.

T'DDAM, Or WODAM, KHBL.-A minor fraction of Nazar Khel, Ali Knan Khel, Sarki Khel, Miadda Khel, Iurahim Khel, Utmanzai, Darwesh Khel Wazir. Headmen: Khadim Khan and Nabi Khan.
UMaR KHaN KHEL.-A minor fraction of Balli Khel, Shadi Khel, Bora Khel, Mohmit Khel, Utmanzai, Darwesh Khel Wazirs. 
UIA KHAN KEEL.-A minor fraction of Malik Shahi, Jani Khel, Wali Khel, Utmanzai, Darwesh Khel Wazirs. Headman : Talibshah.

Uyar KhaN Kher. - A minor fraction of Miri Khel, Land, Malalih, Nallizad, Dawars.

UMar KHel. (1CO).-A division of Tatta, Bhittanis. Headmon : Fateh Khan (Mamli Khel) Gulbagh (Salemi Khel).

U II $\triangle \mathrm{B}$ KHEL. - A section of Chaplai Muia, Waraspun, Bhittanis. Headman : Katal K habardār, Dino.

U Ir AR KHEL.-A minor fraction of Sada Khel, Isperka, Kalu Khel, Ahmadzai, Darwesh Khel Wazirs. Headmen: Lahori and Umar Khan.

UMAR KHEL.-A minor fraction of Khiddar Khel, Mihtar Khel, Muhammad Khel, Hasan Khel, Mohmit Khel, Utmanzai, Darwesh Khel Wazirs.

UMAB KHEL. - A minor fraction of Ali Khel, Khaddar Khel, Mohmit Khel, Utmanzai, Darwesh Khel Wazirs. Headmen: Salih Din, Nazarka, Gul Samid, Zarbat Kban, Mashrai and Nazir Khan.

UMAR KHEL (140), - $\mathbf{A}$ section of Astanai, Shabi Khel, Alizai Mahsuds. Headmen : Alif Shab Khurri.
Unab KHel (10̃0), - a minor fraction of Niliarrab Khel, Khoidad Khel, Gidi Khel, Manzai, Alizai, Mahsuds. Headmen : Badar Din, Muhammad Afzul, Salehin, Sari Band.

UMar KHEL (150).-A sub-division of Nana Khel, Bahlolzai, Mahsuds. Headman : Shekh Amir.

UMAR KHEL (60). - A minor fraction of the Shamshi Khel, Shekh Hassan, Taji Khel, Bomai, Nasrai, Ahmadzai, Darwesh Khel Wazirs. Headman : Kasim.

UMarzaI (600; Bannu and Razmak).-A sub-division of Sain Khel, Ahmadzai, Darwesh Khel Wazirs. Headmen : Pirmal Khan, Jamal Din, Alam Khan, Senian, Niazi, Fazal, Zaid Gul, Ghallai.

UMARZAI (53). - A section of Zira Khel, Amzoni, Mallizad, Dawars。 Headman : Malum Shah.

UMARZAI (213; winter camping ground, Baber, in the Dera Ismail Khan District).-Nomadic, a sabdivision of Sein Khel, Mian Khel, Lohana, Pawindahs. Headmen : Kadir Khan and Hasan Khan.

UMARZaI.-A division of the Ahmadzai, Darwesh Khel Wazirs. Inhabit the north bank of the Kurram partiy in British territory.

URMAR KHEL (150).-A sub-division of Shingi, Bahlolzai, Mahsuds. Hesdman : Gala Khan. 


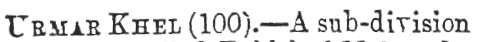
of Nana Khel, Bithlolzai Mahasuds. Headmen : Baharral; Nikarrab.

Trmars $(1,000)$. - A tribe of Saiyids living among the Mabsuds. They hare a language and customs of their orra, and are probably descendants of the original inhabitants of the country. Headmen : Pahalwan and Abdul Karim.

URMeR.-A minor fraction of Balli Khel, Shadi Khel, Bor Khel, Mohmit Khel, Uttmanzai, Dar'wesh Inhel Wazirs.

IRy AR.-A section of Taib Khel,
Amzoni, Mlallizad, Dawars.

Tshe KHeL. (Winter camping grounds, Saggu, Naiwela, and Iniachiwala in the Dera Ismail Than District). $-A$ division of Nasar. Ghilzai Pawindabs. Headmen: Pir Muhammad, Shahzad anç Dis Alubammad.

UsMaU hHax KHEL (40).-A section of Bibizai, Shabi Khel, Alizai, Mahsuds.

TSYAN KHEL (30).-A section of Tappi Khel, Badinzai, Shaman Khel, Mabsuds. Headman: Sad Raman.

CSUrAN KHEL.-A minur fraction of Takhti Khel, Baklka Zhel, Wali Khel, Utmanzai, Darwesh Fhel Wazirs. Headmen : Khojamir, Nozalmir, Islam Khan, Akmad Did, Sakam.
Usmax KHex (British territory)-A minor fraction of Budin Khel, Shadi Khel, Nasradin, Kalu Khel, Abmadzai, Darwesh Khel Wazirs. Headman : Maghapur.

Usman KHel (160).-A sub-division of the Band Khel, Bahlolzai Mahsuds. Headmau : Rahimdad.

Uste KHEL. -A division of Kharoti Ghilzai Parindabs. Headman : Mirza Khan.

Un KHEL (Winter esmping ground, Pata, in the Dera Ismail Khan distriet).-A division of Nasar, Ghilzai Pawindahs. Headmen : $J$ uma Khan and Mir Alam.

Utman-A sub-division of Miram Shab, Tappizad, Dawars. Headmen : Nakkar, Mongul.

UtMan KheI (ã̃o; Wano).-A minor fraction of Zilli Khel, Bomai Nasrai, Kalu Khel, Ahmadzai, Darwesh Khel Wazirs.

UTMAN KHEL. - A section of Kesu, Waruki, Dhana, Bbittanis.

UtMan KHEL. - A minor fraction of Charkhil, Land, Malakh, Mallizad, Dawars.

UTMANZAI $(15,000$; Kurram rivex, Kaitu, Tochi, Khaisora and Shawal). - One of the two clans of Darwesh ז̆hel Wazirs. 
Uz $\triangle$ R KHEL (10). - A minor fraction of the Sikandar Khel, Badiwai, Khalli Khel, Upper Shaman Khel, Shaman Khel, Mahsuds.
UZSHDAH.-One of the principai divisions of the Barak Khataks, inhabiting Bahadur Khel in the Bannu district.
WAJI KHEL (150).-A sub-division of the Shingi, Bahlolzai, Mahsuds. Headman : Imar.

WALA KHEL. - A minor fraction of Sardi Khel, Bakka Khel, Wali Khel, Utmanzai, Darwesh Khel Wazirs. Headman : Rasul Shab.

WALAK KHEL -A minor fraction of Dosalli, Wuzi Khel, Mohmit Khe], Utmanzai, Darwesh Khel Wazirs. Headmen : Zarim Khel, Simon Khan and Nur Mahammad.

WAII KHEL (60).-A section of the Mamin Khel, Shingi Bahlolzai, Mahsuds. Headman : Mad Ali Khan.

WaLI Khel (10).-A minor fraction of Mirdad Khel, Abdur Rahman Khel, Nana Khel, Bahlolzai, Mahsuds.

W 3 great divisions (viz., Mohmit Khel, Ibrabim Khel, and Wali Khel) of the Utmanzai slan of the Darwesh Khel Wazirs. Headmen; see Kabul Khel Malikshahi, Bakka Khel, and Jani Khel。
WaLIDAD KHRL (40).-A minor fraction of the Boya Khel, Malli Khel, Shelh Hassan, Taji Khel, Bomai, Nasrai, Abmadzai, Darwesh Khel Wazirs.

WALIDAD KHEL (248).-A minor fraction of the Lalli Khel, Abdullai, Aimal Khel, Bablolzai, Mahsuds.

WALIDOKI KHEL (40). - A minor fraction of the Boya Khel, Malli Khel, Shekh Hassan, Taji Khel, Bomai, Nasraj, Abmadzai, Darwesh Khel Wazirs. Headman: Salim Khan.

W $\triangle$ LID KHEL (200).-A fraction of the Malai (or Mal Khel), Dachi Khel, Palli Khel, Manzai, Alizai, Mahsuds.

WaLIGaI (Bannu District). -A minor fraction of Musa Khel, Hathi Khel, Shin, or Sain Khel, Abmadzai, Darwesh Khel Wazirs. Headman : Adam Khan.

WaNI KHeL (Banna District).-A minor fraction of Kundi, Pirbu Khel, Hathi Khel Shin or Sain Khel, Ahmadzai, Darwash Khel $\mathrm{W}$ azirs. 


\section{6}

W $\triangle$ BASPON $(1,030)$. - A clan of the Bhittanis. Headmen: Ghaza Khan, Batta Khan, Adam Khan.

WarGaRe (100).-A division of the Dhana, Bhittanis. Headman: Gula Khan (Maruf Khel).

WARIEA.A minor fraction of Ahmad Khel, Zira Khel, Amzoni, Nailizad, Dawars.

WARRIA KHEL:-A section of Ali Khel, Bubak, Dhana, Bhittanis.

$W_{\triangle R C K \triangle}$ ALI KHAN K $K_{H E L}(300)$. A name applied to the Niamat Khel, Khwajahmad Khel, and Janbeg Kbel, minor fractions of the Ali Khan Khel, Sarki Khel, Madda Khel, Ibrahim Khbel, Utmanzai, Darwesh Thel Wazirs. Headmen: Madi and Nizardin.

WARRCLAL.-A minor fraction of Idia Khel, Jani Khel, Wali Khel, Utranzai, Darwesh Khel Wazirs. Headmen : Zargai and Shekl. Majid.

$W_{\triangle R E K I}$ (I $2 \tilde{5}$; winter camping ground, Khana, in Dera Isinail Khan District),-Nomadic, a subdivision of Sen Khel, Mian Khel, Lohana Pawindahs: Head. man : Dost MY Mhammad.
WARUKI.-Division of Dhana, Bhittanis. Headmen: Laisar, Sher Muhammad Kban.

WATAR.-A section of Bar Kaum, Hassu Khel, Mallizad Dawars.

W of Miri Khel, Land, Malakh Mallizad, Dawars.

WatTIRI.-A minor fraction of Aghzan, Zira Khel, Amzoni, Mallizad, Dawars.

$W_{\triangle Z A R}$ KHEL. - A minor fraction of Mir Kban Khel, Asat Khel, Wuzi Khel, Mohmit Khel, Utmanzai, Dar'wesh Khel Wazirs

$\mathbb{W}_{\triangle Z A R}$ KHEL.-A minor fraction of Kiki Khel, Mubammad Khel, Malakh, Mallizad, Dawars.

$W_{A Z I}$ KHeL.-A section of Shammal, Hassu Khel, Mallizad, Dawars.

$W_{\triangle Z I R G A I}(290)$. - A fraction of Gidi Khel, Manzai, Alizai, Mahsuds. Headman : Amardin.

W of Ali Khel, Brabim Khel, Amzoni, Mallizad, Dawars.

WAZIR KHEL, -A clan of J)antani Pawindahs. Headman : Isa Khan. 
WAZIRS $(38,140 *)$ - - A large tribe of Pathans who inhabit the bill "ountry to the west of the Transriver near Thall, to the Gumal Pass. They are divided into two main branches, i.e., the Darwesh Khel and the Mahsuass. The sormer are again divided into the Ahmadzai and the Utmanzal. Wach of these three branches, i.e., the Mahsuds, the Utmanzai, and the Ahmadzais bave little in common with each other. Two Afghan tribes, i.e., the Gurbaz of Khost and the Laili, northern slopes of the Safed Kob, are of the same origin as the Wazirs. A few families of Gurbaz live on the British side of the Durand line. The name Wazir is, generally applied to the Darwesh Khel branch only, which is considered as a separate tribe to the Mahsuds for the purposes of this dictionary.

Wocher Khat (40).-A minor fraction of Mitha Khel, Badiwai. Indus frontier from the Kurram amongst the tribesmen, more

Khalli Khel, Shaman Khel, Mahsuds. Headmen : Jamal, Shabnir.

Wodar KHeL.-See UdDay KHeL.

WODIN KHEL.-A minor fraction of Khazzar Khel, Ali Khan Khel, Sarki Khel, Madda Kihel, Ibrahim Khel, Utmanzai, Darwesh Khel Wazirs.

Wolay KHEL.-A minor fraction of Shamsi Khel, Tojiya Khel, Bomi Khel, Nasradin, Kalu Khel, Ahmadzai, Darwesh Khel Wazirs.

WUJI KHEL (80).-A section of the Haidrai, Chabar Khel, Shaman Khel, Mabsuds.

WUZI KHEL (800; Kliaisora and Kaitu).-A sub-division of Mohmit Khel, Utmanzai, Darwesh Khel Wazirs. Headmen: Wazir Khan, Nakir Khan, Nigaz Gul, Kaloni, Jama Gul.

YA KHEL.-A division of Kharoti, Ghilzai Pawindabs. Headman : Akbar Khan.

$Y_{A} K_{H E L}$ (Winter camping ground, Paniala in the Dera Ismail Khan District).-A division of Nasar, Gbilzai Pawindahs. Headman: Bachu.

YARGUI KHEL (220).-A minor fraction of the Kamal Din, Shekh
Bazid Khel, Isap Khel, Zall Khel, Bomai, Nasrai, Kalı Khel Ahmadzai, Darwesh Khel Wazirs Headinan: Bonsha.

Yar MoHammad Khel (25).-A minor fraction of the Shari Khel, Kasim Khel, Chahar Khel, Shaman Khel, Mahsuds. Headmen : Badarkai, Kamardin, Kakar. 
YasinzaI (Winter camping
ground, Paniala).-A division of Nasar, Ghilzai Pawindabs. Headman : Sardar.

Youranis.-One of the lesser Pawindab trading clans. Headman : Khan.
YUSUF $\mathrm{KHEL}(30)$. - A section of the Tapia Khel, Badinzai, Upper Shaman Khel, Shaman Khel, Mahsnds. Headman : Bazar Din.

\section{Z}

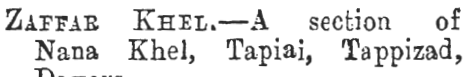
Darrars.

ZaID KHEL. - A sub-dirision of Khadi, Mallizad, Dawars.

ZAEABI (130; rinter camping ground, Rode in the Dera Ismail Khan District).-Nomadic, a subdivision of Sen Khel, Mian Khel, Lohana Pawindahs. Headmeu : Lal Mad Khar and Sardar Khan.

Zakarisa (or Za haB) KHel,-A minor fraction of Khojal Khel, Shadi Khel, Nasradiu, Kalu Khel, Ahmadzai, Darwesh Khel Tazirs. Headman: Amin Khan.

ZaEas KHel (2).-A minor frac. tion of the Khojal Khel, Shodai, Nasrai, Kalu Thel, Ahmadzai, Darresh Khel Wazirs.

ZaKAR KHEL.-A minor fraction of Zarinai, Haibattai, Tori Khel, Ibrahim Khel, Utmanzai, Darwesh Khel Trazirs
ZakRI KHeL (30).-A minor fraction of the Mitba Khel, Badiwai, Khalli Khel, Shaman Khel, Mahsuds.

$Z_{A L L I} K_{H E L}(1,200)$. - A fraction. of Bomai Khel, Nasrai, Kalu Kbel, Ahmadzai, Darwesh Khel Wazirs. Headman : Banocha.

Z MANT KHEL (130)-A fraction of Wazirgai, Gidi Khel, Manzai, Alizai, Mahsuds. Headman :Mian Gul.

ZaMxN KeEI (Bannu District).-A minor fraction of Ali Khel, Musa Khel, Hathi Khel, Shin, or Sain, Khel, Ahmadzai, Darwesh Kheİ Wazirs. Headman : Isa Gul.

ZaYG KHEL (Winter camping ground, Gumab bazar in the Dera. Ismail Khan district).-A divi sion of Nasar, Ghilzai, Pawindahs. Headman: Nazar.

ZaRA KHEL.-A section of Boya, Tappizad, Dawars. 
ZARGAR.-A sub-division of Khaddi, Mallizad, Dawars.

Zargar Kher (60).-A minor fraction of Kharmanz Khel, Nazar Khel, Aimal Khel, Bahlolzai, Mahsuds. Headman : Musa Khan.

$Z_{A R G A R} \quad K_{H E L} \quad(16) .-A$ minor fraction of the Nikarrab Khel, Khoidad Khel, Gidi Khel, Manzai, Alizai, Mahsuds.

ZARGAR KHEL.-A minor fraction of Sarmast Khel, Badi Khel, Dardoni, Wuzi Khel, Mohmit Khel, Utmanzai, Darwesh Khel Wazirs. Headman: Wazir Khan.

ZaRGaR KHel.-A minor fraction of Kutti Khe], Unar Khel, Ali Khel, Khaddar Khel, Mohmit Thel, Utmanzai, Darwesh Khel Wazirs. Headman : Mashrai.

ZaRGAR KHEL (18).-A sub-division of Boya, Tappizad, Dawars. Headman : Gulbat.

ZABGAR KHEL.-A section of Malli Khel, Idak, Tappizad Dawars.

ZARIA KHEL (100). -A sub-division of the Chahar Khel, Shahur Shaman Kinel, Mahsuds. Headman : Faqir.

Zaria KHEL (40).-A section of the Bangish Khel, Ibrahim Khel, Astanai, Shabi Khel, Alizai, Mahsuds.
ZaRIF KHeL (60). - A section of the Shamak Khel, Abdullai, Aimal Khel, Bablolzai, Mahsuds. Headman : Tarakai.

ZaRINAI.-A minor fraction of the Haibattai, Tori Khel, Ibrahim Khel, Utmanzai, Darwesh Khel Wazirs. Headmen: Lal Khan and Shonabat.

Zarke KHeL (10). -A minor fraction of the Mamia Kriel, Kharmarz Khel, Nazar Khel, Aimal Kbel, Bahlolzai, Mahsuds.

Zarmar Kenel (18).-A minor fraction of Karimdad Khel, Abdul Rahman Khel, Sher Kbel, Haibat Khel, Nana Khel, Bablulzai Mahsuds.

ZarMar KHel (10). - A minor fraction of the Mirah Khel, Shami, Khel, Jalal Khel, Nana Khel, Bahlolzui, Mahsuds.

Z fraction of the Shamak Khel, Abdullai, Aimal Khel, Bahlolzai, Mah̀suds. Headman : Tarkai.

Z of Chahar Khel, Shaman Khel, Mahsuds.

Zeraker (203).-A division of Mallizad, Dawars. Headmen : Haibad Khan, Ahmad Khonar, Yargul, and Peshawar.

ZHaO KHeL - - A sub-division of Tapiai, Tappizad, 1)awars. Headman : Mir Kalam. 


\section{$\angle 00$}

ZiraI-A miror fraction of ZIRA KHEL.-A sub-division of Shadi Tibel, Lar Lrrai, Land Banda, Tappizad, Darrars.

Malakb, Mrallizad, Dawars.

Zira Krerc.-A minor fraction of ZoLI KHEI.-A section of Mad Khozai. Khaddar INkel, Atman: Miram Shah, Tappizad. Mohmit Khel, Utmanzai, Darresh Khel Tazirs. Headman: Pir Muhammad.

ZIRA KHEL (24\%).-A sub-division of Amzoni, Mallizad, Dawars. Headmen : Ji uhammaù Alam and Mn uhammad Ayub.

Zoviza KHEL.-A minor fraction of Muhammad Khel, Isperka, Kalu Khel, Ahmadzai, Darrwesh Khel Wazirs. Headmen: Jan Nur, Mruhammad, Shah Kamran . 


\section{PIRT IV. \\ Baluchistan.}

ABBAS KHEL (18)(Quetta-Pishin).A division of Targhara Kakars.

Agdal (5,145) (Quetta-Pishin).The largest clan of Tarins.

ABdulani (303) (Sibi).-A subdivision of Makhiani, Tor, Tarins.

Abdolazal (1,105) (Zhob).-A division of Sanzarkhel, Kakars. Headman : Sherak Khan.

AbdtrlazaI (Quetta-Pishin).-A section of Ashazai, Achakzai, Abdul, Tarins.

Abdulzal (Quetta-Pishin).-A section of Bazai, Harunkhel, Sanatia, Kakars.

AbDul KarimzaI (Quetta-Pishin). -A section of Mehtarzai, Harudkhel, Sanatia, Kakars. Headman : Dil Murad. Headman: Malik Nabo.

ABDoluarmel (Sibi).-A clan of Panis.
Abdel RaHimanzal (78) (QuettaPishin).-A sub-division of Parezun, Sanzarkbel, Kakars. Headman: Muhammad Jan.

Aeder Rahimzal (Quetta-Pishin). -A section of Mehtarzai, Harunkhel, Sanatia, Kakars.

Abder Rahimzal.-See Rahimzai.

AвU BakAE (505) (Quetta.Pishin). -A division of Tor, Tarins. Headnan : Malik Palsar Khan.

Achahrer (97) (Zhob).-A division of Nasir, Ghilzais.

AcHAKzAIS $(4,725)$ (Khwaja Amran Range, Quetta-Pishin).-The largest division of the Abdal, Tarins. In reality the term "Abdal" is but sparingly used for the Achakzais, who bave become localised in the QuettaPishin district, and are regarded as a separate political unit from the rest of the Tarins. Headmen : Sirdar Abdul Hamid Khan ; Sirdar Bahadur Ghulam Haider Khan; Muhammad Hassan Khan and Taj Muhammad Khan. 
AchozaI (Quetta-Pisbin).-A clan of Kansis. Headman : Malik Atta Muhammad Khan.

AdarizaI (Loralai) - A sub-division of Malezai, Rakhanwal, Lunis. Headman : Faqir.

ADArizaI (27) (Quetta-Pishin).A sub-division of Sajgi, Tor, Tarius. No recognised Malik.

ADAYZAI (Loralai)-A division of Ibrabimzai, Zarkuns.

Adayzar (Loralai).--A division of Perozai, Zarkins. Headman: Alihan.

Adayzar (Loralai)-A division of Morezai, Isots. Headman: Dadan.

AderzaI (Toralaj).--A sub-division of Kudezai, Sanzarkhel, Kakar's. Headmen : Khudder and Khazan.

ADIL $z_{A}$ (Quetta-Pishin).-A section of Sarangzai, Harunkhel, Sanatia, Kakars, Headman: Halim Khan.

AdINAZAI (90) (Zhobj.-A minor fraction of Mulazai, Panizaj, Harunkel, Sanatia, Kakars.

AdixazaI (Zhob).-A sub-division of Thoedadzai, Sanzarkhel, Fabars. Headnen: Brabo and Dalel.

AdINxHel (5\%) (Zhob).-À division of Mallakhel, Ghilzais.
AdinzaI (24) (Zhob).-A division of Kapip, Shiranis.

Adinza (30) (Zhob).-A minor fraction of Mallezai, Hassanzai, Kibzaj, Sanzarlshel, Kakar. Headmen : Khan Sahib Paindan Khan.

AdinzaI (North Zhob). - A minor fraction of Khoidadzai, Shadozai, Alizai, Sanzarkbel, Kakars. Headman: Mulla Khalo.

AdixzaI (390) (Sibi).-A section of Sarangzai, Harunkhel, Sanatia, Kakars. Headmen: Din Muham. mad, Halim, Ikbal, Akram.

AdINZAI (Loralai).-A division of Morezai, Isots, Headman : Fatteb Mahammad.

AdinzaI (85) (Loralai).-A subdivision of Belkhel, Musakhel, Panis. Headman : Wir Mulk.

Adozar (Loralai).-A clan of Ustranas (q. v.)

AdozaI (44) (Loralai)-A division of Kibzai, Sanzarkbel, Kakars. Headman: Sahib Khan.

AdozaI (54) (Quetta-Pishin).-A section of Nasratzai, Achakzai, Abda!, Tarins. Headman : Sultan Ali. Resides in the Amir's territory.

ADRAEZAI (29) (Quetta-Pishin).A section of Alizai, Nasratzai, Achakzai, Abdal, Tarins. Head man: Wali Mahammad Khan. 
ADRimzai (23) (Zbob).-A section of Mirzaj, Alizsi, Sanzarkhel, Kakars. Headmen: Mundu and Ali Bakhsh.

$\triangle D W \triangle N I$ (39) (Loralai). - A division of Spin, Tarins. Headman : Ataullah.

AgHDadzaI (Loralai). - A division of Marghzan, Panis. Headman : Mizri Khan.

AHMADFHANZAI (30) (QuettaPishin).-A clan of Kansis. Headman: Arbab Badal Jau.

AHMADKHANZAI

Pishin).-A section of Alizai, Nasratzai, Achakzai, Abdal Tarins. Headman : Mulla Abdul Hamid.

AnMA D KHex (23) (Loralai), A division of Kharot, Ghilzais.

AHMAD KHeL (762) (Quetta-Pishin). -A division of Targhara, Kakars Headmen : Piro, Rahim, Kamat and Pir Muhamad.

A HMa D ZaI (36) (Zhob).-A section of Mamezai, Haidarkhel, Mandokhel (q. จ.) Panis. Headman: Ramzan.

AHMADZaI (Sibi), -A division of Lawana, Panis.

AIMADZAI (Zhob). - A division of Sulemankhel, Ghilzais.
AHiradzaI (11) (Loralai).-A subdivision of Malezai, Rakhanwal, Lunis. Headman; Ahmad.

A HMEDZAI (40) (Zhob).-A minor fraction of Kabalzai, Hassanzai, Kibzai, Sanzarkhel, Kakar. Headman : Faiz Muhammad.

Ahmadzal (35) (West of Dera Ghazi Khan District). - A sub-division of Mangizai, Iraharzai, Musa Khel. Headman : Kalandar.

A madazal (25) (Loralai).-A di vision of Nuhzai, Isots. Headman : Khan Beg.

Ahmadzar (482) (Bori Valley, Loralai).-A section of Mirzai, Alizai, Sanzarkhel, Kakars. Headmen : Miran, Shambe and Mobin.

AHMANAZAI (Zhob).-A section of Ismailzai, Alizai, Sanzarkhel, Kakars. Headmen : Nooraddin and Sadik.

AJABKHEL (Sibi).-A division of Dehpal, Panis.

Afazai (Quetta-Pishin).-A clan of Kansis. Headman : Arbab Khudadad Khan.

AkAKHeL (Zhob).-A sub-division of Harderkhel, Maudokhel (q.v.), Panis. Hea dmen : Ámir and Tajak.

Azbarzal (Toralai).-A division of Perozai, Zarkhaus, 
Agrrozar (135) Quetta-Pishin).A sub-division of Achakazi, Abdal, Tarins. Affiliated with the Badezai sub-division of Achakzais. Headman : Ayub Kban.

Aretarzal (238) (Zhob).-A minor fraction of Ibrahimzai, Shadozai, Ali Zai, Sanzarkhel, Kakars. Headmen: Sher Khan, Sultan, Abdur Rahim, and 'Toran.

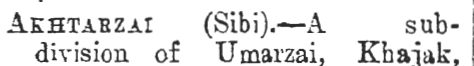
Panis.

AlaEDADZAI (140) (Zhob).-A minor fraction of Bulozai, Panizai Harun Khel, Sanatia, Kakars. Headman : Sher Shah.

Alahdadzai (100) (Zhob).-A section of Shadozai Alizai, Sanzarkhel, Kakars. ZEeadman : Mazzak.

ALAHDADZAI (18) (Zhob).-A division of Chabarkhel, Shiranis.

Alakzai (iT) (Loralai).-A division of Dirgzai, Lunis. Headman : Lal Khan Sbeikh.

ALAMBEGEHEL (63) (Zhob). - A division of Nasir, Ghilzais.

AlamzaI (Loralai).-A division of K'harot, Ghilzais.

Alesai (Zhob and Loralai). - A division of Nasir, Ghilzais.
Alikhanzal (Sibi).-A sub-divi。 sion of Babramzai, Khajak, Panis.

AlikHanzai (40̃) Zhob.-A section of Malezai, Abdullazal. Sanzarkhel, Kakar. Headmen: Kodai and Fazal Khan.

ALIKHEL (Loralai).-A division of Belkhel, Musakhel. Headman: Saraigul. A fer families live also in the Bori tabsil in Tojgi and Kachi Alizai villages. Head. men : Pan and Gullakban.

AlikHel (Zhob).-A division of Sanzarkhel, Kakars. Headman : Sharif.

A IIKHer (69) (Loralai).-A small olan of Panis.

AlikHel (Zhob).-A section of Shadozai, Alizai, Sanzarkbel, Kakars. Headman : Mirza.

Alizar (Zhób and Loralai)-A division of Suleman Khel, Ghilzais.

ALIZAI (Zhob).-A section of Alizai, Sanzarkhel, Kakars. Headman : sobdar.

AlizaI (147) (Zhob, Loralai)-A division of Sanzarkhel, Kakars. Headman : Azim Khan.

Alizai (Zhob).-A section of Mirzai, Alizai, Sanzarkhel, Kakars.

AlizaI (12) (Sibi), - A clan of Isots. 
AlizaI (Sibj).-A division of Kurls, Panis.

Alizar (497) (Loralai). - A subdivision of Wanechi, Spin, Tarins.

Alizal (500) (Quetta-Pishin and Loralai).-A division of T'or, Tarins. Headman : Mubammad Nur.

AlizaI (Loralai).-A division of Umarlihel, Ustranas (q. v.). Headman : Ali Muhammad.

AlizaI (Loralai). - A division of Perozai, Zarkhuns. Headman: Paind Khan.

AlizaI (145) (Zhob).-A minor fraction of Kabalzai, Hassanzai, Kibzai, Sanzarkhel, Kakar. Headman: Talak Khan.

Azrozat (27) (Quetta-Pishin).-A section of Hamidzai, Achakzai, Abdal, Tarins. Headman : MIuhammad Umar Khan.

ALIAHYAREHANZAI (Sibi).-A division of Barozai, Panis.

ALlezAI (48) (Quetta-Pishin).-A sub-division of Parezun, Sanzarkhel, Kakars. Headman: Haji Iskan Khan.

Alizai Naspatzar (622) (QuettaPishin).-A sub-division of Achakzai, Abdal, Tarins. Headran: Samundar Kban.
Aloza (21) (Quetta Pishin).-A division of Khaitar, Kansis. Headman: Wazir Mubammad.

ALOZAI (96) (Zhob).-A section of Shadozai, Alizai, Sanzarkbel, Kakars. Headman : Gud.

AmmezaI (116) (Zhob).-A sub. division of Abdullazai, sanzarkhel, Kakars. Headmen : Altai, Janai, and Mohamadan.

AuIAZAI (21) (Loralai).-A division of Perozai, Zarkuns.

AnaZaI (Sibi).-A division of Saf, Panis.

ANDAR (189) (Zhob, Quetta-Fishin and Loralai). - A clan of Ghilzais. 1900.

ANDWans (Sibi).-A "division. Iof Tolkhi, Ghilzais.

ANezaI (Zhob). -A division of Obolshel, Shiranis.

ANEZAI (North Zhob).-A section of Badsuzai, Alizai, Sanzarkhel, Kakars. Headman : Paind Khan.

Anizar (30).-A section of Land Ahmad, Ahmad Khel, Obokhel, Shiranis.

ANZARI (Loralai).-A sub-division of Zaam, Spin, Tarins.

Astrazar (33) (Quetta-Pishin).A section of Bazai Harunkhel, Sanatia, Kakars. Headman. Muhammad Khan. 
AOLTAZSI (140). - A minor fraction of Shadozai, Bulozai, Panizai, Harun Krbel, Sanatia, Kakars. Headman : Ali Mahammad.

ApozaI (120) (Zhob). -A division of Dawatkbel, Mandokhel (q. r.), Panis. Headman : Dadan Khan.

Apozar (Loralai).-A division of Umarkhel, Ustranas (q. v.).

Ababi KHeL (Loralai-Zhob), - A division of Ssnzarkhel, Kakars. Headinen : Khan Sabib Azam Khan, Mado, Azim Kban, Násiban, Ǩhánu and Dádu.

ArabzaI (200) (Zhob).-A sub-division of Suleimanzai, Dawatkhel, Mandokhel (q. v.), Panis. Headman : Jalat Khan.

ARsezaI (West of Dera Ghazi Khan District). - A section of Mabmadzai, Ahmadzai, Bel Khel, Musa Khel. Headman : Rahimdil.

Arganzar (20) (Zhob).-A minor fraction of Khalwatzai, Badenzai, Abdullazai, Sanzarkhel, Kakar. Headmen: Ahmad Khan and Kamal Khan.

ARMIAEHEI, (ZhOb).- -A division of Hyderkhel, Mandokhel (q. v.), Panis.
ArozaI (250) (Zhob). - A division of Hasan Khel, Shiranis. Headmen: Amir, Azimkhan, Abdulla Shah and Noorak.

Asghorzal (Quetta Pishin)-A section of Malezai, Achakzai, Abdal, Tarins.

AsHEZAI (710) (Quetta.Peshin).A sub-division of Achakzai, Abdal, Tarins. Headman: Paradin Khan.

Aspani (204) (Sibi).-A sub-division of Makhiani, Tor, Tarins. Headman : Ahad.

AtozaI (44) (Quetta-Pishin).-A division of Sargara, Kakars. Headman: Sultan Mubammad Khan.

Aтtozal (25) (Sibi.) - A Khajak sub-division of Ishakzai, Panis.

Arob KenL(54) (Loralai).-A division of Ismail Khel, Zmarais Headman : Tola.

AzBazzal (Zhob).-A division of Suleman Ḱhel, Ghilzais.

AzDAZI (Quetta-Pishin).-A section of Badinzai, Achakzai, Abdal Tarins
Babazabzar (125) (West of Dera Ghazi Khan District). - A sub-division of Hamzazai, Bel Khel, MInsa Khel. Headman: Mehrab Khan.
BABAB (4I1) (Zhob and Kalat).Usually classed as a clan of Shiranis, though actually a tribe of the same origin as the latter. Headmen : Haji Salim Khan and Haji Ahmad Shah. 
BABAB (Quetta-Pishin).-Usually classed with the Achokzais, but actually belong to a separate tribe. No separate head man, the families being distributed among the Achakzai sections.

BababzaI (Loralai).-A division of Alikhel, Panis). Headman : Pail.

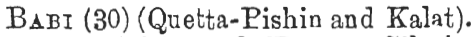
-A division of Hotak, Gilzais. Headman : Shah Jehan Khan.

BABRI (Mastung).-A sub-section of Kansis.

BABO (25)(Loralai.).-A division of Palao clan of Lunis. Headman : Mirkban.

BABULZAI (5) (Loralai),-A subdivision of Salezai, Rakhanwal, Lunis. Headman: Shah Bakhsh.

BABUZaI(120) (Loralai).-A section of Natozai, Hasankhel, Dumar, Sanzarkhel, Kakars. Headman: Payo Khan of Chalez Khalil.

Babezar (Loralai).-A division of Bulfraz, Isots. Headman : Hakim.

BABZAI (Loralai)-A sub-division of Wancchi Spin, Tarins. Headman: Pasta Khan.

BabzaI (40) (West of Dera Gazi Khan District). -A sub-division of Land Palai, Laharzai, Musa Khel. Headman : Ali Khan.
BADANZAI (Sinjawi, Loralaj Dt.)A section of Shabozai, Dumar, Sanzarkhel. Headman : Khalil.

BaDWay (61) (Quetta-Pishin).-A sub-division of Parezun, Sanzarkhel, Kakars. Headman : Sultan Muhammad Khan.

BADEZAI (127) (Quetta-Pishin).-A division of Abdal, Taring. Headman : Ayub Khan.

Badezar (Quetta-Pishin).-A subdivision of Achakzai, Abdal, Tarins.

Badinzai (36) (Loralai).-A division of Muhammadzai, Isots. Head. man : Zala Khan.

Badinzai (200) (Zhob).-A subdivision of Abdullazai, Sanzarkhel, Kakars. Headmen : Abmed Khen and Kamal Khan.

Badinzai (200) (Zhob).-A minor fraction of the Abmedzai, Kibilzai, Hassanzai, Kibzai, Sanzarkhel, Kakars. Headman : Khan Sahib Paindan Khan.

BadinzaI (Bori).-A section of Shabozai Dumar, Sanzarkhel, Kakars. Headman : Rind.

BADOZAI (Sibi).-A division of Luni, Panis.

BadsdzaI (Zhob).-A minor frac. tion of Ali Khel, Sanzarkhel, Kakars. 
BAGBDADZAI (55) (WVest of Dera Ghazi Khan District). - A section of Ahmadzai, Bel Khel, Musa Khel. Headman : Sher Ali.

BAGHOZAI (Loralai). - A division of Perozai, Zarkuns.

Baghor (Sibi). - A clan of Panis.

BaghzaI (Sibi).-A sub-division of Raisani, Spin, Tarins.

BAGIZAI (Zhob). - A minor fraction of Khoodaáziai, Shadozai, A lizai, Sanzarthel, Kakars. Hèadman: Macbakh.

BaHArzaI (West of Dera Ghazi Khan District). - A section of Hasanzai, Ahmadzai, Bel Khel, Husa Khel. Headman: Haro.

BAHIZAI (Loralai).-A division of Massezai, Ustranas (q. v.).

BatiolzaI (20) (Loralai).-A section of Umarzai, Alizai, Tor, Tarins. Headman: Barech.

BaHlolzaI (Loralai). $\rightarrow$ A minor fraction of Khanozai Sultanzai. Headman: Allahdad.

BAHIOLZAI (Zhob).-A division of Kapip, Shiranis. Headman : Sadig.

BaHLOLzaI (Quetta-Pishin).-A division of Sargara, Kakars. Headman: Malik Sultan Muham. mad Khan.
Bahramzai (Loralai) - A sub-division of Malikzai, Ghunji, Zar. kuns.

BanRaMzaI (43) (Sibi).-A division of Khajak, Panis.

BatkHex (10) (Zhob).-A sub. division of Haider Khel Mandokhel (q. v.), Panis.

Barzal (Sibi).-A division of Kariazai, Khajak, Panis.

BAIZAI (Zhob).-A minor fraction of the Badsuzai, Ali Khel, Sanzarkhel, Kakars. Headmen : Sado and Sikandar.

BaJizaI (16). (Loralai)-A sub-division of Muzari, Rakhanwal, Lunis. Headman : See Mazari.

BatalzaI (159) (Zhob)-A subdivision of Isakhel, Sanatia, Kakars. Headman : Galo.

BakHshizaI (24) (QuettaPishin). -4 section of Alizai Nasratzai, Achakzai, Ábdal, Tarins. Headman: Samundar Khan.

BahHtiarzat (25).-A division of Inzra Khel, Zmarais. Headman : Fazil Khan.

BAKHTIARZAI (77) (Quetta$\mathbf{P}$ ishin).-A section of Alizai, Nasratzai, Achakzai, Abdal, Tarins. Headman: Malik Ayub Khan. 
Bafbizat (27) (Quetta-Pishin).A sub-division of Achakzai, Abdal, Tarins. Headman: Bismillah Khan.

Batshozaj (80) (West of Dera (Gbazi Khan disrtict).-A sub. division of Hamzazai, Bel Khel, IIusa Khei. Headman: Sarbadar.

BalalzaI (36) (Quetta-Pishin)-A section of Ashezai, Achakzai, Abdal, Tarins. Headman: Paradin Khan.

Balizzal (Sibi)-A division of Dehpal, Panis.

B section of Panezai, Harunkbel, Sanatia, Kakars. Headman: Malik Wadad Khan.

Batgani (23) (Loralai).-A division of Khidrani, Jafars. Headman: Ǩbalil.

BaNNCEREL (138) (Zhob and Loralai). - A sub-division of Umarzai, Nasir, Guilzais.

BARAKFHEL (Loralai).-A divisoin of Tarak, Ghilzais.

BARAKHEL (Zhob).-A division of Kharot, Ghilzais.

B ABAKZAI (1,660) (Quetta-Pishin). -A division of Targhara, Kakars. Headmen: Suleiman Khan and Zarin Whan.
BARAFZaI (75) (Zhob).-A subdivision of Isakhel, Sanatia, Kakars. Headinen: Mir Alsm Puho and Muhammad Jan.

Barakzar (Sibi).-A sub-division of Bahramzai, Khajak, Panis.

BabakzaI (26) (West of Dera Ghazi Khan district). $-A$ section of Kabalzai, Barkzai, Laharzai, MIusa Khel. Headman: Zhobi.

BaRAEZAI (23) (Zbobl.-A division of Chuhar Khel, Shiranis. Head. man : Gulistan.

BARAEZAT (28) (Kalat).-A division of Abdal, Tarins.

BARANZAI (27) (Sibi and Loralai).A sub-division of Malikzai, Ghunji, Zarkuns. Headman: Yakub.

BABANZAI (40). - A minor fraction of Ahmedzix, Ribilıai, Hassauzai, Kibzai, Sanzarkhel, Kakars. Headman: Khan Sabib Mian Kban.

Barat KeEL (139) (Zhob and Loralai).-A division of (Northern) Sanzarkbel, Kakars. Headmen: Sadulla and Lund.

BarkHEL (75) (Zhob), - A division of Nasir, Ghilzais.

BarKHElzar (Loralaij.-A section of Umarzai, Alizai, Tor. Tarias. 
- Babect (Quetta-Pishin and Chagai).-A small Pathan tribe.

Barozar (3E) (Sibi).-A clan of Panis. Beadmen : Khan Bahadur Sirdar Mustafa Khan and Sirdar Taju Khan.

Barozar (Lozalai), $\mathbf{A}$ division of Ghaibzai, Isots. Headmen: Jalu.

Barozar (Quetta-Pishin).-A section of Bazai, Harunkhel, Sanatia, Eakars. Headman: Isa Khau.

BAROzAI.-A sub-division of Hamzazai, Sanzarkbel, Kakars.

BashamzaI (West of Dera Ghazi Éhan district). -A sub-division of Nozai, Laharzai, Musa Khel. Headman: Sultan.

Batezar (7T) (Quetta-Pishin).-A sub-division of Abu Bakar, Tor, Tarins. Headmen : Wali Muhammad Khan and Kaskyar.

Batozai or BatzaI (659) (Zhob and Loralai). - A sub-division of Alizai, Sanzarkhel, Kakars. Headman: Torak.

Batozar (Quetta-Pishin).-A small clan of Mashwanis (q. v.). Headman : Sher Zaman.

Batozar Quetta-Pishin).-A section of Bazai, Harunkhel sanatia, Kakars. Headman : Khan Sahib Bahawuddin Khan.
Batozar (Loralai).-A division of Massezai, Ustranas (q. v.)

Batwayl (Loralai)-A division of Khidrani, Jafars. Headman: Mirkhan.

BAZAI or BANZA (836) (QuettaPishin).-A sub-division of Harua Khel, Sanatia, Kakars. Headman: I. S. Baba-nd-din Khan, Isakhan, Yusuf Khan and Yakub Khan.

BazanaI-A eub-division of Mak. biani, Spin, Tarins.

BAZDANI (Loralai).-A sub-division of Wanechi, Spin, Tarins. Headman: Kamal Khan.

Bazinzat (21) (Sibi and Loralai).A division of Sharawani, Zarkuns. Headman: Dada Khan.

Bazdani (Loralai).-A division of Umrani, Jafars. Headman : Lashlia: Khan.

BazWanI (Sibi)-A division of Nandhani, Panis.

BEgZaI (Loralai)-A division of Bulfraz, Isots. Headman : Jamal.

BEL KHEL (1,828) (Laralai).-A large division of Musa Kbel. Headman : Mehrab Khan minox under under the guardianship of K. S. S. Mauladad Khan. in the Shocawat District. Only a few families live in the Quetta-Pishin and Chagai Districts. 
BHaIY (Sibi).-A division of Baghan, Pauis.

BIANI (Loralai).-A sub-division of Lasiani, Spin, Tarins. Headman: Baikar.

Bianzar (Quetia Pishin).-A subdivision of Barakzai, Targhara, Eakars.

BianzaI (46) (Quetta-Pishin).-A section of Alizai, Nasratzai, Achakzai, Abdal, Tarins. Headman: Samundar Khan.

Bianzai (30) (Zhob).-A minor fraction of Haiderzai, Hassanzai, Kibzai Sanzarkhel, Kakar. Headman: Sargarah.

BIJRAZaI (Loralai).-A division of Sharawani, Zarkuns. Headman: Fatteh Khan.

BilalzaI (West of Dera Ghazi Khan district). -A section of Kabalzai, Nokuzai, Lanarzai MusaThel. Headman : Rasul.

Bindarzal (33)(Quetta-Pishin).-A division of Lamar, Kakars. Headman : Katta Khan.

BINZAI (Zhob).-A division of Babar, Shiranis. Headman: Sabiban.

BizazaI (50) (West of Dera Ghazi Khan district). - A sub-division of Hamzazai, Bel Khel, Musa Khol. Headman : Gaman.
Borazar (Loralai).-A sub-division of Ladu, Rakhanwal, Lunis. Headman : see Lada.

Bolarzal (Quetta-Pishin).-A section of Panezai, Harunkhel, Sanatia, Kakars, Headman: Haji Harun Khan.

BorifHet (27) (Loralai). - A division of Nasir, Ghilzais.

BorizaI (168) (Quetta-Pishin).-A section of Dialezai, Achakzai Abdal, Tarins. Headman: Pakar Khan.

Bostan KaHol (Quetta-Pishin).A section of Melezai, Achakzai, abdal, Tarins.

BrahiM KHEL (100; (Zhob).-A division of Haripal, Shiranis. Headmen : K. S. Haji Bahawal Haq and Mubammad Yakub.

Brahim Kefel (67) (Zhob).-A division of Babar, Shiranis. Headman: Haji Ahmed Shah.

BratruzaI (West of Dera Ghazi Khan district).-A setion of Kabalzai, Nokuzai, Laharzai, Musa Khel. Headman: Haibatan.

BraHIMZAI (245). A minor fraction of Khanozai, Panezai, Harun Khel, Sanatia, Kakars. Headman: Didan.

Brahimzai (40) (Largha).-A section of Hezai, Yahyazai, Hasan Khel, Shiranis, Headman : Bahim 
Bratiaz.1I (69) (Thest of Deri Ghazi Khan district).-A subdivision of Maghduzai, Bel Khel. Musa Thel. Headman: Sardar IThan.

Branimzal (Loralai).-A sub-disision of Senzaj, Bel Ktel, MI usa Khel.

Bratiuzit 100 (TWest of Dera Ghazi Khan district) - A subdivision of Inagrizai, Laharzai, Musa Khel. Headmin : Azim.

Bbahiuzar or Ibralimzai. (QuettaPishin).--A section of Sarangzai, Haran Khel, Sanatia, Kakars. Headmen : Malik Pir Muhammad and 1 others.

BrAHIMZAI.A section of Land Ahmad, Ahmad Khel, Oba Khel, Shiranis.

Brabimzat (58) (7hob).-A division of Narhel, Shiranis. Headmon : Allabdad.

BRAHIYZZI (Loralai).-A sub-dipision Shaduzai, Alizai; Sanzarkbel, Kakars.

BrateirzaI (Zbob).-A division of Chuhrirkel, Shiranis.

Brahtmzal (60) (Zhob).-A subdivision of Hsrramsai, Sanzarkhel, Kakar. Headman: Rahman.
BRsHIMZAI (40) (Zhob)-A sec. tion of Pakhezai, Abdullaza, Sanzarkhel, Kakar. Headman : Daraz Khan.

BraH Mani (22) (Loralai).-A subdivision of Lasiani, Spin, Tarins. Headman: Gaman Khan.

BraHozaI (100) Sinjawi-Loralai Dt.).-A section of Shabozai, Hasan Khel Dumar, Sanzarkhel, Kakars. Headmen : Akbar and Khanan.

Brahozar (166) (Quetta-Pi shin).A section of Alizai-Nasratzai, Achakzai, Abdal, Tarins. Headmen : Hurmat Khan and Shab Alam.

Brosh KHeL (21) (Zhob).-A division of Nasir, Ghilzais.

Budazar (26) (Quetta-Peshin).-A clan of Kansis.

Belfraz (54) (Loralai).-A clan of Isots.

Bubazat (100) (Sibi Distriot).-A sub-division of Dumar, Sanzas. Kíbel, Kakars.

BormanzaI (75) (Quetta-Pishin).A section of Ashezai, Achakzai, Abdal, Tarins. Headman: Para Din Khan.

\section{C}

ChachezaI Nazarietel (QuettaPishin). $-A$ clan of Mashrwanis (q. v.)

Chachezai Sinrehé (QuettaPishia).-A clan of Mashwanis (q. v.) 
Ghachezai Yashinateris. (QuettrPishin).-A clan of Mashwanis (q. $\mathrm{v}$.)

Chakarzar (Loralai). - A division of Nubzai, Isots. Headman : Pastak.

Chalgabi.-A section of Mekhiani, Tor, Tarins.

Chanazai (Quetta-Pishin).-A division of Samungli, Kansie. Headwan : d bdul Wahid.

Chandezal (Loralai)- -A division of Nubzai, Isots. Headman: Sheran.

Chandozai (Zhob). - A division of Samungli, Kansis.

Chanezai (20) (Zhob).-A subdivision of Abdullazai, Sanzarkhel, Kakar. Headman : Mrulla Wasil.
Chariagzai (Loralai).-A subdivision of Semani, Spin, Tarins. Headman : Nazir.

Chotialiwat.-See Dzam.

Chotza I (Loralai). - A sub-division of Marpani, Spin, Tarins. Headman : Az:z.

Chtharzat (6) (Loralai).-A subdivision of MIalezai, Rakhanwal, Lunis. Headman : Abmad.

CHOHAB KHeL (109) (Bargha, Largha). $-\mathrm{A}$ clan of Shiranis. Headmen: Zarghun, Dorani, Paro, MLehrban, Haji Batal and Gulistan.

Chermat (165) (Quelta-Pishin).A sub-division of Isalkel, Sanatia, Kakars. Headman: Malile Hakim.

Chtrarat (23) (Sibi and Loralai). -A dirision of Sharawani, Zarkuns. Headman: Wazir.
DADAKZAI (236).-A minor fraction of Khanozai, Panezai, Harunkhel, Sanatia Kakrrs. Headman : Kaium.

Dadanr (Loralai), - A sub-division of Zaam, Spin, Tarins.

Dattani (Sibi).-A sub-division of Wanechi, Spin, Tarins.

DANDEHEL (Sibi).-A division of Nasir, Gbilzais.
DAOZAI (125) (West of Dera Ghazi Khan district). - A sub-division of Mangizai, Laharzai, Mriusa Khel Headman : Bangar.

Dar OZaI (Loralai).--A sub-divisioc of Zaam, Spin, Tarins.

DABOZAI (15) (Zbob). - A minor fraction of Khalwatzai, Badinzai, Abdulazai, Sanzarkbel, Kakars. 
Darpate (Sibi).-A sub-division of Wanechi, Spin, Tarius.

Darozar (Loralai).-A sub-division of Laharzai, Musakhel. Head. in an: Kadir.

DARIAEHEL (Loralai).-A division of Nasir Ghilzais.

DarfazaI (Loralai).-A clan of Lunis. Headman: Musa Jan.

Darrazar (26).-A sub-division of Malezui, Rakhanwal, Lunis.

Dariazi (Loralai).-A clan of Zarkuns.

DARTESH (Sibi and Loralai). -A sub-division of Oriazai, Ghunji, Zarkuns. Headman: Halim.

DasozaI (102) (Quetta-Pishin).A division of Sargara, Kakars. Headman: Sarbadal Khan.

DattezaI (Sibi and Loralai).-A division of Sharawani, Zarkuns. Headman: Hassan.

Datdzai (24) (Loralai).-A clan of Ustranas (q. r.).

Datiatzai (Loralai).-A sub-division of Mullanzai, Nasir, Ghilzais.

DaclatzaI (2I) (Sibi). - A division of Khajak, Panis.

Décatzai (Sinjawi-Loralai district). $\rightarrow$ A sub-section of Nathozai Dumor. Headman: Balach.
DatLatzaI (Zhob). -A section of Shadozai, Alizai, Sanzarkhel, Kakars. Heaảman : Isa Khan.

DaclatzaI (336)i(Sibi District). - A division of Dnmar, Kakars.

Datratzai (82) (Quetta-Pishin).A section of Ashezai, Achakzai, Abdal, Tarins. Headman : Mezhai Khan.

DatatheEL (48) (Zhob).-A division of Nasir, Ghilzais.

Datatkeri (650) (Zhob).-A subdivision of Haiderkhel, Mandokhel (q. v.), Panis. Headman: Akhtar Khan and Sher Khan.

DAWr (52) Quetta-Pishin and Zhob).-Classed as Kakars. They are descended from Dawi, brother of $\mathrm{Kakar}$, the progenitor of the haliar tribe.

$D_{A W I}$ (Sibi).-A clan of Panis.

Dempar (Sibi).-A clan of Panis.

DbWarzaI (250) (West of Dera Ghazi Khan district).-A section of Dodazai, Nokuzai, Laharzai, Musa Khel. Headman: Gul Sher.

DETARZAI (40) (Sibi District).-A division of the Damar, Kakars.

DewazaI (300) (West of Dera Ghazi Khan district.) - A sub-division of Nozai, Laharzai, Musa Khel. Headman : Rahmatan. 
DHAHI or Dah (Toralai).-A division of Umrani, Jafars. Headman: Sawan.

Dinabreter (Sibi).-A small clan of Ghilzais.

Dodazar (Zhob).-A sub-division of Abdullazai, Lamar, Kakars.

Dodazal (West of Dera Ghazi Khan district).-A section of Malizai, Ahmadzai, Bel Khel, Musa Khel. Headman: ZZhob.

DodazaI (250) (West of Dera Ghazi Khan district).-A sub-division of Nokuzai, Laharzai, MIusa Khel. Headmen: Alu Krban and Kadar.
Dodozar (33) (Zhob) -A minor fraction of Haidarzai, Hassanzai, Kibzai. Sanzarkhel, Kakar. Headman: Sado Khan.

Dirgzai (930) (Loralai),-A clan of Lunis.

Domars (1,760) (Quetta-Pishin, Sibi and Loralai)._- division of Sanzarkhel, Kakars. Headmen ; Rindw, Shahin, Alikhan, Yakub and Gullo.

Douars (53T) (Bibi)-A Kakar clan. Headman: Sirdar Jelal Khan.

Dorkhanzai (Loralai).-A division of Ghaibzai, Isots. Headman: Kakar.

Dzair, ZaAu, Salur or Chotiwal (28).-A division of Spin, Tarins. Headman : Nasir Khan.
Farzat (30) (East of Quetta).-A division of Dumar, Kakars.

FanirZaI (1,128) (Zhob)--A section of Mirzai, Alizai, Sanzarknel, Kakars. Headman : Malla Dilbar.

Fakirzai (10) (Zhob),-A seotion of Malezai, Abullazai, Sanzarkbel, Kakar. Headman: Hassain Kban.
Fafirzar (Sibi and Loralai).-A division of Sharawani, Zarkuns.

FatarzaI (Quetta-Pishin).-A subdivision of Saigi, Tor, Tarins. Headman: Vadan Kkan.

FantrzaI (Quetta-Pishin). - A section of Bazai, Harnnkhel, Sanatia Kakars. Headman: $K$. S. Bahaud-din Khan. 
FAKIRZaI (Quetta-Pisbinin).-A clan of MIashranis (q. v.).

Fatehrianzai (Zhob).-A division of Cbuharkhel, Shiranis.

FATEHzaI (20) (Quetia-Pishin).-A section of Hanjidzai, Achakzai, Abdal, Tarins. Headman: Wali Irahammad.
FATEHZAI (Loralai). -A division of Marghazani. Panis.

FatozaI-A section of Mirzai, Alizai, Sanzarkibel, Kakars. Headmen: Khodadad, Akhtar, Muhammad and Dadan.
G tion of Arahzai. Suleimanzai, Dawatkhe', Mlandokhel, Panss. Headman: Jalat K han.

GrDazaI (Qnetta-Pishin).-A clan of Kansis. Headman: Khair Nahawnad Khan.

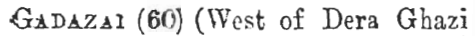
Khan district).-A section of Inzai, Hasan Khel, Bel Khel, Musa Khel. Headman : Jan Gul.

GaDAKaHol (31) (Quetta-Pishin). -A section of Mralezai, A chakzai, Abdal, Tarins.

GadrazaI (16) (Largha).-A section of Land Ahmad, Abmad Khel, Obo Khel, Shiranis.

GAGAIZAIS (450).-A clan of Ust. ranas (q. . .) The divisions, ete., of Grgalzais are not separately indexed in this Dictiocary.
GIJRaI (4) (Loralai).-A sub-division of Shamezai, Rakhanwal, Lunis. Headman: Gaggoo.

GıXfaLZdI (Loralai). - A division of Massezai, Ustranas.

GavozaI (78) (Quetta-Pishin).-A section of Hamidzai, Achakzai, Abdal, Tarins. Headman : Ummar Khan.

GirdaI Nasazai (Zhob).-A subdivision of Kibzai, Sanzarkhel, Kakars. Headman : Paind and Hazzi.

GARI (Zhob).-A division of Nasir Ghilzais.

GazLANI or Gbazlani (Loralai).-A sub-division of Adwani, Spin, Tsirins. Headman : Malikdad.

Ghatbani (Sibi).-A division of Nandhani, Panis. 
GHaibizaI (64) I(Zhob).-A minor fraction of Daulatzai, Shadozai, Alizai, Sanzarkhel, Kakars. Headman : Angushai and Fazal.

GHaibizax (28) (Quetta-Pishin).A section of Bazai, Harunkel, Sanatia, Kalzars. Headman : K. S. Baha-ud-din Khan.

GHaIbIzaI (84) (Quetta-Pishin).-A section of Malezai, Achakzai, Abdal, Tarins. Headmen: Abul Samad and Zakar Khan.

Ghalbzai (29) (Loralai).-A clan of Isots. Headman : Runa.

GenalibzaI (13) (Loralai).-A division of Drugzai, Lunis. Headmen: Alihan (Jafarzai), Wazir (Gaganzai).

GHANIZAI (Loralai).-A division of Nasir, Ghilzais.

GHazizaI (27) (Quetta.Pishin).-A section of Mehtarzai, Harunkhel, Sanatia, Kakars. Headman : Mir Alam.

GHAZIZaI (15):-A sub-division of Shamezai, Rakhanwal, Lunis. Headman: K. B. Haji Sardsr Nawab Khan.

GHilzaIs (3,655). - A large and widespread Afghan tribe, who are to be found in the area estending from Khelat-i-Ghilzai on the south to the Kabul River on the north, and from the Gulkoh range on the west to the Indian border on the east, in many places overflowing these boundaries. The main clans or branches are the Andars, Hotaks, Kharotis, Nasirs, Sulemankhels, Tarakis, Tokbis. The Ghilzais generally execrate the Daranis, whom they regard as usurpers. They are to be found in considerable numbers in Zhob and other districts of the Baluchistan Agency (fighting men 4,000) and many emigrate to India in the cold weather. See also Powindahs, Part IIf.

GHoranat or GHearan (Loralai), -A aivision of Drigzai, Lunis. Headman : Zakaria.

GHorizaI (300) (Zhob).-A subdivision of Alizai, Sanzarkhel, Kakars. Headmen: Bara Khan, Mahmud and Sida MIuhammad.

Ghorizal (Zhub).-A division of Nasir, Ghilzais.

GHoani-a division of Drugzai of Lauis.

GHUN J1 (179) (Sibi and Loralai)A clin of Zarkans. Headman Samaud Khan.

GonazaI (21) (Sibi).-A sub-division of Ishakzai, Khajak, Panis.

GolaezaI (Loralai).-A division of Kharotri, Zarluns. Headman: Mahin. 
Grifbate or Gulfara (12)(Loralai). -A section of Umarzai, Alizai, Tor, Tarins, Headman : Babakar.

GrulazaI (Quetta-Pishin).-A section of Bazai, Harunkhel, Sanatia, Kakars. Headman: K. S. Haji Baha-ud-din Khan.

GrIILHEL (25) (Quetta-Pishin).A section of Ashezai, Achalkzai, Abdal, Tarins. Headman : Paradin Ǩhan.
Grelohelel (69) (Zhob)-A divișion of Sulemanizhel, Ghilzais.

GrmarzaI (West of Dera Ghazi Khan district).-A section of Kabalzai, Nokuzai, Laharzai, Musakbel. Headman: Bahar.

Ge $\mathrm{g}$ ZII (Sibi).-A division of Safi, Panis.

Gurjezai (22) (Zhob).-A section of Nakaran, Abdullazai, Sanzarkhel, Kakar. Headman : Shah Alam.
HiBibzaI (4t) (Quettá Pishin).-A sub-dirision of Parezun, Sanzershel, Kakars. Headman : Ulia and Fadar Dad.

HabiezaI (Quetta-Pishin).-A section of Sarangzai, Harunkhel, sanatia. Fakars. Headman: Haliw Khan.

Habibzai (20) (Loralai).-A dirision of Marghzani, Panis. Headman : Hrji Khanju.

HABIBZAI (Quetta-Pishin).-A subdivision of Alizai, 'T $r$, Tarins. Headman : Faiz MIuhammad.

HA DIZAT. - A sub-dirision of Lada, Rakbanwal, Lunis. Headmen: see Ladn. Headman: Ehandai.

HadizaI (Zhob).--See Shelsh.
HADGKABOL (27) (Quetta-Pishin).A minor fraction of Ghaibeza, Malezei, Achakzai, Abdal, Tarinsi Heudman : Sadik.

HAIAZI.-A division of Mahmnd Khel, Zmarais. Headman : Sirdar Hakim Khan.

HAIBATZAI(22) (Loralai)-A subdivision of Marpani, Spin, Tarins. Headman: Surat Khan.

Hairatzar(24) (Quetta-Pishin).-A section of Hamidzai, Achakzai, Abdal, Tarins. Headman : Mulla Wali Muhammad.

Hajbatzai (Loralai). - A division of Alikhel, Panis.

H_IDERKHEL (Zhob). - A division of İlandokhel, Panis. 
HaIdARZAI (217) (Zhob).-A subdivision of A lizai, Sanzarkhel, Kakars. Headmen : Jan Mubammad and Zardad.

HAIDARZAT -A section of $\mathrm{Na}$ tozai, Hasanthel Dumar, Sanzarkhel, Kakars. Headman : Pandan.

HaIderzaI (40) (Zhob).-A section of Hassanzai, Kibzai, Sanzarkhel, Kakar. Headman : Bangal and Saddo Kban.

HaIralzar (70) (Quetta-Pishin).A sub-division of Abu Bakar, Tor, Tarins. Headwan: Baz Khan.

HaIZAI.-See Hezai.

Hatasani or Lasans (Loralai).-A division of Khidrani, Jafars. Headman : Roidiyar.

Halimzai (Quetta-Pishin).-A section of Bazai, Harunkhel, Sanatia, Kakars, Headmen: Taj Muhammad and Zargar.

Halzozat (Loralai).-A division of Bulfraz, Isots. Headman : Rawan.

Hamr DZaI (930) (Quetta-Pishin).A sub-division of A chakzai, Abdal, Tarins. Headman : Mulla Wali Muhammad.

Hamimzai (Sibi).- $-\Delta$ division of Khajak, Panis.
HamranzaI (Quetta-Pishin).-A. sub-division of Parezun, Sanzarkhel, Kakars. Headman : 11 ir Kalam.

Hajizaketel (21) (Zhob).-A subdivision of Haidarishel, Mandolibe! (q. จ.), Pasis.

Hamzazar (322) (Loralai)- - A clan of Musathel. Headman : Sirdar Mehrab Khan. In Bori tabsil the herdmen are Nadar Khan, Dewa Khan, Feroz Khan, Bala Khan, Mebrban, Hassan Khas, Miran and Mulla Sajad Ǩhan.

HaurazaI (98t) (Zhob).-A subdivision of Arabi Khel, Sanzarkhel Kakars. Headmen : Jamal, Murtaz: Dost Ml uhammad, MIustafa.

HanfezaI (130) (Zhob)-A dirision of Suleimanzai, Babar. Headman : Haji Salim Khan.

HanfezaI (16) (Zhob).-A section of Hassanzai, Kibzai, Sanzarkbei, Kakars. Headman: Saidal.

Havi.-A sub-division of Parez:n, Sanzarkhel, Kakars.

HarzarAI (Loralai).-A section of Umarzai, Alizai, Tor, Tarins. Headman : Malik Mirliban.

Habamzal [16).-A division of Marbel, Shiranis. Headman. Albar.

HarajrzaI (125) (Zhob), -A division of Sanzarkhel, Kakars. Hesdman : Pajo Khan. 
Haranzat (Loralai). -A division of Marghazsni, Panis.

HABDOZAI (48) (Quetta-Pisinin).-A section of Alizai-Nastaztai, Achakzai, Abdal, Tarins. Headsnan : Samaudar Kban.

HaripaL(J00) (Burgha). - A clan of Shiranis. Headmen : MInhammad Yakab, and Khan Sabib Haji Bahawal Hak.

HARIZAI (Loralai). -A division of Bulfraz, Isots. Headman : Alam Khan.

Harex Khet (Zhob, Quetta-Pishin and Sibi).-One of the two main rivisions of Sanatia, Kakars. Headmen: Guldad (Shamozai), Nialik Mir Alam Khan (Mehtar. zai), Khan Sabib Malik Halim Khan (Sarangzai), Baidula (Baza), Khan Sahib IIalik Wahah, Finan (Panizai).

Harexzar (Sibi and Loralai).-A sub-dirision of Malikzai, Ghunji, Zarkuns. Headman : Mirir.

HaEURzaI (191) (Loralai and Znob). - $t$ division of Sargara, Kakars.

Hasar Krasazal.-A sub-division of Salezai, Rakhınwal, Lunis.

HasaxkHeL (356) (Lnralai).-A division of Bel Khel, IIu $\sim$ a Khel. Headman : J an Gul. fl ASAN E HEL (495)(Bargha, Largha). -A clan of Shiranis. Headmen: Rabim Sado Khan, Ázim Khan Ghamni.

Hasankhel (200) (Zhob). -A division of Haripal, Shiranis.

HASAN ZaI (Quetta-Pishin).-A subdivision of Barakzai, Targhara, Kakars. Headman : Guli.

HASANZAI (Sibi).-A sub-division of Daulatzai, Khajak, Panis.

HASANZAI (30) (Zhob).-A section of Suhankhel, Haiderkhel, Mandokhe! (q. v.), Panis. Headman: Mulla Inaam.

HASANZAI $(1,5) 0$ ) (Zhob).-A subdivision of Kibzıi, Sanzarkhel, Kaliar. Headmen: K. S. Mian Khan and K. S. Paindan Khan.

H $_{\triangle S A N Z A I}$ (Quetta-Pishin).-A section of Badinzai, Achalkzai Tarius.

HASANZAI (Zhob). - A division of Chuharkhel, Shiranis.

HASN-A sub-division of Parezun, Sanzarkhel, Kakars.

HezaI (West of Dera Ghazi Kban district).- A sub-division of HamzaZai, Bel Kbel, Musa Khel. Headmen: Wadan and Tawiz Khan. 
HezaI (81). (Bargha, Largha).A sub-division of Yahyazai, Hasankhel, Shiranis. Headman: Rahim, Sarwar Khan.

Hilalzar (24) (Loralai).- A subdivision of Semani, Spin, Tarins. Headman : Miran.

HilalzaI (West of Dera Ghazi Khan District.) A section of Inzai, Hasan Khel, Bel Khel, Musakhel. Headman: Jangul.

Hotak (99) '(Zhob, Loralai and Quetta-Pishin).-A clan of Ghilzais. Headman in Laralai : Sardar Mubammad Shah Khan.

HotarzaI (Quetta-Pishin).-A sub-dirision of Babi, Hotak Gilzais. Headman : Shah Jehan Khan.

Hotizai (Loralai) - A sub-division of Malezai, Rashanwal, Lunis. Headman : Hayat Khan.
HotrzaI (Quetta-Pishin).-A subdivision of Saigi, Tor, Tarins. Headman: Malik Dadan.

HotmalaNi (150) (Loralai and Sibi)-A sub-division of Wanechi, Spin, Tarins. Headman : Zalla Khan.

Hrocy SHazaI. - A minor fraction of Mulazai, Paulzai, Harun Khel, Sanatia, Kakars. Headman : Mulla Nur Nuhammad.

Hesainkerel (Zhob).-d division of Lawana, Panis.

Hossaiszai (Sibi).-A sub-division of Ishakzai, Khajak, Panis.

HessainzaI (Loralai).-A division of Daudzıi, Ustrmas (q. v.).

HUSHEHEL OR UsHKHEL (Zhob).-A division of Nasir, Ghilzais.
IBRAHIMKHEL division of Mullanzai, Nasir. Ghilzais.

IBRABIM KHEL (33) (Loralai).-A division of Perozai, Zarkuns. Headman : Haji Daulat.

IBRAHIMzaI or Brahimzai.-A division of Marhel, Shiranis.
Ibratimzai or Brabimzai (Loralai). -A section of Shadozai, Alizai, Sanzarkbel, Kakars.

IBRAHIMzaI. (Loralai)-A clan of Zarkuns. Headman : Habib.

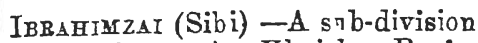
of Bahramzai Khajak Pani. 
IBRAHIMZAI or Brahimzai (Quetta-Pishin).-A sub-division of Sarangzai, Sanatia, Kakars. Headman: Halim Khan.

IBRAHIJTZAI (Quetta-Pishin).-A sub-division of Barakzai, Targhara, Kakars, Headman: Sulieman Khan and Zarin.

IDALZAI (48) (Zhob).-A subdivision of Dawathel, Mandokbel, $\mathrm{Pan}_{\text {as. Headmen : Mehtar }}$ and Mazhai.

JrsaI (15) (Zhob) - A section of Badinzai, A bdullazai, Sanzarli hel, Kakar. Headman : M ohamedan.

InzaI (West of Desa Gbazi Khan district).-A strb-division of Hasan Khel, Bel Khel, Musa Khel. Headmen : Miran and Jangul.

IN zBatheL (66) (Loralai).--A division of Ismailkbel, Zmarais. Headman : Fazil Khan.

IbabzaI. - A sub-division of Ahmad Khel, Targhara, Kakars (Hamsayas).

Is $\triangle B Z_{\triangle I}$ (68) (Sibi).-A division of Margbzani, Panis.

IssezaI (Sibi).-A division of Pirani, Panis.

IsAizaI (Largha).-A sub-division of Ahmad Khel, Obo Khel, Shiranis. Headmen: See Obo Khel.
IsAKHEL. (1,455) (Quetta Peshin, Sibi and Zhob).-One of the two main divisions of Sanatia,Kakars. Headmen-Abdul, Nuhammad Jan, Sumai and Arsala.

IsaZaI (Loralai).-A clan of Isots Headman : Khetran.

Is $\Delta$ ZaI (10) (Zhob).-A sub-division of Haidarkhel, Mandokhel, (q. v.), Panis, Headman : Hamim.

IsazAI (West of Dera Ghazi Khan district).-A sub-division of Nahzaj, Laharzai, Musa Khel. Headman: Saidan.

ISAZ $Z_{\triangle I}$ (Loralai).-A division of Dirgzai, Lunis. Headman : Gulan.

IsEAEZaI (Sibi).-A division of Khajak, Panis.

IstaNI (Loralai).-A division of Dirgzai, Lunis.

IsvaILKHANZAI (Sibi),-A division. of Barozai, Panis.

Isyaich hBL (Loralai), -A division of Nssir, Ghilzais.

ISMAILKHEL (141) (Lora!ai). - A clan of Zmarais. Beadmen : Fazil Khan, Abdul, Roze and Darie.

Isuraillzar (313) (Zhob). - A subdivision of Alizai, Sanzarkhel, Kakars. Headmen : Gula Khar Sheikh and Fateh. 
IsMaILZaI (82) (Zhob).-A division of Obo Khel, Shiranis. Headman: Sher Muhammad.

IsMaItzaI (Loralai).-A division of Muhammadzai, Isots. Head. man : Khan Beg.

IsMailzaI (72) (Zhob).-A division of Lawana, Panis.

IsmaiczaI (Loralai). - A clan of $\mathrm{Us}_{\mathrm{s}}$ tranas $(q, v)$..

Isots (465).-(Loralai) A small tribe of nomads, of the Ghur- ghusht division of Afghans who live in caves in the hills southwest of the Dera Ismail Khan frontier. Alizai clan of the Isots reside in Sibi Tabsil. Headman Manu Khan.

IsozaI (Sibi).-A sub-division of Hamimzai, Khajak, Panis.

ISPANI (Zhob). - A division of Khidrani, Jafars.

IstorezaI (40) (Zhob). -A division of Chuharkhel, Shiranis. Headman: Durani.
J FARS (260) (Drug, west of Dera Ghazi Khion district).-A small tribe of somewhat doubtful origin but generally classed as Pathans. (See Shiranis). Headman: Kalu Khan.

JAFARZAI (Sibi).-A division of Kbajat, Panis.

JAHANZAI (Toralai).-A division of Nubzai, Isots. Headman : Man • nu Kban.

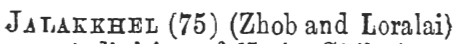
-A division of Nasir, Ghilzais.

JALALKHANZAI,-A section of Mehtarzai Harun Khel, Sunatia, Kakars. Headman : Rozai.
JaLALEHEL (Zhob and Loralai).-A division of Nasir, Ghilzais.

JaralzaI (West of Dera Ghazi Khan district).-A sub-division of Nuluzai, Laharzai, Misa Khel. Headman : MIendak.

JALALZAI (Zhob).-A section of Shadozai, Ali Zai Sanzarkhel, Kakars. Headman : Khadadad, Imran and Kamal Khan.

$J_{A L A L Z_{A} I}$

(T)est of Dera Ghazi Khan district). $\rightarrow$ A sub-division of Hasan Khel, Bel Khel, Musa Khel. Heałmen: Azim Khan (Sadozai), Sarbadar (Mirdadzai).

$J_{A L A L Z A I}(1,405)$ (Zhob).-A section of Shadozai Alizai, Sanzarkhel, Kakars. Headmen : Sarda Muhawmad Khan, Khande Khan. 
JaLALZAI (69) (Zhob).-A division of Sulemankhel, Ghilzais.

JaxALZAI (Quetta:Pishin).-A clan of Mashranis (q. v.). Headman: Sher Zaman.

JALAIZAI (QuettarPishin).-A section of Ashezai, Achakzai, Abủal, Tarius. Headman : Shakur Khan.

JALANDARZAI.-A section of Bazai, Harun Khel, Sanatia, Kabars. Headman : MTir Alzal.

JALANZar-A section of Natozai, Hasan Kbel, Dumar, Sanzarkhel, Kakars. Headman: Dadan.

JalezaI.-A sub-dipision of Ladu, Rakhanmal, Lunis. Headman: See Ladu.

Jarezar (Quetta-Pishin).-A section of Hamidzai, Achakzai, Abdal, Tarins. Headman : Kadar Khan.

JaIFANI (Sibi).-A sub-division of Wanechi, Spin, Tarins.

J AMALZAI (93) (West of Dera Ghazi Khan district), - A subdivision of Senzai, Bel Khel, Musa Khel. Headman : Fagir.

$J_{A M A I Z A I,-A}$ section of Sarangzai, Harun Khel, Sanatia, Kakar. Headman: MIalik Jamal.

JayalzAI.-A sub-division of Ladu Rathanwal, Lunis. Headman : See Ladu.

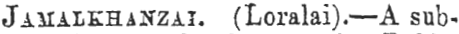
dirision of Shamozai, Ralih, anval, Lunis. Headman : Mis Khan.

JaMalzaI (Sibi)--A sub-division of Daulatzai, Thajak, Panis.

JajralzaI (27) (Loralai).-A sub. division of Malikzai, Ghunji, Zarkuns.

JaratZaI (30) (Zhob).-A section of Shamanzai, Kibzai, Sanzarkhel, Kalars. Headman: Ismail.

JAMALZAI (30) (Zhob).- A section of Arozai, Ahmad Khel, Hasan Thel Stiranis. Headman: Azim Khan.

JAN BEGZaI (Zhob). - A minor fractioa of Khoedadzai, Shadozai Alizai, Sanzarkhei Kakars. Headman Sarbuland,

Jangizar (Sibi).-AA sub-division of Daulatzai, Khajak, Pauis.

JANinher (Loralai).-A division of Sulemankhe], Ghilzais.

JANIKHEL (70) (Zhob).-A subdivision of Haidar Kbel, Mandokhel $(q \cdot v$.$) , Panis. Headmen:$ Jadan, Bahadur Khan and Jume.

Javisher (Zhob).-A small clan of Safis.

JaNIZaI (Sibi).-A division of Dami, Panis. 
JanizaI (48) (Quetta.Pishin).-A sub-division of Alizai, Tor, Tarin. Headraan: Malik Zaman.

$J_{\triangle N O Z A I}$ (Loralai).-A division of Daudzai, Ustranas $(q \cdot v)$.

$J_{\triangle N T I}$ (Sibi).-DAn insignificant clan of Panis.

JATTUL Loralai).-A division of Khidrani, Jafars. Headman: Bashka.

JEERA (Loralai). - A division of Khidrani, Jafars. Headman : Ghulam.
JILAEZAI.-A minor fraction of Shabozai, Hasan Khel, Dumzar Sanzarkhel, Kakars. Headman Haji Khalil.

JinizAI (West of Dera Ghazi Khan district). $-A$ section of Maghduzai, Ahmedzai, Bel Khel Musa Khel. Headman: Lat.

JogizaI (225) (Zhob). - A minor fraction of Jalalzai, Shabozai, Alizai, Sanzar Khel, Ka kars. Headman : Sardar Muhammad Khan.

JogIZAI (22) (Loraiai) - A division of Nuhzai, Isots. Headman: Alihan.
RaBalzaI (West of Dera Ghazi Khan district). - A sub-division of Nokuzai, Laharzai, MI usa Khel. Headman : Babar (Gumarzai), Zhobi (Barakzai), Haibatan (Brahimzai), Rasul (Bilalzai.)

$K_{\triangle B A N A I}$ (Zhob) - A sub-division of Zaam, Spin, Tarins.

KABIRZAI (Quetta-Pishin).- A sub-division of Isakhe!, Sanatia, Kakars. Headman : K. S. Lawang Khan.

$\bar{K}_{\triangle B U L K H E L}(27)$ (Zhob) :-A division of Kharot, Ghilzois.
$\mathrm{K}_{\triangle B}$ ULZAI (Bori, Zhob).-A sub-division of Utman Khel, Sanzarkhel, Kakars. Headmen: Mir Alam, Gullan, Abdul Aziz and Murghi Husain, Isa Khan, Akhtar and Baloch Khan.

KABULZaI (Loralai) A division of Laharzi, Musakhel. Headman : Rasul.

KABULZAI (35) (Zhob). -A Section of Pakhezai, Abdullazai, Sakzarkhel, Kakars,

$K_{\triangle C H H I K H R I}$ (Loralai), - A division of Nasir, Ghilzais. 
KaDUzaI.-A sub-aivision of 1 KaMalzar (28) (Quetta-Pishin).Bazai, Sanatia, Kakars. Head- A sub-division of Nurzai, Tor. men: Mulla Baidula, and Mulla Majib.

KaIMAIZAI (Quetta-Pishin).-A section of Malezai, Achakzai, Abdal, Trins. Headmen: Ghalam Khan and Mir Ahmad.

KaImalzaI (Sibi)--A sub-division of Umarzai, Khajak, Panis.

KAINZ1.-A sub-division of Sbamezai, Rakbanwal, Lunis.

KAKARS (25,222) (Quetta to the Gomal Pass). A large tribe of Pathans. Headman: Sardar M abammad Khan, son of the late Nawab Bangal Khan.

Ka $\operatorname{LZZ}_{A I}$ (824) (Quetta-Pishin).A section of Badinzai, Acbakzai, Abdal, Tarins, Headmen: Kushal Khan and Kosbung.

F $\triangle I \Delta L Z \Delta I(60)$ (Quetta-Pishin).-A sub-division of Parezan, Sanzarkbel, Kakars. Headman: Wad Ullah.

KAYALEHANZAT (Loralai).-A division of Perozai, Zarkuns. Headman : Gal Khan.

KAYAIKHEL (Loralai). - A division of Nasir, Ghilzais.

Kazratk Hed (165) (Sibi, Loralai and Zhob).-A division of Nasir - Ghilzais.

KayarzaI (67) (Quetta-Pishin).A sub-division of Alizai, Tor, Tarins. Headman : Mahammad Nor.

KaMalzaI (Zhob).-A section of Mirzai, Aliza, Sanzarkhel, Kakars. Headmen: Zardad Walo $J$ an and Batal.

KanozaI (Loralai).-A minor fraction of Natozai, Hasan Khel, Dumar, Sanzarkhel, Kakars. Headman : Hamza of Pai. 
$K_{\Delta \text { NSIS OR K.ASIS (215) (Quetta- }}$ Pishin).-A small Patban tribe, bolonging to the Saraban division of the Afohans. Headmen: Khan Bahadur Arbab Khudadad Khan and Khan Bahadur Malik Wazir Muhammad Khan.

KAN UZAI (West of Dera Ghazi Khan district).-A section of Malizai, Ahmadzai, Bel Khel, Musa Khel. Headman : Samand Khan.

$K_{\triangle N U Z \Delta I}$ (Laroha). -A minor fraction of Khidarzai, Isaizai, A bmad Khel, Obo Khel, Shiranis $(q . v$.

KAPIP (72).(Bargha-Zhob). - A clan of Shiranis. Headman. Kakar Khan.

$K_{\triangle B E Z A I}$ (Loralai), - A division of Daudzai, Ustranas (q.v.). Headman : Mauladad.

$K_{A B I A Z A I}(28)$ (Sibi).-A division of Khajak, Panis.

KAREZAI (300) (Zhob).-A sub- division of Haidar Khel, Mandokhel (q. v. ), Panis. Headmen: Sher Khan and Akhtar Khan.

$K_{\triangle B I G \Delta R \Delta N}$ (30) (Zhob). - A subdivision of Haidar Khel, Mandothel $\left(q . v_{.}\right)$, Panis. Headman: Amir.

KARIMZAI (Zhob).-A section of Mehtarzai, Harun Khel, Sanatia, Kakars. Headman : Mulla Hasan.
KaRMANZAI (100) (Zhab). - A division of Hasankhel, Shiranis. Headman : Tarkao, Rahman, Abdulla Khan and Shakoor.

KARMEZAI (60) (Zhob)-A subdivision of Ahmad Khel, Hasan Khel, Shiranis. Headman : Hasan Khan.

KARMUZAI (Zhob).-A section of Mehtarzai, Harun Khel, Sanatia, Kakars. Headman: Muhammad.

$K_{A B W I}$ (Quetta-Pishin),-A section of Panezai, Harnnkhel, Sanatia Kakars. Headman : K. S. Haji Harun Khan.

$\mathrm{K}_{\mathrm{ARZAT}}$ (Loralai).-A division of Ibrahimzai, Zarkuns.

KasikHez (Sibi).-A division of Mizri, Panis.

KaSIS-See Kansis.

Kata Khfl (Loralai). - A division of Dirgzai, Lunis. Headman: Bogat.

KatidzaI (2T) (Loralai). - Á divi sion of Kharot, Ghilzais.

KhachozaI (82) (Quetta-Pishin).-A section of Hamidzai, Acbakzai, Abdal, Tarins. Headman : Mulla Wali Muhammad.

KradizaI (West of Dera Ghazi Khan district).-A sub-division of Mangizai, Laharzai, Maga Khel. Headman : Sado Khan. 
KHaItar (Quetta-Pishin).-A clan of Kansis. Headman : K. B. Arbab Khadadad Khan.

KrainszaI (46) (Quetta-Pishin). -A minor fraction of Bianzai, A lizai-Nasratzai, Achakzai, Abdal, Tarins. Headman: Samundar Khan.

KHAJAK (Sibi and Loralai).-A subdivision of Malikzai, Ghunji, Zarkuns. Headman: Khoidad.

KHAJAE (340) (Sibi).-A clan of Panis.

KHAJABZAI (Loralai).-A clan of Isots. Headman : Bangul.

KHalizaI (Largha). - A sub-division of Grabyazai, Hasan Khel, Shirani (q.v.). Headman : Mir Ajab.

KHalzaI (West of Dera Gbazi Khan district). - A sub-division of Land Palai, Labarzai, Musakhel. Headman : Azal.

BHaMis (Sibi and Loralai).-A sabdivision of Makhiani, Tor, Tarins. Headman : Ibrahim.

KHAMis (Loralai).-A sub-division of Wanechi, Spin, Tarins. Head. man : Haji Sler Dil.

KHANBZAI (Loralai).-A division of Morezai, Isots. Beadman : Rons Khan.
KranezaI (Quetta-Pishin).-A section of Panezai, Haran $K$ hel, Sanatia, Kakars. Headnan: Wadad Khan.

KHanezar (57) (Quetta-Pishin).-A section of Bazai, Haran Kbel, Sanatia, Kakars. Headman: Malik Lal Khan.

KHanZaI (148) (Quetta-Pisbin).-A sub-division of Abu Bakar, Tor, Tarins. Headman: Abdul Rehman Khan; Abdul Aziz Khan and Mir Ali.

EHAROTS (400) Loralai and Zbob.A clan of Ghilzais.

KHARomris (20) (Loralai).-A clan of Zarkuns.

KHARZAI (Sibi). -A section of Natozai, Hasan Khel, Dumar, Sanzarkhel, Kakars. Headmen: Juma and Fazal.

Krastal.-A small tribe living beyond the Dera Ghazi Khan border. Hesdman : Jehan Khan。

Khatolzar (West of Dera Ghazi Khan district).-A section of Inzai, Hasan Khel, Bel Khel, Mnsa Khel, Headman : Azim Khan, minor, under gusrdianship of Jamak.

KrazHUN (Sibi and Loralai).-A division of Perozai, Zarunks Headman : Rabm Ali. 
KHEPZAI (Loralai).-A sub-division of Salezai, Rakhanwal, Lunis. Headman : Shab Bakhsh.

KHIDARZAI (Loralai).-A clan of Zarkuns. Headman : M adad.

KHIDARZA I (Zhob). -A clan of Ustranas $(q \cdot v$.$) .$

KHIDaRzaI (Zhob).-A division of Obo Khel Shiranis. Headmen : Shamir Ashak.

KhidarzaI (71) (Loralai).-Á section of Maryam Kbel, Arabi Khel, Sanzarkhel, Kakars. Headmen: Saidád, Muhammad Nar Ghorat. Din, and Kadar.

KHIDARZaI (Quetta-Pishin).-A section of Bazai, Harun Khel, Sanatia Kakars. Headman: Isa Khan.

KHidarzaI (Loralai).-A division of Morezai, Isots. Headman : Rahim Khan.

KIDARZAI (Loralai).-A section of Natozai, Dumar Sanzarkhel, Kakar. Headman: Izzat.

Khid rani (165) (Loralai).-A clan of Jafars. Headmen: Ahmed Khan:and Mir Muhammad Khan.

Khidrant (240) (Sibi).-A subdivision of Makhiani, Tor, Tarins.

KHIDR KHEL.-A hamsaya section of Shabozai, Hasan Khel, Domar, Sanzarkhel, Kakars. Headman: Rahman.
Krinband (Sibi).-A division of Kark, Panis.

KHOANDr (Lorslai). - A division of Relkhel Mrasakel, Headman Nur Muhammad.

KhordadzaI (690) (Zhob).-A section of Shadozai, Alizai, Sanzar khel, Kakars. Headmen : Machakh, Durani, Sarbuland, Dalel, Paigul, Abdul, Sultan and Saleh.

Khoidani (24) (Loralai). - A subdivision of Lasiani, Spin, Taxins. Headman : Brabuk.

KHojahzaI (22) (Zhob).-A sabdivision of Haidar Khel, Mando kbel $(q . v$ v. Panis. Headman: Batak.

KнолАKZаI (Sibi).-A secticn of Unarzai, Dumar, Samzarkhel Kakar. Headman : Pani.

KHojezaI (Sibi).- - dirision of Lawand, Panis.

Khodadadzar (114) (Quetta-Pishin) - A sub-division of Abu Bakar, Tor, Tarins. Headman : Malik Pakur Khan.

KHUdakzaI (31) (Quetta-Pishin).A section of Sarangzai, Harun Khel, Sanatia, Kalkars. Hesdman : Halim Khas.

KHCJHALKHEL (Sibi).-A division of Marghzani, Panis. Headman Khan Shib Walhari Khan. 
KHODAzI (27) (Quetta-Pishin).-A sub-division of Alizai, Tor, Tarins Headman: Mubammed Nur.

KHUDOZAI (25) (Zhob). - A section of Shamamzai, Kibzai, Sanzarkhel, Kakar. Headman: Mobammed Khan.

KhoraMzaI (4t) (Zhob).-A subdivision of Hamzazai, Bel Khel, MIusa Kbel. Headman: Shah Gul.

KHеRAMZaI (30) (Zhob).-A section of Ahmedzai, Kibzai, Sanzarkbel, Kakars. Headman : Azmir Khan.

KeRAMZaI (40) (Zbob).-A minor fraction of Haiderzai, Hassanzaiat Kibzai, Sanzarkhel, Kakars. Headman : Banja!.

Khushalzar (Loralai).-A division of Umarzai, Isots. Headman;Bangal.

KHWAJAKHEL (Qugtta-Pishin).A clan of Mashwanis. (q. v.). Headman : Sher Zaman.

KHWAJAZAI (34) (Quetta-Pishin).A sub-division of Saigi, 'Tor, Tarins.

KHWAJAZAr (20) (Zhob).一́ subdivision of Abdullazai, Sanzarkhel, Kakars. Headman : Mulla Niaz II uhammad.

$\mathrm{KHW}_{\triangle \mathrm{J}} \mathrm{ZZAI}_{\mathrm{I}}$ (Quetta-Pishin).-A Section of Panezai, Harun Khel, Sanatis. Kakars. Headman: Wahab Khan.
KHW clan of Kansis. Headman : K. B. Malik Wazir Muhasmmad.

$K_{H} \operatorname{HJ}_{\Delta Z_{A} I}$ (Quetta-Pishin).-A section of Malezai, Achakzai, Abdal, Tarins.

KibZAI (KEBZAI). (1816) (Zbob and Loralai).-A division of SanzarKhel, Kakars. Headman : Khan Sahib Mian Khan and K. S. Paindan Khan.

Kosti (117) Sibi).-A division of Khajak, Panis.

Kotwal (Quetta-Pishia).-A clan of Kansis.

Kuchazar (10) (Zhob).-A division of Babar, Shiranis. Headman : Lal Muham mad.

KUDEZAI (40) (Zhob).-A section of Shamamzai, Kibzai, Sanzarkhel, Kakars. Headman : Dourani and Nur Khan.

KodezaI (142) (Loralai). -A subdivision of Ahmaàzai, Bel Khel, Musa Khel. Headman : Karim (Alikhanzai).

KUDEZAI (262) Loralai.-A section of Maryamkhel, Arabi Khel, Sanzarkhel, Kakars. Headmen : Khan Sahib Azam Khan, Haji Khan, Aziz and Nur Muhammad. 
KUNZAI (Loralai). -A sub-division of Marpani, Spin, Tarins. Headman : Dadan.

KURe (43) (Sibi). -A clan of Panis.
KUTIZAI (Loralai).-A division of Morezai, Isots. Headman : Bazai.

KotzaI (Loralai).-A division of Daudzai, Usteanas $(\boldsymbol{q} \cdot \boldsymbol{v}$.$) .$
LADO or LADU (42) Loralai).-A division of Rakhanwal, Lunis. Headman: Azad (Malikzai), Galdad (Hafizai), Lal Khan (Jamalzai), Khandai (Jalezai), Lal Gul (Malwanzai), Dasmal (Boia. zai), Fatehan (Sidzai).

LAGHARZAI.-(Loralai) A sub-division of Shamezai, Rakhanwal, Lunis. Headınan : Mian Khan.

LAHARZAi (633) (Loralia).-A division of Mrusa Khel. Headman : See Nozai Nokuzai, Land Palai, Mangizai.

LAIt or Let (Loralai). - A division of Umrani Jafars. Headman : Phakár.

LASANT (Loralai).-A division of Khidrani, Jafars. Headman . Roidar.

LATAKZAI (10) (Zohb).-A section of Amezai, Abdullazai, Sanzarkhel, Kakars. Headman : Mulla Habib Ullah.

LaLAKZaI.-A section ef Shamozai, Harun Khel, Sanatia, Kakars. Headman : Isaf Kach, Guldad. (Headman of the Shanozai), Ghafur Mian Khan.
LaLizaI (West of Dera Ghazi Khan district). A sub-division of Mangizai, Laharzai, Jusa Khe!. Headman : Khudar.

LalkHanzaI (86) (Quetta-Pishin). -A section of Alizai-Nasratzi, Achakzai, Abdal, Tarins. Headman : Kachkól Khan.

LALOZAI (Sibi).-A division of Usmani, Panis.

LatozaI (Sibi).-A division of Abdulla Khel Panis.

LaLOZaI (Sibi).-A division of Kork, Panis.

LakraR (113) (Quetta-Pishin).-All classed as Kakars, but their origin is doubtful. Hesdman: Katah Khan.

Laxv AHMad (Largha). - A subdivision of Ahmod Khel, Obe Khel, Shiranis. Headman: Pir Gul iI uhammad.

Laxd PataI (Loralai).-A sub. division of Salezai, Rakhanwal, Lanis. Headman : Gulan. 


\section{2}

LAND PaLAT (Loralai).-A division of Labarzai, Musa Khe]. Headmen: Azsl, Kadar Daku.

LASHRARZAT-A sub-division of Mizrai, Rakbanwal, Lanis. Headman: See Mizrai. Headman : Lashkar.

Lastani (88) (Toralai).-A division of Spin, Tarins. Headman: Ismail Khan.

Lasizat (Loralai). - A sub-division of Oriazsi, Ghunji, Zarkuns. Headman : Kaka.

Lutr (Loralai). - A division of Palao clan of Lunis. Headman : Chamchore.

LEWAN (36) (Quetta-Pishin).-A section of Ashezai, Achakzai, Abdal, Tarins, Headman : Mulla Zafran Khan.
LAWATA or LAWANR (272) (Zhob, Shib and Loralai). - A clan of Panis.

LIASzaI.-A section of Shamozai, Haran Khel, Sanatia, Kitkars. Headmen : Nor Muhrumad, Asna Mnlla, Abdulla, Paind, Aulia.

Lodin (Quetta-Pishin).-A clan of Mashwanis $(q, v)$.

LUNI (36) (Sibi). - A small clan of Panis.

LUNrs (600).-From the Bori and Thal plains to the foot of the mair eastern branch of the Suleman bills). - A Pathan tribe nomadic until recent years. Theìr chief is Khan Bahadur Haji Sardar Nawab Khan.
MI ACHABZAI (Zhob).-A section of Mirzai, Alizai and Sanzark hel Kakars. Headmen : Ramzan and Tahya.

$\mathrm{M}_{\triangle D O Z A I}$ (Sibi).-A sub-division of Daulatzai, Khajak, Panis.

MI $\triangle$ GHdozaI (Quetta-Pishin).-A sub-division of Parezun, Sanzar khel, Kakars. Headman : Mir Kalan.
MaghdUzaI (187) (West of Dera Gazi Khan district).-A sub. division of Bel "Khel, Musa Khel. Headmen: "Adina (Patozai), Sardar Khan (Brahimzai), Lat (Janizai), Daulat Khan (Tolazai), and Karam Khan.

Î́AHAKZAI (222) (Quetta-Pishin). -A secticn of Hamidzai. Achakzai, Abdal, Tarins. 


\section{3}

$\mathrm{M}_{\triangle \mathrm{H} I K H E L}$ (Loralai).-A division of Nasir, Ghilzais.

$M_{\triangle A M M D Z A I}$ (78) (Zhob):-A Section of Ismailzai, Alizai, of Sanzarkhel, Kakars. Headmen : Raz Mahammad and Payo.

MAHMODKHEL (Zhob).-A division of Kharot, Ghilzais.

MaHMODKHEL
division of Sula division of Sulemankhel, Ghilzais.

MAHMED or MUHAMMAD KHEL.A clan of Zmarais. Headmen : Sardar Hakin Kban, Amir Kban, Abdul and Pirak. MAHMUDZAI (Sibi).-A division
of Kurk, Panis.

MAHMUDZAI (33) (Loralai).-A section of Umarzai, Alizai, Tor, Tarins. Headman: Saddar.

MAHORA (Loralai).-A division of Kbidrani, Jafars. Headman: Eaizul.

MaHOZAI (Loralai). -A súd-division of Hamzazai, Sanzarkhel, Kakars. Headmen : Murtaza, Allan and Dunia Khan.

MaIZaI.-A sub-division of Nas Khel, Sanzarkhel, Kakars.

MakHaIzaI (Sibi),-A division
of Luni, Panis.
$M_{\triangle K H A L Z A I}-\mathrm{A}$ section of Sarangzai, Hurun Khel, Sanatia, Kakars. Headman: Malik Akram.

MAKHARAT. - A sub-division of Utuarzai, Lahrzai, MIusakhel, Headman : Rahman.

$M_{A K H I}$ ANI $(1,066)$ (Sibi).-A division of Tor, Tarins.

MAKOZAI (Loralai).-A sub-division of Marpani, Spin, Tarins.

MLLaZaI (96) (Bori Tabsil).-A minor fraction of Eudezai, Marma khel, Arabi Khel, Sanzarkhel, Kakars. Headmen :

Nasiban and Dost MInhammad.

M MLANGZAI (Loralai).-A division of Nuhzai, Isots. Headman : Hemal.

Marbzar (72).-A division of Rakhanwal, Lunis. Headman : $\mathrm{H}$ abil (Chnarzai), Bilanda, Khairat, Baze (Dariazai), Dilwash, Bangi (Marufzai), Madat (Ahmedzai), Nura Khan (Sadazai), Juma Baloch Khan (Hotizai)

MaLezaI (57) (Loralai, Sibi and Zhob).-A division of Nasir, Ghilzais.

M $\triangle$ LEZAI (250) (Zhob).-A sub. division of Abdullazai, Sanzarkhel, Kakars. Headman: Shoeak Khan. 
MaLezaI (96) (Quetta-Pishin)-A sub-division of Abu Bakar, Tor, Tarins. Headmen : Alli Mahammad Khan, Faiz Muhammad and Kadir.

MalezaI (1,443) (Quetta-Pishin).A sub-division of Achakzai. Abdal, Tarins. Headman : Pakar Khan.

M MIEZAI (102) (Quetta.Pishin).A section of Hamidzai, Achakzai, Abdal, Tarins. Headman : Mulla Wali Muhammad Khan.

$M_{A L E Z A I}$ (109) (Lorrlai).-A division of Bel Khel, Musa Khel. Headman : Samand Khan.

MalbzaI (Quetta-Pishin).-A subdivision of Parezun, Sanzarkhel, Kakars. Headman : Muhammad Jan.

MalezaI (28) (Quetta-Pishin).-A division of Sargara, Kakars. Headman: Sultan Muhammad Khan.

MaLezaI (126) (Quetta-Pishin).A sub-division of Harun Khel, Sanatia, Kalars. Headmon : A bdul Sattar.

$M_{\text {ALGARANAI.-A division of Spin, }}$ Tarins. Headman : Mulla Nazir.

MALIKKHEL (Zhob). $-\mathrm{A}$ division of Nasir, Ghilzais.
Malikfar (110) (Quetta-Pishin). -A division of Tor, Tarins. Headman: Malik Agha Muham. $\mathrm{mad}$.

MalikzaI (West of Dera Ghazi Khan district). - A sub-division of Mangizai, Laharzai, Musa Khel. Headman : Azim.

MALIKZAI (Loralai).-A section of Utman Khels, Sanzarkbel, Kakars. Headman: Mir Alam, Husain, and Isa Khan and Abdul Aziz.

Matikzar.-A sub-division of Ladn Rakhanwal, Lunis. Headmen: see Ladu.

MaLikzai (60) (Quetta-Pishin).A sub-division of Nurzai, Tor, Tarins.

MalikzaI (Loralai) -A division of Umar Khel, Ustranas.

Malikzar (93) (Sibi \& Loralai).-A division of Ghunji, Zarkuns. Headman: Khálá.

MaLizaI (West of Dera Ghazi Khan District).-A sub-division of Ahmadzai, Bel Khel, Musa Khel. Headmen: Samand Khan (Kanuzai), Shah Gul (Mursenzai), Z hobi (Dudazai), Rashiơ (Marezai).

MaIIKzaI (Quetta-Pishin).-A section of Alizai, Achakzai, Abdul, Tarins. 
MalizaI (Zhob). A section of Earanzai, Kibzai, Sanzarkhel Kakars. Headmon : Malla Rozi and Baz Gul.

MALIZAI-A division of Ajub Khel, Zmarai.-Headman : Amir Khan.

MaLJANI (Loralai).-A sub-division of Wanechi, Spin, Tarins.

MaLKRZAI (Loralai).-A division of Bel Khel, Musa Khel. Headmen : Samand Khan (Malezai); Mir Mulk (Adizzai); Hussan (Raghdinzai), Mulla Faizulla (salmazi); Karam Khan and. Daulat Khan (Mlaghdozaij.

MaLlakHeL (Zhob).-A division of Kharot, Ghilzais.

MaLLAKHeL (57) (Zhob).-A clan of Ghilzais.

MalwanzaI.-A sub-division of Ladu, Rakbanwal, Lunis. Headmen : See Ladu.

MaMaDZaI.-A section of Hasn Parazun, Sanzarkhel, Kakars.

MaMeZaI (78) (Zhob).-A sub-division of Haidar Khel, Mandokbel (q.v.), Panis. Headman: Rashid.

MamezaI (Largha).-A division of Obo Khel, Shiranis.

MamezaI (25) (Loralai).-A subdivision of Kabulzai, of Laharzai Musa Khel. Headman : Daku.
MaMizaI (West of Dera Ghazi Khan district). - A sub-division of Kabalzai, Laharzai, MIusa Khel. Headman : Daka.

M $\triangle$ MBEZKHRL (26) (Zhob). -A division of Tokhi, Ghilzais.

MaMUN.-A sub-division of Nas Khel, Sanzarkbel, Kakars.

MANAKZAI (Quetta-Pishin). A section of Ashezai, Achakzai, Abdal, Tarins.

MANAKZAI (Quetta-Pishin). A section of Hamidzai, Achakai, Abdal, Tarins.

M $\triangle$ NCHDNEHEL (2T) (Zhob.-A division of Nasir, Ghilzais.

MaNDARZaI (144) (Zhob).-A division of Lawana, Panis.

MaNDAZAI (33) (Zhob), - A division of Sargara, Kakars. Headman : Golai.

MandeKAHoL (262) (Zhob).-A division of Babar, Shiranis. Headman : Nek Mubsmmad.

MandazaI (45) West of Dera Ghazi Khan district). - $A$ division of Laharzai, Mura Khel. Headman : Kadar.

MandezaI (36) (Zhob)-A subdivision of Haidar Khel, Mandokhel (q. v.), Panis. Headman : Abdul Hamid. 


\section{6}

MandezaI (Sibi and Loralai).-A division of Nasir, Ghilzais.

MaNDBZaI (West of Dera Ghazi Khan district).-A section of Dodazai, Nokuzai, Laharzai, Musa Khel. Headman : Gagrai.

MaNdokhel $\quad(1,000)$ (Zhob). Classified as a cian of $\mathrm{P}$ anis according to the Census of 1901, a classification retained by Zhob Gazetteer, 1907. In reality the Mandokhel have no connection either ethnically or in practice with the $\mathrm{Panis}$, but belong to the Ghurghusht division of the Afghans, their divisions, etc., however, are indexed in this dictionary in accordance with the Census of 1901. Headmen : Sher Khan and Akhtar Khan.

Mandokmel (Sibi and Loralai).-A division of Nasir, Gbilzais.

MandozaI.-A sub-division of Hamzazaj, Sanzarkhel, Kakars.

MandozaI (Chagai).-A clan of Barech.

Mangizai (186) (Quetta-Peshin), A section of Bazai, Harun Khel, Sanatia, Kakars. Headmen : Saidal, Yusuf and Yakub Khan.

Mangizar (152) (Loralai).-Nomadic, a division of Laharzai, Musa Kbel, Headmen : Khudar (Lalizai) Bangar (Davzai), Janu (Neknamzai), Sado Khan (Khaeizai), Dadu (Brahimzai), Dadu (Sadozai)
Azim (Mâlikzai), Kalanda Ahmadzai).

Manizar (West of Dera Ghazi Khan district). -A sub-division of Magbduzai, Bel Khel, Musa Khel. Headman : Malla Khan Mahammad.

MantalzaI.-A division of Haripal Sbiranis. Headman: Rahmat.

Manozar (Loralai).-A division of Palao, Lunis. Headmen : Rahman, (Ahmadzai), Alan Khan (Isazai), Karm Khan (Baozaj).

Mantatzat (63) (Quetta-Pishin). A section of Nasratzai, Achokzai, Abdal, Tarins. Headman : Ashak Khan.

MARDAK (Loralai), -A division of Kharot, Ghilzais.

MaRDanzaI (702) (Zhob and Loralai).-A section of Shadozai, Alizai, Sanzarkhel, Kakars. Headmen : Ali Sher, Abjul Rahim, Saidulla anả Fazal.

Mabdanzat (Largha).-A section of Isaizai, Ahmud Khel, Oba Khel, Shiranis. Headmen : Saiyid Gul, Rustam.

MareghotzaI (Zhob).-A subdivision of Kibzai, Sanzarkhel Kakars. Headman : Khan Sahib Paindan Khan (Zakariazai).

Marghzant (205) (Sibi and Loralai).-A clan of Panis. 
MARHRL (64) (Bargha), Largha.A clan of Shiranis. Headman: Alladad Khan.

MarjanzaI (32) (Loralai).-A division of Dirgzai Tunis. Headmen: Alif Khan (Husszai), Rahim Khan (Umrzai), Fateh Khan (Jitianai), Azmat (Ishkun).

MaRMakHel OR MaRPaMkHEL (555) (Loralai).-A sub-division of Arabi Khel, Sanzar Khel, Kakars.

M of Sargara, Kakars.

MaROZAI (28) (Zhob).-A sub-division of Shadozai, Alizai, Sanzarkhel, Kakars. Headman : Zakaria and Khanagul.

MaRPant (67) (Loralai).-A division of Spin, Tarins. Headman : Khan Muhammad.

Marrani (294) (Loralai).-A subdivision of Wanechi, Spin, Tarins.

Marsenzat (Loralai).-A clan of Isots. Headman : Mashore.

MarsinzaI (33) (Zhob).-A subdivision of Haidar Khel, Mandokhel (q.v.), Panis. Headman: Mebtar and Mazbai.

Marufzal (15) (Zhob).-A section of Badinzai, Abdullazai. Sanzarkhel, Kakar. Headman : Mulla Mebrban.
MaRUfzaI (100) (Zhob).-A section of Mamezai, Mandokhel, Panis. Headman : Rashid.

Mardfzar (Loralai). A sub-division of Malezai, Rakhanwal, Lunis. Headmen: Hussain Khan (Marufzai), Faizal (Bangizai).

MabUFZaI (Largha).-A minor fraction of Brahimzai, Hezai, Gahyazai, Hasan Khel, Shiranis (q.v.).

MASA (Zbob).-A division of (Northern) Sanzarkhel, Kakars.

MasaqIzaI (48) (Quetta-Pishin).-A section of Panezai, Harunkbel, Sanatia, Kakars. See Masezai, Parezun Kakars.

MazarzaI (Quetta-Pishin).-A section of Mehtarzai, Haran Khel, Sanatia, Kaizars. Headman: Dil Murad.

Masazai, Machazal or MatsazaI (109).-A minor fraction of shamozai, Shadozai, Alizai sauzarkhel, Kakars. Headman : Shanbai.

MaSheZaI (30) (Zhob).-A section of Subankhel, Mandokbel, Panis. Headman : Rshmat Khan.

MaSHWANI (140) (Qnetta-Pishin)A small tribe of Saiyids, not infrequently classed as Afghans, owing to a marked similarity as regarảs habits, physique, etc. Unly the clans, etc., of the Mashwanis and Estranas recorded 
doring the Census of 1901 as A fghan tribes, are indexed in this dictionary. Headman : Sher Zaman Khan.

Mastzar (313) (Quetta-Pishin).-A sub-division of Parezun, Sanzarkhel, Kakars. Headmen : Malik Mazbin and Ali Khan.

MASSEZaI (93) (Quetta-Pishin).-A section of Alizai-Nasratzai, Achakzai, Abdal, Tarins. Headman : Lamar K han.

MASSEZAI (43) (Quetta-Pishin).-A sub-division of Nurzai. Tor, Tarins. Headman : Abdulla Jan.

II $\triangle$ SSEZAI (51) (Loralai).-A clan of Ustranas $(q \cdot v$.$) Headman :$ Dauran.

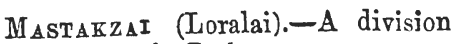
of Perozai, Zarkuns.

Matiani (Loralai and Sibi)-A sub-division of Lasiani, Spin, Tarins. Headman : Yar Mulammad.

MattakHei (27) (Zhob).-A division of Sulemankhel, Ghilzais.

MatTakzaI (Loralai).-A division of Kbidarzai, Ustranas (q. v.)

Mehmani (Loralai).-A sub-division of Wanechi, Spin, Tarins.

MegrabzaI (30) (Quetta-Pishin).A section of Bazai, Harunkhel, Sanatia, Kakars. Headman : Isa Khan.
MehbabZaI (53) (Zhob). -A minor fraction of Khoidadzai, Shadozai, Alizai, Sanzarkhel, Kakars. Headmen: Atta Ullah and Sorko.

Mehrasi (Sibi).-A sub-division of Wanechi, Spin, Tarins.

Mentarzar (958) (Quetta-Pishin and Zhob). - A suk-division of Harun Khel, Sanatia, Kakars, Headman : Malik Mir Alam Khan.

MeKHIANI.-A division of Tor, Tarins. Headmen : Mauladad, Azim, Abad.

Melmani (88) (Loralai and Sibi).A sub-division of Wanechi, Spin, Tarins. Headman : Barat.

MessoozaI (Quetta-Pishin).-A. section of Ashezai, Achak, Abdal, Tarins.

Miani (63) (Zhob).-A division of Nasir, Ghilzais.

MIANKHANZAI.-See Baranzai.

MIANk HaNZaI (36) (Quetta-Pishin) - A section of Alizai-Nasratzai, Achakrai, Abdal, Tarins. Headman : Panid Kban.

MiankenaxzaI (Quetta-Pishin).-A clan of Mashwanis $(q \cdot v)$.

M IANKHEL (Zhob).-A division of Nasir, Ghilzais. 
Minzai (Loralai).-A division of Drigzai of Lunis. Headman : Alam Sheikb.

MrnzaI (87) (Zhob). -A division of Sulemankbel, Ghilzais.

Mir ALIKHEL (20) (Zhob). - A subdivision of Haidarkhel, Mandokhel $(q . v$.$) . Panis. Headmen :$ Barat and Pahlwan.

Mrr Alizai (23) (Quetta-Pishin).A sub-division of Nurzai, Abdal, Tarins. Headman : Lal Beg.

Mrranis. - See Shiranis.

Miranzai.-A division of Palao, Lunis. Headmen : Sarmast (Khanikzai), Haibtán (Karimdadzai), Umr (Narizai), Chargul (Janguzai), Maksu (Shikar Khanzai).

MÍRDádzaI (West of Dera Ghazi Khan district).-A section of Jalalzai, Hasan Khel, Bel Khel, Musa Khel. Headman : Sarbadar.

RínDÁDZAI (Quetta-Pishin).-A section of Bazai, Harunkhel, Sanatia, Kakars. Headman : K. S. Bahawuddin Khan.

MírDáDZaI (Zhob and Loralai).-A section of Sbadozai, Alizai, Sanzarekhel, Kakars. Headman in Loralai : Ramzan. Headman in Zhob, Muhammad Yusuf.

MindadzaI (Loralai).-A sub-division of Adwani, Spin, Tarins. Headman : Sabzal.
Mir KHanzaI.-A sub-division of Walainai, Rakhanwal, Lunis. Headmen : See Walainai.

Mir KhanzaI (66) (Zhob).-A division of Sulemankhel, Ghilzais.

MirozaI (Quetta-Peshin).-A section of Mehtarzai, Harun Khel, Sanatia, Kakars.

Mirzar. - A section of Mehtarzai, Harun Khel, Sanatia, Kakars. Headmen: Malik Mir Alam Khan (Headman of Mehtarzais), Dad Gul, Shah Murad, Langar and Nadar.

MirzaI (1,445) (Zhob).-A sub-ảivison of Alizai, Sanzarkhel, Kakars. Headmen : Khoidad, Akhtar Muhawmad and Baran.

MrrzaI (Quetta-Pishin).-A clan of Kanais. Headmen: Shah Pasand and Islam Khan.

MirzaI (Sibi).-A division of Mizri, Panis.

MirzaI (Sibi).-A division of Safi, Panis.

MIRZAI (61) (Zhob).-A division of Babar, Shiranis. Headman: NeMuhummad.

MisRizaI (Quetta-Pishin).-A clan of Mashwanis $(q \cdot v$.$) .$ 
Misaizai (Quetta-Pishinj.-A section of Ashezai, Achakzai, Abdal, Tarins. Headman : Paradin Khan.

MithaZaI (Largha).-A sub-division of Khidarzai, Oba Khel, Shiranis.

MiZBI (22) (Sibi).-A clan of Panis.

MrzaIs.-See Zmarais.

MocchezaI (20) (Zhob).-A subDivision of Mamezai, Mando Khel Panis. Headman : Adin.

Modzar (10) (Zhob).-A sub-division of Mirzai, Bbar, Shiranis. Headman : Lal Muhammad.

Mohan KHel (Loralai).-A division of Nasir, Ghilzais.

Mohmand (Loralai).-A division of Kharotri, Zarkuns. Headman : Khudaidad.

Mohmanzai (Loralai).-A division of Perozai, Zarkuns. Headman : Mulla Jafar.

Morizai (72) (Loralai).- A clan of Isots. Headman: Runa Khan.

Morizai (54) (Zhob).-A sub-division of Isakhel, Sanatia, Kakars. Headman: Mulla Abdul.

MorizaI (West of Dera Ghazi Khan district).- A section of Malizan Ahmadzai, Bel Khel, Musa Kbel Headman : Rashid.
Mu bararzar (36) (Sibi) - -A subdivision of Koshi, Khajak, Pani.

MughalzaI (Quetta-Pishin).-A section of Sarangzai, Harun Khel, Sanatia, Kakars. Headman: Halim Khan.

MughatzaI (Quetta-Pishin).-A section of Bazai, Harun Khel, Sanatia, Kakars. Headman : $K$. $\mathrm{S}$. Bahawuddin Khan.

MUHaMMAD KHel (Loralai). - A clan of Zmarais. Headman: Tola.

Monammad Khel (Loralai). - A division of Perozai, Zarkun.

MUHAMMAD KHeL (Quetta-Pishin). -A clan of Mashwanis (q.v.)

MuHammad Krel (Loralai).-A division of Kharot, Ghilzais.

MUHaMmad KHel (Loralai).-A sub-division of Mullanzai, Nasir, Ghilzais.

MUHaMmad KHæL Gazni KHeL (Quetta-Pishin).-A clan of Mashwanis $(q \cdot v$.$) .$

MuHaMmadrHeL
(Quetta-Pishin). - A clan of
Mashwanis $(q \cdot v)$.

MUHAMMADEHEL SHAKDRKHEL (Quetta-Pishin).-A clan of Mashwanis $(q \cdot v$.). 
MUHaMmaDKHet (Quetta-Pishin).-A clan of Mashwanis (q.v.).

MUHAMMADZaI (102) (West of Dera Ghazi Khan District).-A subdivision of Ahmadzai, Bel Khel, Musa Khel. Headman : Dost Gul.

MU HAMMADZAI (Loralai)-A division of Bel Khel, Musa Khel. Headman: Jost Gul.

Mu hammadzaI (24) Quetta-Pishin. -A sub-division of Saigi, Tor, Tarins. No headman. Distributed among otber sections.

MonamMADZAI (70) Loralai-DA clan of Isots. Headman: J an Muhammad.

\section{Mohammadzai (22) (Sibi).-A} division of Barozai, Panis.

MUHAMMADZAI (Largba), - A minor fraction of Mardanzai, Isaizai, Ahmad Khel, Oba Khel, Shiranis $(q \cdot v \cdot)$.

MoxaZAI.-A section of Panezai Harun Khel, Sanatia, Kakars. Headman : Mushkai.

MollanZaI (48) (Zhob and Loralai). A division of Rasir, Ghilzais.

MuluanzaI (Sibi). - A gub-ditision of Kosni, Khajak, Panis.

Muluanzat (Sibi).-A division of Safi, Panis.
MUNDRANI (Sibi).-A dirision of Naudhani, Panis.

MursenzaI (West of Dera Ghazi Khan District).-A section of Malizai, Ahmadzai, Bel Fhel, Musa Khel. Headman : Samand Khan.

Musakmel $(2,500)$ (West of Dera Ghazi Khan District). - A tribe of Pani Pathans, descended from Pani. Though ethnically correct to classify them as Panis, they are now a separate tribe for all practical purposes. Headmen : Sirdars Mehrab Kban and Ala Khan. A fer families live at $\mathrm{Nali}$ Musakhel in Eori. Their Headman is Bahadur.

MUSALMaN RI (Loralai).-A subdivision of Wanechi, Spin, Tarins.

MusazaI (West of Dera Ghazi Khan District). - A division of Bel Khel, Musa Khel. Headman: Sahib Khan.

MUsazaI (Largha).-A subdivision of Mamezai, Oba Khel, Shiranis $(q \cdot v$.$) . Headman:$ Ahmad Khan.

Mosaza: (Q0) (Zhob).-A division. of Nasir, Ghilzais.

MosazaI (Zhob).-A division of Sulemankhel, Ghilzais.

MUSA ZAI (39) Quetta-Pishin\}.-A clan of Kansis. Healman : Arbab Khudadad Khan. 
Mosazar (Loralai)-A clan of Musiani (Sibi).-A division of Ustranas $(q \cdot v$.$) . Headman : Ali$ Khan.

Museza: (Loraiai).-A division of Nuhzai, Isots. Headman : Musa Jan.

MUZARI (Loralai). - A division of Raknanwal, Lunis. Headmen : Lashkar, Saiyad and Bahadur .

\section{N}

Nachozal (110) (Zhob).-A sub. division of Abdullazai, Sanzarkhel Kakar. Headman : Atai.

NADAZAr (39) (Quetta-Pishin).-A section of Hamidzai, Achakzai, Abdal, Tarins. Headman : Mulla Wali Mubammed.

NADAZAI (37) (Quetta-Pishin).-A section of Malezai, Achakzai, Abdal, Tarins. Headman : Eakar Khan.

NAGRI (Sibi).-A division of Kurk, Panis.

NerozaI (159) (Quetta-Pishin).A section of Hamidzai, Achakzai, Abdal, Tariess. Headman: Mulla Wali Muhammad.

Nanezar (Zhob).-A section of Ghorezai, Alizai, Sanzarkhel: Kakars. Headman: Lohan. Haripal, Shiranis.
NaraIZaI (80) (Zhob).-A sub-division of Haidark bel, Mandokhel $(q . v)$, Panis. Headman: Rashid.

NARGOZAI (80) (Zhob).-A section of Malezai, Abdullazai, Sanzarkhel, Kakar. Headman: Khodai Raham.

NARUKHEL (Quetta-Pishin).-A section of Bazai, Haruntsel, Sanatia, Kakars. Headman: K. S. Bahawuddin Khan.

NasarzaI (Loralai). - A division of Umarkhel, Ustranas $(q \cdot v)$. Headman : Miran.

NaSARZaI (Loralai).-A division of Inzra Khel, Zmarais. Headman : Karimdad Khan and Annu.

NAs Kaed (168) (Zhob, Loralai). - A division of (Southern) Sanzarkhel, Kakars. Headmen: Rabab, Paindi Zoabe, Mian Khan and Tal Khan.

NASIR (1,60̃6) (Zhob, Sibi, Loralai and Quetta-Pishin).-A clan of Ghilzais. 
NasirzaI (Loralai).-A division of Kharotri, Zarkuns.

Nasratzat or Alizai, Nasratzai (309) (Quetta-Pishin).-A subdivision of Achakzai, Àbdal, Tarins. Headman : Samundar Khan.

NAtho KHeL (Zhob).-A division of Nasir, Ghilzais.

Natozal (Sinjawi).-A subdivision of Hasan Khel, Dumar, Sanzarkhel, Kakars.

Naddhaani (57) (Sibi).-A clan of Panis.

NaZAB KHEL (Quetta-Pishin), - A clan of Mashwanis $(q \cdot v \cdot)$.

NernamzaI (West of Dera Ghazi Khan listrict).-A sub-division of Hamzazai, Bel Khel, Musa Khel. Headman : Khan Dauran.

Neknamzal (West of Dera Ghazi Klian I istrict.) - A sub-division of Mangizil, Laharzai, Musa Khel. Headman: Janu.

NernamzaI (Loralai).-A clan of Isots. Heudwan: Khan Jehan.

Nernamza I (Loralai).-A subdivirion of Wanechi, Spin, 'larins. Headman : Surat.

Niamat KneL (Quetta-Pishin and Zhob).-A divisior of Nasir, Ghilzais.
NI ZI (Zbob).-A division of Sulemankhel, Ghilzais.

NiazI (Zhob).-A division of Nasir, Ghilzais.

Nisari (Loralai),-A sub-division of Zaam, Spin, Tarins. HeadDan : Nazar.

NizAM KHEL (Zhob).-A division of Suleman Khel, Ghilzais.

Nokdzar (West of Dera Ghazi Khan District).-A division of Laharzai, Musa Khel. Headmen: Sirdar Alu Khan. Kadar (Dodazai), Bahar, Zbobi,Haibtan, Rasul (Kabalzair).

Notai (Loralai).-A sub-division. ot Zaam, Spin, Tarins.

NozaI OR NoHzaI (165). - A clan of Isots. Headman: Mano Khan.

NozaI oR NuHzaI (39) (West of Dera Ghazi Khan District).-A division of Laharzai, Musa Kbel. Headmen : Rahmtan (Dawizai), Sultan (Banazai), Saidan (Isazai), Mendak (Jalalzai).

Norani (Loralai).-A division of Khidrani, Jafars. Headman : Duran.

Norizar (Loralai).-A division of Suleman Khel, Ghilzais.

NORKHBL (Zhob).-A division of Nasir, Ghilzais. 


\section{4}

Nobzar (Quetta-Pishin).-A subdivision of Babi, Hotak, Ghilzais. No recognized headman.

NorzaI (60) (Quetta-Pishin and khel, Sanatia Kakars. Headman : Lowang Khan. Kalat).-A sub-division of Isa-

Nurzar (139) (Quetta-Pishin).-A division of Abdal, Tarins. Headmen : Lal Beg, and Sahib Dad. A fow families live in Kalat.

Norzal (134) (Quetta-Pishin).-A division of Tor, Tarins. Headman: Abdulla Jan.

O

OBA KHEI (132) (Bargha, Largha).-A clan of Shiraniz (q. v.). Headmen: Baluch Khan, Fateh Khan, Karim Khan. $W$ azir Khan, Inam Pir Gul, Shahmir (Isaizai) and sher Muhammad and Khanak.

Odhiadizar (Quetia-Pisbin).-A small sub-digision of Nurzai.
Abdal, Tarins. Headman : Lal Beg.

ONDHA (Sibi).-A division of Naudhani, Panis.

OriazaI (84) (Sibi and Loralai).A division of Gbunji, Zarkuns. Headman: Samand Khan.
Patar Khet (Loralai). -A division of Nasir, Ghilzais.

PaIsZaI (30) (Quetta-Pishin). - A section of Ashezaj, Achakzai, Abdal, Tarins. No recognized headman: Malik Para lin is the head of the Ashezais and is recongnized as such.

PatkzaI (25).- - A division of Inzra Khel, Zarnarais. Headman: Bazid.

Painda Khel. (71) (Zhob).-A clan of Safis.
Paindazai (24) (Loralai).-A division of Morezai, Isots, Headman : Miran Kban.

Paindeher (Sibi).-A division of Kharot, Ghilzais.

PaIndzaI (Iuargha), $-\mathbf{A}$ minor fraction of Khidarzai, Isaizai, A hmad Khel, Oba Khel, Shiranis (q. v.). Headmen: Ashak, Shahmir.

Pakhezai. (Loralai)-A sub-division of Hamzazai, Sanzar Khel, 
Kakars. Headmen : Jaimal, Safar and Mazhak.

P division of Abdullazai, SanzarKhel, Kakar. Headmen : Draz Khan.

Pargrazar (15) (Zhob). A minor fraction of Ahmedzai, Kibilzai, Hassanzai, Kibzai Sanzarkhell, Kakar. Headman : Baloch Khan.

PAIAO (135) (Loralai).-A clan of Lunis. Headmen: See Babu, Manozai, Miranzai.

PaNi $(4,730)$ (Zhob, Loralai and Sibi).-A Pathan tribe.

PANIZAI (785) (Quetta-Pishin, Sibi.)-A sub-division of Harun, Khel, Sanatia, Kakars. Headman: Khan Sabib Malik Wabab Khan. Panizais of local importance in Quetta-Pashin District are Haji Harun and Haji Wahidad.

PanizaI :(25) (Quetta-Pishin).-A section of Badinzai, Achakzai, Abdal, Tarins. Headman : Allah Din.

Panizun.-See Parezun.

PANJI (Loralaì).--A clan of Zarkuns. Headman : Adam Khan.

PANZaI (Loralai).-A division of Umarzai, Isots. Headman: Chhinku.
Parzat (West of Dera Ghazi Khan District). - A section of Dodazai, Nokuzai, Laharzai, Musa Khel. Headman : Sirdar Aln Khan.

$P_{\triangle N Z A I}$ (24) (Loralai).-A division of Laharzai, Musa Khel. Headman : Sardar Alu Khan.

PAPAZAI (Loralai).-A clan of Ustranas $(q . v)$. Headman : Fatteh.

PAREZTN $_{\text {or PaNIZUN }}(690$ (Quetta-Pishin).-A division of Sanzar Khel, Kakars. Headmen : Muhammad Jan and Majbin.

$P_{\triangle S N I}$ (Loralai).-A division of Kharotri, Zarkuns. Headman : Ghafur.

PASNI (Zhob).-A division of Nasi, Ghilza is.

PatozaI (West of Dera Ghazi Khan District). - A section of Maghdnzai, Bel Khel, Musa Khel. Headman : Kata.

PatozaI (Loralai). - A division of Umarkhel, Ustranas $(q \cdot v$. $)$ Headman : Sarfraz.

PatozaI (Loralai).-A division of Palao clan of Lunis.

P $_{\triangle T O Z A I}$ (Quetta-Pishin).- $-A$ division of Samungli, Kansis. Headman : Hamid Khan.

Patwani (Loralai). -A division of Umrani, Jafars. Herdman : Rahim. 
Perozal (110) (Sibi and Loralai).A clan of Zarkuns. Headman : Paind Khan.

Pirakzar (Largha).-A minor fraction of Khidarzai, Isaizai, Ahmad Khel, Oba Khel, Shiranis $(q \cdot v$.$) .$

Piralizar (99) (Quetta-Pishin).-A section of Mrlezai, Achakzai, Abdal, Tarins. Headman : Malik Agba.

Prbant (Sibi). - A clan of Panis.
Prsezal (Loralai).-A sub-division of Umarzai, Laharzai, Musa Kbel. Headman: Sher.

Popalzai (30) (Quetta-Peshin).-A sub-division of Parezan, Sugar Khel, Kakars. Headman : Taimur.

Popalzar (63) (Quetta-Pishin).A division of Ablul, Tarius. Headman : Abdul Wabid Khan.

Prang (Sibi).-A division of Margbzani, Panis.
QABALZaI (400) (Zhob).-A section Hassanzai, Kibzai, Sanzarkhel, Kakar. Headmen : K. S. Mian Khan and K. S. Paindan Khan.

Qaiandrani (Sibi).-A sub-dirision of Wanechi, Spin, Tarins.

QАIIM KHEL (Sibi).-A division of Tarak Ghilzais.
QASM1 (Sibi).-A division of Dehpal, Paniõ.

QбтбвzaI (57) (Quetta-Pishin).-A section of Alizai-Nasratzai Achakzai, Abdul, Tarins. Headman Qazi Khudadad and Qazi Saleh.
RAGHDANZAI (54) (Loralai).- A division of Bel Khel, Musa Khel. Headman : Hussan.

RaHmatkahol (Quetta-P ishin).-A small section of Malezai, Achakzai, Abdal, Trains. No recognized headman.
RAHATzAI (84) (Zhob) - A minor fraction of Knoidadzai, Shadozai, Alizaj, Sanzarkhel, Kakars. Head. man : Kushdil and l ladmal.

RaHimzaI or ABDtl RaHimzaI. -A section of Mirzai Alizai, Sanzarkhel, Kakars. Headman: Sultan Vuhammad. 


\section{7}

RAHMANZaI (Quetta-Pishin).-A section of Alizai-Nasratzi, Acbakzai, Abdal, Tarins.

RAHMANZAI.-A sub-division of Zakarzai, Rakhanwal, Lunis. Headman : Shambe.

RAMDANI (Loralai).-A division of Khidrani, Jafars. Headman : Khalil.

Ratsani (40) (Sibi).-A division of Spin, Tarins. Headman : Paind Khan.

RAJANI (Loralai).-A division of Khidrani, Jafars. Headman: Khanu.

RAJUNZAI (93) (Quetta-Pishin).-A section of Alizai-Nasratzai, Achakzai, Abdal, Tarins. Headman : Samundar Khan.

RAKHANWALS (Loralai).-A clan of Lunis. Headmen : See LaduMalezai, Mizrai, Saiyadan, Walainai, Zakarzai.
RANAZAI (Sibi).-A sub-division of Kariazai, Khajak, Panis.

RASHID $K_{\text {HEI }}$ (Sibi).-A division of Dehpal, Panis.

Rutta (Loralai).-A division of Khidrani, Jafars. Headman : Gharib.

RAWANI (Loralai).-A division of Khidrani, Jafars. Headman : Lal Ǩ han.

RaZI (Sibi).-A division of Kurk, Panis.

RIANI (Sibi).-A division of Nandhani, Panis.

RodsnzaI (Sibi).-A sub-division of Bahramzai, Khajak, Panis.

Roshan Khel (Loralai).-A division of Nasir, Ghilzais.

PústamzaI (94) (Zhob and Loralai). -A section of $\mathrm{Hamzazai,} \mathrm{Arabi}$ Khel, Sanzarkhel, Kakars. Headman : Kalla Khan.
S_AMr. See Zaam, Dzam.

BabakzaI (40) (Zhob).-A section of Khojalzai, Abdullazai, Sanzarkhel, Kakars. Headman : Jighai.
SabirzaI-A minor (Hamsaya) fraction of Saiyidzai, Barakzai, T'arghara, Sanzarkhel, Kakars.

SABOzaI (Loralai).-A division of Umarzai, Isots. Headman: Jamadar. 
SADAKzaI (West of Dera Ghazi Khan District).-A sub-division of $\mathrm{H}_{a}$ mazai, Bel Khel, Musa Kbel. Headman: Sezgai.

SADAZAI (10).-A sub-division of M alezai, Rakhanwa), Lunis. Headman: See Malezai.

SADOO KHEL (Zhob). - A division of Kharot, Ghilzais.

Sadianzal or Shadyani (Loralai).A division of Palao, Lunis. Headman: Ali Mubammad.

SADIEZAI.-A minor (Hamsaya) fraution of Husainzai, Parokzai, Targhara, Eanzarkbel, Kakars.

SALOZAI.-A sub-division of Largha Mamezai, Oba Khel, Shiranis.

SADOZAI.-A minor fraction of Haidarzai, Natozai. Dumar, San zarkhel, Kakars.

Sadozar-A minor (Hamsaya) fraction of Husainzai, Barakzai, Targhara, Sanzarkhel, Kakars.

SADOZdI (48) (Anambar Loralai).A division of Palao, Lunis. Headman : Miran.

SadozaI (West of Dera Ghazi Khan district). - A section of Jalalzai, Hasan Khel, Bel Kbel, Musa Khel. Headman: Azim Khan.

SADOZAI (West of Dera Ghazi Khan District). - A sub-division of $\mathrm{M}_{\mathrm{an}}$ - gizai, Laharzai, Musa Khel. Headman : Dadu.

SADOZAI (63) (Zhob).-A subdivision of Mirzai, Babar, Shirani. Headman : Nek Muhammad.

SADRANI (Loralai).-A division of Umani, Jafars. Headman: Mewa.

SAEMANZAI.-A minor fraction of Masezai, Hani, Parezun, Sanzarkhel, Kakars.

SafarzaI (94) Loralai and Zhob).A section of Hamzazai, Arbi Khel, Sanzarkhel, Kakars. Headmen: Muistfa and Bagolai.

S $\triangle$ FARZAI. - A section of Bazai, Harun Khel, Sanatia, Kakars. Headiman: Ikbbal.

SAFARZAI (Loralai).-A division of Nulzai, Isots. Headman: Badak.

SafarzaI (Quetta-Pishin).-A section of Hamidzai, Achakzai, Abdal, Tarins. Headman : Taj Muhammad.

SaFARZAI (Quetta-Pishin)-A small section of Malezai, Achakzai, Abdal, Tarins. No recognized heaủman.

SafarzaI (Sibi and Loralai).-A sub-division of Malikzai, Ghunji, Zarkuns.

SAFI (100).-A small tribe of Pathans in the Zhob district. Headman : Toran. 
SAFI (27) $-\Delta$ clan of the Pathan tribe in the Sibi district.

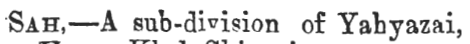
Hasan Khel, Shiranis.

SAIGI OB SEgI (228) (QuettaPishin).-A division of Tor,Tarins, Headman: Mir Baz; Dadun, Ruidad and Kamran.

SAIYID (Quetta-Pishin).-A subdivision of Barakzai, Targhara, Kakars. No recognised headman.

SAITIDAN, - A division of Rakhanwal, Lunis. Headman : Lal Shah.

SAIYIDANZAI.-A sub-division of Zakarzai, Rakhanwal, Iunis. Headman : Mian Khan.

SAIYIDKHANZAI. $-A$ section of Maizai, Nas Khel, Sanzarkhel Kakars.

SAIYIDS KHEL (Pishin and Loralai), $\rightarrow$ A division of Nasir, Ghilzais.

SAIYADS (Quetta-Pishin, Sibai, Zhob, Chagai, Kalat, Las Bela).-Consist of a number of scattered groups and cannot aceurately be described as a tribe; descendants of the family of the prophet. The original settlers were refugees from Central Asia, probably about 12th and 13th centuries, whose descendants by intermarriage, etc., have gradually become affliated to various Afghan tribes in Baluchistan, whom they resemble in babits, physique, etc., and hence the not infrequent confusion of Saiyads with Afghans.

The clans or groups, as enumerated in 1901 are :-

Ahmdunia, Arab, Bahlolzai, Baidar, Bakhari, Fatehalizai, Ghazi, Gilani, Haibatzai, Hussaini, Karal, Karbala, Kharsin, Kbosti, Mashuq, Mandudi, Pechi, Qadian, Qureshi, Razai, Taran.

These are not separately indexed in this Dictionary.

The customs of the Saiyads in the Chagai District resemble those of the Baloch among whom they are living.

The Chief Saiyads in the Quetta District are Saiyad Umar Shah, Saiyad Atta Muhammad and Saiyad Ali Jan. Chief Saiyads in Peshin are Muhammad Hassan Khan; Sayad Muhammad; Shah Alam and Doulat Shah.

SaIrIDzaI (Loralai).-A sub-division of Mizrai, Rakhanwal, Luni. Headman: Şe Mizrai. Headman : Paindai.

SaIYIDZar. - A (Hamsaya) section of Barakzai, Targhara, Kakars. Headmen : Kalaudar of Takhor and Rahmatulla of Bagh.

SAIYIDZAI (39) (Quetta-Pishin).A section of Sarangzai, Harun Khel, Sanatia, Kakars. Headman: Sirdar Halim Khel, chief of all the Sarangzais. 
SaIYidzaI (Zhob).-A section of Mehtarzai, Harun Khel, Sanatia, Kakars. Headman: Faiz Muhammad.

SaIyidezaI (Laralai).-A division of Nuhzai, Isots. Headman : Jangul.

Sakan I (32) (Loralaj).-A subdivision of Lasiani, Spin, Tarins. Headman : Ismail Khan.

SAKHIZAI (Sibi).-A division of Luni, Panis.

SAkHex (Zhob).-A division of Oba Khel, Shiranis.

Sakmezal (102) (Quetta-Pishin).A section of Ashezai, Achakzai, Abdal, Tarins. Headman : Paradin Khan,

SAKRAN I (Loralai)-A sub-division of Marpani, Spin, Tarins. Headman : Malikdad.

SARzaI (Quetta-Pishin).-A subdivision of Nurzai, Abdal, Tarins. Headman : Molla Walo.

SALAK KHEL (Zhob and Loralaj), A sub-division of Umarzai, Nasir, Ghilzais.

Salakzai or TsalakzaI (Zhob and Loralai).-A section of Hamzazai, Arbi Khel, Sanzarkel, Kakars. Headmen: Hassan Khan and Paindi.
Salar KHel (Sibi).-A division of Debpal, Panis.

SALARZaI (51) (Quetta-Pishin).-A division of Lamar, Kakars. Headman: Katta Khan.

SALARzaI (Loralaj).-A section of Hamzazai, Arbi Khel, Sanzarkhel, Kakars. Headmen : Hassan Khan and Gulla Khan.

SalemzaI (78) (Quetta Pishin).-A section of Alizai-Nasratzai, Achakzai, Abdal, Tarins. Headman: Kargha Khan.

SaleHzar (Sibi).-A sub-division of Khosi, Kbajak, Panis.

SALEHzaI (21) (Quetta-Pishin).-A section of Panezaj, Harunkhel, Sanatia, Kakars. Headman of the Panezai : Sardar Wahab Kban.

SaleHzaI (Sibi).-A division of Sodi, Panis.

Salem KhanzaI (West of Dera Ghazi Khan District).-A section of Jalalzai, Hasan Khel, Bel Khel, Musa Khel. Headmen : Wedar and Sabban.

Salehzar (Loralai).-A division of Rukhanwal. Lunis.

SaIIM KHanzaI (21). (Zhob), -A division of Kapip, Shiranis.

SamadinzaI.-A sub-division of Isa Khel, Sanatia, IKakars. H eadman : Malikdad-Muhammad. 
SAMAND (36) (Loralai).-A division of Drugzai of Lunis. Headman : Fatteh Khan.

SAMkHec (66) (Zhob). - \& division of Sargara, Kakars. Headmen: Malik, Hukmat, and Taj-ud-din.

SAMLI (Quetta-Pishin).-A clan of Kansis.

SAMUNGII (Quetta-Pishin).-A clan of Kansis. Headmen: Hamid, Nek-Muhammad and Abdul Wahid.

Sanarias (5,425) (Quetta-Pishin), Loralai, Sibi, and Zhob).-A clan of Kakars. Headmen: Guldad (Shamczai), Malik Mir Alam Khan (Mehtarzai), Khan Sahib Malik Halim Khan (Sarangzai), Baidula (Sarangzai), Khan Sahib Malik Wahab Khan (Panizai), Malik Dad Muhammad (Samadinzai).

SANGASZAI (Loralai).-A division of Marghzani, Panis.

SaNinzaI (Sibi).-A sub-division of Wanechi, Spin, Tarins.

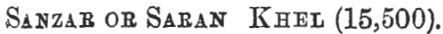

(Quetta-Pishin, Sibi, Loralai and Zhob).-The most powerful of the Kakar clans. Headman : Sirdar Muhammad Khan, Jogezai.

SARANGZAI (1,032) (Sibi, QuettaPishin, Zhob).-A sub-division of Harun Khel, Sanatia, Kakars. Headman : Khan Sahib Sirdar Halim Kban.
SaRATAR (Sibi).-A division of Luni, Panis.

SARGARA (600). (Quetta-Pishin, I oralai and Zhobj.-A clan of Kakars. Headmen: Jalal Khan and Mulla Abdul Haq. The Headman of the Sargaras of Quetta (200) is Sultan Muhammad.

SARKUN (Sibi).-A division of Luni, Panis.

SARW AN KHEL (25) Zhob).-A division of Sulemankhel, Ghilzais.

Satanzar (Loralai).-A division of Morezai, Isots. Headman : Runa.

SaWAR (Loralaij.-A division of Kharotri, Zarkuns.

Sebz.ar (Zhob).-A section of Shadozai, Alizai, Sanzarkhel, Kakars. Headman: Daulat Khan.

Sebzar.-A section of Ibrahimzai, Shadzai, Alizai, Sanzarkhel, Kakars. Headman : Daulat Khan.

Selani (Loralai). - A sub-division of Marpani, Spin, Tarins.

SEmani (51) (Loralai).-A division of Spin, Tarins. Headman : Isa Khan.

Sen KHEL.-See Hasan Khel.

Senzar (81) (Loralai).-A division of Bel Kbel, Musa. Khel. Headman : Haru. 
SgnzaI (21) (Loralai).-A division of Ismaillkhel, Zmarais. Headmen : Abdul and Roze.

\section{Shabarizar (Quetta-Pishin).-A sub-division of Barakzai, Targhara Kakars.}

Shabezar (Loralai).-A section of Isaizai, Ahmad Khel, Oba Khel, Shiranis $(q \cdot v$.).

SHabozaI (92) (Loralai).-A section of Marma Khel, Arabi Khel, Sanzar Khel, Kakars. Headmen : Maddo, Karim, and Sadid.

Shabozal (Sinjawi).-A sub-division of Dumar, Sanzarkhel Kakars. Headmen : Khanan, Nadar and Shahab.

ShadezaI (78) (Loralai)-A subdivision of Hamzazai, Bel Khel, Mrusa Khel. Headmen :-Bazai and Lawang.

SHADIANI (Loralai).-A division of - Pala Lunis. Headman : Ali Muhammad.

Shadizar.-A sub-division of Ahmad Khel, Targhara, Kakars. .

ShadizaI (40) (Quetta-Pishin).-A sub-division of Malikyar, Tor, Tarins. Headman : Agha Mabammad.

ShadizaI Kachun (87) (QuettaPishin).-A section of Malezai, Achabzai, Abdal, Tarins. Head. man : Baran.
Shadizar (Sibi).-A sub-division of Kariazai, K hajk, Panis.

ShadizaI (Loralai).-A division of Kharot, Ghilzais.

Shadrzar (45) (Zhob and Loralai). -A division of Nasir, Ghilzais.

ShadizaI (15) (Zhob).-A division of Babar, Shiranis. Headman: Nek Muhammad.

ShadozaI - A section (Hamsaya) of Hasanzai, Barakzai, Targhara, Kakars.

Shadozar.-A minor fraction of Rulozai, Panizai, Harun Khel, Sanatia, Kakdars. Headmen: Ali Muhammad, Ramzan, Faiz Muhammad.

ShadozaI (96) (Loralai).-A subdivision of Kibzai, Sanzarkhel, Kakars.

ShadozaI (Zhob and Loralai). - A sub-division of Alizai, Sanzarkhel, Kakars. Headmen : Abdur Rahim (Aktarzai), Sharif (Ali Khel), Isa Khan (Daulatzai), Daulat Khan (Sebzai).

SHaghalzaI (46) (Quetta-Pishin). -A sub-division of Malikyar, Tor, Tarins.

SHлHABZAI (39) (Zhob),-A section of Malezai, Abdullazai, Sanzarkhel, Kakars. Headman : Jindai. 
Shahalam KHel (Loralai), - A division of Hotak, Ghilzais. Headman : Sardar Muhammad Shali Khan.

Shat Budinzar. (West of Dera Gha\%i Khan district).-A subdivision of Hamzazai, Bel Khel, Musa Khel. Headman : Kalandar.

Shahezal (Quetta-Pishin).-A division of Samungli, Kansis. Headman: Hacoid and Nek Muhainmad.

Shatezai (Sinjawi) -A minor fraction of Kanozai, Natozai, Hasankhel, Dumar, Sangarkhel, Kakar. Headman : Jungihan

ShaHlizaI (Zhob).-A minor fraction of Khoidadzai, Shadozai, Alizai, Sanzarkhel, Kakars. Headman : Saleh.

Sramozal (West of Dera Ghazi Khan District). - A sub-division Umarzai, Zahrzai, Musa Kbel. Headman : Khodaidad.

Shanozal-A sub-division of Yabyazai, Hasan Khel, Shiranis.

ShaHoZaI (20) (Sibi and Loralai).A sub-division of Malikzai, Ghunji, Zarkuns.

ShatzaI (Zhob).-A Section of Shadozai, Alizai, Sanzarkhel, Kakars.

ShaIR (Shibi).-A division of Naudhani, Panis.
ShaKkARZaI (Largha).-A section of Land Abmad, Ahmad Khel, Oba Khel, Shiranis $(q \cdot v$. )。

ShamakzaI (36) (Quetta-Pishin). -A section of Ashezai, Achakzai, Abdal, Tarins. Headman : Paradin Khan.

ShamalzaI (32) (Zhob)-A division of Tolihi, Ghilzais.

ShamamzaI (485) (Zhob).-A section of Kibzai, Sanzarkhel, Kakars. Headmen : Sharbat and Muhammad Azam.

SHambozar (Toralai). -A sub-division of Semani, Spin, Tarins. Headman : Pasta Khan.

ShamezaI (42) (Loralai).-A division of Rakhanwal, Lunis. Headman :-K. B. Sirdar Nawab Kban.

ShaMezaI (Loralai).-A section of Hamzazai, Arbi Khel, Sanzarkhel, Kakars. Headmen: Dost Muhammad (Mahrizai), Mardan (Kashmirzai), Dewa (Mirakzai), Feroz Khan, who is the headman of all the Hamzazais, Saido (Miratizai) ; and Mulla Said Khan (Naurangzai).

ShamezaI (Loralai).-A division of Massezai, Ustranas.

Shamozar (Chagai) A division of the Mandozai Barech. 
Shamil KHeL (Zhob).-A division of Sulemankhel, Ghilzais.

Shamir Khel (Quetta-Pishin), -A clan of Mashwanis (q. ".)

ShamozaI (West of Dera Ghazi Khan District). -A sub-division of Kudizai, Bel Khel, Musa Krhel. Headman : Pir Muhammad.

SHAMozaI (201) (Quetta-Pishin).-A sub-division of Harun Khel, $\mathrm{S}_{3}$ natia, Kakars. Headmen : Nur Muhammad (Iliaszai), Adro (Lalakzai, Shamozai).

SHamozaI (Quetta-Pishin).-A division of Sargara, Kakars. Headman Sultan Muhammad.

Shamsher KHanzaI (Loralai).- - A division of Perozai, Zarkuns. Headman : Rasul.

Sharawani Or Shardi (118) (Sibi and Loralai). - A clan of Zarkuns. Headman : Dada Khan.

SHAWAND (Loralai).-A clan of Zarkuns. Headman : Azad.

SHEIKH (Quetta-Pishin).-A clan of Kansis. Headraan: Biland Khan.

SHEIKH (Sibi).-A sub-division of Bahramzai, Khajak, Panis.

SHeIKH (Sibi).-A sub-division of Umarzai, Khajak, Panis.
Sheikg or Hadizai (30) (Zhob). A division of Mandokhel $(q \cdot v$.), Panis. Headman : Bazgul.

SheikH (220) (Sibi). - A sub-division of Makbiani, Tor, Tarins.

SheikHzaI (Zhob).-A division of Hotak, Gbilzais.

SHEIKHZa1. - A minor fraction of Masezai, Hani, Parezum, Sanzarkhel, Kakars.

Sheman I or Semani (Loralai). -A division of Murani, Jafars. Headman : Musad.

Sherezai (toralai).-A minor fraction of Ali Khanzai, Hamzazai, Sanzarkbel, Kakars. Headmen: Jahan, Feroz Khan and Badani.

ShIK עN (42) (Loralai and Sibi).-A sub-division of Oriazai, Ghunji, Zarkuns. Headman in Loralai : Waziran.

ShIN KHUR. - A minor fraction of Khoidadzai, Shadizai, Alizai, Sanzarkhel, Kakars. Headman : Yabya.

ShinwaR (41) (Loralai).-A clan of Gbilzais.

SHIRANis $\quad(1,643)$, also called Maranis (country around Takht-iSuleman).-A tribe of Pathans, divided politically into two portions; Largha $(1,300)$ and Bargha $(2,000)$; the former term is applied to those east of the 
Takht-i-Suleman, and the latter to those living west of it. The Largha Shiranis are under the control of Deputy Commissioner, Dera Ismail Khan, and the Bargha Shiranis under that of the Political Agent, Zhob. (For convenience sake the whole of the Shirani clans, etc., are given in Part IV).

Strictly speaking, the Shiranis are divided into 6 clans, i.e., Oba Khel, Marhel, Kapip, Haripal, Hasan Khel, and Chuhar Khel. All of these trace their descent to Omar, eldest son of Shiran. The Babars and Mianis, who are sometimes called Shiranis, are descended from Babar and Mianai, younger brothers of Shiran.

The fighting men of the Babars are included among those of the Bargha Shiranis, given above. Miani is not recognized as a tribal name in Baluchistan, but certain tribes, such as the Lunis and Jafars, are supposed to be descended from them.

ShiraNzaI.-A minor fraction of Babuzai, Natozai, Dumar, Sanzarkhel, Kakars.

SibZaI (53) (Zhob).-A division of Sanzarkbel, Kalzars.

SIDQZAI (Quetta-Pishin).-A subdivision of Barakzai, Targhara, and Kakars. Headmen : Suleiman and Zarin.

Sipzar.-A sub-division of Lada, Rakhanwal, Lunis. Headman: See Ladu.
Sitmezar (54) (Loralai).-A division of Bel Khel, Musa Khel. Headman: Faizullah.

SImzaI (110) (Quetta-Pishin). - A sub-division of Alizai, Tor, Tarins Headman : Malik Rahu.

SIN, SUIN oR SIUN.-A clan of Kakars, residing in the Meerut district of Afghanision.

Sirgirt or Sargaba (QuetitaPishin, Zhob, Loralai). - A small Kakar clan. Headman of the Quetta-Pishin Sargaras: Sultan. Muhammad.

Slarani (Loralai).-A division of Umrani, Jafars. Headman : Fakis Hamid Sahib.

Suailani (Toralai).-A sub-division of Adwani, Spin, Tarins. Headman : Sadar.

Sodr (Sibi).-A clan of Panis.

SODI (Sibi).-A division of Marghzani, Panis.

SOMat (Toralai).-A division of Khidrani, Jafars. Headman : Nuran.

SrIn $(1,125)$ (Loralai and Sibi).A clan of Tarins. Headman in Loralai Ismail Khan Lasiani.

Syin KнетtaI (26) (Zhob).-A. division of Shinwar, Ghilzais. 
Spixzar (Loralai). - A sub-division of MI ullanzai, Nasir, Ghilzais.

Starayi (Loralai).-A division of Khidrani, Jafars. Headman: Hakim.

StrayzaI (20) (Quetta-Pishin).-A sub-division of Alizai, Tor, Tarins. Seadman : Sher Muhammad.

Sthax Krel (250) (Zhob). -A subdivisicn of Haidar Khel, Mandokhel (q. v.), Panis.

Stleyan KHer (700) (Zhob, Loralai and Quetta-Pishin).-A clan of Ghilzais.

Suleman Khel (746) (QuettaPishin). -A division of Targhara, Kakars.

Selguar MithamadzaI.-A section of Arozai, Ahmad Khel, Hasan Khel. Shiranis. Headman: Abdulla Shah.

ScremaxzaI. (Quetta-Pishin and Loralai, - A division of Nasir, Ghilzais.

StremaxzaI (21) (Loralai).-A division of Muhammadzai, Isots. Headman : Jan IIuhammad.

StemmanzaI (600) (Zhnb).-A section of Dawatkhel, Haidarkhel, Mandokbel $(q . v$.$) , Panis.$

Strgaraxza (160) (Zhob)-A sub-dirision of Hassanzai, Kibzai,
Sanzarkhel, Kaisar. Headmen Tuayab and Khanan.

StremanzaI (196) (Zhob).-A division of Babar, Shirani. Headman : Haji Salim Khan.

SULTaNkHEL (Zhob). - A division of Sulemankhel, Ghilzais.

SultanzaI (Largha).-A subdivision of Mamezai, Oba Khel, Shiranis $(q . v$.$) . Headmen :$ Islam and Bahawal.

SeltanzaI.-A section of Natozai, Hasan Khel, Dumar, Sanzar khel, Kakars. Headman: Allahdad of Sinjawi.

SoltanzaI (121) (Quetta-Pishin, Zhob). $-\mathrm{A}$ ' sub-division of Isa Khel, Sanatia, Kakars. Headmen: M uhammad Jan and Shado.

StrtanzaI (43) (Quetta-Pishin).A sub-division of Nurzai, Abdal, Tarins. Headman : Sahibdad.

SUNDRANI (Loralai).-A subdivision of Adwani, Spin, Tarins. Headman : Fatteh.

SUR (27) (Quetta-Pishin).-A division of Targhara, Kakars. Headma : Mulla Amir.

Sorr (Quetta-Pishin).-A section of Sarangzai, Harun Khel, Sanatia, Kakars. Headmen : Saleh Muhammad and Anwar. 


\section{T}

TadozaI (35) (Zhob).--A section of Badinzil, Abdullizai, Sanzar Khel, Kakars. Headman : Noor Ahmad.

TaL KeanzaI (Luralai).-A section of Shabozai, Hasan Khel, l)umar, Sanzar Khel, Kakars. Headman : Mahin.

TamaM KenL (Quetta-Pishin). - A division of Sargara, Kakars. Headman : Sultan Minhammad.

TAMN I (Herat).-A division of Sanzar Khel, Kalzars.

TANZaI (Loralai). - A division of Anjra Khel, Zmarais. Headman : Bilak.

TARAK (Zhob).-A division ol Oba Khel, Shiranıs.

TARAK (Quetta-Pishin).-A clan of Mashwanis $(q \cdot v$.

TARAK OB T TRAKI (275) (QuettaPishin, Loralıi, Zhob and Chayai). - A clan of Ghilzais. Maj rity are powindahs. Baz Muhrmmad is the headman in Loralai.

TARAKAI.-A sub-division of Mamerai, Ob، Khel, Shiranis. Headman : Inam.

T $\triangle B B U L$ (Sibi).-A division of Khajak, Panis.
TaRghara or TarakzaI $\quad(3,272)$

(Quetta-Pishin).-A clan of Kakars. Headmen: Abo, Firoz, Zarim, Sulieman and Saido.

Tarins $(9,000) \quad$ Quetta-Pishin, Sibi, Lorelai and Chagai).- tribe of Pathans, comprising the three clans, Abdal, Spin and Tor. Hadman in tho Quetta. Pishin district: K. B. Iskhan Khan.

Tarozar (Luralai). $-A$ clan of Ustranas. Headmin : Kamardin.

Tentizai (Lo:a?ai):-A clan of Zarkuns. Headman: Wallan.

TumarzaI (Quetta.Pishin).-A section of Sarangzai, Harunkhel, Sanatia, Kakars. Headman: Sardar Halim Khan.

TokH I (135) (Quetta-Pishin, Sibi and $\mathrm{Zhob).-A}$ (lan of Ghilzais.

TokzaI (Quetta-Pishin).-A section of Panezai, Harurkhel, Sanatia, Kakar's. Headman: Sardar Wahub Khan.

TolazaI (West of Dera Ghaz $\mathrm{K}$ han district). - A sub-division of Maghduzai, Ahmadzal, Bel Kl.el, Musa Khel. Headman: Karum Khan.

Tor (2,546) (Quetta-Pishin, Sibi, Loralai).-A cilan of Tarins. 
Headmen in the Quetta district:|TorzsI (126) (Quetta-Pishin).-A K. B. Iskhan Khan and Wali section of Hamidzai, Acbakzai, Muhammad.

Tов (42) (Zhob). - A division of Nasir, Ghilzais.

TOR K日EL (Loralsi).--A subdivision of Adin Khel, Malla Khel, Ghilzais. Abdal, Tarins. Headmen : Mir Hatim and Kowat.

TorzaI (Sibi).-A division of Lawana, Panis.

Trangani.-A sub-division of Makhiani, Tor, Tarins.

UIIazaI (22) (Quetta-Pishin).-A division of Sargara, Kakars. Headman : Sultan Mahammad.

Luab KHEL (39) (Loralai).-A clan of Ustranas $(q \cdot v$.$) . Head-$ man : Ali Muhammad.

UmarzaI (Zhob).-A division of Haripal, Shiranis.

U MABZAI (156) (Zhob and Loralai). -A division of Nasir, Ghilzais.

UraRZaI (30) (Loralai). - A clan of Isots. Headman : Manu Khon.

UMARZAI is alleged to be the head tribe of 8ub-clans Jahanzai, Jogezai and Wazirzai.

UYARZAI (24) (Loraipi).-A clan of Lunis. Headman : Mir Khan.

UmarzaI (Sibi).-A division of Janti, Panis.
UMABZAI (28) (Sibi).-A division of Khajak, Panis.

UMarzaI (4:2) (Sibi aud Loralai).A division of Laharzai, Musa Khel. Headman in Loralai: Sher.

UMARZAI (15l) (Loralai).-A subdivision of Alizai, Tor, Tarins. Headman : Mulla Rahim.

UMABZaI (Loralai).-A sub-division of Dumar, Sanzarkhel, Kakars. Headman : Himran.

UMARZAI (Loralai).-A division of Drugzai, Lunis. Headman : Mir Khan (Hamalzai), Dabai (Amranzai), Laban (Dungarzai), Jan Gul (1safz:i), Mir Khan (Watarzai), Mohabat (Goramzai).

UMARZAI. - A minor fraction of Bulozai, Panizai, Harun Khel, Sanatia, Kakars.

UMARZAI (105) (Zhob).-A section of Badinazai, Abdullazai, Sanzar- 
khel, Kakar. Headman : Nur Mubammad.

UMRANI (Loralai).-A clan of Jafars. Headman: M. Kalu Khan.

UriazaI (Sibi).-A division of Khajaǩ, Panis.

UsmanI (Sibi).-A clan of Panis.

UsmanzaI (Sinjawi).-A minor traction of Kanozai, Natozai, Hasankhel, Dumar, Sanzarkhel, Kakar. Headman : Hamza.

UsmanzaI (Zhob).-A division of Kapip, Shiranis

UsManzaI (Quetta.Pishin), -A section of Ashezai, Achakzai, Abdul, Tarins. Headman : Mehrab Khan.

UsmanzaI (Loralai). - A division of Ghaibzai, Isots. Headman : Shadigul.

UsmanzaI (36) (Zhob).-A subdivision of Suleimanzai, Babar,

Shirsni. Headman : Abdulla Khan.

Ustranas (162) (Hills opposite the southernmust portion of Dera Ghazi Khan District).-Although classed (Census, 1901) as an Afghan tribe, they are descended from a Saiyid, who settled among the Shirani Afghans, and married a Shirani woman; hence their intimate connection with the Shiranis. The clans, etc., as enumerated in Census Tables, 1 o0l (Provincial Table No. 2) will be found indexed in this dictionary. Headmen : Khoidad Khan and Hiyat Khan.

UTMaN K\#еL (410) (Bori valley).A division of (southern) Sanzarkhel, Kakars. Headmen: Mir Alam, Vakil, Haji Karam, Abdul Aziz, Gullan, Murghai and Mulla Jalandar.

UTMANZAI (15) (Zhob).-A minor fraction of Suleimanzai, Hassanzai, Kibzai, Sanzarkhel, Kakar. Headman : K hanan.

UTMANZAI (Zhob).-A division of Dawi, Kakars.

W ALAINAI or WAIIANI(31) (Loralai). -A division of Rakanwal, Lunis. Headmen : Baloch (Umrzai), Muhammadan.

WalizaI (Sinjawi).-A minor fraction of Haiderzai, Natozai, Hasan- khel, Dumar, Sanzarkhel, Kahar. Headman : Lajmar.

WaIIzaI (78) (Quetta-Pishin.) - A section of Ashezai, Achakzai. Abdul, Tarins, Headman : Akbat Khon. 
WallezaI (43! (Loralai.) - A minor fraction of Sliabozai, Harmakhel, Arabi Khel, sanzarkhel, Kikirs: Headweo : Khánu and Dádu.

WANECHI (665) (Loralai and Sibi). -A division of Spin, Tarins. Headman : K. S. Narab Khan. Lives in Shirin.

WARDAK (18j iquetta-Pishin and Loraiai).-A clan of Grilzais. Headman : Shaista Khan.
WAB YAZAI-A section of Isrizai, Ahmad Khel, Oba Khel, Shiranis.

Wash Khel (5l) (Zhob). - A division of Nasir, Ghilzais.

WAZIRZAI (39) (Loralai).- - dirision of Nuhzai, Isots. Headmen: Mulia Rindo and Yasin.

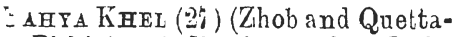
Pishin).-A dipision of Nasir, Ghilzais.

YAHYAZAI (Largha).-A division of Hasan Khel, Shirdnis (q. v.) Headman : Rahim.

YAKHEL (Zhob).-A division of Tharot, Ghilzais.

YAKUBZAI (Loralai).-A section of Umarzai, Du:nar, Sanzarkhel, Kitkar, Headinan : Sultan.

Y $\triangle Q O B Z A I(25)$ (Zhob).-A section of Khojalzai, Abdullazai. Sanzarhhe', K.thors. rreadman : Malot.

Y $\triangle Q U B Z A Y$ (Sibi).-A division of Dawi, Panis.

$\mathrm{Y}_{A Q U B Z A T}$ (Zhob).-A division of Kapip, Shiranis.

YasinzaI,-A section of Umarzai, Dumar, Sanzarkhel, Kakars. Headmen Sultan and Ghani.
YasjnzaI (523) (Quetta-Pishin).-A sub-division of Isa $\mathbb{E}$ hel, Sanatia, Kakars. Headmen : K. S. Lowang Khan, Ghafur, $\mathrm{Baz}$ and Maruf.

YaSinZaI (20) (Zhob).- $-\underline{\Delta}$ sub-divi.* sion of Haidarkhel, Mandokhel (q. v.), Panis. Headman : Khudai Noor.

$\mathrm{Y}_{\triangle \mathrm{SIN} Z A I}(20)$ (Zhob). - A section of Pakhezai, Abdullazai, Sanzarkhel, Kakar. Headman : Málik.

YaSinzaI (Largha and Bargha).A sub-division of Ahmad Khel, Hasan Khel, Shiranis (q.v.). Headman : Ghamai in Zhob.

YosafzaI (47) (Sibi and Pirangabad) (Kalat). - A division of Marghzani, Panis. Headmen in Kalat: Malik Rassolo and Peer Muhammad. 
ZaAM or SaAM (34) (Toralai)-A division of Spin, Tarins. Headman: Nasir Krhan.

ZaHrozaI (45) (Zhob). - A minor fraction of Badinzai, Ahmedzai, Hassanzai, Kibzai. Sar zarkhel, Fakir Headman: K. S. Eaindan Khan.

Zakariazai (50) (Zhob).-A section of Marcletzai, Kibzai, Sanzarkhel, Kalsars Headman: Khan Sahib Paindan Khan.

ZaKariazaI (120) (Quetta-Pishin). -A sub-division of Sulemankhe! Targhara, Kakars. Headman : Dadulla.

ZAEARZAI.-A division of Rakhanwal, Lunis. Headmen: Khaneh Saiyidanzai), Hadis (Rahmanzai).

ZAKHPEL (186) (Loralai). -A hamsaya division of Dumar, Sanzarkhel, Kakars. Headmen : Kabir, Alihan, Sadiq, Yakub and Gullo and $Y_{\text {asin. }}$.

ZAKOZAI (60) (Zhob).-A section of Shamamzai, Kibzai, Sanzarikhel, Kakar. Headmen: Jalat and Raman.

ZakozaI (Chagai).-A sim of the Barech.
ZakriazaI (46) (Quetta-Pishin).-A sub-division of Al'zai, Tor, Tarins. Headman : Karim.

ZaLlozar (Sibi).-A sub-division of Koshi, Khajak, Panis.

Zayankerer (Zhob).-A clan of Safis.

Zamrani (Loralai), - A division of Nasir, Ghilzais.

ZaNgi KHeL (42) (Loralai and Zhobj--A division of Nasir, Ghilzais.

ZARGHONZAI (Sibi).-A division of Lawana, Panis.

ZARGWAL (Loralai).-A sub-division of Wanechi, Spin, Tarins. Headmen : Zalla Khan and Misri.

ZaRIP KHeL (Loralai), -A division of Shinwar, Ghilzais.

ZARKHEL (Kalat and Quetta-Pishin).-A sub-division of Parerun Sanzarkhel, Kakar, who live near Rilla Abdulla Khan in (QuettaPishin) and Adam Khan (Mastnag) Kalat. Headinan : Adam Khan.

ZARKON (466) (Sibi and Loralai).A small Pathan tribe. Headmen in Sibi : Dada Khan and Samand Khan. Chiefman in Loralai is Rossd Khan of Hosri. 


\section{2}

ZA WAL KHEL (Loralai). -A division of Kharot, Ghilzais.

ZECHI (Loralai).-A Sub-division of Adwani, Spin, Tarins.

ZERA (27) (Sibi and Loralai).-A division of Sharswani, Zarkuns. Headman : dzad.

Zieway (Loralai).-A sub-division of Wanechi, Spin, Tarins.
Zirak zaI (Loralai).-A sub-division of Wanechi, Spin, Tarins. Headman : Rasta Khan of Kaza.

Trrkiza (West of Dera Ghazi Khan District). -A sub-division of the Hamzazai, Bel Khel, Musa Khel. Headman : Kalandar.

ZMaRaIs, MIRSIS oR MIZRIS (150) (Loralai). - A small tribe descended from Miani, and hence connected with the Lunis and Jafars. A few of them under the name of Mizris are to be found among the Panis of Sibi. Headman : Sirdar Haji Hakim Khan. 


\section{APPENDIX I.}

The following note by Captain A. H. McMahon, C.S.I., C.I.E.,

Political Agent, Dir, Swat and Chitral, explains the various spiritual titles and denominations in use among Pathans.

"The denominations under which the descendants of all Mubammadan spiritual leaders come according to Patban, and I might say Indian (usage), are, in order of spiritual rank, as follows :-

* 1. SaIyads. -This is the term given to descendants of the Prophet. Owing to their large number and rarying circumstances, it does not follow that a Saiyad, as such, is given precedence over other spiritual denominations, but a Saiyad who comes into prominence as a religious man takes precedence of all other religious denominations.

2. Mians.-These are the descendants of saints and spiritual leadors who have acquired a wide reputation among many tribes, and have a merely local reputation. All Mians are, or are supposed to be, descendants of saints of some past century. The term is not given to descendants of modern saints, but some of these may in course of time become Mians. The remarks made regarding Saiyads apply to Mians also. The prinoipal saints of this class on the northern frontier are ranked as follows:-

(1) Pir Baba of Ilai, Buner (as a Saiyad, he ranks first).

(2) Kaka Sahib of Nowshera.

(3) Hazrat Ji, near Attock.

(4) Mian Umar, at Chamkanni near Peshawar. He died childless, but his disciples have claimed the rank of Mians as if descendants.

(5) Haji Bahadur, of Kohat.

(6) Diwana Baba, of Buner.

Nots.-(a) The Akhund of Swat does not as yet rank in this class. His descendants are given the title of Miangul by courtesy. They should, strictly speaking, be only Akhundzadas. If

* SaIrads. A true Saijad is the descendant of Ali, the son-in-Iaw of Muhammad, by Fatima, Muhammad's daughter. Many of the Pathan tribes, sa ch as the Bangash of Kohat, and the Mishwanis of the Hazara border, claim Saiyad origin. The apostles who completed the conversion of the Pathans to Isalam were called Saiyads if theg came from the west, and Shekhs if from the east; henoe doubtless, many false claims to Saiyad origin. In Afghanistan the Saiyada have much of the commerce in their hands, as thoir hols character allows them to pass unharmed, where other Pathans would infallibly be mardered.

SнEK is an Arabic word meaning elder or cbief. It is a title properly con* fined to tribes of Arab descent, but is very commonly used to denote convert to Islam. 
the family keep up their spiritua record, which is doubtful, future descendants mag in time be classed as Mians.

(b) The Koreshis * are ranked as Mians.

3. AkHundzadas. - Sometimes known also as Pirzadas. Thesa are descen dants of saints of merely local or tribal reputation. Thus we have Alkundzadas of Khal (Dir), of Mayar (Jandol). of Bamboli (Adinzai, Swat), and so on. The descendants of "Mushki Alam" † are classed as Akhuudzadas, because Mulla Mushki Alam was hims ?f an Akhundzada, otherwise they would be only sahibzaden.

4. SAHIBZADas,-These are descendants of mullas who have gained a reputation for learning or sanctity. As such are classed the descendants of the Kotah Mulla, Manki Mulla, Adda Mulla, Karbogha Mulla, etc.

All of the above elasses are, according to Pathan custom, entitled to grants of free iand called Seri. The amount of land varies, as a general rule, acr ording to the above-described ranks. Lands on the border between two villages, disputed lands, and lands whick for some reasun or other are diffientt to hold, are gencrally given as Seri, as the religious status of their holders makes them useful buffers and enables them to enjoy disputed lands in peace."

* Koreshi or Qureshi is the name of the Arab tribe to :which the Prophet belonged. The Kureshis of the Punjab are mostly descendants of Balawal Hak, the renowned saint of Multan.

+ The religions and military leader of the Ghilzais in the 2nd Afghan War. 

